\title{
SUPPLEMENTARY DC CONTROL IN A \\ TWO AREA AC/DC POWER SYSTEM
}

\author{
A Thesis submitted to \\ the College of Graduate Studies and Research \\ in Partial Fulfilment of the Requirements for \\ the Degree of \\ Master of Science \\ in the \\ Department of Electrical Engineering \\ University of Saskatchewan
}

by

Jose Miguel Castellanos Iturrate

Saskatoon, Saskatchewan

March 1992

The author claims copyright. Use shall not be made of the material contained herein without proper acknowledgement, as indicated on the following page. 


\section{COPYRIGHT}

The author has agreed that the Library, University of Saskatchewan, may make this thesis freely available for inspection. Moreover, the author has agreed that permission for extensive copying of this thesis for scholarly purposes may be granted by the professor or professors who supervised the thesis work recorded herein or, in their absence, by the head of the Department or the Dean of the College in which the thesis work was done. It is understood that due recognition will be given to the author of this thesis and to the University of Saskatchewan in any use of the material in this thesis. Copying or publication or any other use of the thesis for financial gain without approval by the University of Saskatchewan and the author's written permission is prohibited.

Request for permission to copy or make any other use of the material in this thesis in whole or in part should be addressed to :

Head of the Department of Electrical Engineering University of Saskatchewan

Saskatoon Canada S7N OW0. 


\section{ACKNOWLEDGEMENTS}

The author wishes to express his gratitude to Dr. Ronald J. Fleming for his guidance and assistance during the course of this thesis research. Thanks are also due to various members of the Electrical Engineering Department of the University of Saskatchewan for their valuable suggestions and comments.

The author acknowledges the encouragement provided by his family for the realization of this work. $\mathrm{He}$ is also grateful to all those who were helpful in the development of this study.

Financial support provided by the National Research Council of Canada, Research Grant OGPIN 011 and the University of Saskatchewan is thankfully acknowledged. 


\title{
UNIVERSITY OF SASKATCHEWAN
}

Electrical Engineering Abstract 92A361

\section{SUPPLEMENTARY DC CONTROL IN A TWO AREA AC/DC POWER SYSTEM}

\author{
Student: Jose M. Castellanos \\ Supervisor: Dr. Ronald J. Fleming
}

M.Sc. Thesis presented to the College of Graduate Studies and Research.

March 1992

\section{ABSTRACT}

In this thesis results of research are reported for a study of the dynamic performance of a two-area power system interconnected by AC and DC tie-lines. The system includes supplementary DC control interacting with the conventional AC area controls. Taking advantage of the fast controllability of DC links, supplementary control utilizing DC power modulation improves system damping, reduces unnecessary governing system operation and reduces inadvertent energy interchange between the two areas. DC power modulation is based on variations of AC system signals such as net power interchange deviation and/or area frequency deviation.

A linear model was used for the power system to study small changes around a base reference state and only the power/ frequency control aspects of the overall power system control problems were considered. The model used and the simulation of it are described in this thesis.

Eigen-structure analysis of the state space model of the power system was used to evaluate system stability, with and without supplementary control. Control optimization was achieved by minimization of a performance index to adjust the values of the controller parameters. The performance index selected is a function of Area Control Error (ACE) and is a good measure of control effectiveness. The results of the eigenstructure analysis and the control optimization are presented.

Computer simulation was used to obtain power system dynamic responses to step load disturbances and to estimate optimal controller parameters. The simulation studies considered various $\mathrm{AC}$ and $\mathrm{AC} / \mathrm{DC}$ interconnection types and control features of the two area interconnected power system. Simulation results are presented in the form of time responses graphs and in summary tables.

It was found that the dynamic performance of the two-area power system could be significantly improved with the aid of the controls in the DC line. 


\section{TABLE OF CONTENTS}

COPYRIGHT

ACKNOWLEDGEMENTS

ABSTRACT

TABLE OF CONTENTS

LIST OF FIGURES

LIST OF TABLES

NOMENCLATURE

1. INTRODUCTION

1.1. General

1.2. Background Survey

1.2.1. Control Area Structure

1.2.2. Area Control Error

1.2.3. AGC Controller

1.2.4. Area Governing Characteristic

1.2.5. Area Load Frequency Characteristic

1.2.6. Area Frequency Response Characteristic

1.2.7. Tie Line Bias Control

1.2.8. HVDC Links

1.2.9. Influence of HVDC Links on AC Systems

1.2.10. Dynamic Stability

1.3. Review of Literature

1.4. Purpose of the Thesis

2. THE SYSTEM MODEL

2.1. General

ii

iii

iv

$\mathbf{v}$

vii

xii

xiii

1

2.2. Frequency Deviation 26

2.3. Net Power Interchange Deviation $\quad 27$

2.4. Speed Governing System Model 27

2.5. Steam Turbine Generator Model 29

2.6. Power System Model $\quad 30$

2.7. The AC Link Model 32

2.8. The DC Link Model 34

2.9. Automatic Generation Control Model 35

2.10. Supplementary Control Model 37

2.11. Block Diagram of Two Area Interconnected Power System 38

2.12. Power System Parameters $\quad 41$

3. STATE SPACE NOTATION

3.1. General $\quad 43$

3.2. State Space Representation 43

3.3. State Space Representation of the AC System 45

3.4. State Space Representation of the AC/DC System 52 
4. SYSTEM STABILITY

4.1. General $\quad 58$

4.2. Stability in the Complex Plane 59

4.3. Eigenstructure 60

4.4. AC System Stability 62

4.4.1. Effect of AGC Controller Gain Variations 64

4.5. AC/DC System Stability 68

4.5.1. Effect of Supplementary Controller Gain Variation 71

4.6. Conclusions 75

5. SIMULATION STUDIES 77

5.1. General 77

5.2. Control Optimization $\quad 79$

5.2.1. Performance Index $\quad 80$

5.2.2. Control Optimization of the Two Area Interconnected
Power System

5.3. AC System with AGC Control 81

5.4. AC/DC System with AGC and Supplementary DC Controls 91

5.5. AC/DC System with AGC and SC Controls, Including DC
Power Limiter

5.5.1. System Dynamic Responses for Various DC Power Limiter Settings

5.5.2. System Dynamic Responses for Various Step Load Disturbances

100

106

5.6. Simulation Results for Various Interconnection Types and Control Systems of the Two area Power System

5.7. Conclusions

6. SUMMARY AND CONCLUSIONS

6.1. Summary

6.2. Conclusions

REFERENCES

APPENDIX A Simulation Model Structure

APPENDIX B AC System Dynamic Responses for Various AGC Controller Parameters

APPENDIX C AC/DC System Dynamic Responses for Various 


\section{LIST OF FIGURES}

Figure 1.1 Two Area Interconnected Power System via parallel AC/DC Tie-lines.

Figure 1.2 (a) HVDC transmission link, (b) bridge converter, (c) rectifier waveforms and (d) inverter waveforms.

Figure 1.3 (a) Operating characteristic with " $A$ " rectifier and " $B$ " inverter ;

(b) Operating characteristic after power reversal.

Figure 2.1 The Two Area Interconnected Power System (TAIPS). 25

$\begin{array}{ll}\text { Figure 2.2 Speed governing system block diagram. } & 29\end{array}$

$\begin{array}{ll}\text { Figure 2.3 Turbine generator block diagram. } & 30\end{array}$

Figure 2.4 Power system block diagram.

Figure 2.5 The AC link block diagram. 34

Figure 2.6 Simplified model of a DC link.

Figure 2.7 AGC controller block diagram. 37

Figure 2.8 Supplementary controller block diagram. 38

Figure 2.9 Transfer function block diagram of a two area thermal system interconnected by AC and DC tie-lines.

Figure 3.1 Block diagram of a MIMO system. 44

Figure 3.2 Block diagram of an AC TAIPS. 46

Figure 3.3 State coefficient matrix $A_{1}$. 46

Figure 3.4 Block diagram of an AC/DC TAIPS. $\quad 51$

Figure 3.5 Block diagram of an AC/DC TAIPS, with $\Delta \mathrm{P}_{12}$ as
input of the DC system controller.

Figure 3.6 State coefficient matrix $\boldsymbol{A}_{3}$. 57

Figure 4.1 Eigenvalue locations for various $\mathrm{k}_{\mathrm{P} 1}$ and $\mathrm{k}_{\mathrm{P} 2}$. 64

Figure 4.2 Detail of Figure 4.1 for modes $\lambda_{1}$ and $\lambda_{2}$. 65

Figure 4.3 Detail of Figure 4.1 for modes $\lambda_{3}, \lambda_{6}$ and $\lambda_{7}$. 65

Figure 4.4 Detail of Figure 4.1 for modes $\lambda_{5}$ and $\lambda_{9}$. 66

Figure 4.5 Eigenvalue locations for various $\mathrm{k}_{\mathrm{I} 1}$ and $\mathrm{k}_{\mathrm{12}}$. 67

Figure 4.6 Detail of Figure 4.5 for modes $\lambda_{1}$ and $\lambda_{2}$. 67

Figure 4.7 Detail of Figure 4.5 for modes $\lambda_{3}, \lambda_{5}, \lambda_{6}$, $\lambda_{7}$ and $\lambda_{9}$.

Figure 4.8 Eigenvalue locations for various $\mathrm{k}_{\mathrm{p}}$.

Figure 4.9 Detail of Figure 4.8 for modes $\lambda_{1}$ and $\lambda_{2}$.

Figure 4.10 Detail of Figure 4.8 for modes $\lambda_{3}, \lambda_{6}$ and $\lambda_{7}$. 73

Figure 4.11 Detail of Figure 4.8 for modes $\lambda_{5}$ and $\lambda_{9}$. 73

Figure 4.12 Eigenvalue locations for various $\mathrm{k}_{\mathrm{f}}$.

Figure 4.13 Detail of Figure 4.12 for modes $\lambda_{5}$ and $\lambda_{9}$.

Figure 4.14 Detail of Figure 4.12 for modes $\lambda_{6}$ and $\lambda_{7} . \quad 75$

Figure 5.1 Frequency deviation responses in Area 1 for various AGC proportional gain. 
Figure 5.2 Frequency deviation responses in Area 1 for various AGC integral gain.

Figure 5.3 Frequency deviation responses in Area 2 for various AGC proportional gain.

Figure 5.4 Frequency deviation responses in Area 2 for various AGC integral gain.

Figure 5.5 Power interchange deviation responses for various AGC proportional gain.

Figure 5.6 Power interchange deviation responses for various AGC integral gain.

Figure 5.7 Performance index for various AGC proportional gain.

Figure 5.8 Performance index for various AGC integral gain.

Figure 5.9 Inadvertent energy interchange for various AGC proportional gain.

Figure 5.10 Inadvertent energy interchange for various AGC integral gain.

Figure 5.11 Frequency deviation responses in Area 1 for various SC controller proportional gain.

Figure 5.12 Frequency deviation responses in Area 1 for various SC controller integral gain.

Figure 5.13 Frequency deviation responses in Area 2 for various SC controller proportional gain.

Figure 5.14 Frequency deviation responses in Area 2 for various SC controller integral gain.

Figure 5.15 Power interchange deviation responses for various SC controller proportional gain.

Figure 5.16 Power interchange deviation responses for various SC controller integral gain.

Figure 5.17 Performance index for various SC controller proportional gain.

Figure 5.18 Performance index for various SC controller integral gain.

Figure 5.19 Inadvertent energy interchange for various SC controller proportional gain.

Figure 5.20 Inadvertent energy interchange for various SC controller integral gain.

Figure 5.21 Frequency deviation responses in Area 1 for various DC power limiter.

Figure 5.22 Frequency deviation responses in Area 2 for various DC power limiter.

Figure 5.23 Power interchange deviation responses for various DC power limiter.

Figure 5.24 Inadvertent energy interchange for various DC power limiter. 
Figure 5.25 AC power interchange deviation responses for various $D C$ power limiter.

Figure 5.26 DC power interchange deviation responses for various DC power limiter.

Figure 5.27 Performance index for various DC power limiter settings.

Figure 5.28 Frequency deviation responses in Area 1 for various step load disturbance in Area 1.

Figure 5.29 Frequency deviation responses in Area 2 for various step load disturbances in Area 1.

Figure 5.30 Power interchange deviation responses for various step load disturbances in Area 1.

Figure 5.31 Inadvertent energy interchange for various step load disturbances in Area 1.

Figure 5.32 AC power interchange deviation responses for various step load disturbances in Area 1.

Figure 5.33 DC power interchange deviation responses for various step load disturbances in Area 1.

Figure 5.34 Performance index for various step load disturbances in Area 1.

Figure 5.35 Frequency deviation responses in Area 1 for various interconnection types and control systems of the TAIPS.

Figure 5.36 Frequency deviation responses in Area 2 for various interconnection types and control systems of the TAIPS.

Figure 5.37 Power interchange deviation responses for various interconnection types and control systems of the TAIPS.

Figure 5.38 Inadvertent energy interchange for various interconnection types and control systems of the TAIPS.

Figure 5.39 Control error of Area 1 for various interconnection types and control systems of the TAIPS.

Figure 5.40 Control error of Area 2 for various interconnection types and control systems of the TAIPS .

Figure 5.41 Performance index for various interconnection types and control systems of the TAIPS.

Figure B.1 Control error in Area 1 for various AGC proportional gain.

Figure B.2 Control error in Area 1 for various AGC integral gain.

Figure B.3 Control error in Area 2 for various AGC proportional gain. 
Figure B.4 Control error in Area 2 for various AGC integral gain.

Figure B.5 Generated power deviation in Area 1 for various AGC proportional gain.

Figure B.6 Generated power deviation in Area 1 for various AGC integral gain.

Figure B.7 Generated power deviation in Area 2 for various AGC proportional gain.

Figure B.8 Generated power deviation in Area 2 for various AGC integral gain.

Figure B.9 Control signal in Area 1 for various AGC proportional gain.

Figure B.10 Control signal in Area 1 for various AGC integral gain.

Figure B.11 Control signal in Area 2 for various AGC proportional gain.

Figure B.12 Control signal in Area 2 for various AGC integral gain.

Figure C.1 Control error in Area 1 for various SC controller proportional gain.

Figure C. 2 Control error in Area 1 for various SC controller integral gain.

Figure C.3 Control error in Area 2 for various SC controller proportional gain.

Figure C. 4 Control error in Area 2 for various SC controller integral gain.

Figure C.5 Generated power deviation in Area 1 for various SC controller proportional gain.

Figure C.6 Generated power deviation in Area 1 for various SC controller integral gain.

Figure C.7 Generated power deviation in Area 2 for various SC controller proportional gain.

Figure C.8 Generated power deviation in Area 2 for various SC controller integral gain.

Figure C.9 Control signal in Area 1 for various SC controller proportional gain.

Figure C.10 Control signal in Area 1 for various SC controller integral gain.

Figure C.11 Control signal in Area 2 for various SC controller proportional gain.

Figure C.12 Control signal in area 2 for various SC controller integral gain.

Figure C.13 Control signal DC system for various SC controller proportional gain.

Figure C.14 Control signal DC system for various SC controller integral gain. 
Figure C.15 AC power deviation for various SC controller proportional gain.

Figure C.16 AC power deviation for various SC controller integral gain.

Figure C.17 DC power deviation for various SC controller proportional gain.

Figure C.18 DC power deviation for various SC controller integral gain. 


\section{LIST OF TABLES}

Table 4.1 Eigenvalues of the AC system.

Table 4.2 Eigenvalues of the AC/DC system.

Table 4.3 Participation factors corresponding to mode $\lambda_{11}$.

Table 5.1 Effects of changes of AGC parameters on system

Table 5.2 Effects of changes of SC controller parameters on system performance.

Table 5.3 Effects of changes of DC power limiters on system performance.

Table 5.4 Effects of changes of step load disturbance in Area 1 on power system performance.

Table 5.5 System performance for various interconnection types and control systems of the TAIPS. 


\section{NOMENCLATURE}

$\mathrm{P}_{\mathrm{r}} \quad$ area capacity (power base), $\mathrm{MW}$

$f^{*} \quad$ nominal system frequency, $\mathrm{Hz}$

i subscript referring to area $(i=1,2)$

$\Delta \mathrm{P}_{\mathrm{Gi}}$ generated power deviation, puMW

$\Delta \mathrm{P}_{12}$ net power interchange deviation, puMW

$\Delta \mathrm{P}_{\mathrm{Li}}$ change in load demand (load disturbance), puMW

$\Delta \mathrm{f}_{\mathrm{i}}$ frequency deviation, $\mathrm{Hz}$

$\Delta \mathrm{P}_{\mathrm{AC}} \mathrm{AC}$ tie line power deviation, puMW

$\triangle \mathrm{P}_{\mathrm{DC}} \mathrm{DC}$ tie line power deviation, puMW

$U_{i} \quad$ AGC control signal

$\mathrm{U}_{3} \quad$ supplementary control signal

$A_{C E}$ area control error, puMW

$T_{G i}$ speed governor time constant, $s$

$R_{i}$ generation regulation characteristic, $\mathrm{Hz} / \mathrm{puMW}$

$T_{T i} \quad$ steam chest time constant, $s$

$\mathrm{H}_{\mathrm{i}} \quad$ inertia constant, $\mathrm{s}$

$D_{i} \quad$ load frequency characteristic, $\mathrm{puMW} / \mathrm{Hz}$

$\left(\mathrm{K}_{\mathrm{Pi}}=1 / \mathrm{D}_{\mathrm{i}}, \mathrm{T}_{\mathrm{Pi}}=2 \mathrm{H}_{\mathrm{i}} / \mathrm{f}^{*} \mathrm{D}_{\mathrm{i}}\right)$

$\mathrm{T}_{12}$ synchronising coefficient, $\mathrm{puMW} / \mathrm{Hz}$

$\mathrm{B}_{\mathrm{i}}$ frequency bias constant, puMW/Hz

$k_{\mathrm{Pi}} \quad$ proportional gain of AGC controller

$k_{1 i}$ integral gain of AGC controller

$T_{D C} \quad$ DC system time constant, $s$

$k_{p} \quad$ proportional gain of supplementary controller

$k_{1} \quad$ integral gain of supplementary controller

s Laplace operator 


\section{INTRODUCTION}

\subsection{General}

As interconnected power systems grow in size and complexity, it is necessary to employ various control systems to maintain quality, reliability and economy of operation. Power system control is required to maintain a continuous balance between generation and varying load demand, while system frequency, voltage levels and security are also maintained.

The variable nature of the consumer power demand requires continuous changes of the total generation, therefore the difference between generated and consumed power must be continuously monitored and supervisory control action must be executed to restore the balance following a disturbance.

The research reported in this thesis concerns the performance of supervisory controls associated with high voltage systems interconnected by AC and DC tie-lines. As such these controls are important to successful system operation.

By way of introduction to the studies carried out consider the response of a normal power system interconnected by AC tie-lines with neighbouring power systems. An increment in system load causes a speed reduction and the inertia of the 
rotating masses of the generating units provides the energy necessary for a temporary balance. However the speed of the generators determines the system frequency, thus rate of change of frequency represents an indirect measure of the unbalance between consumed and generated power. The speed governing system (primary control) of each controlled generating unit senses the speed change and responds by adjusting its load in proportion to its governing characteristic for the restoration of the system frequency. Subsequently the system reaches a new equilibrium in which the system frequency has decreased slightly and the tie line power interchanges with neighbouring systems have deviated from their previous values.

The requirements for control of frequency and net power interchanges can be implemented by a secondary control, called Automatic Generation Control (AGC). The AGC control provides automatic variation of generation set points on the speed governors to restore system frequency and tie-line power interchanges to scheduled values. The AGC system is an important part of the control hierarchy which helps each control area to operate independently with respect to other control areas in an multiarea interconnected power system.

Due to economic incentives, bulk power interchanges between large, interconnected power systems are desired. The need for dynamic performance analysis of large systems with weak HVAC and HVDC links is increasing. 
Power flows in an AC system are related to differences in phase angles across the systems, that means a change in power angle must precede a change in stabilizing power flow. With a DC system, the power flow can be forced on and precede terminal voltage or phase angle changes; so a DC link can be used to reduce power angle changes at its terminals, and if at the same time in parallel with an $\mathrm{AC}$ link, to increase the permissible power transfer over that link.

Normally HVDC systems are operated under constant power control in accordance with a fixed scheduled DC power transmission, without assisting the AGC action. The controllability of HVDC links is often cited as an important advantage of DC systems, because of the fast DC power control. This controllability of HVDC links can be valuable in improving the dynamic performance of overall AC/DC interconnected power systems.

Utilizing the fast power control characteristic of HVDC systems with a suitable supplementary controller to modulate the DC power based on control signals derived from the AC system, it is possible to influence favourably the damping of the natural modes of system oscillations. Also, it is possible to minimize the area control error (ACE) to avoid excessive governing system operation and to reduce the inadvertent energy interchange (IEI) between neighbouring areas (control areas) in the multiarea interconnected power system. 
In the context of optimal control, an optimization technique based on a performance index can be used as a reference parameter to optimize the controller parameters to achieve the system desired behaviour.

\subsection{Background Survey}

In this section the terminology of interconnected system controls is discussed along with a brief review of the essential control features of HVDC power lines.

\subsubsection{Control Area Structure}

A control area is defined ${ }^{1}$ as a part of an interconnected power system to which a common generation control scheme is applied. The conventional control strategy for area control is the one based on the "tie line bias" concept, where the main objectives of area control operation are to compensate for the changes in the frequency and the tie line power interchanges with neighbouring control areas.

The conventional method ${ }^{41}$ of keeping the system frequency and tie-line power interchanges at preset levels within scheduled limits depends on the hierarchical control structure which includes primary, secondary and tertiary control systems defined as follows:

\section{Primary Control: Speed Governing System}

* Usually analog or digital/analog devices,

* fast acting, in the order of fraction of a second to a few seconds, 
* regulates about $15 \%$ to $30 \%$ of total area generation,

* operates on an individual generating unit in accordance with its regulation characteristic.

Secondary Control: Automatic Generation Control (AGC)

* Analog or digital devices,

* slow acting, in the order of a few seconds to a few minutes,

* system frequency and tie line power flow control tasks.

Tertiary Control: Economic Dispatch Control (EDC)

* Digital,

* slow acting, in the order of a few minutes to a few hours,

* economic generation allocation task.

In a hybrid $\mathrm{AC} / \mathrm{DC}$ power system, the $\mathrm{DC}$ system control is capable of functions at all three hierarchical control levels.

\subsubsection{Area Control Error}

The tie line bias control strategy for area control is sensitive to changes in the frequency and the tie line power interchange. One of the measures of quality of such a control scheme is the area control error (ACE) signal. ACE is defined ${ }^{1}$ as the linear combination of the net power interchange error and the system frequency

error. It is the amount of generation required in an area to restore net power 
interchange and frequency back to scheduled values. The mathematical expression of ACE is:

$$
\begin{aligned}
& A C E=\Delta P_{\text {tie }}+B \Delta f \\
& \Delta P_{\text {tie }}=P_{\text {tie }}-P_{s} \\
& \Delta f=f-f_{s} \\
& P_{\text {tie }}=\text { actual net power interchange, MW } \\
& P_{s}=\text { scheduled net power interchange, MW } \\
& f=\text { actual system frequency, Hz } \\
& f_{s}=\text { scheduled system frequency, } \mathrm{Hz} \\
& B=\text { area frequency bias setting, } \mathrm{MW} / \mathrm{Hz}
\end{aligned}
$$

\subsubsection{AGC Controller}

Usually AGC controllers are designed based on a PI algorithm (proportional plus integral). Under this characteristic, the control signal sent to the participating generators is the sum of the ACE and its time integral as shown in Figure 1.1. The $\mathrm{ACE}$ is a function of time, and is very random in nature. The AGC controller output (control signal) takes the form of raise/lower pulses which drive governor speed changers at each generating unit under control. It is uneconomical and technically undesirable to force generation plant outputs to make fast changes, up and down, in an endless sequence of unnecessary control actions. This causes severe stresses in the turbine/generator parts and large control energy expenses. 


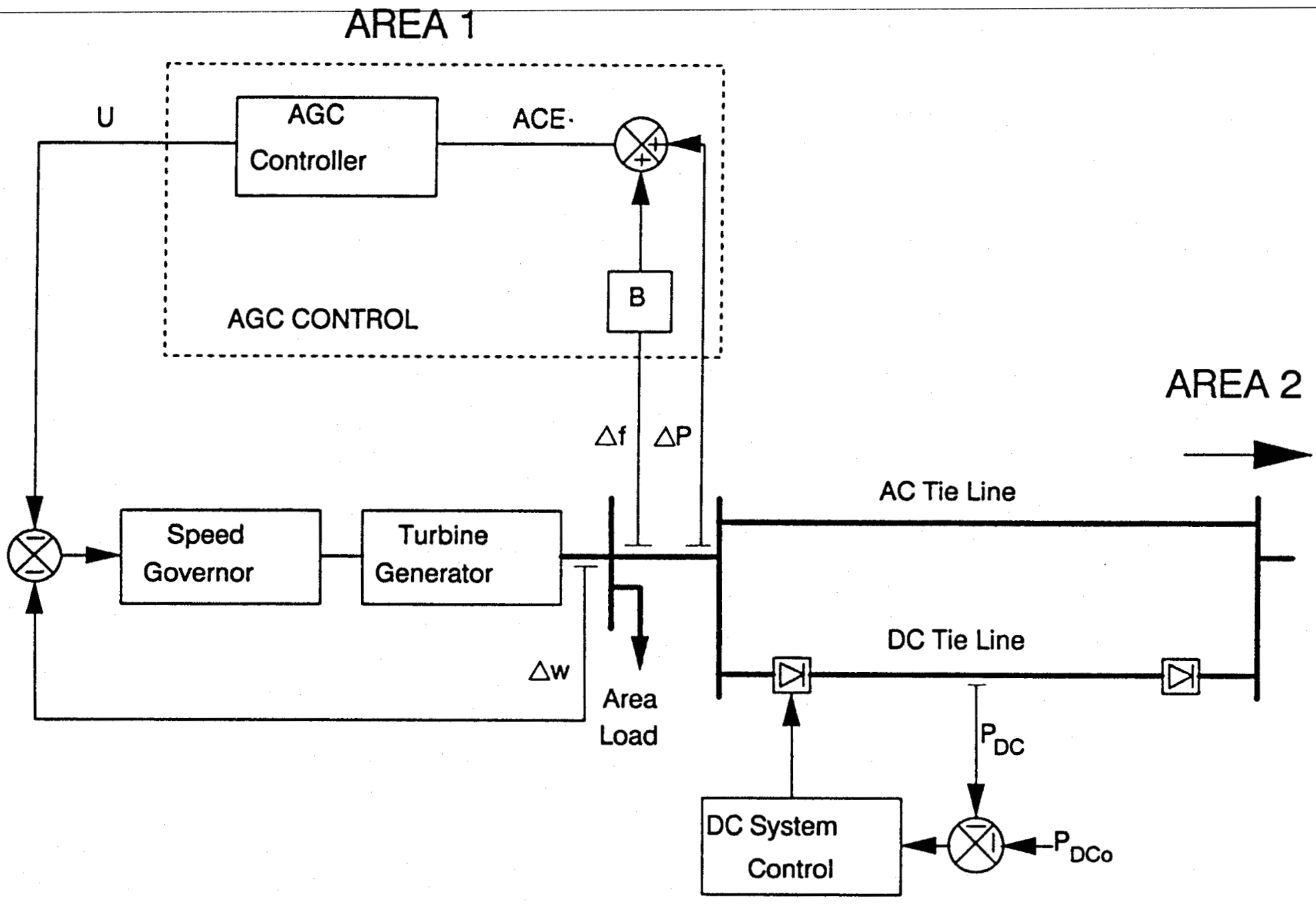




\subsubsection{Area Governing Characteristic}

For a control area, the combined effect of all the generating units in operation has a composite governing characteristic (1/R), which is an expression of the relationship between generation changes and frequency changes in $\mathrm{MW} / \mathrm{Hz}$. It normally has a negative slope (dP/df).

\subsubsection{Area Load Frequency Characteristic}

This defines the frequency load coefficient of the connected load in an area. In other words, it is the change in the total area load caused by a change in the system frequency. It is expressed in $\mathrm{MW} / \mathrm{Hz}$ and is designated by " $\mathrm{D}^{n}$. It usually has a positive slope $(\mathrm{dP} / \mathrm{df})$.

\subsubsection{Area Frequency Response Characteristic}

The combined effect of the area governing characteristic and the change in area load with frequency is defined ${ }^{1}$ as the area frequency response characteristic $(\beta)$. It is expressed as $B=(1 / R+D)$ in $M W / H z$. It usually has a negative slope $(\mathrm{dP} / \mathrm{df})$.

\subsubsection{Tie Line Bias Control}

In a multiarea interconnected $\mathrm{AC}$ system all the areas share in system load changes naturally in proportion to their respective area frequency response characteristics (B). However the automatic generation control supplements the control of generation depending on the bias setting "B" of the AGC control, in an 
area in which the load change occurs. The tie line bias control ${ }^{34}$ can be regarded as having three functions:

i) it causes each area to absorb its own local load changes,

ii) it determines the steady state response of an area to a remote load change following the primary governor action,

iii) it causes each area to share in the system frequency control.

When the controller bias setting (B) is set lower than the area natural frequency response characteristic (B), the area will not respond adequately to take its fair share in the control of the whole interconnected system, resulting in a control burden on the other areas.

When the controller bias setting is greater than the area response characteristic, the area will be over controlled, which will also put an excessive counteracting control burden on the other areas. Therefore, in a control area the bias is normally set close to the area frequency response characteristic $(B \sim B)$ such that it responds in such a way that the area control error (ACE) is minimized, without imposing an undesired control burden on the other control areas.

\subsubsection{HVDC Links}

An HVDC transmission link consists of the sending end AC bus, transformer, rectifier, HVDC transmission line, $\mathrm{DC}$ to $\mathrm{AC}$ converter and receiving end $\mathrm{AC}$ bus as shown in Figure $1.2(\mathrm{a})$. 
The control of HVDC transmission is based on the characteristic of the bridge type converter circuit. These characteristic are illustrated in Figures 1.2 and 1.3.

The HVDC power transmission system depends on continuous operation of two interacting control loops. At the rectifier the direct current level is controlled while at the inverter the direct voltage is controlled either directly or by maintenance of a constant extinction angle. These loops are relatively fast by power system standards, requiring in the order of 20 to 50 milliseconds for completion of a step change. A somewhat slower constant power control is often added which adjusts the set point of the current control according to available DC voltage.

With reference to Figures 1.2 and 1.3 the normal mode of operation is with the rectifier on constant current (C.C.) control and the inverter on constant extinction angle (C.E.A.) control. The operation point is located at the intersection of the rectifier and inverter characteristics. Operation at either (1) or (2) depends on the sign of the margin setting $\left(I_{d m}\right)$. A reversal of this sign reverses the direction of DC power flow by reversal of the polarity of the converter voltage.

The current control adjusts the firing delay angle $(\alpha)$ to keep desired current in the DC line. Normally the changes in $\alpha$ are kept small and are utilized to cope with small disturbances. Major changes in DC power transfer are controlled by simultaneous adjustments of the transformer tap changers on the bridges. The VAR consumption at the rectifier is proportional to the firing delay angle $(\alpha)$. 
-AC-Transformer Rectifier-HVDC Line- Inverter-Transformer-AC-

(a)

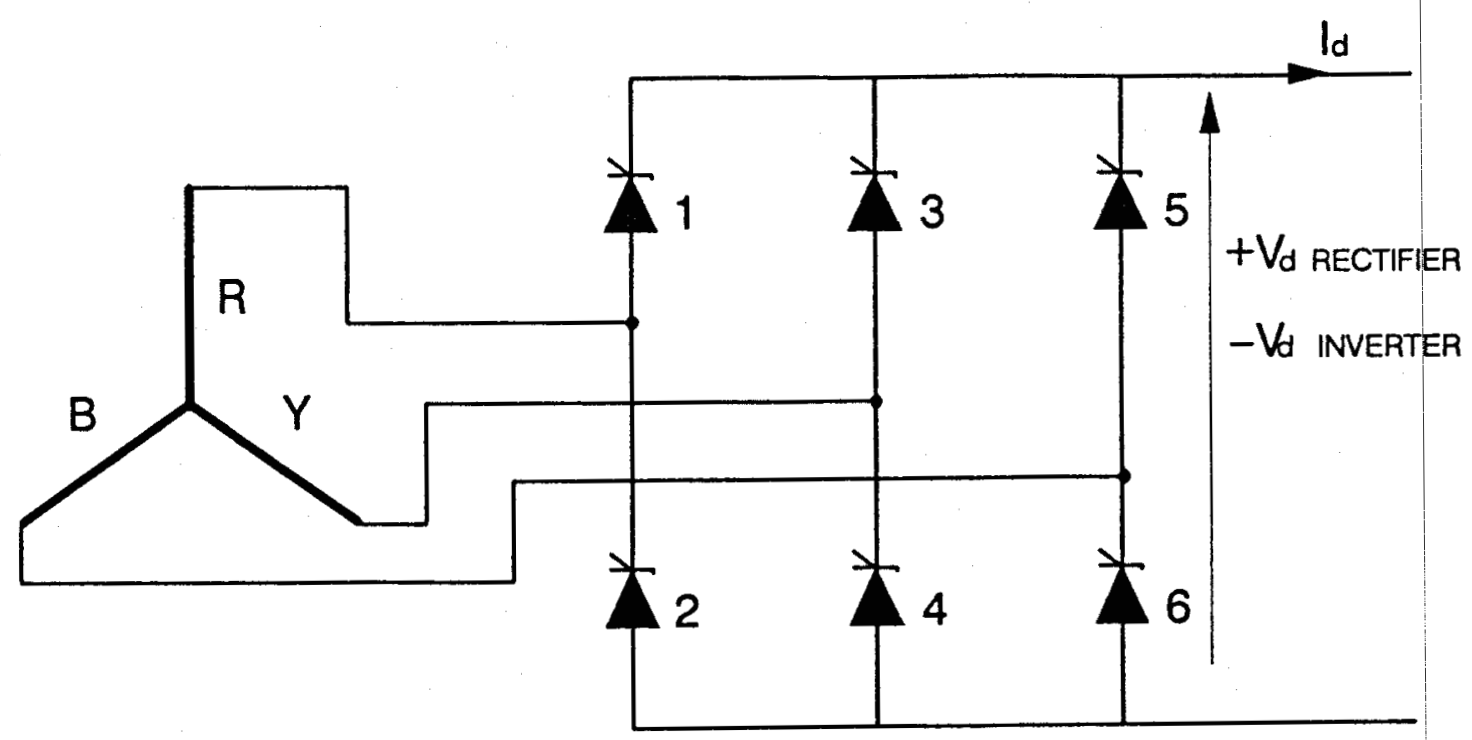

(b)

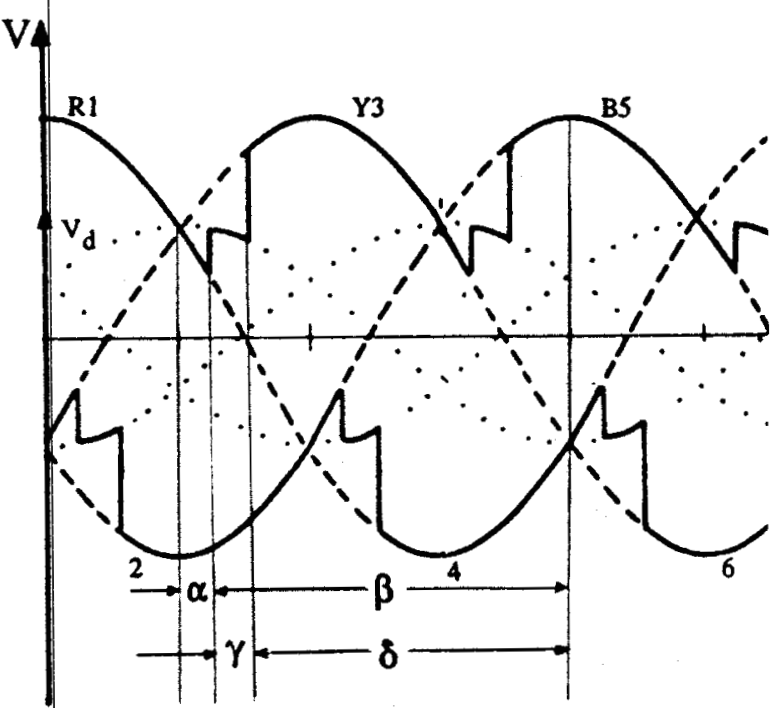

(c)

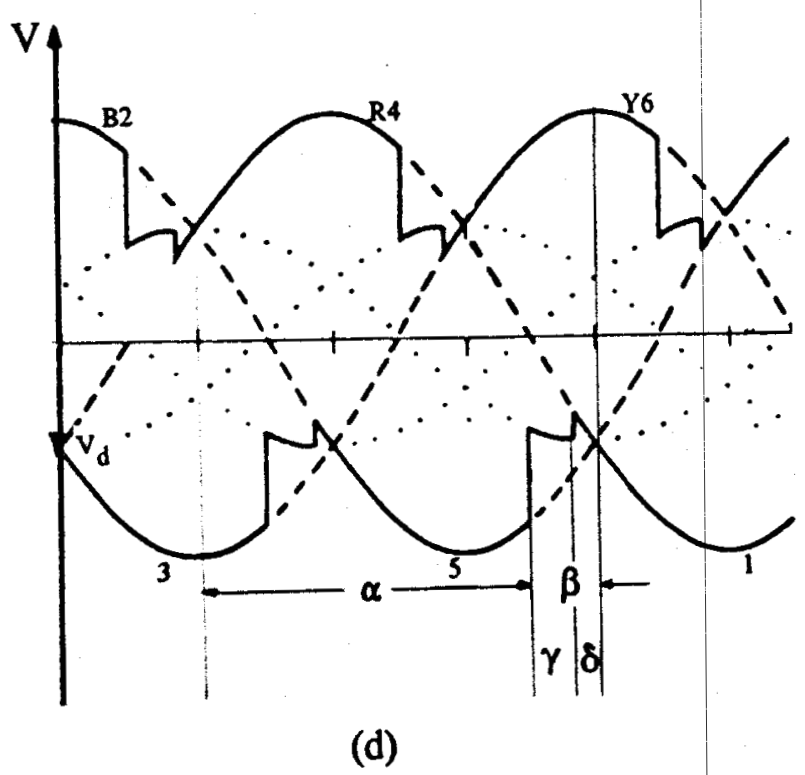

(d)

Figure 1.2 (a) HVDC transmission link, (b) bridge converter, (c) rectifier waveforms, (d) inverter waveforms. 


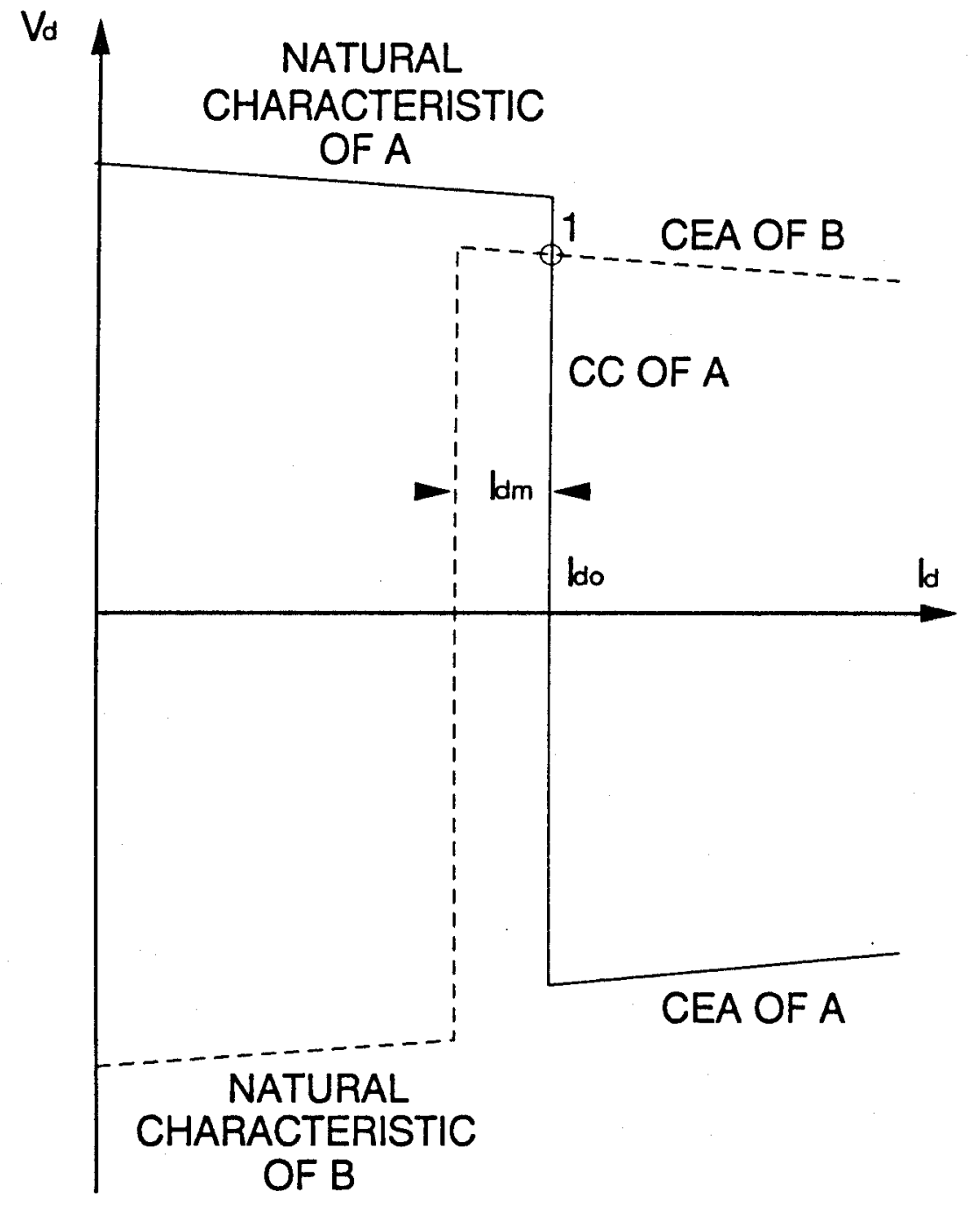

(a)

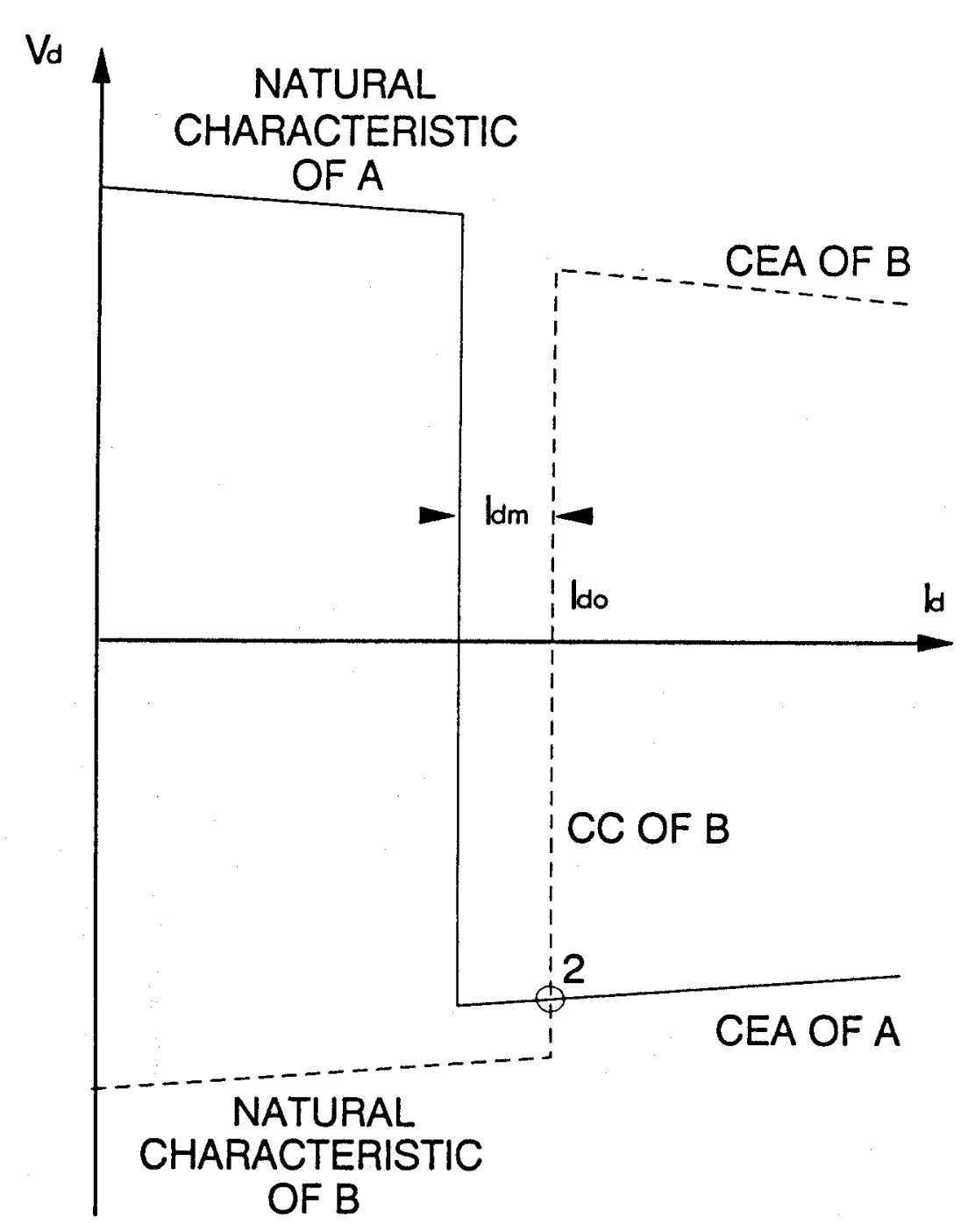

(b)

Figure 1.3 (a) Operating characteristic with "A" rectifier and "B" inverter; (b) Operating characteristic after power reversal. 
The constant extinction angle $(\gamma)$ control of the inverter adjusts the firing advance angle (B) to maintain a safety range in $\delta$ to assure current decay to zero as require for commutation. On the other hand, $\delta$ would not be large because the output voltage reduces as $B$ increases resulting in poor utilization of equipment. Also the VAR consumption of the inverter increase when $B$ increases.

One of the common requirements of HVDC transmission schemes is that the DC link should deliver a scheduled level of power. Although constant current control comes near to meeting this requirements if the direct voltage remains reasonably constant, more accurate power control can be obtained by automatically varying the direct current so as to compensate for changes in the DC voltage caused by the variation of the $\mathrm{AC}$ network voltage.

Power control could be accomplished in either of two ways. The first way would be to measure the power on either the AC or DC circuit, compare it with the power order, and use the difference (error signal) to advance or retard the ignition of the thyristor valves. In order to keep the advantages of current control (including its speed and the current limits), the power control does not replace the current control but supplements $\mathrm{it}^{6,7}$. Alternatively, the power order and the measured direct voltage are fed in to an analog divider, whose output signal represents the direct current. This becomes the current order $\left(I_{d o}\right)$, which is one of the input signals to the current control. Other inputs to the current control are a current feedback signal (the DC line current) and a current margin signal $\left(I_{d m}\right)$, both are of reverse polarity with 
respect to the current order signal. In the event of the inverter taking over the current control, the current controller boosts the current order first to the rectifier and a little later to the inverter by the amount of the current margin, and thus restores the scheduled DC power level in a few tenths of a second.

Constant power control helps to minimize the effect on the AC networks of changes within the HVDC system. Power flow controls can also be designed to vary the DC power interchange in any desired way to satisfy the particular requirements of a HVDC transmission scheme. In addition to the desired DC power and voltage, other signals (supplementary control signals) may be used to modulate the power transmitted over the DC link. DC power modulation can be made in response to various $\mathrm{AC}$ system variables such as the phase angle between terminal buses, difference in frequency deviation between control areas ${ }^{28,30,37}$ and deviation of AC power interchange from its scheduled value.

\subsubsection{Influence of HVDC Links on AC Systems}

HVDC links have been used for various purposes, such as:

i) Reinforcing the AC system in areas of high load density without increasing the interrupting capacity of circuit breakers, using underground cables (short distance transmission) as in the case of Kingsnorth scheme $e^{6,9}$ and Inga Shaba?.

ii) Transmitting of bulk power, long distance, as in the case of the Nelson River scheme ${ }^{6,9}$. 
iii) Interconnecting $\mathrm{AC}$ systems having different frequencies as in the case of Sakuma scheme $e^{6,9}$ in Japan and Itaipu scheme $e^{9}$ in Brazil/Paraguay. In both cases the DC link interconnects the 50 and $60 \mathrm{~Hz}$ systems.

iv) Sea crossing using submarine cables as in the case of Gotland cross channel $^{6,9}$ and New Zeland ${ }^{6,9}$ schemes.

v) Back-to-back interconnection of AC systems where loop stability problems exist as in the case of Sakuma and Eel River ${ }^{6,9}$ schemes, where the length of the link is practically zero.

In all the above cases, two $\mathrm{AC}$ systems are interconnected only by a DC line which has no inherent problem of synchronous stability. HVDC links are also used to operate in parallel with $\mathrm{AC}$ lines as in the case of Vancouver Island ${ }^{37}$ and Pacific Northwest Southwest intertie $e^{6,9,16,20}$ schemes. This type of interconnection combines both economical and technical advantages of HVDC systems, and the possibility of supplying intermediate loads.

A common requirement in all HVDC power systems is that the power transfer over the DC line be maintained within a scheduled range, which is determined by the rectifier and inverter controls within constraints imposed by the AC system voltages and the inherent current limitation of the converters. However, DC power control can be accomplished for the purpose of improving the whole system dynamic performance. In this regard, a variety of DC line control strategies have been suggested $^{7,20,21,28,30,31,32,47}$. 


\subsubsection{Dynamic Stability}

This denotes the stability of synchronous machines subjected to small and relatively fast disturbances. In normal operation small frequency deviations occur continuously with corresponding variations in the rotor angle differences and generator loadings. These oscillations are associated with changes in generator outputs, bus voltages, line power flows and system loads. If the variations resulting from any initial change decrease with time, the system is said to be dynamically stable. Conversely, if these oscillations increase with time, the system is dynamically unstable. Due to the effects of non linearities, such oscillations may be limited at some magnitudes ${ }^{2}$. In general, these oscillations are in the frequency range of 0.01 to $0.2 \mathrm{~Hz}$, associated with governors, and 0.2 to $3 \mathrm{~Hz}$, associated with exchanges of power between generating plants in the system.

\subsection{Review of Literature}

In the last three decades several studies have been conducted to emphasize the performance improvements of power systems because of HVDC controllability. \$ome of this studies are related with development of suitable models for studying hybrid AC/DC systems and a more detailed simulation of power systems. In others, the influence of $\mathrm{DC}$ power modulation on the stability of $\mathrm{AC} / \mathrm{DC}$ power systems for yarious control schemes has been researched. Some of these studies are reviewed briefly in the following paragraphs to illustrate the extent of past work and to place the present work in context. 
Ühlman ${ }^{7}$ has demonstrated analytically the use of a DC link to stabilize an AC transmission line. By using a control signal based on frequency deviations, he showed that any degree of system damping could be obtained with the appropriate control of the DC power and the AC system could be stabilized for large values of phase difference between the AC terminal bus voltages. Ühlman's analysis was developed for a simplified system composed of two machines represented by inertial models, connected by AC and DC lines in parallel. He also assumed constant voltages and negligible time constants for the DC link and the associated control system. In addition he concluded that:

i) The damping introduced by the DC link control remains satisfactory even under practical current limitations of the DC link.

ii) Within limits, some time delay in the application of the control signal has no serious effect.

iii) Reactance common to the power flow over the $\mathrm{AC}$ and $\mathrm{DC}$ lines has an unfavourable effect on the DC stabilizing action.

Machida and Yoshida ${ }^{28,29,30}$ present a method of automatic frequency ratio control (AFRC) by a DC system. This control also provides a tie line bias control action. The operating principle is that the frequency deviations of the two interconnected AC systems are detected and the controller adjusts the DC power for constant frequency control. They conclude that:

i) By applying the AFRC device to the random load disturbances in a steady 
state, not only are the frequency fluctuations improved (decreased) but the power changes of the regulating power stations in both $\mathrm{AC}$ systems are also reduced.

ii) In order to apply an AFRC device effectively for a random load disturbance with the magnitude of $\pm 1.5 \%$ of system capacity, it is necessary to have a controllable DC power margin of 0.7 to $1.0 \%$ of a smaller AC system capacity.

Dougherty and Hillesland ${ }^{47}$ made an evaluation of effectiveness of DC power modulation in improving the steady state and transient stability of power systems. Their work was performed on the Edison Electric Institute (EEI) $700 \mathrm{KW}$ model of a parallel $\mathrm{AC} / \mathrm{DC}$ power system. The DC power modulation is based on the rate of change of the power angles of machine rotors and its derivative (frequency signal). They conclude that:

i) The very fast control of power possible on DC transmission can provide strong damping to disturbances within the power system.

ii) Even if the source of disturbance is a temporary outage of the DC line itself, its dynamic response provides effective damping immediately after restarting the line.

iii) The DC power modulation based on frequency deviations was the most effective control for the EEI model system.

iv) Substitution of a dynamically responsive DC line for one of two parallel 
AC lines will provide a marked improvement in the transfer capability, using either steady state or transient stability as the criterion.

Cresap and Mittelstadt ${ }^{20}$ confirmed experimentally the fact that DC power can be modulated to improve the performance of a parallel AC network. The Pacific HVDC intertie control, uses rate of power changes on the AC line as the modulation signal for the DC power transfer. For small perturbations, and assuming constant bus voltages of the intertie, the change in power transmitted is related to power angle. They have also concentrated on the development and implementation of a control algorithm based on the time derivative of the power transmitted over the AC line. The results obtained from both the simulation studies and the field experience have shown that the DC power modulation provides a positive damping for the natural mode of system oscillation. The rating increment of the Pacific AC intertie, from $2100 \mathrm{MW}$ to $2500 \mathrm{MW}$, resulted from the successful operation of the DC power modulation scheme.

\subsection{Purpose of the Thesis}

The purpose of the research reported in this thesis was to extend the studies reported above to investigate how HVDC control could be used to simultaneously affect damping of system oscillation modes as well as reduce area control errors (ACE) and inadvertent energy interchange (IEI). 
The controllability of HVDC links can be valuable in improving the overall dynamic performance of an AC/DC interconnected power system. Usually HVDC systems are operated with constant power control in accordance with a fixed scheduled DC power transmission; on the other hand, due to load variation (small disturbance) from time to time on the $\mathrm{AC}$ systems, automatic generation control action is required to match the generation to power demand, within predefined frequency limits. Utilizing the fast power control characteristic of HVDC systems with a suitable supplementary controller to modulate the DC power transfer, based on an AC system signal (e.g. net power interchange deviation from its scheduled value) it should be possible to reach the following objectives:

i) improve system dynamic stability providing a positive damping for the natural modes of system oscillations,

ii) minimize the area control error (ACE) in both $\mathrm{AC}$ systems to avoid excessive governing system operation, and

iii) reduce the inadvertent energy interchange (IEI) between neighbouring power systems (control areas).

Therefore a small signal analysis of two area interconnected power system (TAIPS) via parallel AC/DC tie lines was developed.

A transfer function block diagram representing the power frequency problem of the system under study is presented. The system state space equation and the 
eigenvalue analysis of the system is developed to evaluate system stability and the participation factors of each eigenvalue in the system dynamic response.

To evaluate the control system effectiveness, with and without supplementary control, a performance index is used as a reference parameter of system performance improvement. Then a simulation technique is applied to the system model under study to obtain the system dynamic response and also to compute the optimal controller parameters based on the performance index minimization.

From the simulation process an extensive analysis of results is presented including different cases as follows:

i) effect of AGC controller parameter variation without supplementary control,

ii) effect of supplementary controller parameter variation,

iii) effect of supplementary controller parameter variation with DC power limiter,

iv) optimal supplementary controller parameter for various DC power limiters,

v) optimal supplementary controller parameter for different step load disturbances.

Also reported in this thesis are the results of simulation studies of dynamic responses in the following cases: 
i) Dynamic response of a TAIPS via two AC tie lines,

ii) dynamic response of a TAIPS via AC/DC tie lines, without supplementary control,

iii) dynamic response of a TAIPS via AC/DC tie lines, with supplementary control, and

iv) dynamic response of a TAIPS via AC/DC tie lines, with supplementary control and DC power limiter. 


\section{THE SYSTEM MODEL}

\subsection{General}

For any power system dynamic study, a suitable power system model must be chosen to include in the model all significant components relevant to the problem, and to exclude from the model insignificant components irrelevant to the problem.

Typically in studies of power system stability, one is concerned with transients in the range of 0.1 to 20 seconds duration, response characteristics in the range of over $10 \mathrm{~Hz}$ usually may be considered instantaneous. In this context, the high frequency dynamics of a DC transmission line and pole controls may be ignored just as the high frequency dynamics of $\mathrm{AC}$ transmission lines and transformers are ignored. Then the current control, voltage control, valve firing circuit and DC system (L/R and RC time constants) usually can be considered to respond instantaneously to changes in AC system voltage, desired direct current, desired direct voltage or margin angle.

In AC systems, an unbalance between generated power and load affects primarily the system frequency, leaving bus voltages magnitudes practically unaffected. On the other hand, unbalance in reactive power primarily affects only bus yoltages, leaving the system frequency essentially unaffected. Therefore the control 
problem can be divided in two decoupled cases. It is emphasized that these characteristics can be considered only when the changes involve only a few percent of normal operating values (i.e. are first order in a mathematical sense). In this study, only the power/frequency control problem is analyzed.

A simplified line diagram of an interconnected power system and its functional control scheme is illustrate in Figure 2.1. The power system proposed in this thesis is composed of two power system areas interconnected by parallel AC and DC tie lines. Each AC power system is represented by thermal generation (a turbine/generator), area load $\left(P_{L}\right)$ and system interconnection bus. The DC link includes two converter stations, one performing as a rectifier at the sending end, and the other performing as an inverter at the receiving end.

The basic control system includes the speed governing system, the AGC control system and the DC system control. A supplementary controller is added to the basic control scheme to introduce a new control signal $\left(\mathrm{U}_{3}\right)$ to the $\mathrm{DC}$ system. This control signal is derived from AC system signals and used by the DC system control to modulate the DC power transfer over the DC link.

Since the purpose of this research was to investigate the dynamic performance improvements due to supplementary DC power modulation, the study considered principally the optimization of the AGC controller parameters and supplementary controller parameters to improve control effectiveness. 


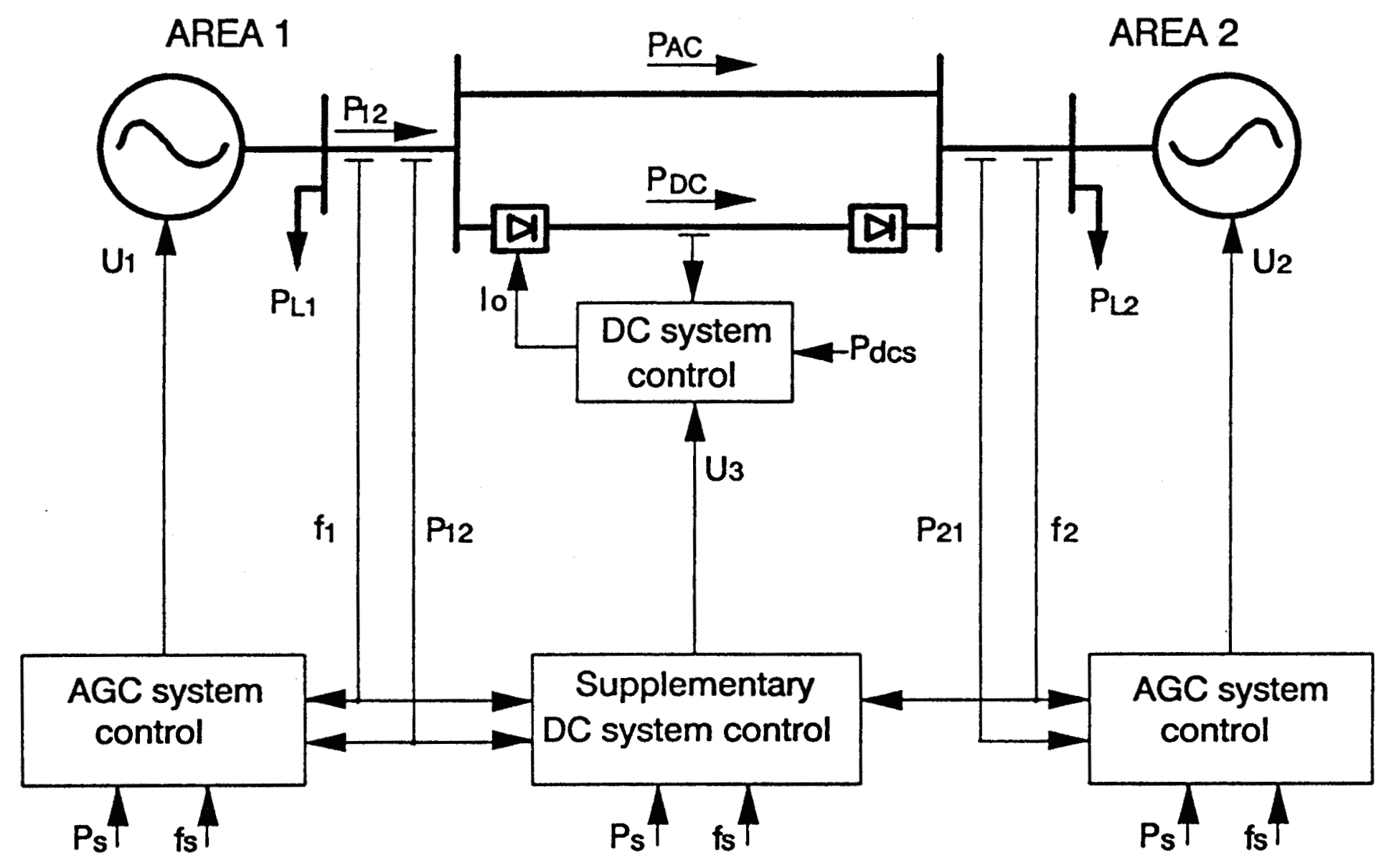

Figure 2.1 The Two Area Interconnected Power System (TAIPS). 
The power frequency control problem required a simplified linearised and time invariant model for low frequency oscillations studies. The linear model was satisfactory because only small changes around a reference state were to be considered.

In the derivation of the model for the two area interconnected power systems, the following assumptions were made:

i) the electrical interconnections within each individual control area are so strong, at least in relation to the ties with the neighbouring area, that the whole area could be characterized by a single frequency and can be represented by one equivalent machine;

ii) the voltage magnitudes at the high voltage $\mathrm{AC}$ buses were maintained constant by the voltage regulation action;

iii) incremental mechanical and electrical losses were considered to be negligible, including those of the $\mathrm{AC}$ and $\mathrm{DC}$ links.

\subsection{Frequency Deviation}

System frequency serves as an indication of any unbalance between load and generation. Frequency deviation " $\Delta \mathrm{f}$ " is defined ${ }^{1}$ as the actual system frequency " $\mathrm{f}$ " minus the scheduled frequency " $f_{s}$.

$$
\Delta \mathrm{f}=\mathrm{f}-\mathrm{f} \quad \mathrm{Hz}
$$


In general, a negative frequency deviation represents a deficiency of generation while a positive frequency deviation represents an excess of generation.

\subsection{Net Power Interchange Deviation}

Net power interchange deviation is defined ${ }^{1}$ as the algebraic sum of the powers on the area tie lines of a control area. Positive net interchange due to excess of generation is out of the area. Net power interchange deviation " $\Delta \mathrm{P}_{12}$ " is the actual net interchange minus the scheduled net interchange, from area 1 to area 2.

$$
\Delta \mathrm{P}_{12}=\mathrm{P}_{12}-\mathrm{P}_{\mathrm{s}} \quad \mathrm{puMW}
$$

Since the interconnection between area 1 and area 2 includes two tie lines, one AC link and one DC link, the net power interchange deviation is expressed as

$$
\Delta \mathrm{P}_{12}=\Delta \mathrm{P}_{\mathrm{AC}}+\Delta \mathrm{P}_{\mathrm{DC}} \quad \text { puMW }
$$

where $\Delta \mathrm{P}_{\mathrm{AC}}$ and $\Delta \mathrm{P}_{\mathrm{DC}}$ are the net power interchange deviations for the $\mathrm{AC}$ line and DC line respectively.

\subsection{Speed Governing System Model}

The real output power in a power system is controlled by controlling the driving torques of the individual turbines of the system. By controlling the position of the control valve, one can exert control over the flow of steam trough a turbine. The position of the valve can be affected either directly by the speed changer, by changing the reference power setting $\left(\Delta \mathrm{P}_{\text {ref }}\right)$, or indirectly via feedback from changes 
in the speed or frequency $(\Delta f)$ of the generator. Then, an increment in governor output $\left(\Delta P_{g}\right)$ results from an increment in $\Delta P_{\text {ref }}$ and a decrement in $\Delta f$.

$$
\Delta P_{g}=\Delta P_{\text {ref }}-\frac{1}{R} \Delta f \quad \text { puMW }
$$

The constant " $\mathrm{R}$ " is usually called the generating regulating characteristic or droop, in $\mathrm{Hz} / \mathrm{puMW}$. Laplace transformation of Equation 2.4 gives

$$
\Delta P_{g}(s)=\Delta P_{r e f}(s)-\frac{1}{R} \Delta f(s)
$$

In an hydraulic valve actuator, the input position of the valve actuator increases as a result of an increment in governor output $\left(\Delta \mathrm{P}_{\mathfrak{g}}\right)$ but decreases due to an increment of valve output $\left(\Delta \mathrm{P}_{\mathrm{v}}\right)$. Thus the relationship for the actuator is

$$
\Delta P_{v}(s)=\frac{1}{1+T_{G} s} \Delta P_{g}(s)
$$

where $T_{G}$ is the time constant of the speed governing system, which is depending on the geometric and fluid pressure characteristics of the valve actuator.

The transfer function block diagram of the speed governing system is shown in Figure 2.2. Further information about detailed models may be found in references $3,5,8,10,14$ and 17 . 


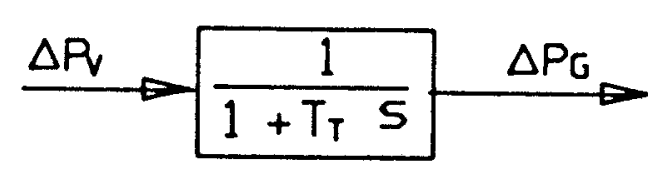

Figure 2.3 Turbine generator block diagram.

\subsection{Power System Model}

To obtain a mathematical relation between generated power deviation $\left(\Delta \mathbf{P}_{\mathbf{G}}\right)$ and frequency deviation $(\Delta f)$ it is necessary to make reasonable assumptions about area behaviour. The system is originally in power balance, that is, generated power equals area load plus net power interchange $\left(P_{G}=P_{L}+P_{12}\right)$, and the system frequency is at scheduled value $\left(f_{s}\right)$. All rotating equipment provide a total kinetic energy of $W_{8}[M W \times s]$. If the area load is increased by $\Delta \mathrm{P}_{\mathrm{L}}$ the speed or frequency in the area will decrease and the power unbalance will be initially compensated by the kinetic energy. Then, as the kinetic energy is proportional to the square of the speed, the area kinetic energy is

$$
W=W_{s}\left(\frac{f}{f}\right)^{2} \quad \text { MWs }
$$

The area load has a frequency dependency $\partial \mathrm{P}_{\mathrm{L}} / \partial \mathrm{f}$ that is usually called the mechanical damping coefficient or area load frequency characteristic (D). Area power balance requires that the increase in turbine power equals the sum of total 
area load plus the rate of change of kinetic energy and the change in net power interchange with the neighbouring area; so, the area power balance is

$$
\Delta \mathrm{P}_{\mathrm{G}}-\Delta \mathrm{P}_{\mathrm{L}}-\Delta \mathrm{P}_{12}=\frac{2 \mathrm{~W}_{\mathrm{l}}}{\mathrm{f}^{*}} \frac{\mathrm{d}}{\mathrm{dt}}(\Delta \mathrm{f})+\mathrm{D} \Delta \mathrm{f} \quad \mathrm{MW}
$$

Dividing Equation 2.9 by the generator rating and introducing the per unit inertia constant

$$
\mathrm{H}=\frac{W_{\mathrm{s}}}{\mathrm{P}_{\mathrm{r}}} \quad \mathrm{MWs} / \mathrm{MW}
$$

Equation 2.9 becomes

$$
\Delta P_{G}-\Delta P_{L}-\Delta P_{12}=\frac{2 H}{f^{*}} \frac{d}{d t}(\Delta f)+D \Delta f \quad \text { puMW }
$$

and by Laplace transformation

$$
\Delta \mathrm{P}_{\mathrm{G}}(\mathrm{s})-\Delta \mathrm{P}_{\mathrm{L}}(\mathrm{s})-\Delta \mathrm{P}_{12}(\mathrm{~s})=\frac{2 \mathrm{H}}{\mathrm{f}^{*}} \mathrm{~s} \Delta \mathrm{f}(\mathrm{s})+\mathrm{D} \Delta \mathrm{f}(\mathrm{s})
$$

equation (2.12) can be wrtten in the form

$$
\begin{aligned}
& \Delta f(s)=\frac{K_{P}}{1+T_{P} s}\left[\Delta P_{G}(s)-\Delta P_{L}(s)-\Delta P_{12}(s)\right] \\
& T_{P}=\frac{2 H}{f^{*} D} \quad s \quad \text { (power system time constant) }
\end{aligned}
$$

*Note: in Equation (2.9) $\mathrm{P}_{\mathrm{G}}, \mathrm{P}_{\mathrm{L}}$ and $\mathrm{P}_{12}$ bave units of $\mathrm{MW}$, but in Equation (2.11) they are in per unit. 


$$
\mathrm{K}_{\mathrm{p}}=\frac{1}{\mathrm{D}} \mathrm{Hz} / \mathrm{puMW}
$$

The transfer function block diagram of the power system is shown in Figure 2.4. Further detailed information on power system models may be obtained from references $3,5,8,10$ and 14 .

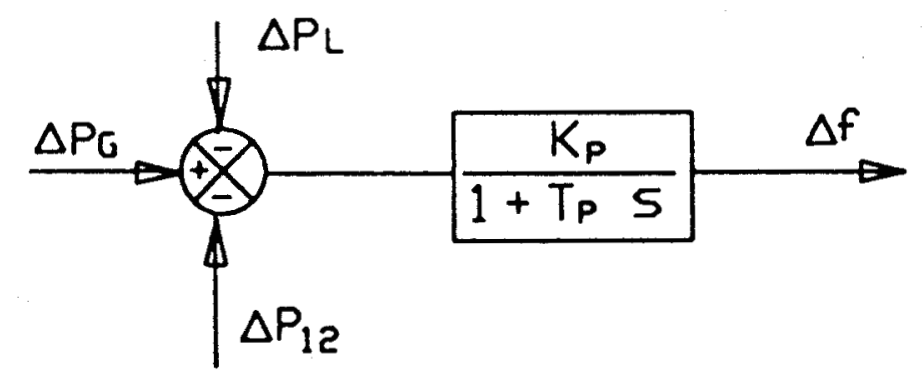

Figure 2.4 Power system block diagram.

\subsection{The AC Link Model}

In a single area case the frequency deviation is represented by the single variable $\Delta \mathrm{f}$. In the present case, of a two area interconnected power system, it is assumed that each area is individually strong and the two areas are interconnected by a weak tie line. Then the frequency deviations in the two areas can be represented by two variables $\Delta f_{1}$ and $\Delta f_{2}$ for area 1 and area 2 respectively.

Under normal operation the AC net power interchange between areas can be 
represented as

$$
P_{A C}=\frac{V_{1} V_{2}}{X} \sin \left(\delta_{1}-\delta_{2}\right) \quad \text { puMW }
$$

where $\delta_{1}$ and $\delta_{2}$ are the phase angles of the voltages $V_{1}$ and $V_{2}$ respectively relative to a common reference and $\mathrm{X}$ is the reactance of the $\mathrm{AC}$ link.

Small deviations of the net power interchange due to deviations in the $\delta$ angles are obtained from $\partial \mathrm{P}_{\mathrm{AC}} / \partial \delta$. So the net power interchange deviation can be expressed as

$$
\Delta \mathrm{P}_{\mathrm{AC}}=\mathrm{P}_{\mathrm{AC}} \max \cos \left(\boldsymbol{\delta}_{1}-\boldsymbol{\delta}_{2}\right)\left(\Delta \boldsymbol{\delta}_{1}-\Delta \boldsymbol{\delta}_{2}\right) \quad \mathrm{puMW}
$$

where $P_{A C} \max =V_{1} V_{2} / X$.

The synchronizing coefficient of the link is defined as

$$
\mathrm{T}_{12}=2 \pi \mathrm{P}_{\mathrm{AC}} \max \cos \left(\boldsymbol{\delta}_{1}-\boldsymbol{\delta}_{2}\right) \quad \mathrm{puMW} / \mathrm{Hz}
$$

and the frequency deviation $\Delta \mathrm{f}$ is related to the reference angle by

$$
\Delta \delta=2 \pi \int \Delta f d t \quad r a d
$$

By expressing the net power interchange in terms of $T_{12}$ and $\Delta f$ one obtains

$$
\Delta P_{A C}=T_{12}\left(\int \Delta f_{1} d t-\int \Delta f_{2} d t\right) \quad p u M W
$$


and by Laplace transformation

$$
\Delta P_{A C}=\frac{T 12}{s}\left[\Delta f_{1}(s)-\Delta f_{2}(s)\right]
$$

The transfer function block diagram of the AC link is shown in Figure 2.5. A more detailed information about modelling $\mathrm{AC}$ tie lines may be found it in references $3,5,7,8,14$ and 33 .

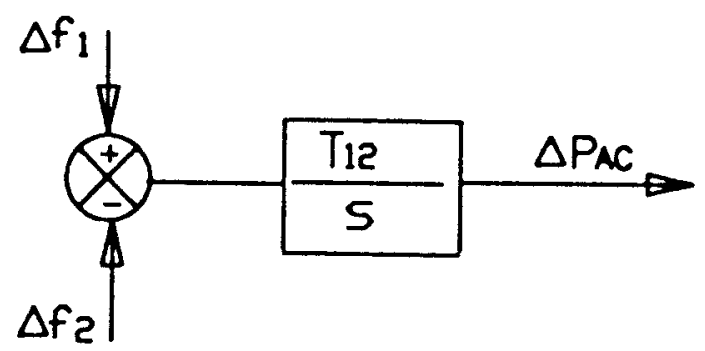

Figure 2.5 The AC link block diagram.

\subsection{The DC Link Model}

The transfer function of a constant DC power control system including the

DC line, is generally represented by a second order control system ${ }^{29}$. Since the dynamic response of automatic generation control in the AC power system is slow (i.e. of the order of a few seconds) the DC converter can be safely represented as a first order control system.

A DC transmission line has many natural modes of oscillation, generally the 
first resonant frequency is between 10 to $100 \mathrm{~Hz}^{6}$ and the remaining resonant frequencies are greater. However in this research interest is in the power frequency interactions under $3 \mathrm{~Hz}$, much smaller than the DC line resonance frequency; therefore the dynamics in the DC link are neglected and the variation of DC link power is treated as a control input which is applied at the DC terminal bus. This is justified in view of the fast response of modern converters with thyristor valves.

The DC link is represented by a simplified model shown in Figure 2.6, where $T_{D C}$ is the time constant of $D C$ power control system, $\mathbf{s}$ is the Laplace operator, $\Delta P_{D C}$ is the deviation in DC power transfer from its scheduled value, and $U_{3}$ is the modulation signal for the DC power control. Further information may be obtained from references $6,7,9,29,31,38,39$ and 42 .

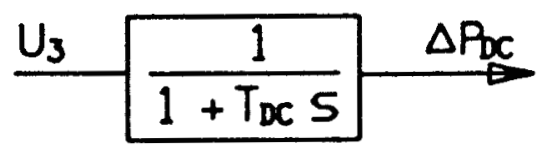

Figure 2.6 Simplified model of a DC link.

\subsection{Automatic Generation Control Model}

The AGC control regulates the area generated power in response to changes in area load, system frequency, net power interchange, or the relation of these to 
each other so as to maintain these variables within scheduled limits.

The conventional AGC approach employs a system controller which is usually implemented as a proportional plus integral action based on the area control error (ACE). The area control error results from a linear combination of the contribution from both the frequency deviation and the net power interchange deviation.

$$
\mathrm{ACE}=\Delta \mathrm{P}_{12}+\mathrm{B} \Delta \mathrm{f} \quad \mathrm{puMW}
$$

The bias setting $\mathrm{B}$, in puMW/Hz, determines the control contribution of an area to maintain the scheduled frequency in the interconnected system. The ACE signal represents the amount of generation required in the area to restore system frequency and net power interchange back to scheduled values.

The AGC control senses frequency deviation and net power interchange deviation to compute the ACE signal, which is processed by the AGC controller to provide the control signal (reference) to the speed governing system. The AGC controller output is a control signal $\mathrm{U}$, that includes a component that is proportional to, plus one that is the time integral of, the ACE signal.

$$
\mathrm{U}=\mathrm{k}_{\mathrm{p}} \mathrm{ACE}+\mathrm{k} \int \mathrm{ACE} \mathrm{dt}
$$

By Laplace transformation 


$$
U(s)=\left[k_{p}+\frac{k_{1}}{s}\right] \operatorname{ACE}(s)
$$

where $k_{\mathrm{p}}$ and $k_{\mathrm{I}}$ are the proportional and integral gain respectively.

A block diagram of the AGC controller model is shown in Figure 2.7. Further information may be obtained from references $3,5,14,34$ and 41 .

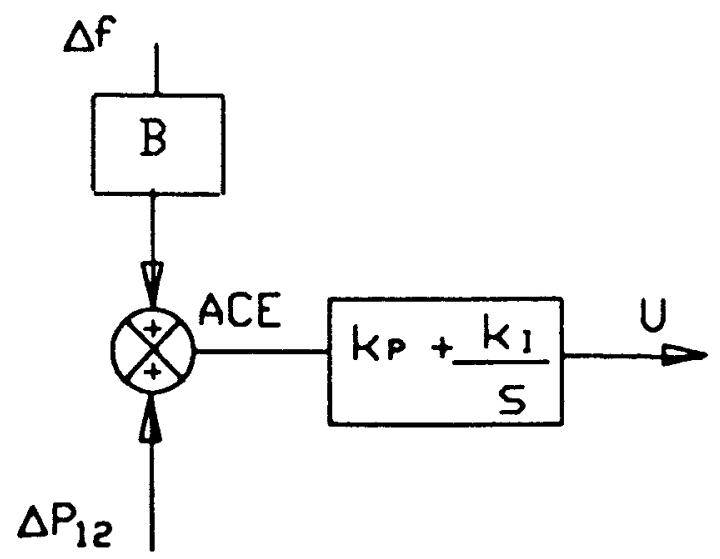

Figure 2.7 AGC controller block diagram.

\subsection{Supplementary Control Model}

A supplementary controller is added to the conventional control scheme, to improve overall dynamic performance of the two areas interconnected power system (TAIPS). This supplementary PI controller (proportional plus integral control) provides a new control signal $\mathrm{U}_{3}$ (reference) to the constant DC power system control to modulate the DC power transfer based on AC system signals. The modulation signals from the AC system, can be net power interchange deviation $\Delta P_{12}$ and/or difference in frequency deviation from both areas $\left(\Delta f_{1}-\Delta f_{2}\right)$. A block diagram 
of the supplementary controller is shown in Figure 2.8, where $k_{p}$ and $k_{1}$ are the proportional and integral gain, and $K_{\mathbf{f}}$ is the frequency sensitivity of the controller.

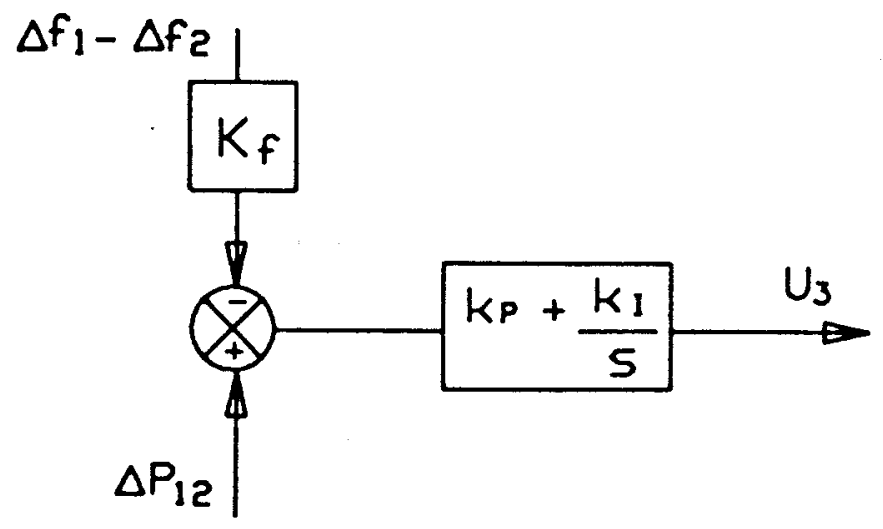

Figure 2.8 Supplementary controller block diagram.

\subsection{Block Diagram of Two Area Interconnected Power System.}

A small perturbation transfer function block diagram of a two area thermal \$ystem, interconnected via $\mathrm{AC}$ and $\mathrm{DC}$ tie lines is shown in Figure 2.9. The \$ubsystems discussed above have been combined in a suitable way to constitute the main model to satisfy the objectives of this research.

Automatic generation control (AGC) of interconnected power systems is centred around tie line frequency bias control strategy. A supplementary controller is implemented to regulate DC power transfer according to changes in net power interchange and/or difference in area frequencies. The fast supplementary control interacts with the conventional AGC controller to restore system frequency and net power interchange to scheduled values (zero steady state area control error). 


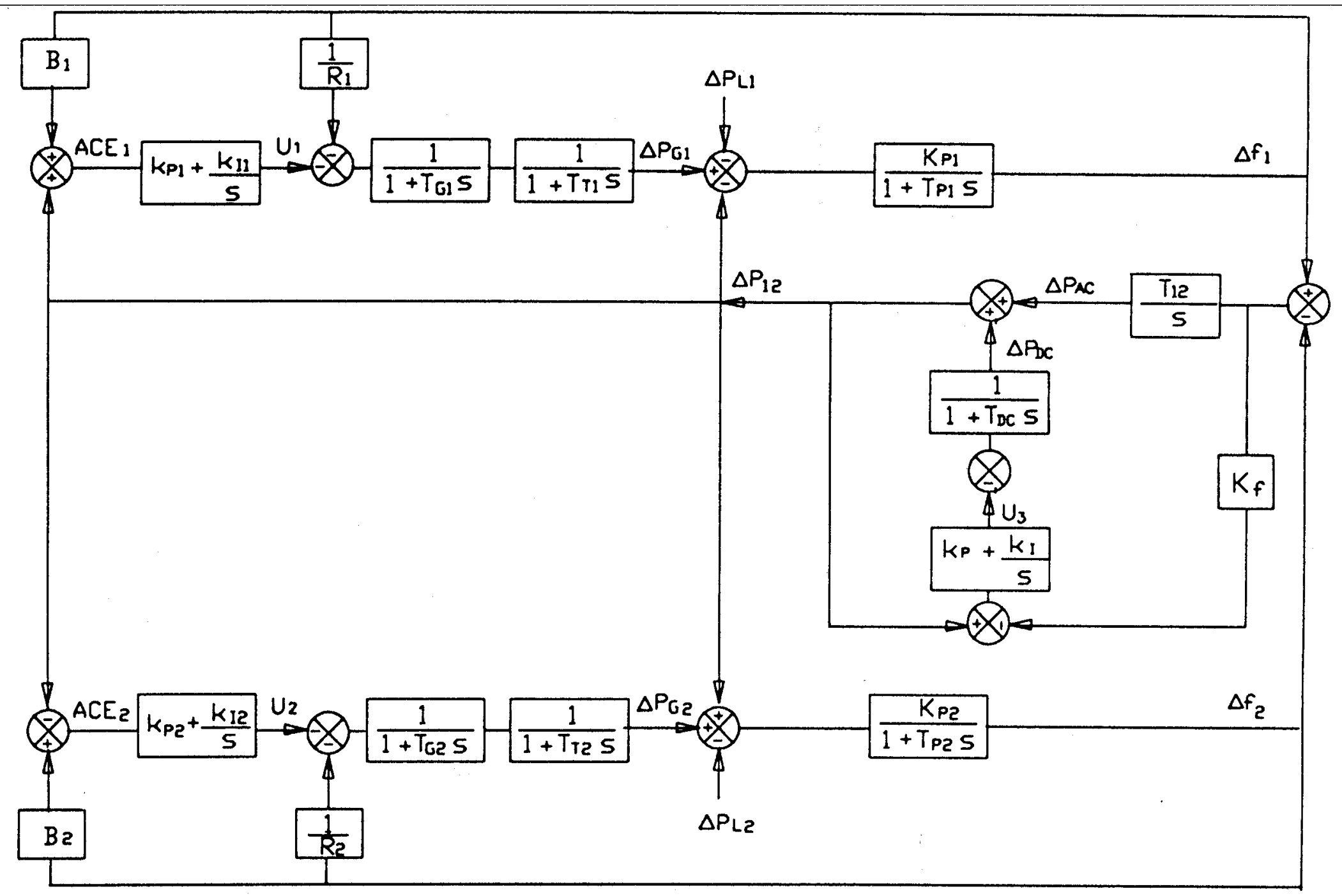

Figure 2.9 Transfer function block diagram of two area thermal system interconnected by AC and DC tie-lines. 
Nomenclature:

Pr Area capacity (power base), MW

f nominal system frequency, $\mathrm{Hz}$

subscript referring to area $(i=1,2)$

$\Delta \mathrm{P}_{\mathrm{Gi}}$ generated power deviation, puMW

$\Delta \mathrm{P}_{12}$ net power interchange deviation, puMW

$\Delta \mathrm{P}_{\mathrm{Li}}$ change in load demand (load disturbance), puMW

$\Delta \mathrm{f}_{\mathrm{i}}$ frequency deviation, $\mathrm{Hz}$

$\Delta \mathrm{P}_{\mathrm{AC}} \mathrm{AC}$ tie line power deviation, puMW

$\triangle P_{D C}$ DC tie line power deviation, puMW

$U_{\mathrm{i}} \quad$ AGC control signal

$\mathbf{U}_{3}$ supplementary control signal

ACE area control error, puMW

$\mathrm{F}_{\mathrm{Gi}}$ speed governor time constant, $\mathrm{s}$

$\mathrm{R}_{\text {i }}$ generation regulation characteristic, $\mathrm{Hz} / \mathrm{puMW}$

$\mathrm{T}_{\mathrm{Ti}}$ steam chest time constant, $\mathrm{s}$

H inertia constant, $s$

$D_{1}$ load frequency characteristic, puMW/Hz

$\left(\mathrm{K}_{\mathrm{Pi}}=1 / \mathrm{D}_{\mathrm{i}}, \mathrm{T}_{\mathrm{Pi}}=2 \mathrm{H}_{\mathrm{i}} / \mathrm{f}^{*} \mathrm{D}_{\mathrm{i}}\right)$

$\mathrm{T}_{12}$ synchronising coefficient, puMW/Hz

B frequency bias constant, puMW/Hz

$k_{\text {pi }}$ proportional gain of AGC controller

$k_{\text {ii }}$ integral gain of AGC controller 
$\mathrm{T}_{\mathrm{DC}} \quad$ DC system time constant, $\mathrm{s}$

$k_{p} \quad$ proportional gain of supplementary controller

$\mathrm{k}_{\mathrm{I}}$ integral gain of supplementary controller

s Laplace operator

\subsection{Power System Parameters}

For the purpose of this study both area power systems have the same characteristics. So it is assumed that both areas have equal system parameters (equal time constants and gain coefficients). The nominal system parameters are:

$$
\begin{aligned}
& \mathrm{P}_{\text {base }}=2000 \mathrm{MW} \\
& \mathrm{f}^{*}=60 \mathrm{~Hz} \\
& \mathrm{P}_{\mathrm{ri}}=2000 \mathrm{MW} \\
& \mathrm{H}_{\mathrm{i}}=5 \mathrm{MWs} / \mathrm{MW} \\
& \mathrm{D}_{\mathrm{i}}=8.33 \times 10^{3} \mathrm{puMW} / \mathrm{Hz} \\
& \mathrm{R}_{\mathrm{i}}=2.4 \mathrm{~Hz} / \mathrm{puMW} \\
& \mathrm{T}_{\mathrm{Gi}}=0.08 \mathrm{~s} \\
& \mathrm{~T}_{\mathrm{Ti}}=0.3 \mathrm{~s} \\
& \mathrm{~T}_{\mathrm{Pi}}=20 \mathrm{~s} \\
& \mathrm{~K}_{\mathrm{Pi}}=120 \mathrm{~Hz} / \mathrm{puMW} \\
& \mathrm{T}_{\mathrm{DC}}=0.05 \mathrm{~s}
\end{aligned}
$$

The AC and DC tie lines have a capacity of $10 \%$ of area capacity, and the AC system is operating at a power angle ( 8 ) of $30^{\circ}$. Then the synchronising torque 
coefficient is: $\mathrm{T}_{12}=0.544 \mathrm{puMW} / \mathrm{Hz}$

The frequency bias constant $\left(B_{1}\right)$ is set equal to the area frequency response $\left(\beta_{\mathrm{i}}\right)$ to minimize the control action in the control area where no disturbance occurs. Then the bias constant is: $\mathrm{B}_{1}=0.544 \mathrm{puMW} / \mathrm{Hz}$

The PI controller parameters will be chosen to optimize the control effectiveness. To evaluate the control effectiveness a performance index is computed, which is related to the control error (ACE) in both control areas. 


\section{STATE SPACE NOTATION}

\subsection{General}

A mathematical model of a system can be obtained from the structure of the system and the properties of individual elements of the system. A suitable model is a compromise between the mathematical complexity attached to complicated equations and the desired accuracy in the results. Equations describing the system dynamics can often be approximated by ordinary differential equations of order " $n$ " with time " $\mathrm{t}$ " as the independent variable, or a set of " $\mathrm{n}$ " first order ordinary differential equations. The difficulty of analyzing and solving a system depends on the type of differential equations which describe it. Usually a system described by linear and time invariant differential equations is easier to study, but unfortunately, in constructing models for physical systems one arrives more often at a nonlinear system of equations. However the power frequency control problem studied in this research required a simplified linear and time invariant model. The linear and time invariant characteristics are adequate because small changes around a reference state and slow changes in the system's characteristics are considered.

\subsection{State Space Representation}

The state of a system is defined ${ }^{13}$ as the minimum set of numbers or variables, the state variables, which contain sufficient information about the past history of the 
system to permit us to compute all future states of the system, assuming known all future inputs (control forces) and equations describing the system.

For a multiple input multiple output (MIMO) system the block diagram representation including optimal control feedback is shown in Figure 3.1.

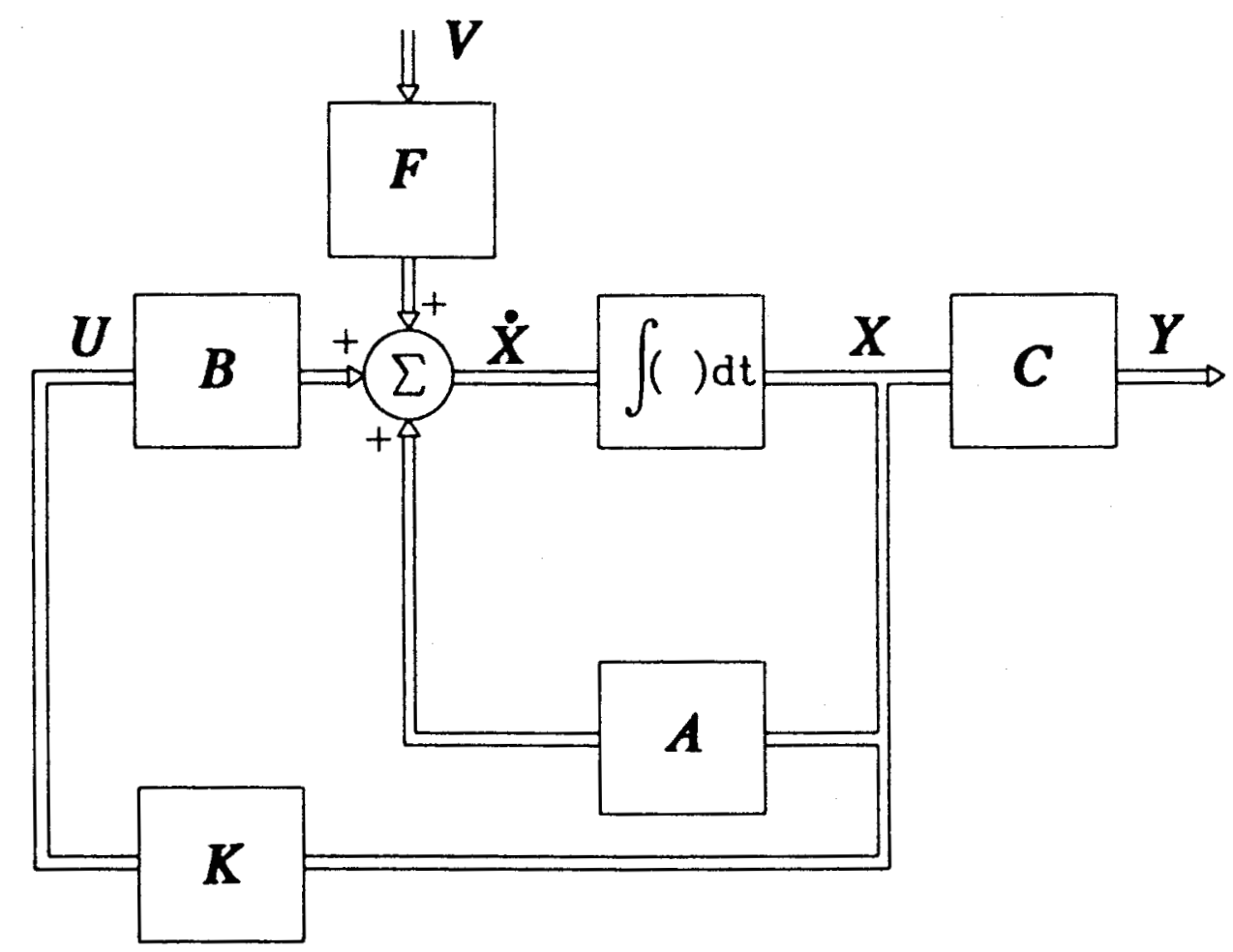

Figure 3.1 Block diagram of a MIMO system.

The state space equations are:

$$
\begin{gathered}
\dot{X}=A X+B U+F V \\
U=K X
\end{gathered}
$$




$$
Y=C X
$$

then the state space equation can be rewritten as:

$$
\begin{gathered}
\dot{X}=[A+B K] X+F V \\
Y=C X
\end{gathered}
$$

$X:[n \times 1]$ state vector

$U:[\mathrm{r} \times 1]$ control vector

$V:[p \times 1]$ disturbance vector

$Y:[\mathrm{m} \times 1]$ output vector

$4:[n \times n]$ state coefficient matrix

$B:[\mathrm{n} \times \mathrm{r}]$ control coefficient matrix

$C:[\mathrm{m} \times \mathrm{n}]$ state output coefficient matrix

$K:[r \times n]$ optimal feedback coefficient matrix

$F:[n \times p]$ disturbance coefficient matrix.

\subsection{State Space Representation of the AC System}

For a two area interconnected power system (TAIPS) interconnected by AC link only, the state space equations can be obtained from the transfer function block diagram shown in Figure 3.2. 


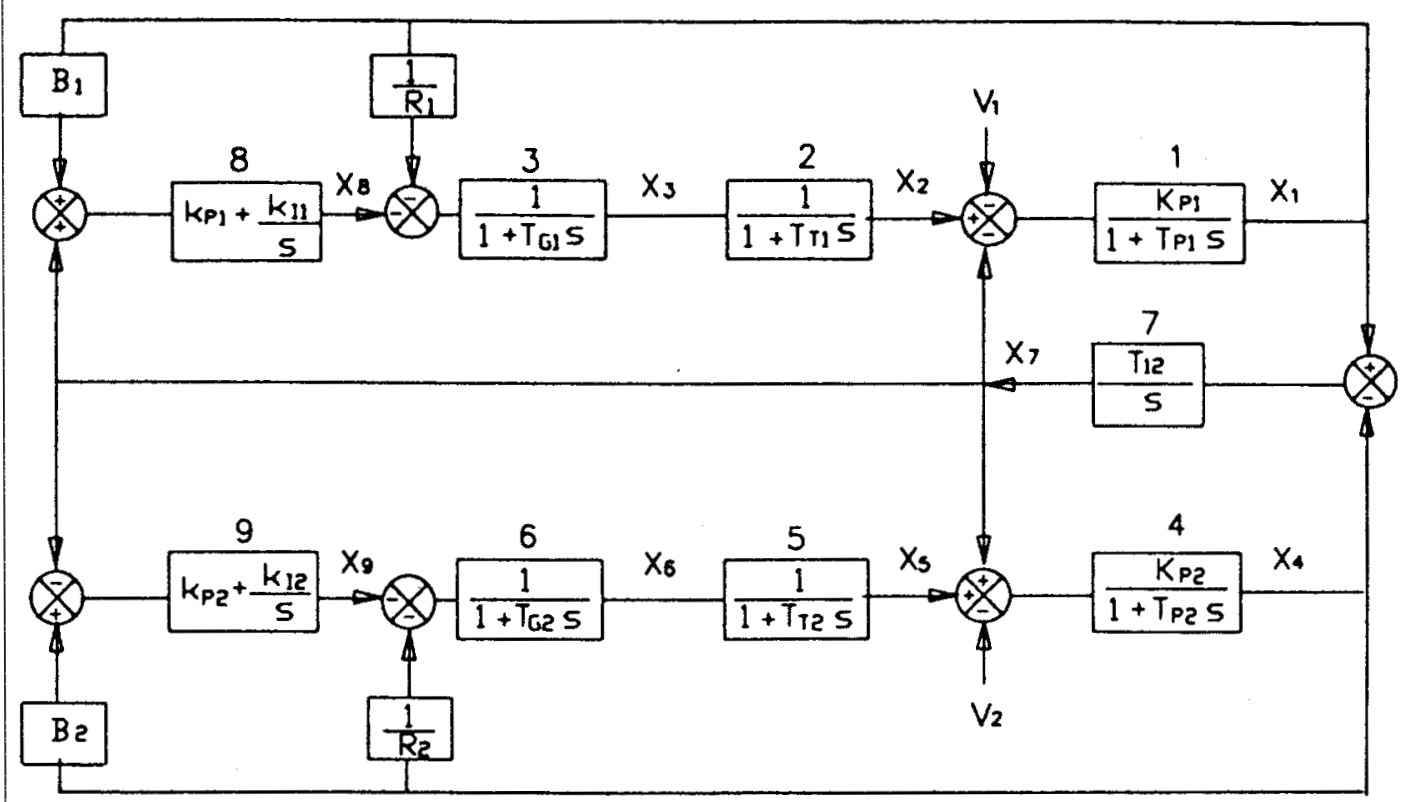

Figure 3.2 Block diagram of an AC TAIPS.

The state variables are:

$\mathrm{x}_{1}=\Delta \mathrm{f}_{1} \quad$ : frequency deviation, area 1

$\mathbf{x}_{2}=\Delta \mathrm{P}_{\mathrm{G} 1}$ : deviation in generated power, area 1

$\mathrm{x}_{3}$ : deviation in governor position, area 1

$x_{4}=\Delta f_{2}$ : frequency deviation, area 2

$x_{5}=\Delta P_{G 2}$ : deviation in generated power, area 2

$\mathbf{x}_{6}$ : deviation in governor position, area 2

$x_{7}=\Delta P_{12}$ : net power interchange deviation

$\mathrm{u}_{1} \quad$ : control signal area 1

$\mathrm{u}_{2} \quad$ : control signal area 2

$\mathrm{v}_{1}=\Delta \mathrm{P}_{\mathrm{L} 1}$ : change in load (disturbance), area 1 
$v_{2}=\Delta P_{L 2}:$ change in load (disturbance), area 2 then $X=\left[\begin{array}{llll}x_{1} & x_{2} & \ldots & x_{7}\end{array}\right]^{\mathrm{T}}, U=\left[\begin{array}{ll}u_{1} & u_{2}\end{array}\right]^{\mathrm{T}}$ and $V=\left[v_{1} v_{2}\right]^{\mathrm{T}}$. Translating the transfer functions which use Laplace notation into the state space form, the model can be described by a set of first order differential equations as follows:

block 1: $\dot{\mathrm{x}}_{1}=-\frac{1}{\mathrm{~T}_{\mathrm{P} 1}} \mathrm{x}_{1}+\frac{\mathrm{K}_{\mathrm{P} 1}}{\mathrm{~T}_{\mathrm{P} 1}} \mathrm{x}_{2}-\frac{\mathrm{K}_{\mathrm{P} 1}}{\mathrm{~T}_{\mathrm{P} 1}} \mathrm{x}_{7}-\frac{\mathrm{K}_{\mathrm{P} 1}}{\mathrm{~T}_{\mathrm{P} 1}} \mathrm{v}_{1}$

block 2: $\dot{\mathrm{x}}_{2}=-\frac{1}{\mathrm{~T}_{\mathrm{T} 1}} \mathrm{x}_{2}+\frac{1}{\mathrm{~T}_{\mathrm{T} 1}} \mathrm{x}_{3}$

block 3: $\dot{x}_{3}=-\frac{1}{R_{1} T_{G 1}} x_{1}-\frac{1}{T_{G 1}} x_{3}-\frac{1}{T_{G 1}} u_{1}$

block 4: $\dot{\mathrm{x}}_{4}=-\frac{1}{\mathrm{~T}_{\mathrm{P} 2}} \mathrm{x}_{4}+\frac{\mathrm{K}_{\mathrm{P} 2}}{\mathrm{~T}_{\mathrm{P} 2}} \mathrm{x}_{5}+\frac{\mathrm{K}_{\mathrm{P} 2}}{\mathrm{~T}_{\mathrm{P} 2}} \mathrm{x}_{7}-\frac{\mathrm{K}_{\mathrm{P} 2}}{\mathrm{~T}_{\mathrm{P} 2}} \mathrm{v}_{2}$

block 5: $\dot{\mathrm{x}}_{\mathrm{S}}=-\frac{1}{\mathrm{~T}_{\mathrm{T} 2}} \mathrm{x}_{5}+\frac{1}{\mathrm{~T}_{\mathrm{T} 2}} \mathrm{x}_{6}$

block 6: $\dot{\mathrm{x}}_{6}=-\frac{1}{\mathrm{~T}_{\mathrm{T} 2}} \mathrm{x}_{5}+\frac{1}{\mathrm{~T}_{\mathrm{T} 2}} \mathrm{x}_{6}$

block 7: $\dot{\mathrm{x}}_{7}=\mathrm{T}_{12} \mathrm{x}_{1}-\mathrm{T}_{12} \mathrm{x}_{4}$

block 8: $u_{1}=B_{1}\left(k_{p 1}+\frac{k_{11}}{s}\right) x_{1}+\left(k_{p 1}+\frac{k_{11}}{s}\right) x_{7}$

block 9: $u_{2}=B_{2}\left(k_{P 2}+\frac{k_{12}}{s}\right) x_{4}-\left(k_{P 2}+\frac{k_{12}}{s}\right) x_{7}$ 
where $p=d / d t$. Then the state space vector equations are:

$$
\begin{gathered}
\dot{X}=(A+B K) X+F V \\
Y=C X
\end{gathered}
$$

The coefficient matrices are:

$$
\begin{aligned}
& {\left[\begin{array}{ccccccc}
-\frac{1}{\mathrm{~T}_{\mathrm{P} 1}} & \frac{\mathrm{K}_{\mathrm{P} 1}}{\mathrm{~T}_{\mathrm{P} 1}} & 0 & 0 & 0 & 0 & -\frac{\mathrm{K}_{\mathrm{P} 1}}{\mathrm{~T}_{\mathrm{P} 1}}
\end{array}\right]} \\
& \begin{array}{lllllll}
0 & -\frac{1}{\mathrm{~T}_{\mathrm{T} 1}} & \frac{1}{\mathrm{~T}_{\mathrm{T} 1}} & 0 & 0 & 0 & 0
\end{array} \\
& \begin{array}{lllllll}
-\frac{1}{R_{1} T_{G 1}} & 0 & -\frac{1}{T_{G 1}} & 0 & 0 & 0 & 0
\end{array} \\
& \boldsymbol{A}=\left[\begin{array}{lllllll}
0 & 0 & 0 & -\frac{1}{\mathrm{~T}_{\mathrm{P} 2}} & \frac{\mathrm{K}_{\mathrm{P} 2}}{\mathrm{~T}_{\mathrm{P} 2}} & 0 & \frac{\mathrm{K}_{\mathrm{P} 2}}{\mathrm{~T}_{\mathrm{P} 2}}
\end{array}\right. \\
& \begin{array}{lllllll}
0 & 0 & 0 & 0 & -\frac{1}{\mathrm{~T}_{\mathrm{T} 2}} & \frac{1}{\mathrm{~T}_{\mathrm{T} 2}} & 0
\end{array} \\
& \begin{array}{lllllll}
0 & 0 & 0 & -\frac{1}{\mathrm{R}_{2} \mathrm{~T}_{\mathrm{G} 2}} & 0 & -\frac{1}{\mathrm{~T}_{\mathrm{G} 2}} & 0
\end{array} \\
& \left.\begin{array}{lllllll}
\mathrm{T}_{12} & 0 & 0 & -\mathrm{T}_{12} & 0 & 0 & 0
\end{array}\right] \\
& \boldsymbol{B}=\left[\begin{array}{cc}
0 & 0 \\
0 & 0 \\
-\frac{1}{\mathrm{~T}_{\mathrm{G} 1}} & 0 \\
0 & 0 \\
0 & 0 \\
0 & -\frac{1}{\mathrm{~T}_{\mathrm{G} 2}} \\
0 & 0
\end{array}\right] \quad \boldsymbol{F}=\left[\begin{array}{cc}
-\frac{\mathrm{K}_{\mathrm{P} 1}}{\mathrm{~T}_{\mathrm{P} 1}} & 0 \\
0 & 0 \\
0 & 0 \\
0 & -\frac{\mathrm{K}_{\mathrm{P} 2}}{\mathrm{~T}_{\mathrm{P} 2}} \\
0 & 0 \\
0 & 0 \\
0 & 0
\end{array}\right]
\end{aligned}
$$


$K=\left[\begin{array}{cccccccc}\mathrm{B}_{1}\left(\mathrm{k}_{\mathrm{p} 1}+\frac{\mathrm{k}_{11}}{\mathrm{p}}\right) & 0 & 0 & 0 & 0 & 0 & \mathrm{k}_{\mathrm{p} 1}+\frac{\mathrm{k}_{11}}{\mathrm{p}} \\ 0 & 0 & 0 & \mathrm{~B}_{2}\left(\mathrm{k}_{\mathrm{P} 2}+\frac{\mathrm{k}_{12}}{\mathrm{p}}\right) & 0 & 0 & -\left(\mathrm{k}_{\mathrm{p} 2}+\frac{\mathrm{k}_{12}}{\mathrm{p}}\right)\end{array}\right]$

The $\boldsymbol{K}$ matrix has some elements dependent on time because of the integral component in the feedback control loop; therefore the $[A+B K]$ matrix also is dependent on time, and this renders it impossible to do eigenvalue computation for stability analysis. However if we consider the augmented system, where the control signals are considered as state variables $\left(u_{1}=x_{8}\right.$ and $\left.u_{2}=x_{9}\right)$, the vector state space equation is increased by two differential equations.

block 8: $\dot{x}_{8}=k_{p 1} B_{1} \dot{x}_{1}+k_{p 1} \dot{x}_{7}+k_{11} B_{1} x_{1}+k_{11} x_{7}$

replacing Equations (3.6) and (3.12) in Equation (3.20)

$$
\begin{aligned}
\dot{x}_{8}= & \left(\frac{-k_{P 1} B_{1}}{T_{P 1}}+k_{P 1} T_{12}+k_{11} B_{1}\right) x_{1}+\frac{k_{p 1} B_{1} K_{P 1}}{T_{P 1}} x_{2}-k_{P 1} T_{12} x_{4} \\
& +\left(\frac{-k_{P 1} B_{1} K_{P 1}}{T_{P 1}}+k_{11}\right) x_{7}-\frac{k_{P 1} B_{1} K_{P 1}}{T_{P 1}} v_{1}
\end{aligned}
$$

block 9: $\dot{\mathrm{x}}_{9}=\mathrm{k}_{\mathrm{p} 2} \mathrm{~B}_{2} \dot{\mathrm{x}}_{4}-\mathrm{k}_{\mathrm{p} 2} \dot{\mathrm{x}}_{7}+\mathrm{k}_{12} \mathrm{~B}_{2} \mathrm{x}_{4}-\mathrm{k}_{12} \mathrm{x}_{7}$

replacing Equations (3.9) and (3.12) in Equation (3.22)

$$
\begin{aligned}
\dot{x}_{9}= & -k_{p 2} T_{12} x_{1}+\left(\frac{-k_{P 2} B_{2}}{T_{P 2}}+k_{p 2} T_{12}+k_{12} B_{2}\right) x_{4}+\frac{k_{p 2} B_{2} K_{P 2}}{T_{P 2}} x_{5} \\
& +\left(\frac{k_{P 2} B_{2} K_{P 2}}{T_{P 2}}-k_{12}\right) x_{7}-\frac{k_{P 2} B_{2} K_{P 2}}{T_{P 2}} v_{2}
\end{aligned}
$$


then the augmented matrices are:

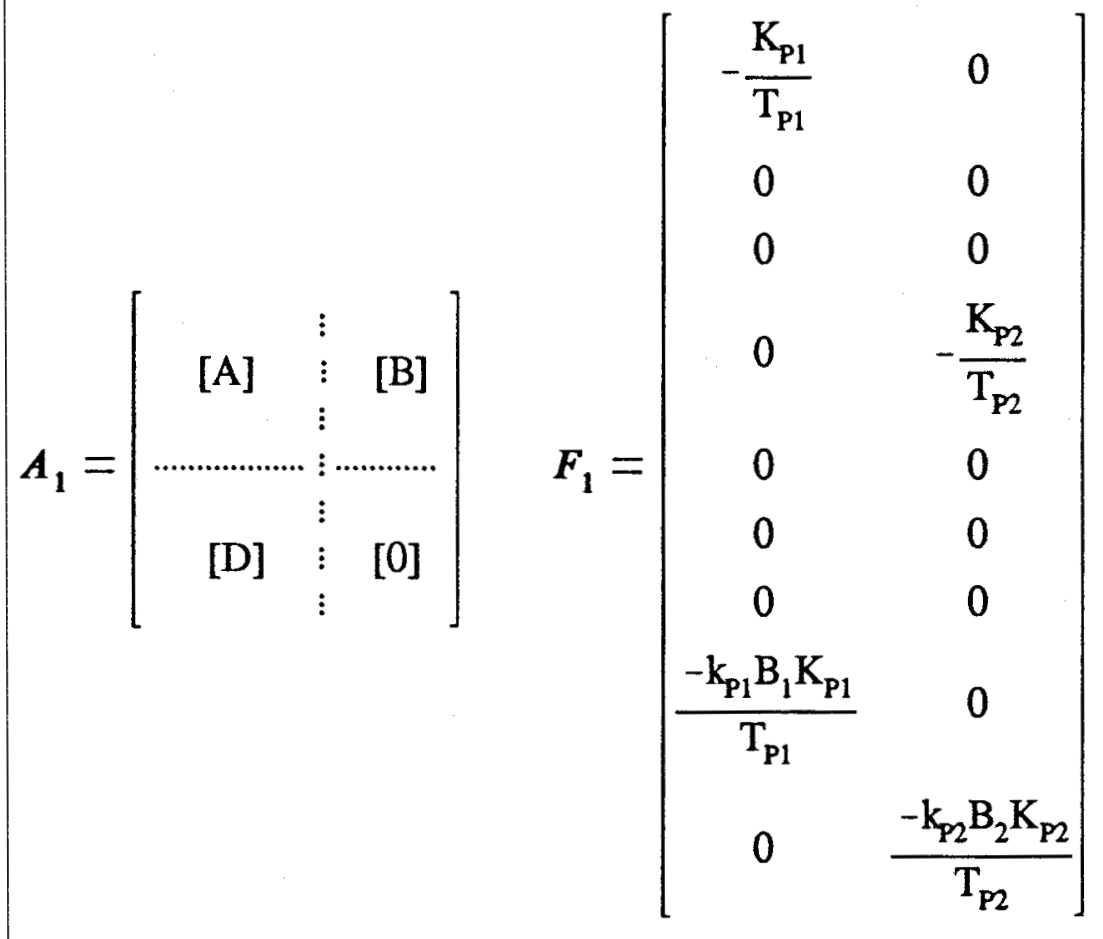

$$
D=\left[\begin{array}{cc}
k_{\mathrm{P} 1}\left(\mathrm{~T}_{12}-\frac{\mathrm{B}_{1}}{\mathrm{~T}_{\mathrm{P} 1}}\right)+\mathrm{k}_{11} \mathrm{~B}_{1} & -\mathrm{k}_{\mathrm{P} 2} \mathrm{~T}_{12} \\
\frac{\mathrm{k}_{\mathrm{P} 1} \mathrm{~B}_{1} \mathrm{~K}_{\mathrm{P} 1}}{\mathrm{~T}_{\mathrm{P} 1}} & 0 \\
0 & 0 \\
-\mathrm{k}_{\mathrm{P} 1} \mathrm{~T}_{12} & \mathrm{k}_{\mathrm{P} 2}\left(\mathrm{~T}_{12}-\frac{\mathrm{B}_{2}}{\mathrm{~T}_{\mathrm{P} 2}}\right)+\mathrm{k}_{12} \mathrm{~B}_{2} \\
0 & \frac{\mathrm{k}_{\mathrm{P} 2} \mathrm{~B}_{2} \mathrm{~K}_{\mathrm{P} 2}}{\mathrm{~T}_{\mathrm{P} 2}} \\
0 & 0 \\
\frac{-\mathrm{k}_{\mathrm{P} 1} \mathrm{~B}_{1} \mathrm{~K}_{\mathrm{P} 1}}{\mathrm{~T}_{\mathrm{P} 1}}+\mathrm{k}_{11} & \frac{\mathrm{k}_{\mathrm{P} 2} \mathrm{~B}_{2} \mathrm{~K}_{\mathrm{P} 2}}{\mathrm{~T}_{\mathrm{P} 2}}-\mathrm{k}_{\mathrm{p}}
\end{array}\right]^{\mathrm{T}}
$$

The matrix $A_{1}$ is shown in Figure 3.3 and the augmented state space equation is

$$
\dot{X}=A_{1} X+F_{1} V
$$




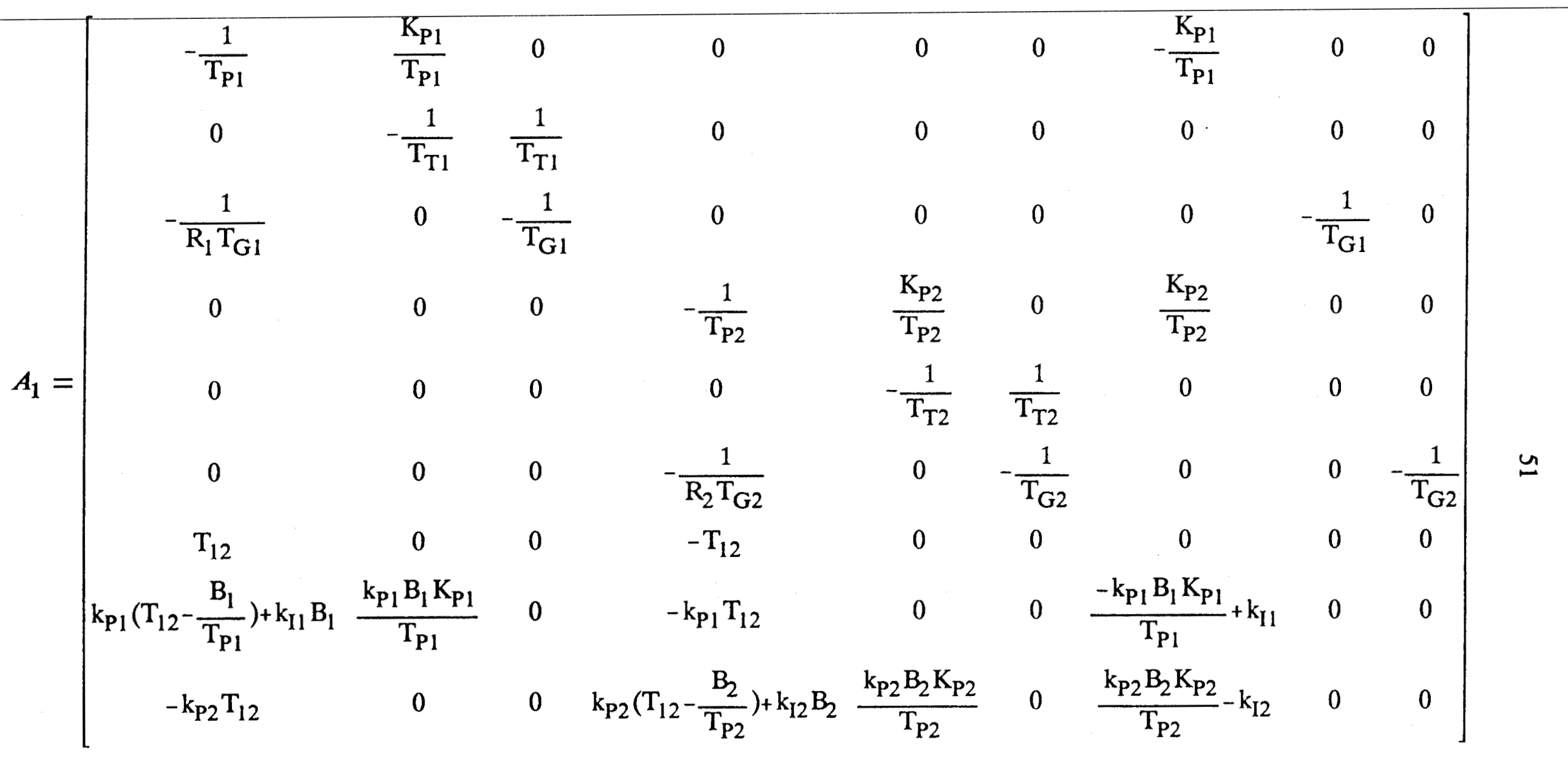




\subsection{State Space Representation of the AC/DC System}

The state space equations of a two areas power system (TAIPS) interconnected via parallel $\mathrm{AC}$ and $\mathrm{DC}$ links can be derived from the dynamic model shown in Figure 3.4.

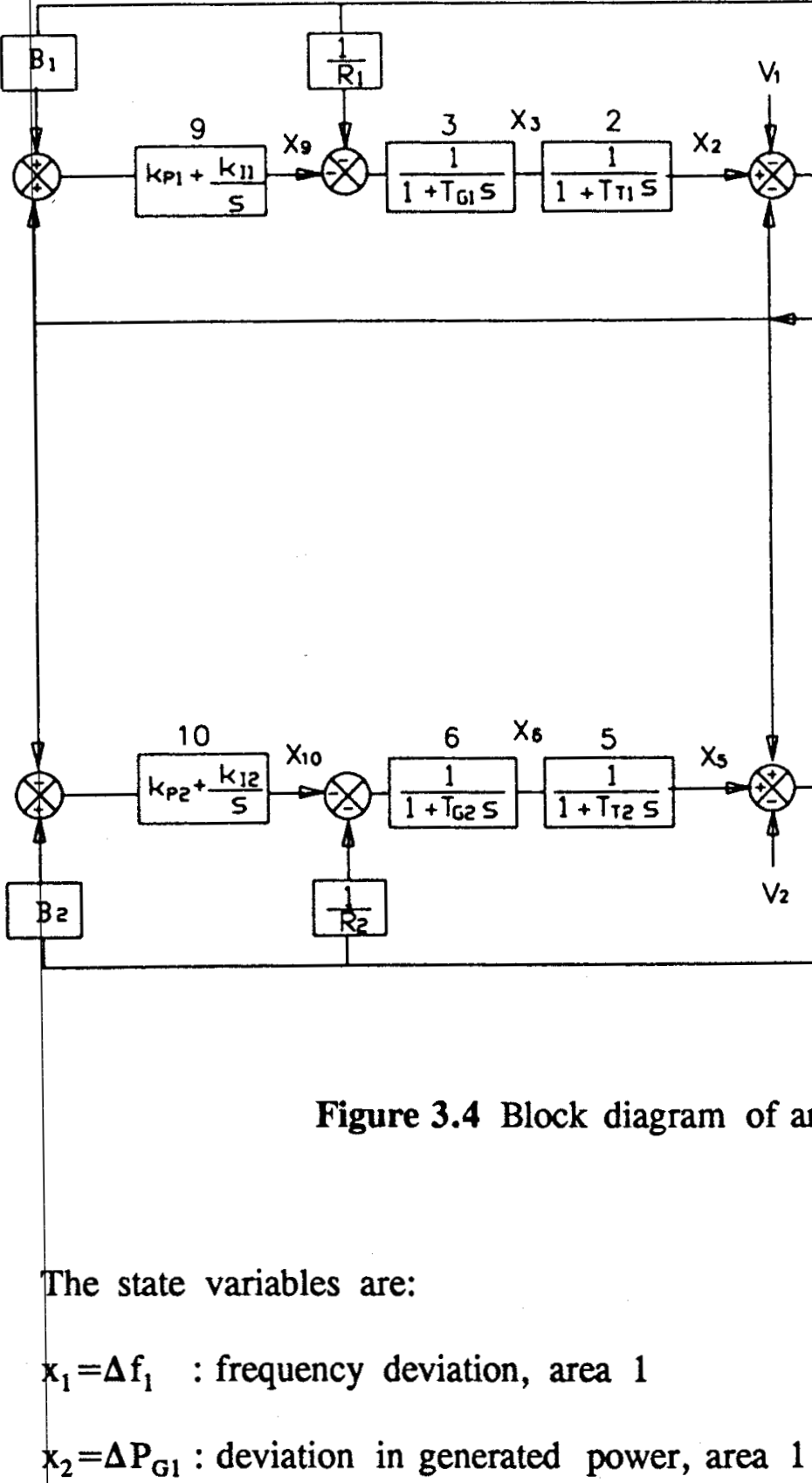


$x_{3} \quad$ : deviation in governor position, area 1

$\mathrm{x}_{4}=\Delta \mathrm{f}_{2}$ : frequency deviation, area 2

$\mathrm{x}_{5}=\Delta \mathrm{P}_{\mathrm{G} 2}:$ deviation in generated power, area 2

$x_{6} \quad$ : deviation in governor position, area 2

$x_{7}=\Delta P_{A C}: A C$ power interchange deviation

$x_{8}=\Delta P_{D C}: D C$ power interchange deviation

$x_{9}=u_{1} \quad$ : control signal, area 1

$x_{10}=u_{2} \quad$ : control signal, area 2

$\mathrm{x}_{11}=\mathrm{u}_{3} \quad$ : control signal DC system

Then $X=\left[x_{1} \ldots x_{11}\right]^{\mathrm{T}}\left(\right.$ state vector) and $V=\left[v_{1} v_{2}\right]^{T}$ (disturbance vector). Applying a similar procedure as in Section 3.3, the set of differential equations is :

block 1: $\dot{x}_{1}=-\frac{1}{T_{P 1}} x_{1}+\frac{K_{P 1}}{T_{P 1}} x_{2}-\frac{K_{P 1}}{T_{P 1}} x_{7}-\frac{K_{P 1}}{T_{P 1}} x_{8}-\frac{K_{P 1}}{T_{P}} v_{1}$

block 2: $\dot{x}_{2}=-\frac{1}{T_{T 1}} x_{2}+\frac{1}{T_{T 1}} x_{3}$

block 3: $\dot{x}_{3}=-\frac{1}{R_{1} T_{G 1}} x_{1}-\frac{1}{T_{G 1}} x_{3}-\frac{1}{T_{G 1}} x_{9}$

block 4: $\dot{\mathrm{x}}_{4}=-\frac{1}{\mathrm{~T}_{\mathrm{P} 2}} \mathrm{x}_{4}+\frac{\mathrm{K}_{\mathrm{P} 2}}{\mathrm{~T}_{\mathrm{P} 2}} \mathrm{x}_{5}+\frac{\mathrm{K}_{\mathrm{P} 2}}{\mathrm{~T}_{\mathrm{P} 2}} \mathrm{x}_{7}+\frac{\mathrm{K}_{\mathrm{P} 2}}{\mathrm{~T}_{\mathrm{P} 2}} \mathrm{x}_{8}-\frac{\mathrm{K}_{\mathrm{P} 2}}{\mathrm{~T}_{\mathrm{P} 2}} \mathrm{v}_{2}$

block 5: $\dot{\mathrm{x}}_{5}=-\frac{1}{\mathrm{~T}_{\mathrm{T} 2}} \mathrm{x}_{5}+\frac{1}{\mathrm{~T}_{\mathrm{T} 2}} \mathrm{x}_{6}$ 
block 6: $\dot{\mathrm{x}}_{6}=-\frac{1}{\mathrm{R}_{2} \mathrm{~T}_{\mathrm{G} 2}} \mathrm{x}_{4}-\frac{1}{\mathrm{~T}_{\mathrm{G} 2}} \mathrm{x}_{6}-\frac{1}{\mathrm{~T}_{\mathrm{G} 2}} \mathrm{x}_{10}$

block 7: $\dot{\mathrm{x}}_{7}=\mathrm{T}_{12} \mathrm{X}_{1}-\mathrm{T}_{12} \mathrm{x}_{4}$

block 8: $\dot{\mathrm{x}}_{8}=-\frac{1}{\mathrm{~T}_{\mathrm{DC}}} \mathrm{x}_{8}-\frac{1}{\mathrm{~T}_{\mathrm{DC}}} \mathrm{x}_{11}$

block 9: $\dot{\mathrm{x}}_{9}=\left[\mathrm{k}_{\mathrm{p} 1}\left(\mathrm{~T}_{12}-\frac{\mathrm{B}_{1}}{\mathrm{~T}_{\mathrm{P} 1}}\right)+\mathrm{k}_{11} \mathrm{~B}_{1}\right] \mathrm{x}_{1}+\frac{\mathrm{k}_{\mathrm{p} 1} \mathrm{~B}_{1} \mathrm{~K}_{\mathrm{P} 1}}{\mathrm{~T}_{\mathrm{P} 1}} \mathrm{x}_{2}-\mathrm{k}_{\mathrm{p} 1} \mathrm{~T}_{12} \mathrm{x}_{4}$

$$
\begin{aligned}
& +\left(\frac{-k_{P 1} B_{1} K_{P 1}}{T_{P 1}}+k_{11}\right) x_{7}+\left[-k_{P 1}\left(\frac{B_{1} K_{P 1}}{T_{P 1}}+\frac{1}{T_{D C}}\right)+k_{11}\right] x_{8} \\
& -\frac{k_{P 1}}{T_{D C}} x_{11}-\frac{k_{P 1} B_{1} K_{P 1}}{T_{P 1}} v_{1}
\end{aligned}
$$

block 10: $\dot{x}_{10}=-k_{P 2} T_{12} x_{1}+\left[k_{P 2}\left(T_{12}-\frac{B_{2}}{T_{P 2}}\right)+k_{12} B_{2}\right] x_{4}+\frac{k_{P 2} B_{2} K_{P 2}}{T_{P 2}} x_{5}$

$$
\begin{aligned}
& +\left(\frac{\mathrm{k}_{\mathrm{P} 2} \mathrm{~B}_{2} \mathrm{~K}_{\mathrm{P} 2}}{\mathrm{~T}_{\mathrm{P} 2}}-\mathrm{k}_{\mathrm{L} 2}\right) \mathrm{x}_{7}+\left[\mathrm{k}_{\mathrm{P} 2}\left(\frac{\mathrm{B}_{2} \mathrm{~K}_{\mathrm{P} 2}}{\mathrm{~T}_{\mathrm{P} 2}}+\frac{1}{\mathrm{~T}_{\mathrm{DC}}}\right)-\mathrm{k}_{\mathrm{P} 2}\right] \mathrm{x}_{8} \\
& +\frac{\mathrm{k}_{\mathrm{P} 2}}{\mathrm{~T}_{\mathrm{DC}}} \mathrm{x}_{11}-\frac{\mathrm{k}_{\mathrm{P} 2} \mathrm{~B}_{2} \mathrm{~K}_{\mathrm{P} 2}}{\mathrm{~T}_{\mathrm{P} 2}} \mathrm{v}_{2}
\end{aligned}
$$

block 11: $\dot{\mathrm{x}}_{11}=\left[\mathrm{k}_{\mathrm{P}}\left(\mathrm{T}_{12}+\frac{\mathrm{K}_{\mathrm{f}}}{\mathrm{T}_{\mathrm{P} 1}}\right)-\mathrm{k}_{1} \mathrm{~K}_{\mathrm{f}}\right] \mathrm{x}_{1}-\frac{\mathrm{k}_{\mathrm{P}} \mathrm{K}_{\mathrm{P}} \mathrm{K}_{\mathrm{P} 1}}{\mathrm{~T}_{\mathrm{P} 1}} \mathrm{x}_{2}+\left[-\mathrm{k}_{\mathrm{P}}\left(\mathrm{T}_{12}+\frac{\mathrm{K}_{\mathrm{f}}}{\mathrm{T}_{\mathrm{P} 2}}\right)+\mathrm{k}_{1} \mathrm{~K}_{\mathrm{f}}\right] \mathrm{x}_{4}$

$$
\begin{aligned}
& +\frac{\mathrm{k}_{\mathrm{P}} \mathrm{K}_{\mathrm{P}} \mathrm{K}_{\mathrm{P} 2}}{\mathrm{~T}_{\mathrm{P} 2}} \mathrm{x}_{5}+\left[\mathrm{k}_{\mathrm{P}} \mathrm{K}_{\mathrm{f}}\left(\frac{\mathrm{K}_{\mathrm{P} 1}}{\mathrm{~T}_{\mathrm{P} 1}}+\frac{\mathrm{K}_{\mathrm{P} 2}}{\mathrm{~T}_{\mathrm{P} 2}}\right)+\mathrm{k}_{1}\right] \mathrm{x}_{7}+\left[\mathrm{k}_{\mathrm{P}} \mathrm{K}_{\mathrm{f}}\left(\frac{\mathrm{K}_{\mathrm{P} 1}}{\mathrm{~T}_{\mathrm{P} 1}}+\frac{\mathrm{K}_{\mathrm{P} 2}}{\mathrm{~T}_{\mathrm{P} 2}}\right)-\frac{\mathrm{k}_{\mathrm{P}}}{\mathrm{T}_{\mathrm{DC}}}+\mathrm{k}_{1}\right] \mathrm{x}_{8} \\
& -\frac{\mathrm{k}_{\mathrm{P}}}{\mathrm{T}_{\mathrm{DC}}} \mathrm{x}_{11}+\frac{\mathrm{k}_{\mathrm{P}} \mathrm{K}_{\mathrm{P}} \mathrm{K}_{\mathrm{P} 1}}{\mathrm{~T}_{\mathrm{P} 1}} \mathrm{v}_{1}-\frac{\mathrm{k}_{\mathrm{P}} \mathrm{K}_{\mathrm{P}} \mathrm{K}_{\mathrm{P} 2}}{\mathrm{~T}_{\mathrm{P} 2}} \mathrm{v}_{2}
\end{aligned}
$$

Therefore the system shown in Figure 3.4 can be represented by the vector equation:

$$
\dot{X}=A_{2} X+F_{2} V
$$


where $A_{2}$ is a $[11 \times 11]$ matrix and $F_{2}$ is a $[11 \times 2]$ matrix whose coefficients are obtained from the state space equations. The above state space equation developed from the transfer function blocks, includes a DC power modulation in accordance with a linear combination of net power interchange deviation and the difference of power systems frequency deviation $\left(\Delta P_{12}-K_{f}\left[\Delta f_{1}-\Delta f_{2}\right]\right)$. However, in this research a particular case was studied in more detail, regarding a DC power modulation based only on net power interchange deviation $\left(\Delta \mathrm{P}_{12}\right)$. The transfer function block diagram is shown in Figure 3.5.

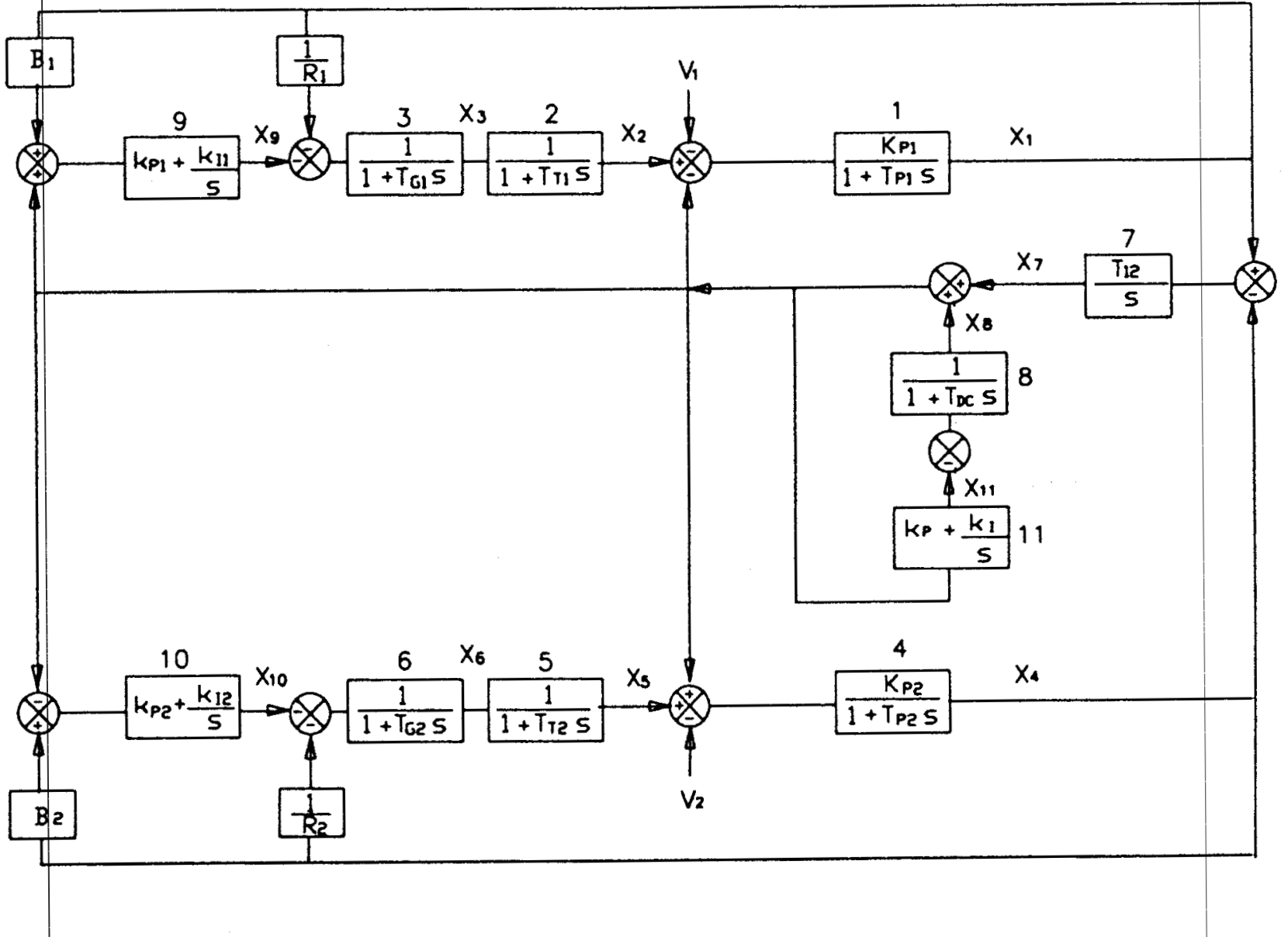

Figure 3.5 Block diagram of an AC/DC TAIPS, with $\Delta \mathrm{P}_{12}$ as input of the $\mathrm{DC}$ system controller. 
In this case, the state variable \#11 is defined as:

$$
\begin{aligned}
& x_{11}=\left(k_{p}+\frac{k_{1}}{s}\right)\left(x_{7}+x_{8}\right) \\
& \dot{x}_{11}=k_{P} T_{12} x_{1}-k_{p} T_{12} x_{4}+k_{1} x_{7}+\left(-\frac{k_{P}}{T_{D C}}+k_{1}\right) x_{8}-\frac{k_{p}}{T_{D C}} x_{11}
\end{aligned}
$$

Therefore the state coefficient matrix $\boldsymbol{A}_{\mathbf{3}}$ is similar to matrix $\boldsymbol{A}_{\mathbf{2}}$ with exception of the now 11, and the disturbance coefficient matrix $F_{3}$ is equal to $F_{2}$. Then the system dynamics are represented by the state space equation:

$$
\dot{X}=A_{3} X+F_{3} V
$$

The state coefficient matrix $A_{3}$ is shown in detail in Figure 3.6. 


\begin{tabular}{|c|c|c|c|c|c|c|c|c|c|c|c|}
\hline & $-\frac{1}{T_{p 1}}$ & $\frac{K_{p_{1}}}{T_{p_{1}}}$ & 0 & 0 & 0 & 0 & $-\frac{K_{p 1}}{T_{p 1}}$ & $-\frac{K_{p 1}}{T_{p 1}}$ & 0 & 0 & 0 \\
\hline & 0 & $-\frac{1}{T_{T 1}}$ & $\frac{1}{T_{T 1}}$ & 0 & 0 & 0 & 0 & 0 & 0 & 0 & 0 \\
\hline & $-\frac{1}{R_{1} T_{G 1}}$ & 0 & $-\frac{1}{T_{G 1}}$ & 0 & 0 & 0 & 0 & 0 & $-\frac{1}{T_{61}}$ & 0 & 0 \\
\hline & 0 & 0 & 0 & $-\frac{1}{T_{P 2}}$ & $\frac{K_{P 2}}{T_{P 2}}$ & 0 & $\frac{K_{P 2}}{T_{P 2}}$ & $\frac{K_{P 2}}{T_{P 2}}$ & 0 & 0 & 0 \\
\hline & 0 & 0 & 0 & 0 & $-\frac{1}{T_{T 2}}$ & $\frac{1}{T_{T 2}}$ & 0 & 0 & 0 & 0 & 0 \\
\hline$A_{3}=$ & 0 & 0 & 0 & $-\frac{1}{R_{2} T_{G 2}}$ & 0 & $-\frac{1}{T_{62}}$ & 0 & 0 & 0 & $-\frac{1}{T_{G 2}}$ & 0 \\
\hline & $T_{12}$ & 0 & 0 & $-T_{12}$ & 0 & 0 & 0 & 0 & 0 & 0 & 0 \\
\hline & 0 & 0 & 0 & 0 & 0 & 0 & 0 & $-\frac{1}{T_{D C}}$ & 0 & 0 & $-\frac{1}{T_{D C}}$ \\
\hline & $k_{p 1}\left(T_{12}-\frac{B_{1}}{T_{p 1}}\right)+k_{11} B_{1}$ & $\frac{\mathrm{k}_{\mathrm{p} 1} \mathrm{~B}_{1} \mathrm{~K}_{\mathrm{p1}}}{\mathrm{T}_{\mathrm{P} 1}}$ & 0 & $-k_{p 1} T_{12}$ & 0 & 0 & $\frac{-k_{p 1} B_{1} K_{p 1}}{T_{p 1}}+k_{I 1}$ & $-k_{p 1}\left(\frac{B_{1} K_{p 1}}{T_{P 1}}+\frac{1}{T_{D C}}\right)+k_{I 1}$ & 0 & 0 & $\frac{k_{p 1}}{T_{D C}}$ \\
\hline & $-k_{p 2} T_{12}$ & 0 & 0 & $k_{p 2}\left(T_{12}-\frac{B_{2}}{T_{P 2}}\right)+k_{12} B_{2}$ & $\frac{k_{p 2} B_{2} K_{p 2}}{T_{p 2}}$ & 0 & $\frac{k_{p 2} B_{2} K_{p 2}}{T_{P 2}}-k_{12}$ & $k_{P 2}\left(\frac{B_{2} K_{P 2}}{T_{P 2}}+\frac{1}{T_{D C}}\right)-k_{12}$ & 0 & 0 & $\frac{k_{P 2}}{T_{D C}}$ \\
\hline & $k_{p} T_{12}$ & 0 & 0 & $-k_{p} T_{12}$ & 0 & 0 & $k_{l}$ & $-\frac{k_{p}}{T_{D C}}+k_{I}$ & 0 & 0 & $-\frac{k_{p}}{T_{D C}}$ \\
\hline
\end{tabular}




\section{SYSTEM STABILITY}

\subsection{General}

The stability of an interconnected power system is measured in terms of its capability to return to normal or stable operation after having been subjected to some kind of disturbance. On the other hand, if the machines fall out of step after a disturbance the system is unstable. Generally power system stability problems are classified into three basic types ${ }^{10}$ :

i) Steady state stability is basically concerned with the determination of the upper limit of machine loadings before losing synchronism provided the loading is increasing gradually.

ii) Dynamic stability refers to the stability of a power system subject to a relatively small and sudden or periodic disturbance, including the effect of automatic control devices.

iii) Transient stability refers to the stability of a power system subject to a sudden and large disturbance beyond the capability of the basic controls. The system may lose its stability at the first or subsequent swings unless an effective countermeasure is taken.

In normal power system operation, small disturbances are continually occurring (variations in loading, changes in turbine speeds, etc.), which are small 
enough not to cause the system to lose synchronism but can excite natural oscillations. Therefore, one of the important features that describes the behaviour of a power system is its dynamic response capability.

This chapter presents the effects of various controller parameters on the system stability by describing their influences on the eigenvalues of the system, especially those of the critical modes of oscillation. The critical modes of oscillation of the power system are defined by the eigenvalues which determine the system instability as a result of a variation in any of the system parameters.

\subsection{Stability in the Complex Plane}

The system characteristic stability is a property of the system itself and does not depend on the input or driving function of the system. The stability of a linear closed loop system can be determined from the location of the closed loop poles in the $s$ plane. If all closed loop poles lie to the left of the jw axis, any transient response eventually reaches equilibrium. This represents a stable system. Closed loop poles lying on the $j \omega$ axis will yield oscillations, the amplitudes of which neither decay nor grow with time. This represents a critically stable system. On the other hand, of the transient response oscillates with increasing amplitude, this represents an unstable system. The fact that all closed loop poles lie in the left half of the s plane does not guarantee satisfactory dynamic response characteristics. If dominant complex poles are located close to the $j \omega$ axis, the dynamic response may show excessive oscillations or a long settling time. 


\subsection{Eigenstructure}

It is known that the eigenvalues of the state space coefficient matrix are the closed loop poles of the model system. For the system represented by the state equation :

$$
\dot{X}=\boldsymbol{A X}+\boldsymbol{F} \boldsymbol{V}
$$

the eigenvalue spectrum is the set of roots of the characteristic equation :

$$
|\lambda I-A|=0
$$

The right eigenvector $\mu_{\mathrm{i}}$ and the left eigenvector $e_{\mathrm{i}}$ associated with an eigenvalue $\lambda_{\mathrm{i}}$ $\left(i^{\text {th }}\right.$ mode) are obtained from the equations :

$$
\begin{aligned}
& {\left[\lambda_{i} I-A\right] \mu_{i}=0} \\
& e_{i}^{T}\left[\lambda_{i} I-A\right]=0
\end{aligned}
$$

such that for normalized values of $e$ and $\mu$

$$
e_{i}^{T} \mu_{j}=\left[\begin{array}{l}
1 \text { for } i-j \\
0 \text { for } i \neq j
\end{array}\right.
$$

The homogeneous solution part of Equation (4.1) is independent of the input $V$ and depends only upon the initial state $X(0)$. The particular solution part (forced solution) is independent of $X(0)$ but depends upon the input $V$ throughout the whole control period. 
The homogeneous solution (transient response) of Equation (4.1) can be written

$$
X(t)=\sum_{\mathrm{i}=1}^{\mathrm{n}} \mu_{\mathrm{i}} \mathrm{e}^{\lambda_{\mathrm{it}}} e_{\mathrm{i}}^{\mathrm{T}} X(0)
$$

for $\mathrm{i}^{\text {th }}$ mode $\lambda_{\mathrm{i}}$

$$
\begin{gathered}
X_{\mathrm{i}}(t)=\mathrm{C}_{\mathrm{i}} \mathrm{e}^{\lambda_{\mathrm{i}} \mathrm{t}}\left[\begin{array}{c}
\mu_{\mathrm{i} 1} \\
: \\
\vdots \\
\mu_{\mathrm{in}}
\end{array}\right] \\
\mathrm{C}_{\mathrm{i}}=\sum_{\mathrm{j}-1}^{\mathrm{n}} \epsilon_{\mathrm{ij}} \mathrm{x}_{\mathrm{j}}(0)
\end{gathered}
$$

Then the transient response of the system is a linear combination of $n$ exponential functions which describe the dynamical modes of the system. The shape of a mode is determined by the right eigenvector $\mu_{\mathrm{i}}$, and its time domain characteristic is determined by the eigenvalue $\lambda_{i}$. The right eigenvector $\mu_{i}$ measures the activity of state variables in participating in the $i^{\text {th }}$ mode dynamics. The left eigenvector $\varepsilon_{i}$ weighs the contribution of state variables $X(t)$ to the future response of the $\mathrm{i}^{\text {th }}$ mode. Another index defined as participation factor ${ }^{45}$ may be obtained as follows

$$
P_{i k}=\epsilon_{i k} \mu_{i k}
$$


$P_{i k}$ represents the participation factor of state variable $x_{k}$ corresponding to $i^{\text {th }}$ mode $\lambda_{i}$. Therefore, the participation factors provide a measure of the participation of each state variable in each oscillation mode.

In this research, eigen-analysis was performed to evaluate the effects of variation of controller parameters on system stability. The eigenvalues and eigenvectors were computed using subroutines EVLRG and EVCRG of the IMSL MATH/LIBRARY on a VAX computer system at the University of Saskatchewan. The reference parameters of the system controllers utilized in the eigen analysis are optimal. The optimization of controller parameters is described in Chapter 5.

\subsection{AC System Stability}

The stability analysis of the two area interconnected power system via an AC link was based on the eigenvalue analysis of its state space model.

The state space equation of the $\mathrm{AC}$ system is

$$
\dot{X}=A_{1} X+F_{1} V
$$

The state space coefficient matrix $A_{1}$ as a function of the system parameters is given in Figure 3.3 and the optimal controller parameters in both AC areas are:

$$
\text { * } \mathrm{k}_{\mathrm{P} 1}=\mathrm{k}_{\mathrm{P} 2}=0.3 ; \mathrm{k}_{11}=\mathrm{k}_{\mathrm{1} 2}=0.6
$$


The remainder of the system parameters are provided in Chapter 3. The state space $A_{1}$ matrix of constant coefficients is

$$
\boldsymbol{A}_{1}=\left[\begin{array}{ccccccccc}
-0.05 & 6 & 0 & 0 & 0 & 0 & -6 & 0 & 0 \\
0 & -3.333 & 3.333 & 0 & 0 & 0 & 0 & 0 & 0 \\
-5.208 & 0 & -12.5 & 0 & 0 & 0 & 0 & -12.5 & 0 \\
0 & 0 & 0 & -0.05 & 6 & 0 & 6 & 0 & 0 \\
0 & 0 & 0 & 0 & -3.333 & 3.333 & 0 & 0 & 0 \\
0 & 0 & 0 & -5.208 & 0 & -12.5 & 0 & 0 & -12.5 \\
0.544 & 0 & 0 & -0.544 & 0 & 0 & 0 & 0 & 0 \\
0.412 & 0.765 & 0 & -0.163 & 0 & 0 & -0.165 & 0 & 0 \\
-0.163 & 0 & 0 & 0.412 & 0.765 & 0 & 0.165 & 0 & 0
\end{array}\right]
$$

and the eigenvalues of $A_{1}$ are shown in Table 4.1.

Table 4.1 Eigenvalues of the AC system.

\begin{tabular}{|l|l|}
\hline$\lambda_{1}$ & $-13.47+\mathrm{j} 0.00$ \\
\hline$\lambda_{2}$ & $-13.40+\mathrm{j} 0.00$ \\
\hline$\lambda_{3}$ & $-1.57+\mathrm{j} 0.00$ \\
\hline$\lambda_{4}$ & $-0.94-\mathrm{j} 2.88$ \\
\hline$\lambda_{5}$ & $-0.94+\mathrm{j} 2.88$ \\
\hline$\lambda_{6}$ & $-0.55+\mathrm{j} 0.00$ \\
\hline$\lambda_{7}$ & $-0.53+\mathrm{j} 0.00$ \\
\hline$\lambda_{8}$ & $-0.18-\mathrm{j} 3.76$ \\
\hline$\lambda_{9}$ & $-0.18+\mathrm{j} 3.76$ \\
\hline
\end{tabular}


All the eigenvalues lie in the left side of the complex plane indicating a stable system.

\subsubsection{Effect of AGC Controller Gain Variations.}

The effect of variation of proportional gain of the $\mathrm{AC}$ controllers on the system stability is shown in Figures 4.1, 4.2, 4.3 and 4.4. Those Figures show that the dominant poles move to the right in the complex plane as the proportional gain is increased. The oscillation frequency rises and damping is decreased. Therefore the system is less stable when the proportional gain of the controllers is higher, reaching a critical stability limit for $\mathrm{k}_{\mathrm{P} 1}=\mathrm{k}_{\mathrm{P} 2}=0.9$.

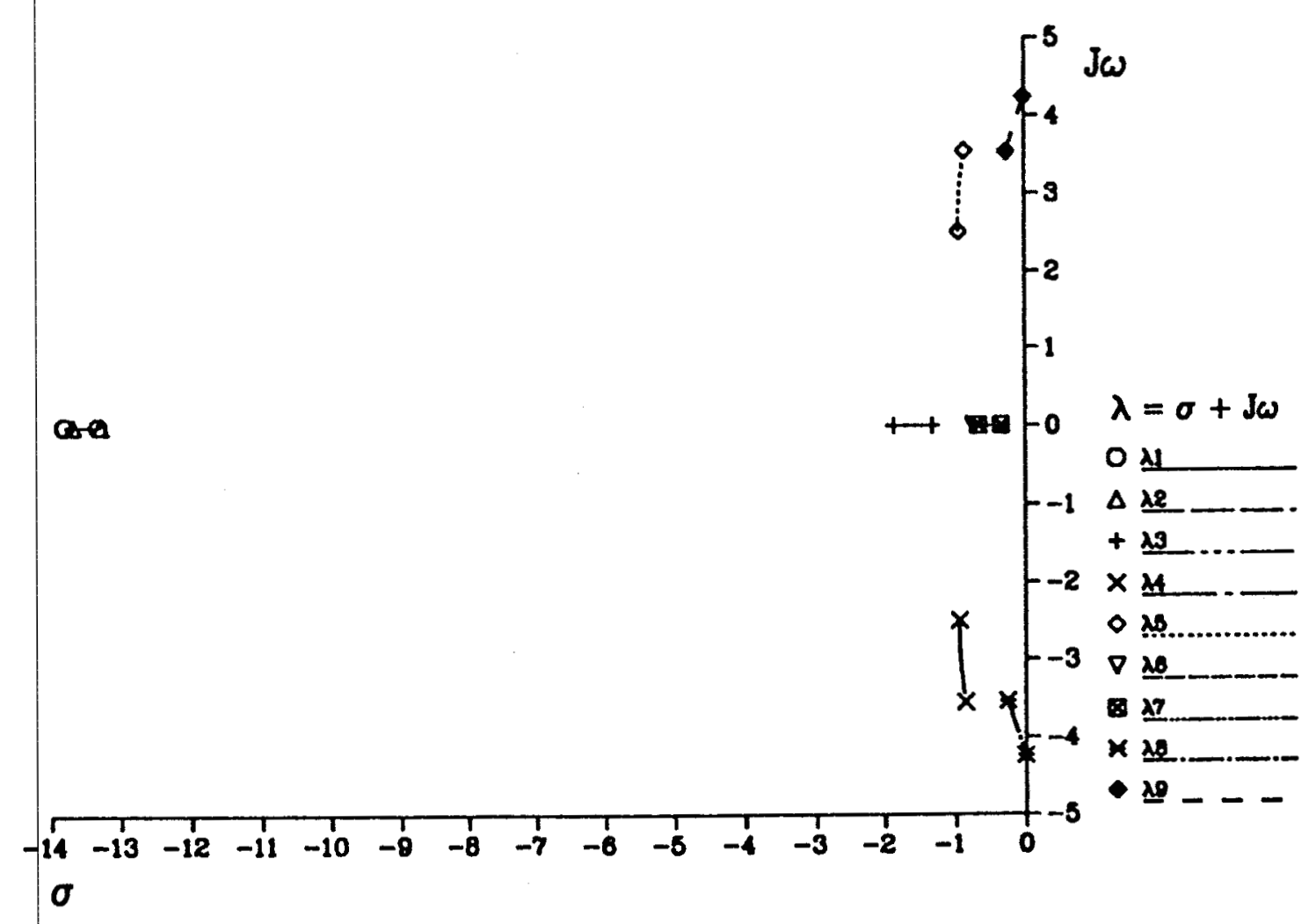

Figure 4.1 Eigenvalue locations for various $k_{\mathrm{P} 1}$ and $k_{\mathrm{P} 2}$. 


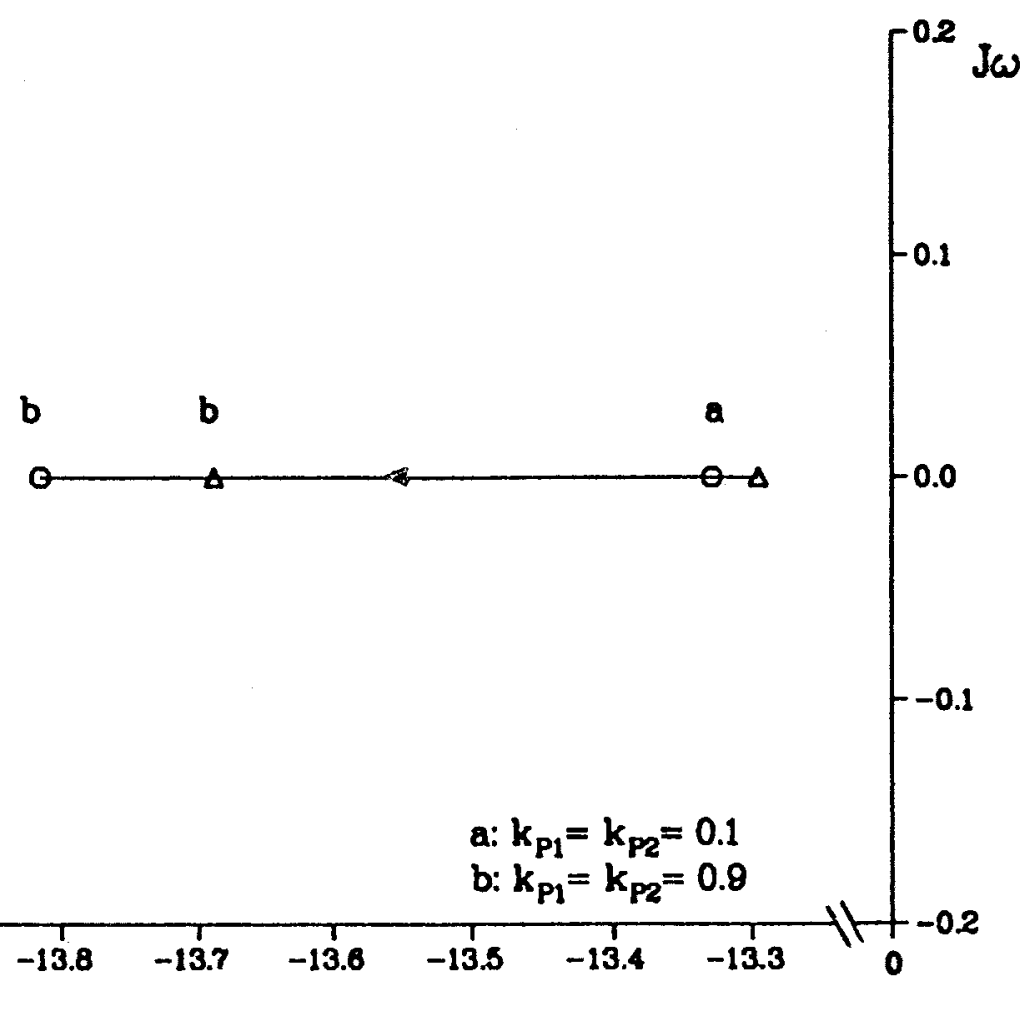

Figure 4.2 Detail of Figure 4.1 for modes $\lambda_{1}$ and $\lambda_{2}$.

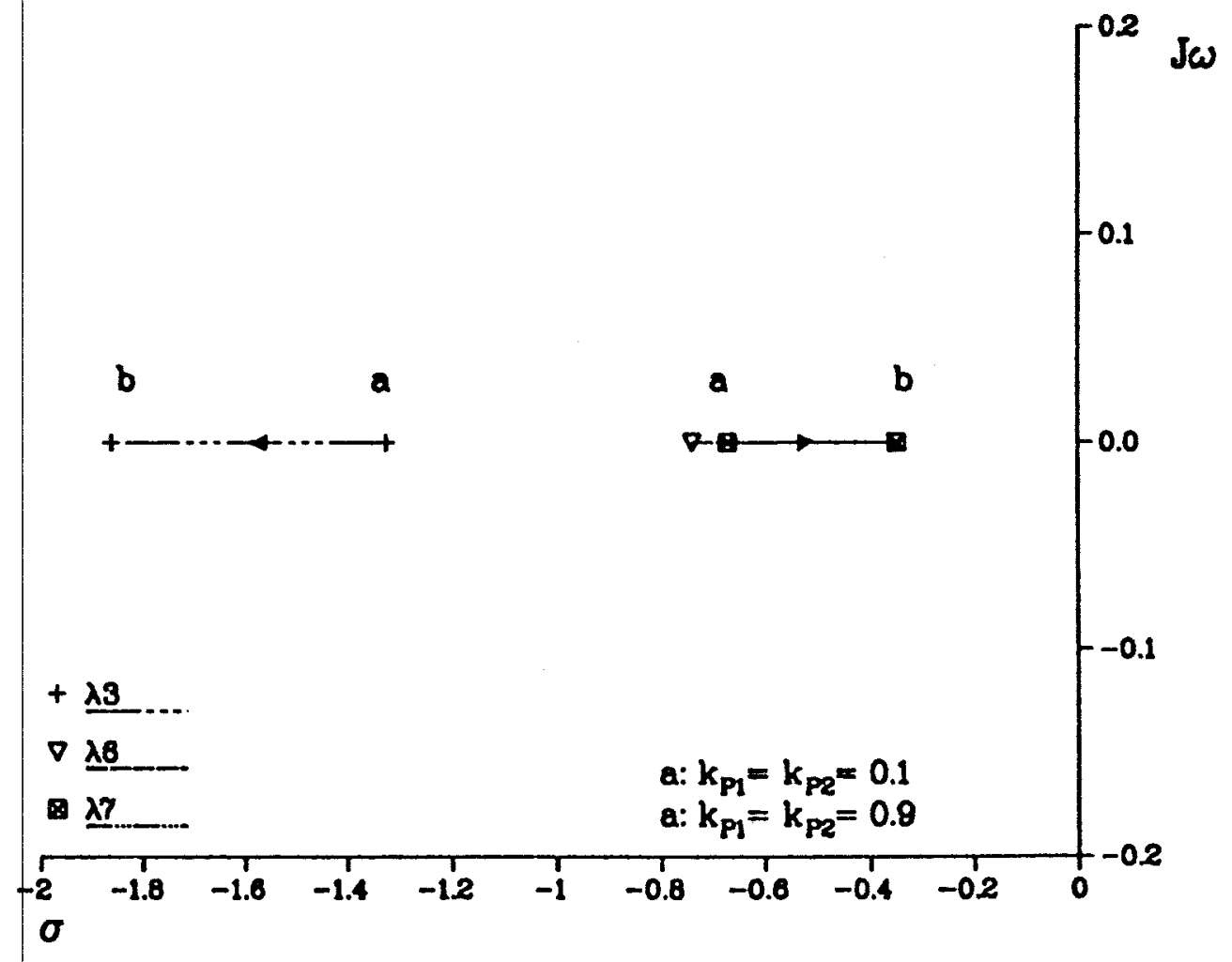

Figure 4.3 Detail of Figure 4.1 for modes $\lambda_{3}, \lambda_{6}$ and $\lambda_{7}$. 

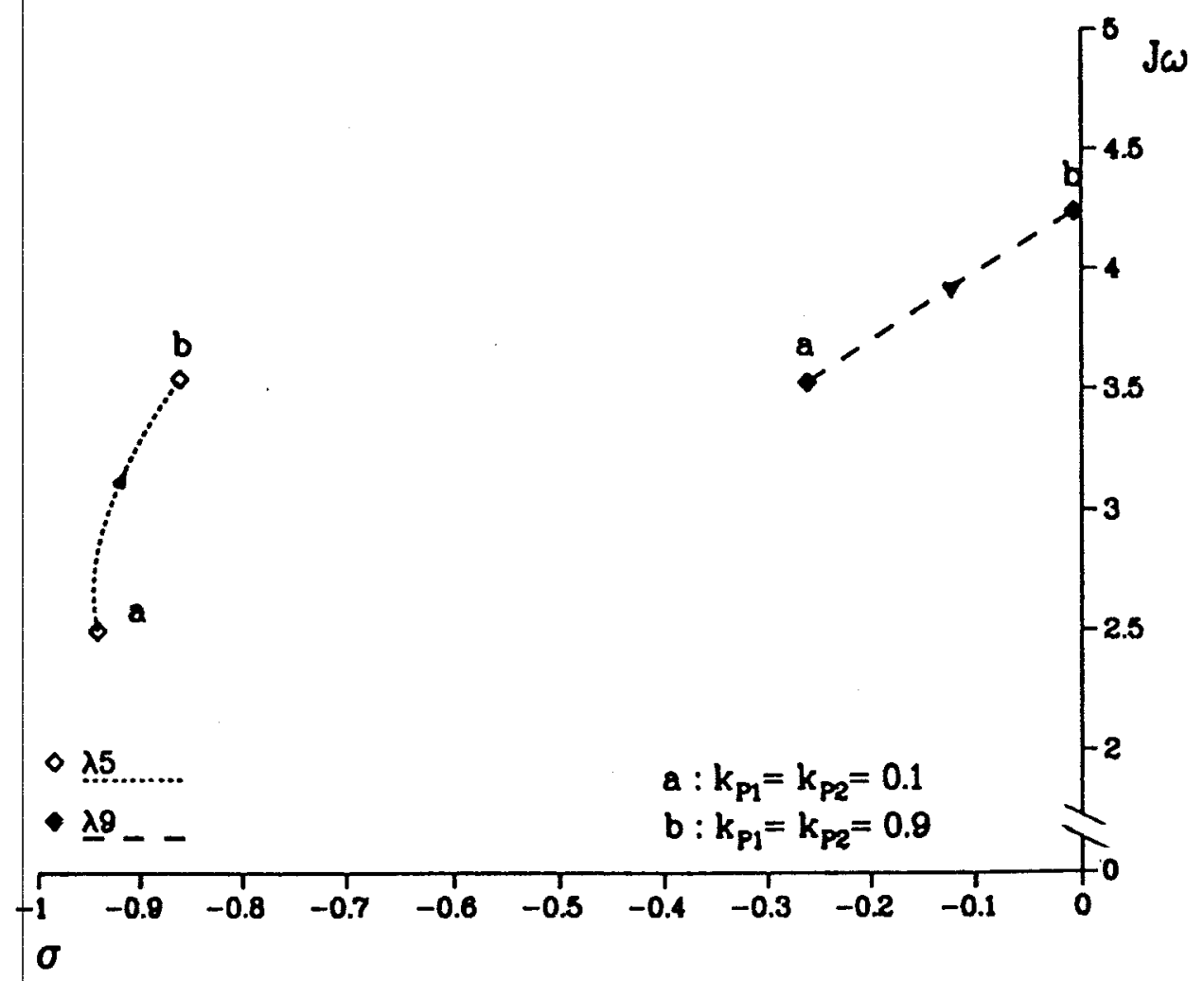

Figure 4.4 Detail of Figure 4.1 for modes $\lambda_{5}$ and $\lambda_{9}$.

The effect of variation of integral gain of the AC controllers on the system stability is shown in Figures 4.5,4.6 and 4.7. Figures 4.5 to 4.7 show that dominant poles move to the right in the complex plane as the integral gain is increased. The oscillation frequency tends to decrease slightly as well as the damping. Therefore the system is less stable for higher integral gain, reaching a critical stability limit for $\mathrm{k}_{\mathrm{I} 1}=\mathrm{k}_{\mathrm{I} 2}=1.2$. 


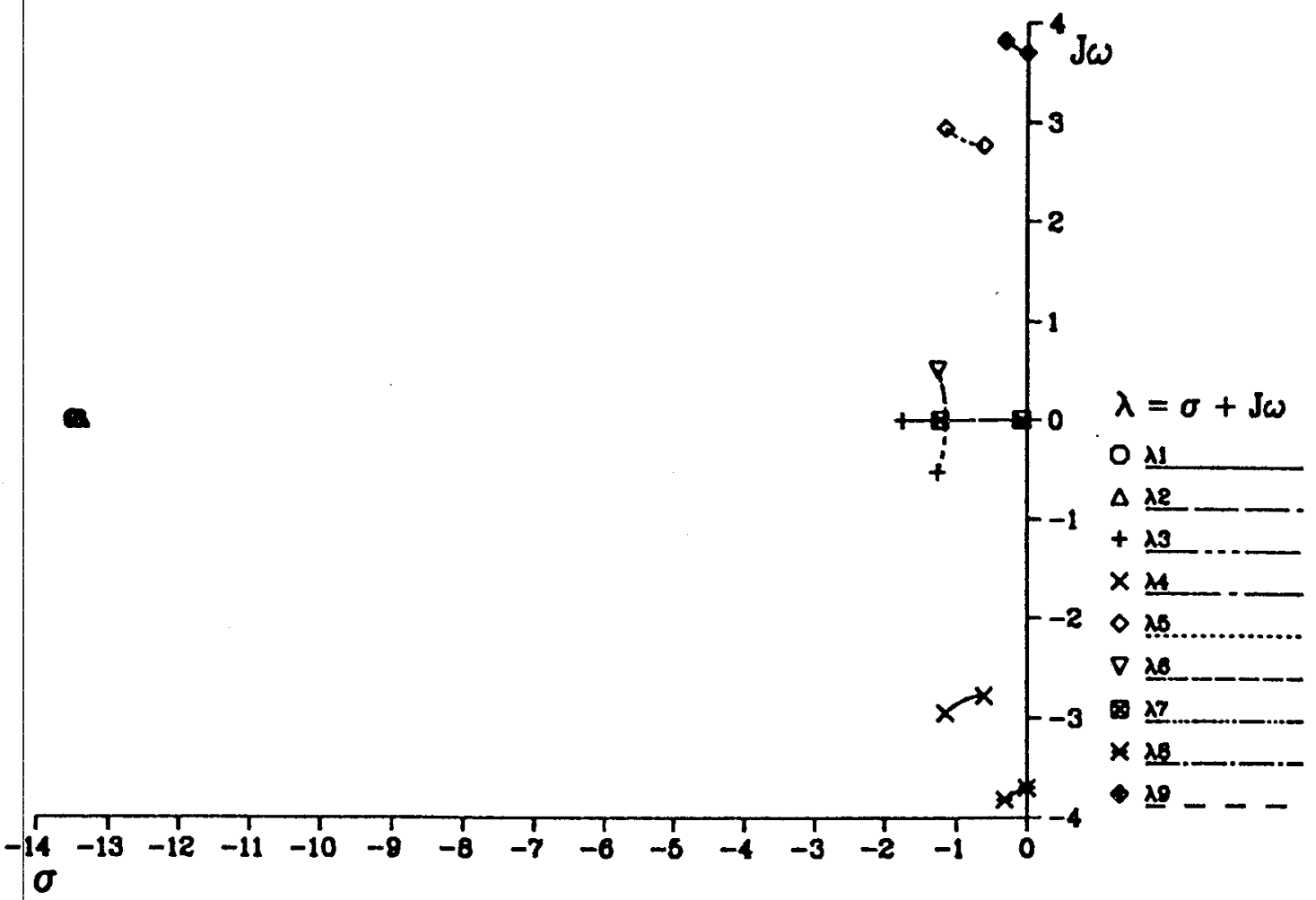

Figure 4.5 Eigenvalue locations for various $k_{11}$ and $k_{12}$.

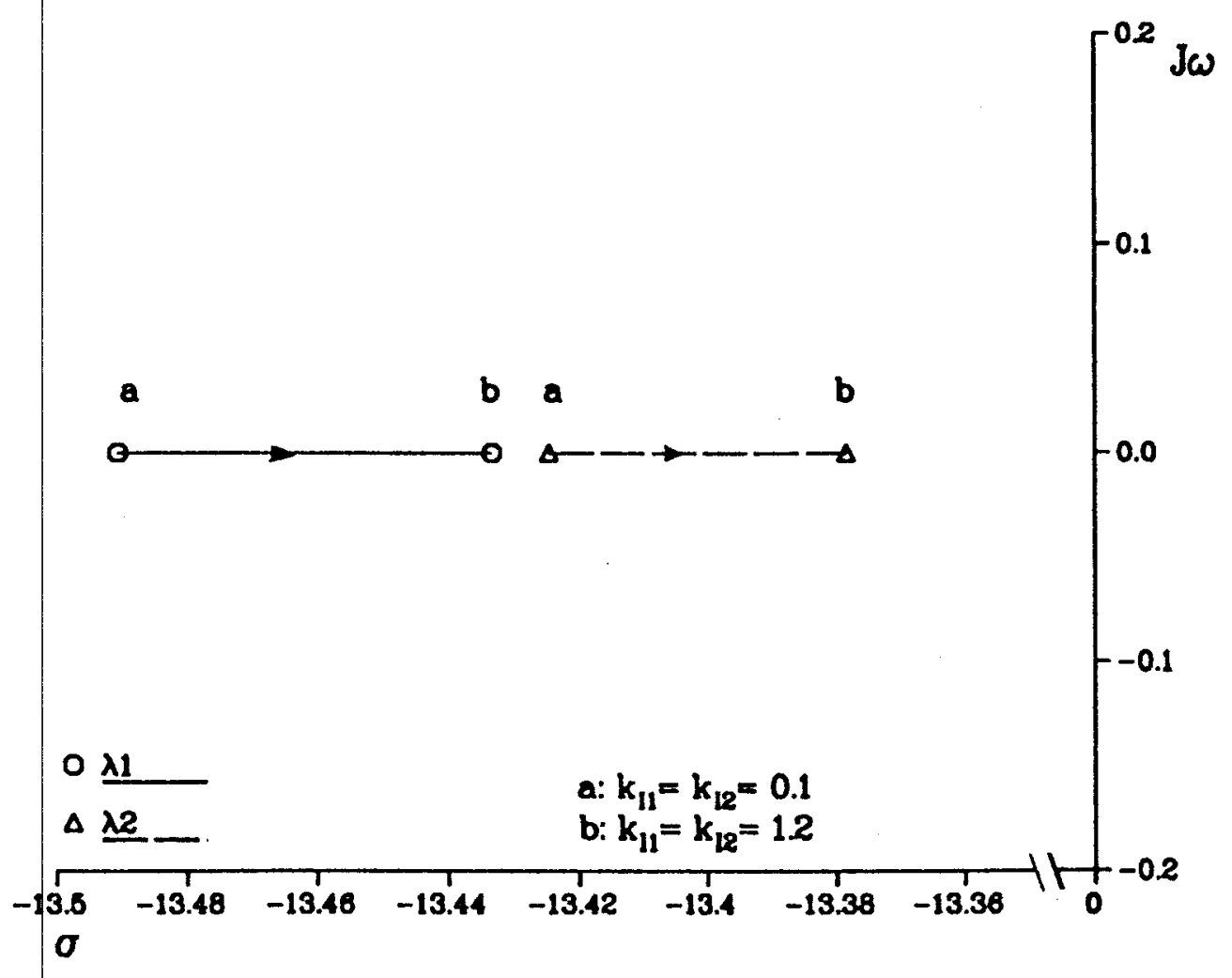

Figure 4.6 Detail of Figure 4.5 for modes $\lambda_{1}$ and $\lambda_{2}$. 

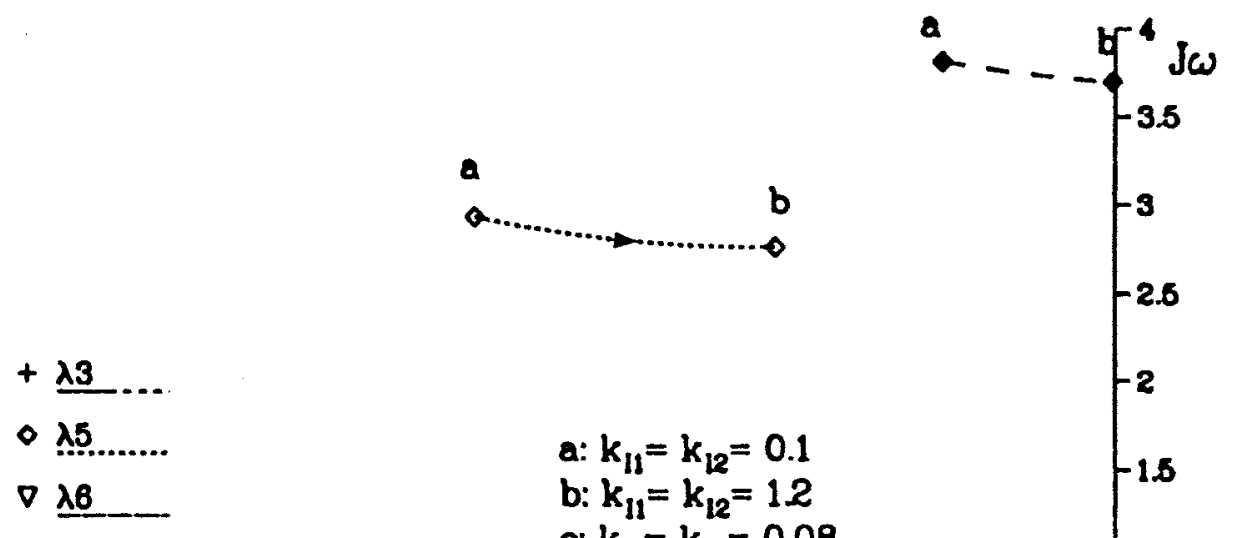

a: $k_{11}=k_{12}=0.1$

b: $k_{11}=k_{12}=12$

a

c: $k_{11}=k_{12}=0.08$

$-2$

- $\underline{\lambda} \boldsymbol{\theta}$

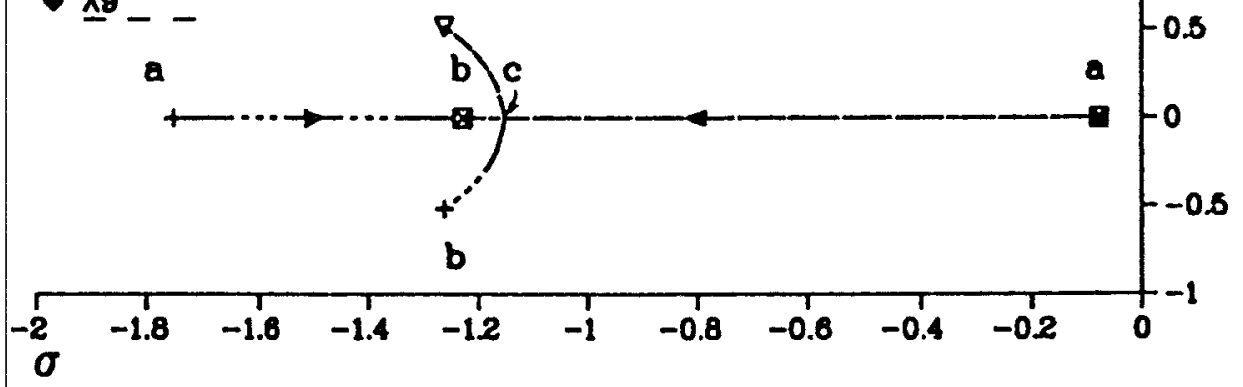

Figure 4.7 Detail of Figure 4.5 for modes $\lambda_{3}, \lambda_{5}, \lambda_{6}, \lambda_{7}$ and $\lambda_{9}$.

\subsection{AC/DC System Stability}

The stability of the two area power system interconnected via parallel $\mathrm{AC}$ and DC links was evaluated by eigenvalue analysis of its state space model.

The state space equation of the AC/DC system is

$$
\dot{X}=A_{3} X+F_{3} V
$$

The state space coefficient matrix $A_{3}$ as a function of the system parameters is given in Figure 3.6. The parameters of the AC controllers are kept constant, and the computed optimal parameters for the DC controller are:

* $\mathrm{k}_{\mathrm{P}}=0 ; \mathrm{k}_{\mathrm{I}}=12$ 
The remainder of the system parameters are the same as in Section 4.4. The state space matrix of constant coefficients is as follows

$\boldsymbol{A}_{\mathbf{3}}=\left[\begin{array}{ccccccccccc}-0.05 & 6 & 0 & 0 & 0 & 0 & -6 & -6 & 0 & 0 & 0 \\ 0 & -3.333 & 3.333 & 0 & 0 & 0 & 0 & 0 & 0 & 0 & 0 \\ -5.208 & 0 & -12.5 & 0 & 0 & 0 & 0 & 0 & -12.5 & 0 & 0 \\ 0 & 0 & 0 & -0.05 & 6 & 0 & 6 & 6 & 0 & 0 & 0 \\ 0 & 0 & 0 & 0 & -3.333 & 3.333 & 0 & 0 & 0 & 0 & 0 \\ 0 & 0 & 0 & -5.208 & 0 & -12.5 & 0 & 0 & 0 & -12.5 & 0 \\ 0.544 & 0 & 0 & -0.544 & 0 & 0 & 0 & 0 & 0 & 0 & 0 \\ 0 & 0 & 0 & 0 & 0 & 0 & 0 & -20 & 0 & 0 & -20 \\ 0.412 & 0.765 & 0 & -0.163 & 0 & 0 & -0.165 & -6.165 & 0 & 0 & -6 \\ -0.163 & 0 & 0 & 0.412 & 0.765 & 0 & 0.165 & 6.165 & 0 & 0 & 6 \\ 0 & 0 & 0 & 0 & 0 & 0 & 12 & 12 & 0 & 0 & 0\end{array}\right]$

Table 4.2 Eigenvalues of the AC/DC system.

\begin{tabular}{|l|l|}
\hline$\lambda_{1}$ & $-13.47+\mathrm{j} 0.00$ \\
\hline$\lambda_{2}$ & $-9.75-\mathrm{j} 11.88$ \\
\hline$\lambda_{3}$ & $-9.75+\mathrm{j} 11.88$ \\
\hline$\lambda_{4}$ & $-0.94-\mathrm{j} 2.83$ \\
\hline$\lambda_{5}$ & $-0.94+\mathrm{j} 2.83$ \\
\hline$\lambda_{6}$ & $-0.53+\mathrm{j} 0.00$ \\
\hline$\lambda_{7}$ & $-0.53+\mathrm{j} 0.00$ \\
\hline$\lambda_{8}$ & $-1.17-\mathrm{j} 3.09$ \\
\hline$\lambda_{9}$ & $-1.17+\mathrm{j} 3.09$ \\
\hline$\lambda_{10}$ & $-13.50+\mathrm{j} 0.00$ \\
\hline$\lambda_{11}$ & $0.00+\mathrm{j} 0.00$ \\
\hline
\end{tabular}


The eigenvalues of matrix $\lambda_{3}$ are shown in Table 4.2. The eigenvalue $\lambda_{11}$, located at the origin of the complex plane, represents a critical stability condition. In order to evaluate the incidence of $\lambda_{11}$ in the transient response of the system, an eigenvalue computation for various values of system parameters was carried out. This analysis included variations of all system parameters and their effects on eigenvalue $\lambda_{11}$. The eigenvalue $\lambda_{11}$ did not show any change for variations of any of the system parameters. Since the $\lambda_{11}$ mode is not sensitive to any system parameter variation, this mode can be considered neutral. It represents a steady state offset in state yariables. Therefore the dynamic stability of the system is not affected by the neutral mode $\lambda_{11}$. In addition, participation factors for the $\lambda_{11}$ mode is shown in Table 4.3.

Table 4.3 Participation Factors corresponding to mode $\lambda_{11}$.

\begin{tabular}{|c|c|}
\hline $\begin{array}{c}\text { State } \\
\text { Variable }\end{array}$ & $\begin{array}{c}\text { Participation } \\
\text { Factors }\end{array}$ \\
\hline \hline$x_{1}$ & 0 \\
\hline$x_{2}$ & 0 \\
\hline$x_{3}$ & 0 \\
\hline$x_{4}$ & 0 \\
\hline$x_{5}$ & 0 \\
\hline$x_{6}$ & 0 \\
\hline$x_{7}$ & -1 \\
\hline$x_{8}$ & 0.561 \\
\hline$x_{9}$ & 0 \\
\hline$x_{10}$ & 0 \\
\hline$x_{11}$ & -0.094 \\
\hline
\end{tabular}


As we can see from Table 4.3, only the state variables $\mathrm{x}_{7}$ (AC power interchange deviation), $x_{8}$ (DC power interchange deviation) and $x_{11}$ (supplementary control signal) have some degree of participation in the mode $\lambda_{11}$ and are thus subject to steady state offsets following a system disturbance.

\subsubsection{Effect of Supplementary controller Gain Variation}

The effect of variation of proportional gain of the supplementary controller on the system stability is shown in Figures $4.8,4.9,4.10$ and 4.11. These figures show that dominant poles $\left(\lambda_{8}, \lambda_{9}\right)$ move to the left side in the $\mathbf{s}$ plane as proportional gain is increased. The damping is increased and the oscillation frequency is decreased, and system stability is improved. $\lambda_{6}$ moves to the right in the $s$ plane, and it is slightly sensitive to proportional gain variation.

The effect of integral gain variation of the supplementary controller on the system stability is shown in Figures $4.12,4.13$ and 4.14 . These figures show that dominant poles $\left(\lambda_{8}, \lambda_{9}\right)$ moves to the left in the s plane as integral gain is increased. For low values of gain, oscillation frequency is increased slightly and after that it decreases faster around the optimal gain. The damping is continuously increased until the gain is a little less than optimal gain, after that starts to decrease slowly. The pole $\lambda_{6}$ moves to the right in the $\mathbf{s}$ plane with little sensitivity as the integral gain is increased. Therefore the system stability is improved in a range close to the optimal gain. 


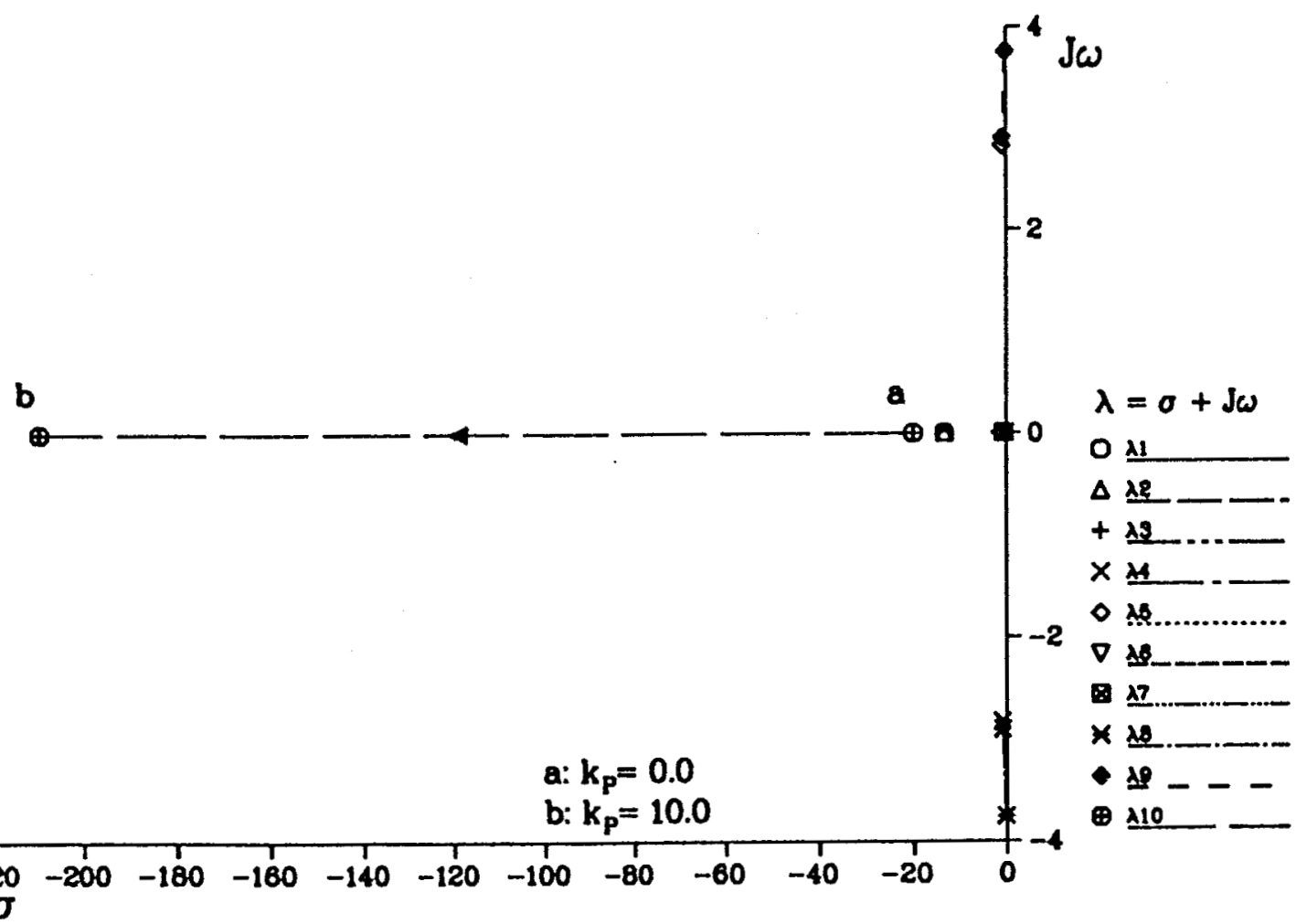

Figure 4.8 Eigenvalue locations for various $k_{p}$.

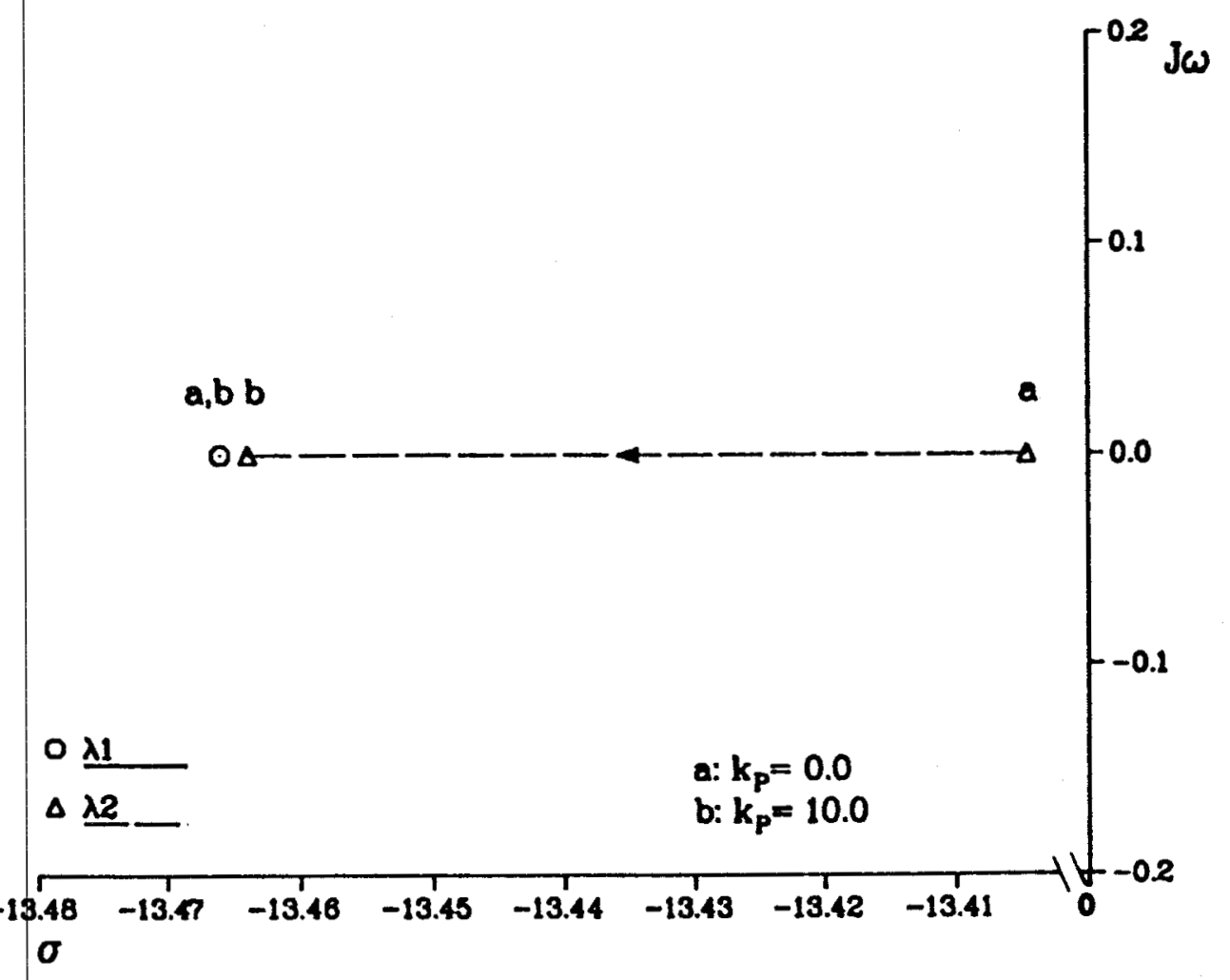

Figure 4.9 Detail of Figure 4.8 for modes $\lambda_{1}$ and $\lambda_{2}$. 


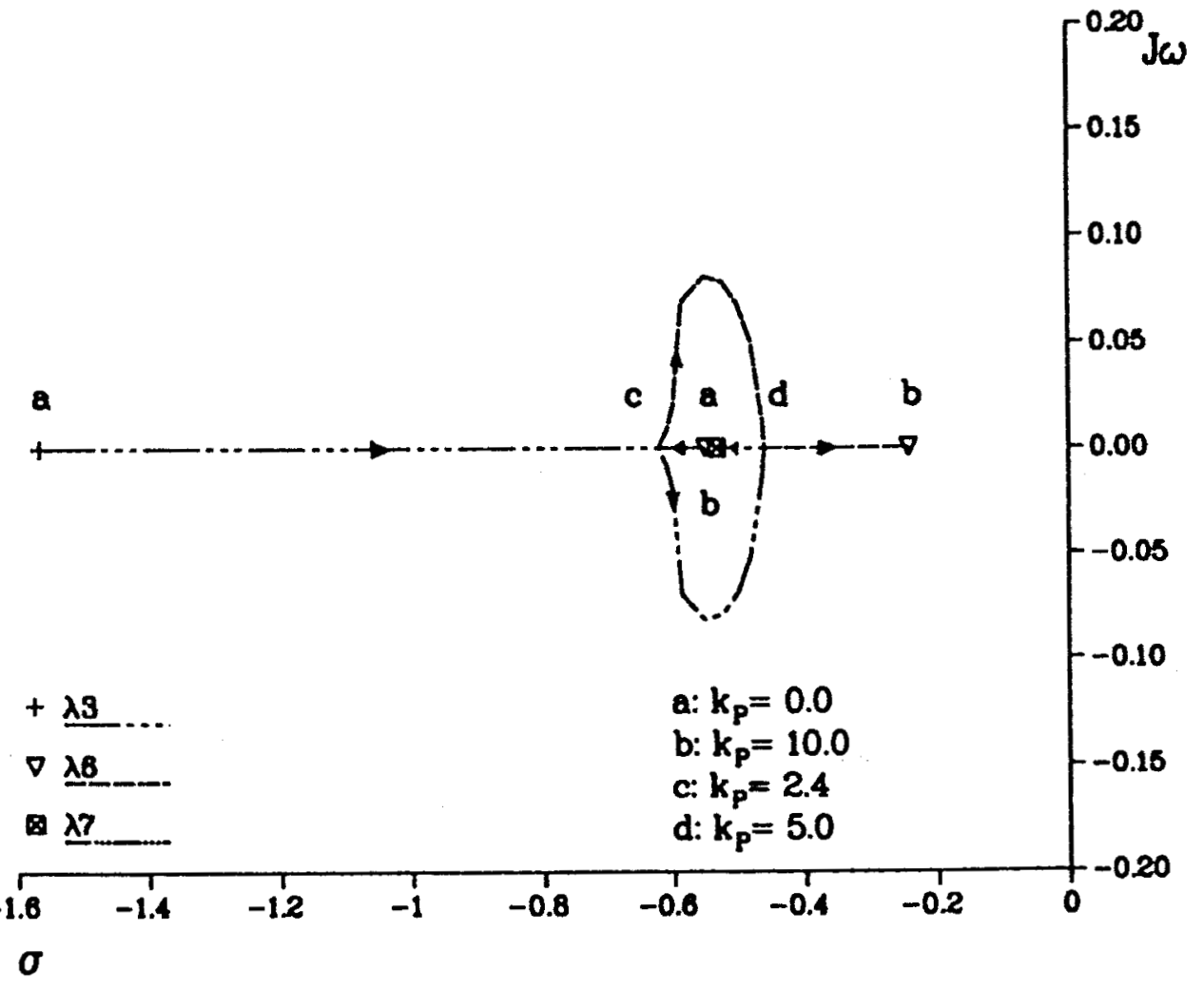

Figure 4.10 Detail of Figure 4.8 for modes $\lambda_{3}, \lambda_{6}$ and $\lambda_{7}$.

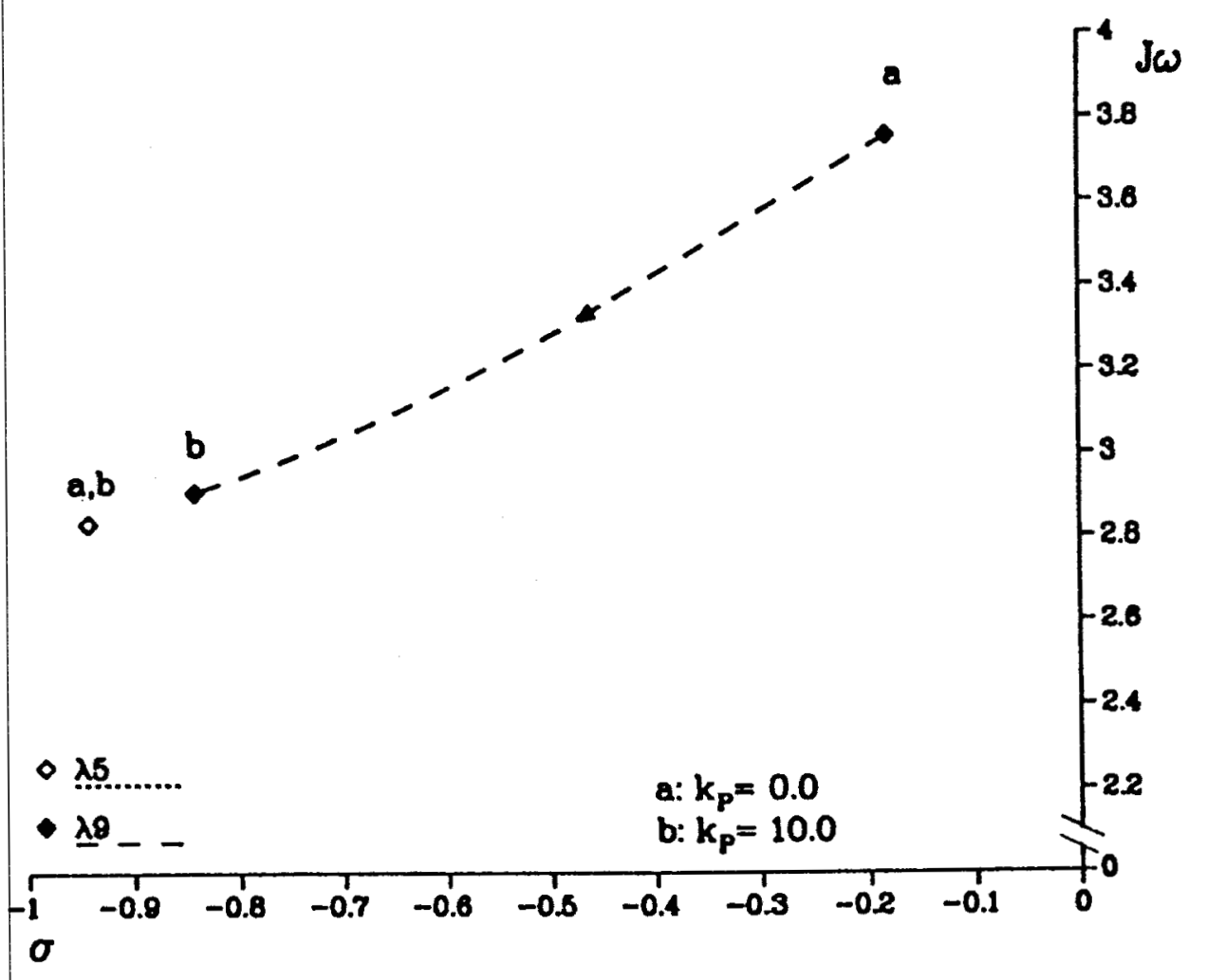

Figure 4.11 Detail of Figure 4.8 for modes $\lambda_{5}$ and $\lambda_{9}$. 


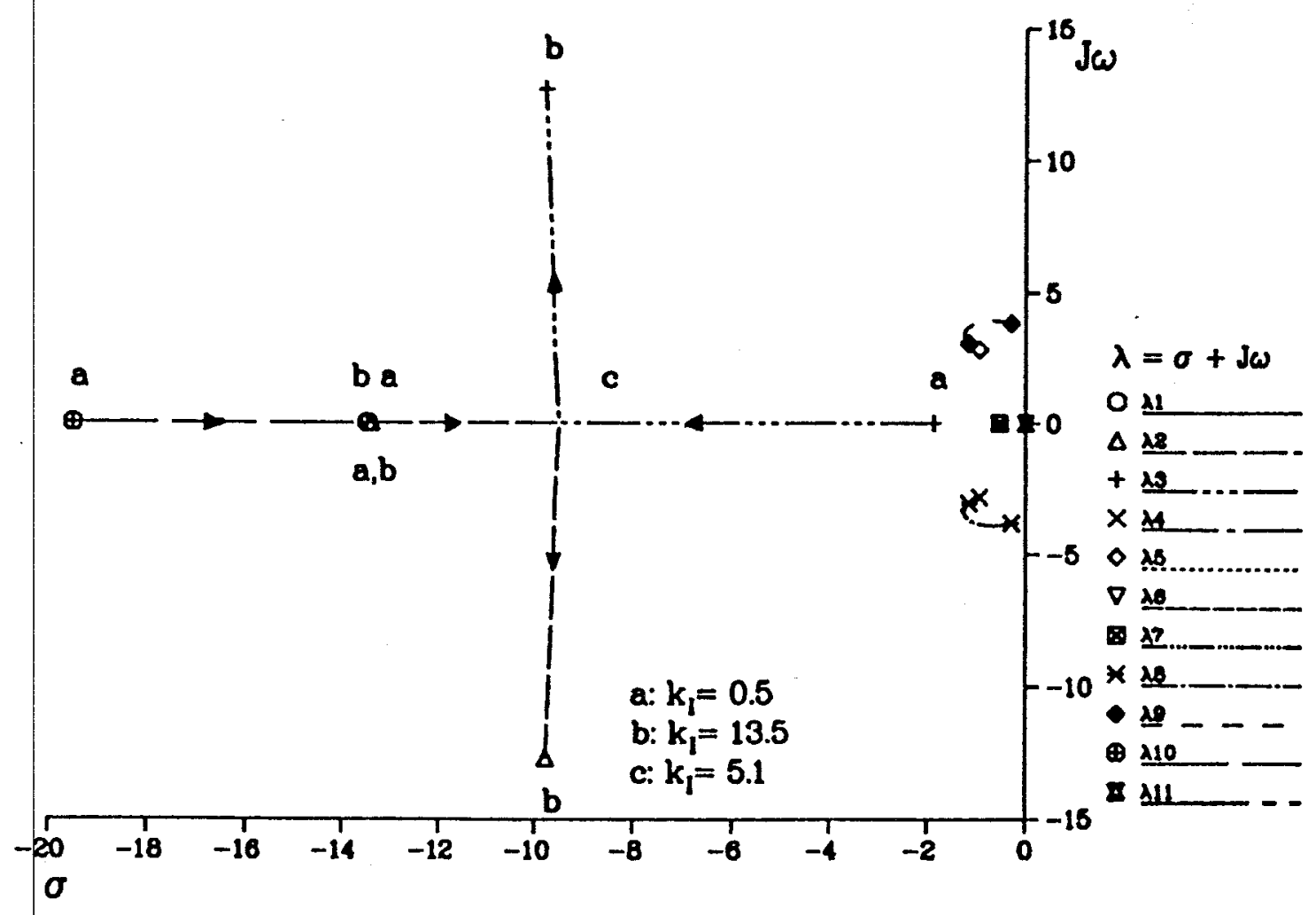

Figure 4.12 Eigenvalue locations for various $k_{1}$.

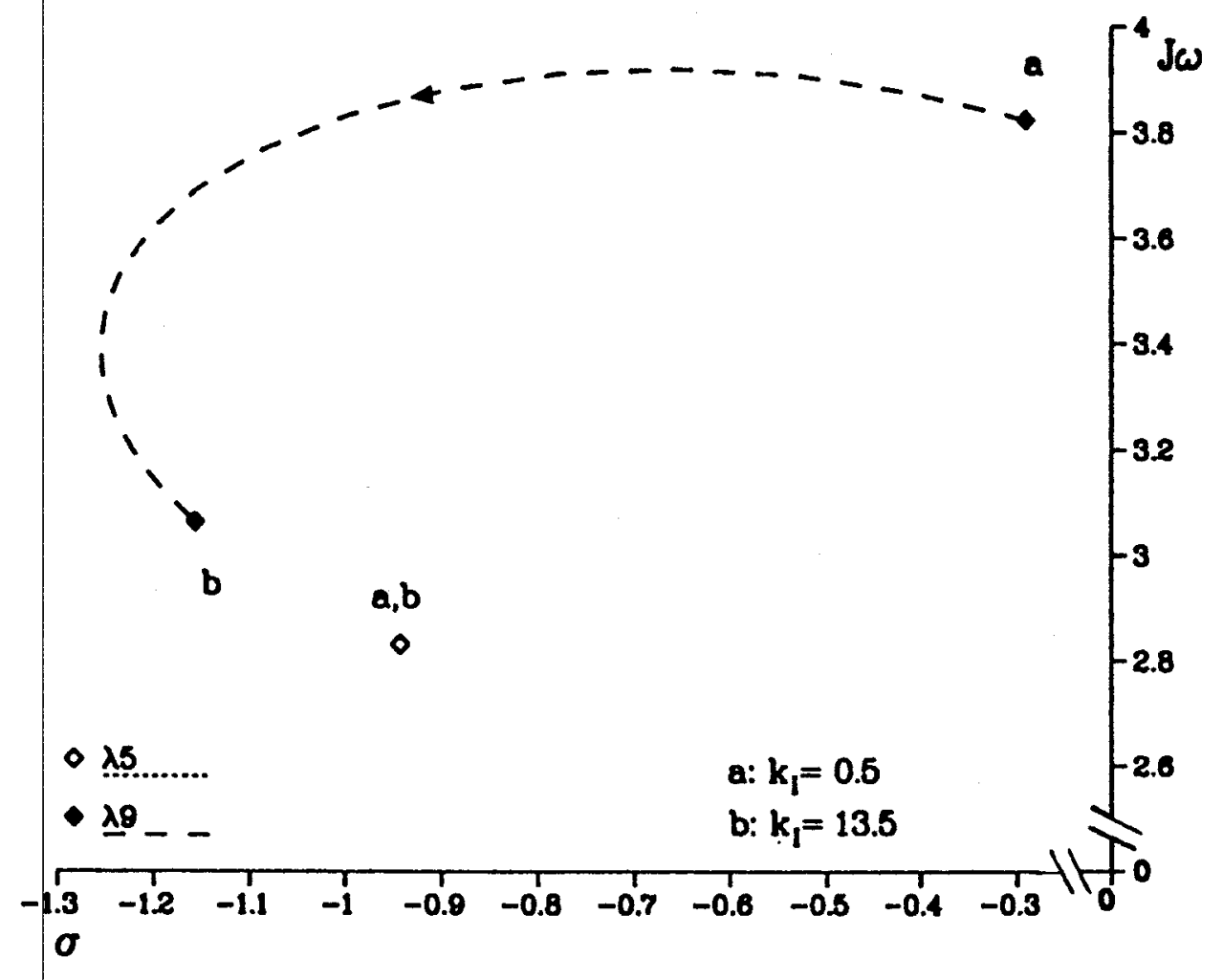

Figure 4.13 Detail of Figure 4.12 for modes $\lambda_{5}$ and $\lambda_{9}$. 


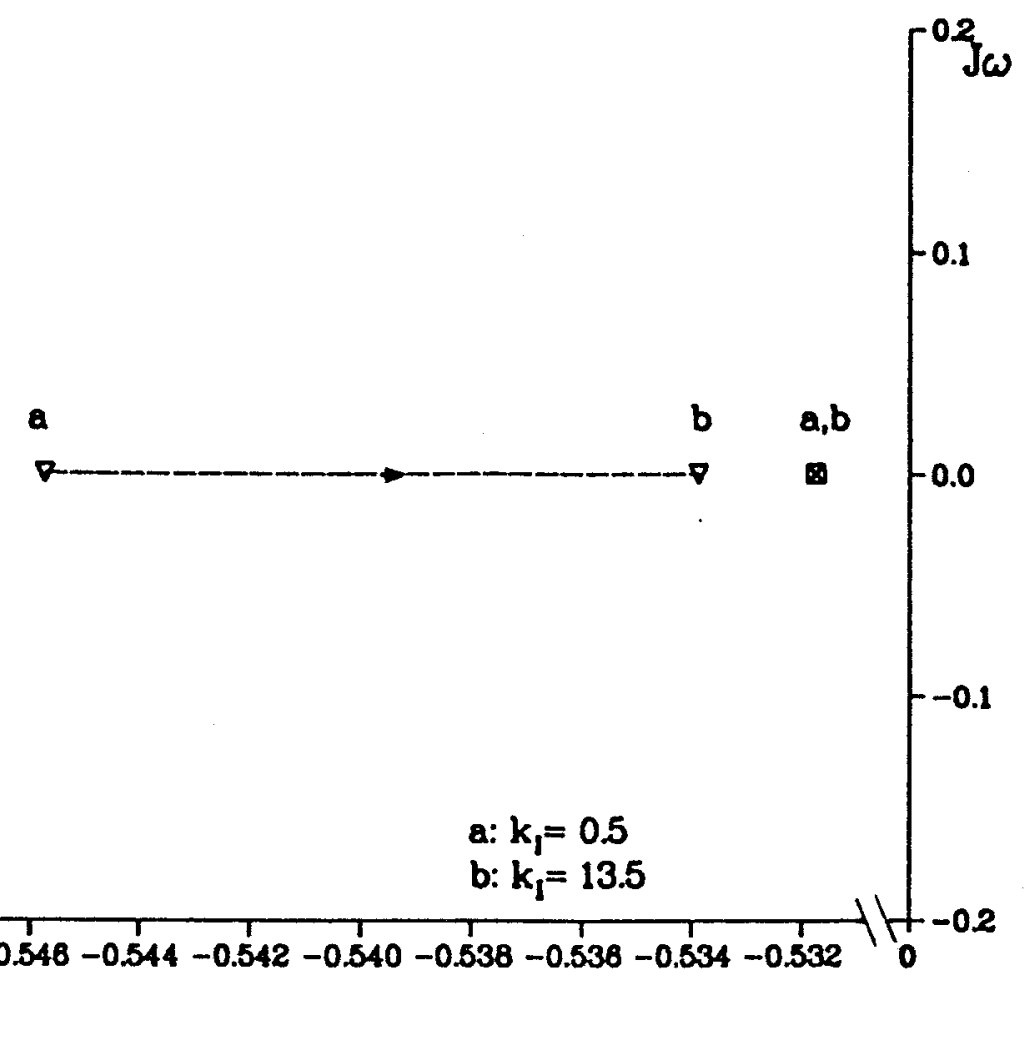

Figure 4.14 Detail of Figure 4.12 for modes $\lambda_{6}$ and $\lambda_{7}$.

\subsection{Conclusions}

In this Chapter stability analysis of the $\mathrm{AC}$ and $\mathrm{AC} / \mathrm{DC}$ systems, based on their eigenstructure is reported. The eigenvalue computation of the state coefficient matrix of the system for various AGC and supplementary controller parameters carried out to evaluate system stability are described. The following general observations are based on the location and movements of dominant poles in the complex plane.

The variation of AGC controller parameters on the system stability show system responses with increasing oscillation frequency and reduction of damping as the proportional gain increases. Similar effects, but in smaller degree, occur as the 
integral gain increases.

The variation of supplementary controller parameters on system stability show improvements in system damping and oscillation frequency reduction as proportional gain is increased and the integral gain is set in a range close to its optimal value. It appears that the system stability could be improved by action of the supplementary DC control. 


\section{SIMULATION STUDIES}

\subsection{General}

Simulation studies can be used to analyze and evaluate the dynamic performance of a system. Computer simulation is often the only feasible technique to determine system dynamic performance over a range of operating conditions.

In this research the computer simulation process was carried out using a computer program called TUTSIM $^{49}$. It is an interactive program which simulates the dynamics of systems. The TUTSIM system accepts models in the form of block diagrams. It simulates these models and allows one to change system parameters interactively and compare resulting changes in system responses. This feature make it possible to optimize a system easily and quickly. In the research reported here the model input to the TUTSIM system was based on the transfer function block diagram of the Two Area Interconnected Power System (TAIPS) representation. Through this simulation program the dynamic response of the system was obtained for a specific input disturbance. The model structure developed for this study is shown in Appendix A.

The simulation studies presented in this chapter include mainly two cases as follows: 
i) Simulation of a two area power system interconnected by an AC tie line, with AGC control. For the purposes of system response studies from the control system point of view, this system is equivalent to a two area power system interconnected by parallel $\mathrm{AC}$ and $\mathrm{DC}$ tie lines, with AGC control and constant DC power control. Constant DC power control does not affect the dynamic responses of the $\mathrm{AC}$ interconnected power system when an area load change occurs.

ii) Simulation of a two area power system interconnected by parallel $\mathrm{AC}$ and DC tie lines, with AGC and supplementary DC control.

The simulated system responses were obtained for the two-area power system model assuming it had been subjected to a step load disturbance in one of the system areas. It was assumed that each area was working independently with no mutual assistance of power transfer scheduled through the link except following a disturbance. Initially the power system was in steady state condition determined by normal system operation. That means there were no state variable deviations from scheduled values, in other words all the state variables of the system model were zero. Subsequently the area load was increased by a step $\left(\Delta P_{\nu}\right)$ in one of the control areas, so the system model responses oscillated until they were settled down by the action of the AGC and supplementary DC controls. The AGC control was based on the Tie-line Bias concept described in Chapter 1. The supplementary DC control, the main object of this research work, imposed power modulation of the DC link based 
on the deviation of the power interchange $\left(\Delta \mathrm{P}_{12}\right)$ between the individual power system areas.

The inadvertent energy interchange (IEI) which is represented by the time integral of the net power interchange, was also computed in the simulation process. Furthermore the simulation process was used for the optimization of controller parameters (proportional and integral gains) of the AGC and supplementary DC controls.

Since the smallest time constant of the system model utilized is $T_{D C}=0.05$ seconds (DC system time constant) the simulation time step chosen is 0.01 seconds, which is small enough so as not to compromise the accuracy of system responses. The time period of the simulation was determined by the reset time of the slowest system response examined. In this research work the time period of the simulation was 20 seconds.

\subsection{Control Optimization}

In the design of a control system, the system must satisfy given performance specifications. Since control systems are dynamic, the performance specifications may be given in terms of either the transient response behaviour to specific inputs or in terms of a performance index. In this case the latter approach was used.

A desired performance index was selected, and using that a unique system 
design was obtained. This system is called "optimal control" in terms of the defined performance index.

\subsubsection{Performance Index}

A performance index is a quantitative measure of the performance of a system and it is chosen such that the important system specifications are emphasized. The performance index can be used to determine the nature of the resulting control system. The system is considered to be an optimum control system when the system parameters are adjusted so that the index reaches an extreme value, usually a minimum value. The "optimal" values of the parameters depend directly on the performance index selected.

\subsubsection{Control Optimization of the Two Area Interconnected Power System}

The formal optimal control approach includes all system state variables in the optimal feedback control; however, in this study, it is not feasible to include all the system state variables in the feedback loop because of the actual characteristic of a power system. Moreover, the configuration of the system controllers is predetermined (proportional plus integral control). Therefore a pseudo optimal control was utilized in this research, based only on the optimization of the controller parameters to minimize a selected performance index which includes a subset of the state variables.

The performance criterion chosen must lead to the minimisation of the Area Control Error (ACE) in both control areas. The performance index selected is 
represented by the time integral of the sum of the square of control error (ISACE) in Area 1 and the square of control error in Area 2, averaged over a time period T. The mathematical representation of the performance index ISACE is

$$
\text { ISACE }=\frac{1}{T} \int_{0}^{T}\left[\left(\mathrm{ACE}_{1}\right)^{2}+\left(\mathrm{ACE}_{2}\right)^{2}\right] d t
$$

The performance index of Equation (5.1) is based directly on generation requirements in both control areas, which represents a good measure of control effectiveness.

The performance index minimisation was carried out by a sub routine called Parameter Estimation ${ }^{49}$ of the TUTSIM program. It is an implementation of the SIMPLEX METHOD ${ }^{50}$ by Nelder and Mead. This subroutine minimizes the ISACE function by adjusting the controller parameters. In the computation of the optimal parameters a constraint of system frequency deviation was also included. The peak yalue of the first swing of the system frequency deviation was not allowed to exceed $0.025 \mathrm{~Hz}$. This is an arbitrary limit based on accepted North American practice.

\subsection{AC System with AGC Control}

The simulation tests for a two area power system interconnected by an $\mathrm{AC}$ tie line with AGC control was based on the transfer function block diagram shown in Figure 3.2. The parameters associated with the system are shown in Section 2.12. 
The AC link had a capacity of $10 \%(200 \mathrm{MW})$ of area capacity, and the power system was operating at a power angle of $30^{\circ}$ between the two areas of the system. Then from equation (2.16) the power interchange in steady state condition was $P_{12}=100 \mathrm{MW}$, and from equation (2.17) the synchronizing torque coefficient was $\mathrm{T}_{12}=0.544 \mathrm{puMW} / \mathrm{Hz}$.

The performance of the system was examined for a step load increase in Area 1 of $1 \%(20 \mathrm{MW})$ of area capacity.

The simulation tests were carried out such that, initially (before disturbance) the system was in steady state condition. The step load change in Area 1 represented a situation of lack of generation, resulting in a decrease of power interchange from Area 1 to Area 2. This imbalance between generation and load in area 1 caused a decrease of frequency in both areas. Thereafter, by action of the governors and AGC controllers the system was restored to normal steady state condition, such that system frequency and power interchange came back to their scheduled values.

A series of simulation tests were carried out to compute the optimal AGC controller parameters to minimize the ISACE. The optimal parameters were found to be:

$* \mathrm{k}_{\mathrm{P} 1}=\mathrm{k}_{\mathrm{P} 2}=0.3$ (proportional gain)

$* \mathrm{k}_{11}=\mathrm{k}_{\mathrm{12}}=0.6$ (integral gain) 
The simulation results illustrated in Figures 5.1 to 5.10 and Table 5.1 show the effects of changes of the AGC controller parameters on the dynamic responses of the system. Two modes of response are evident; one under damped mode about $0.3 \mathrm{~Hz}$ and the other, a relatively over damped mode. The higher frequency mode is not affected significantly by governor operation; however, the other mode is.

Figure 5.1 illustrates the frequency deviation dynamic response in Area 1 for various values of proportional gain of the AGC control. The frequency oscillation of the response increases and the system damping decreases as $k_{\mathrm{P} 1}$ and $\mathrm{k}_{\mathrm{P} 2}$ increase; so the area system frequency came back to scheduled value more quickly for small values of proportional gain.

In Figure 5.2 the frequency deviation responses in Area 1 for various values of integral gain of the AGC control show practically the same oscillation frequency in all the cases. Smaller $k_{11}$ and $k_{12}$ provide an over damped response, and larger $k_{11}$ and $\mathrm{k}_{\mathrm{1} 2}$ provide a poor damping response, compared with the optimal parameters. Therefore the area system frequency is seen to settle down faster with optimal AGC controller parameters.

Figures 5.3 and 5.4 illustrate the frequency deviation responses in Area 2 for various values of AGC proportional gain and AGC integral gain respectively. The curves shown similar characteristics to Figures 5.1 and 5.2, respectively, with the exception of the size of the first swing of the responses $\left(\Delta f_{1} \max , \Delta f_{2} \max \right)$. Since the 
change in load was in Area 1, the disturbance affected mainly the transient response in this area.

In Figure 5.5 the power interchange deviation responses show a higher oscillation frequency and less damping as $\mathrm{k}_{\mathrm{p} 1}$ and $\mathrm{k}_{\mathrm{p} 2}$ increase. The response settled down faster for smaller proportional gain, but the first swing increased.

In Figure 5.6, with smaller values of $k_{11}$ and $k_{12}$ the power interchange deviation response was over damped, with a larger swing. Conversely larger values of $k_{11}$ and $k_{12}$ provided a response with poor damping and smaller first swing. Optimal integral gain provide a well damped response with the smallest reset time.

Figures 5.7 and 5.8 illustrate the effect of changes in proportional gain and integral gain, respectively, on the performance index value. The performance index (ISACE) was found to be more sensitive to changes of $k_{11}$ and $k_{12}$ than to changes of $k_{P 1}$ and $k_{P 2}$, reaching a minimum value with the optimal controllers parameters.

Figures 5.9 and 5.10 show the inadvertent energy interchange (IEI) for various values of proportional gain and integral gain respectively. The IEI was found to be practically insensitive to changes of proportional gain but very sensitive to changes of integral gain. The IEI was minimized as the $\mathrm{k}_{\mathrm{I} 1}$ and $\mathrm{k}_{\mathrm{L} 2}$ increase.

Table 5.1 summarizes the effects of changes of AGC controller parameters on 
system performance, supplying relevant numeric information as obtained from the dynamic simulation.

Other system dynamic responses such as area control error (ACE), deviation in generated power and control signals are shown in Appendix B.

Additionally a set of simulation tests were carried out to verify how well the optimal control worked for different sizes of step load disturbances. Whenever the performance index was varied as a consequence of size changes of the step load disturbance, the optimal controller parameters were found to keep the same values. Therefore, the optimal values of AGC controller parameters were found to be independent of step load size variations. 


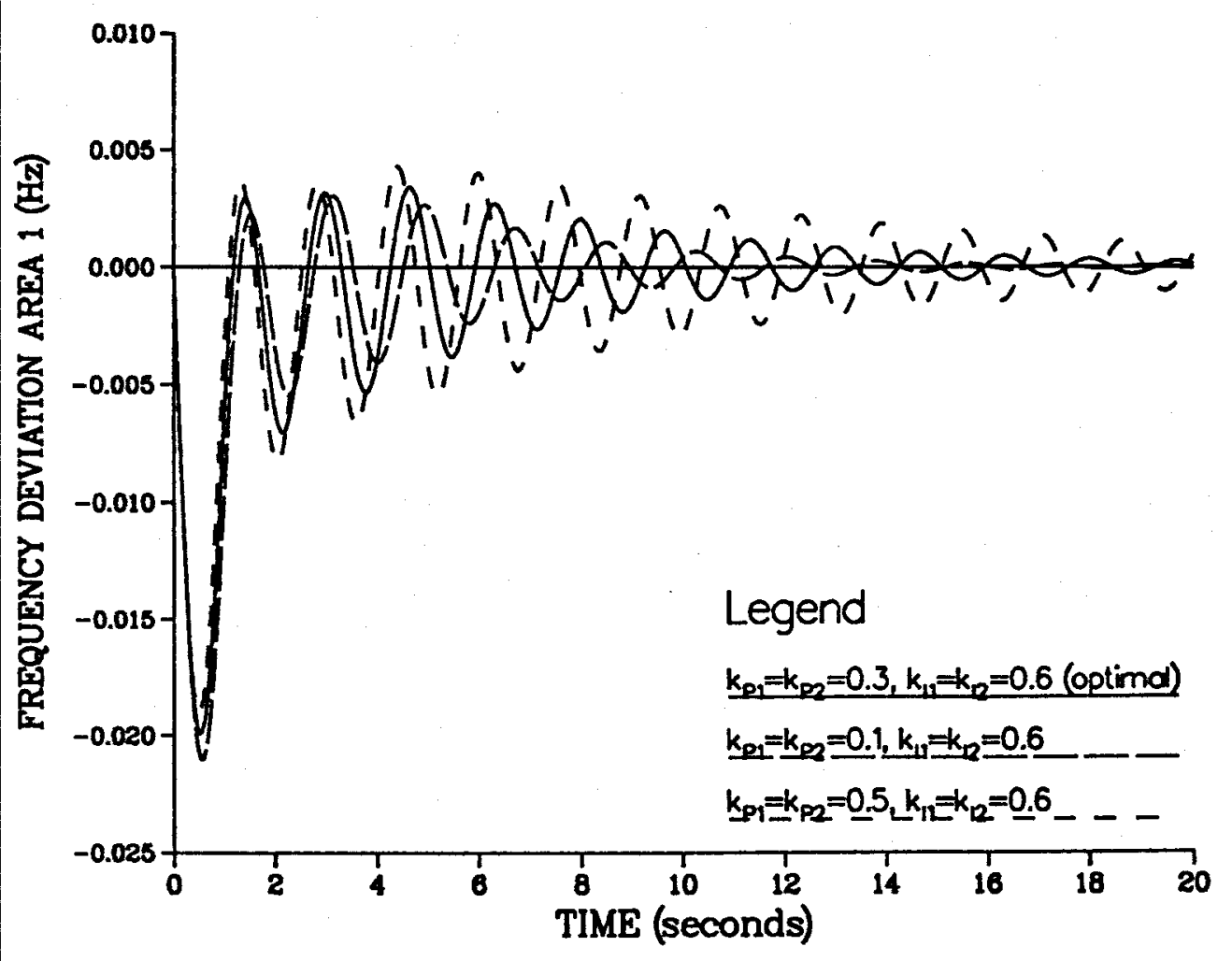

Figure 5.1 Frequency deviation responses in Area 1 for various AGC proportional gain.

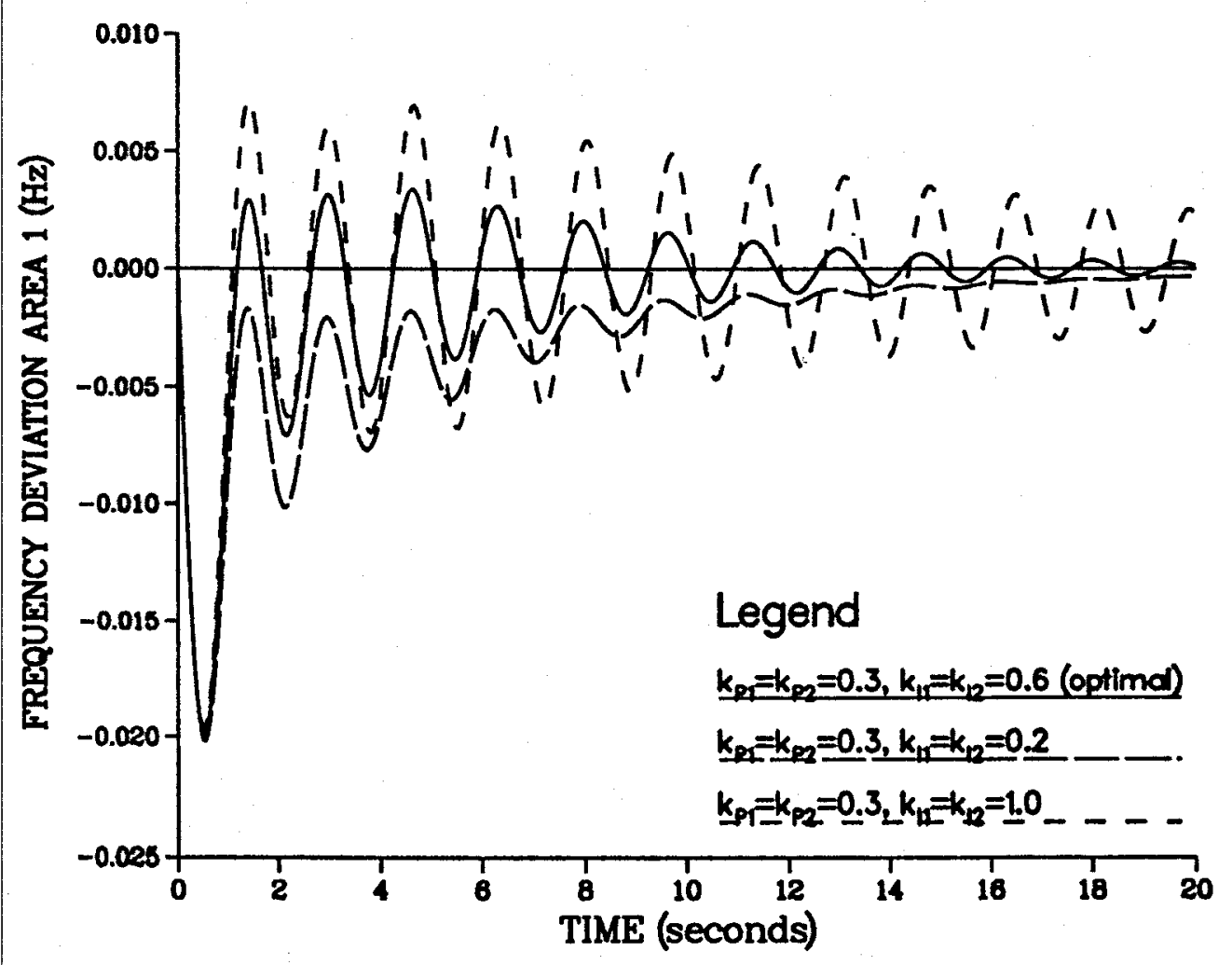

Figure 5.2 Frequency deviation responses in Area 1 for various AGC integral gain. 


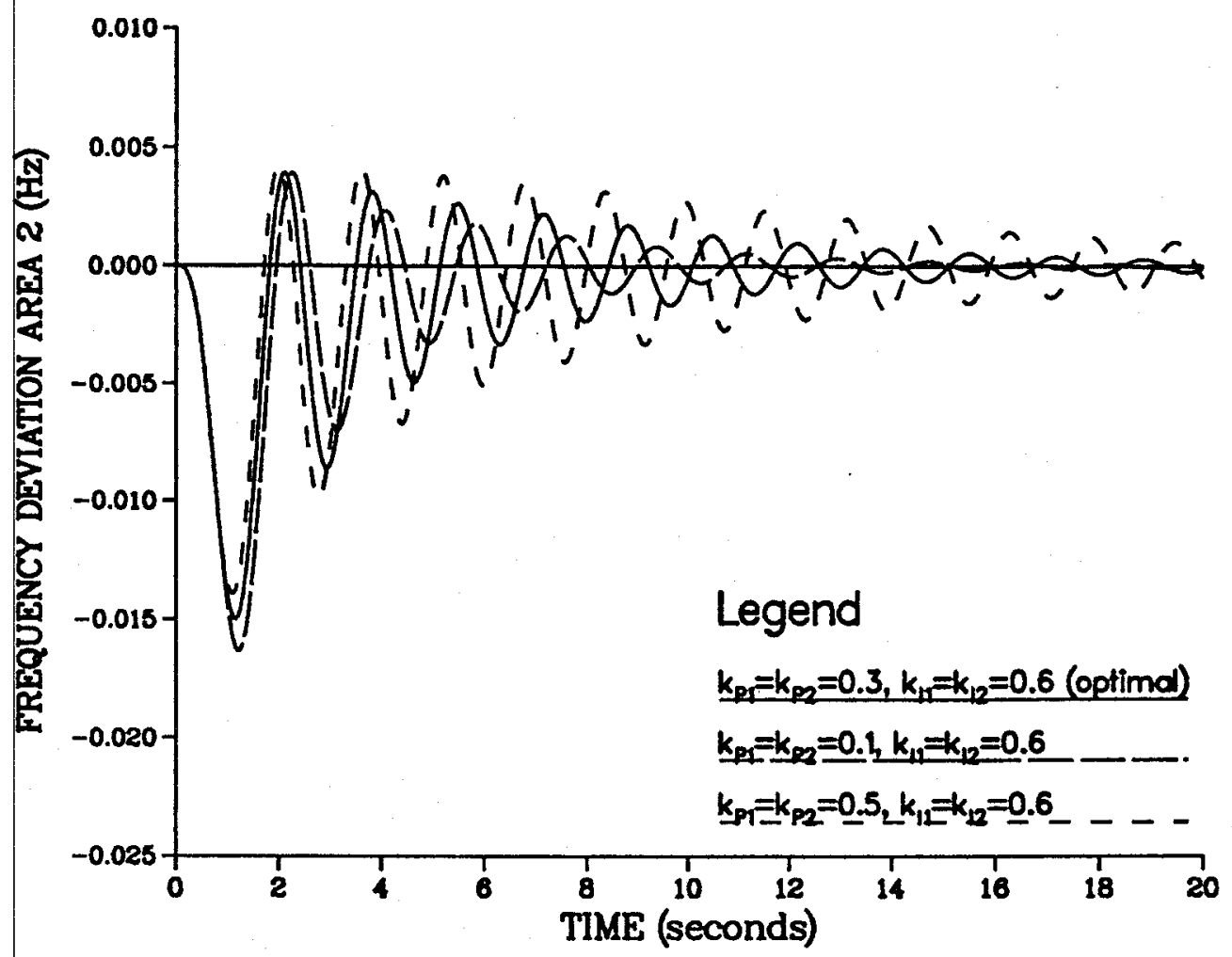

Figure 5.3 Frequency deviation responses in Area 2 for various AGC proportional gain.

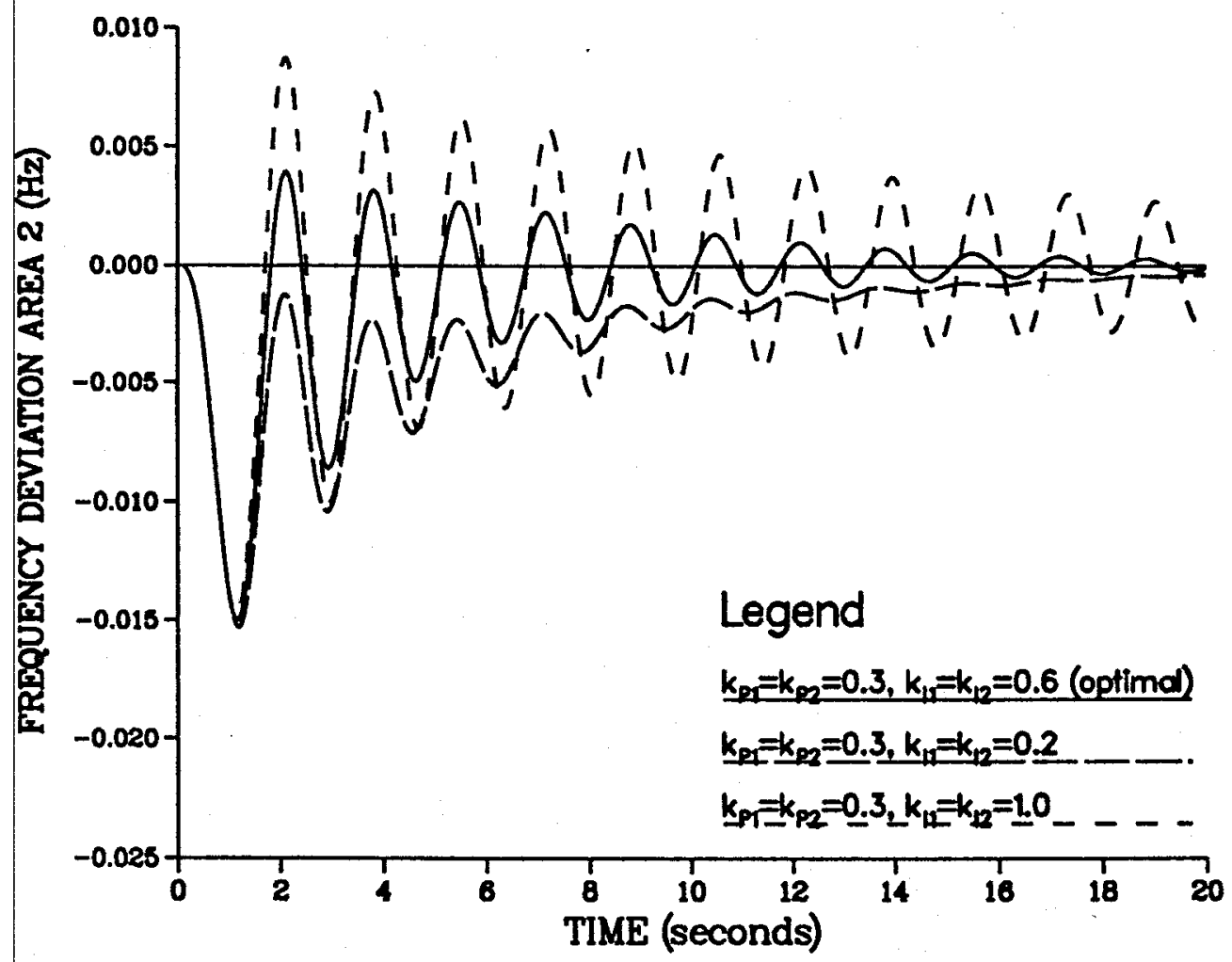

Figure 5.4 Frequency deviation responses in Area 2 for various AGC integral gain. 


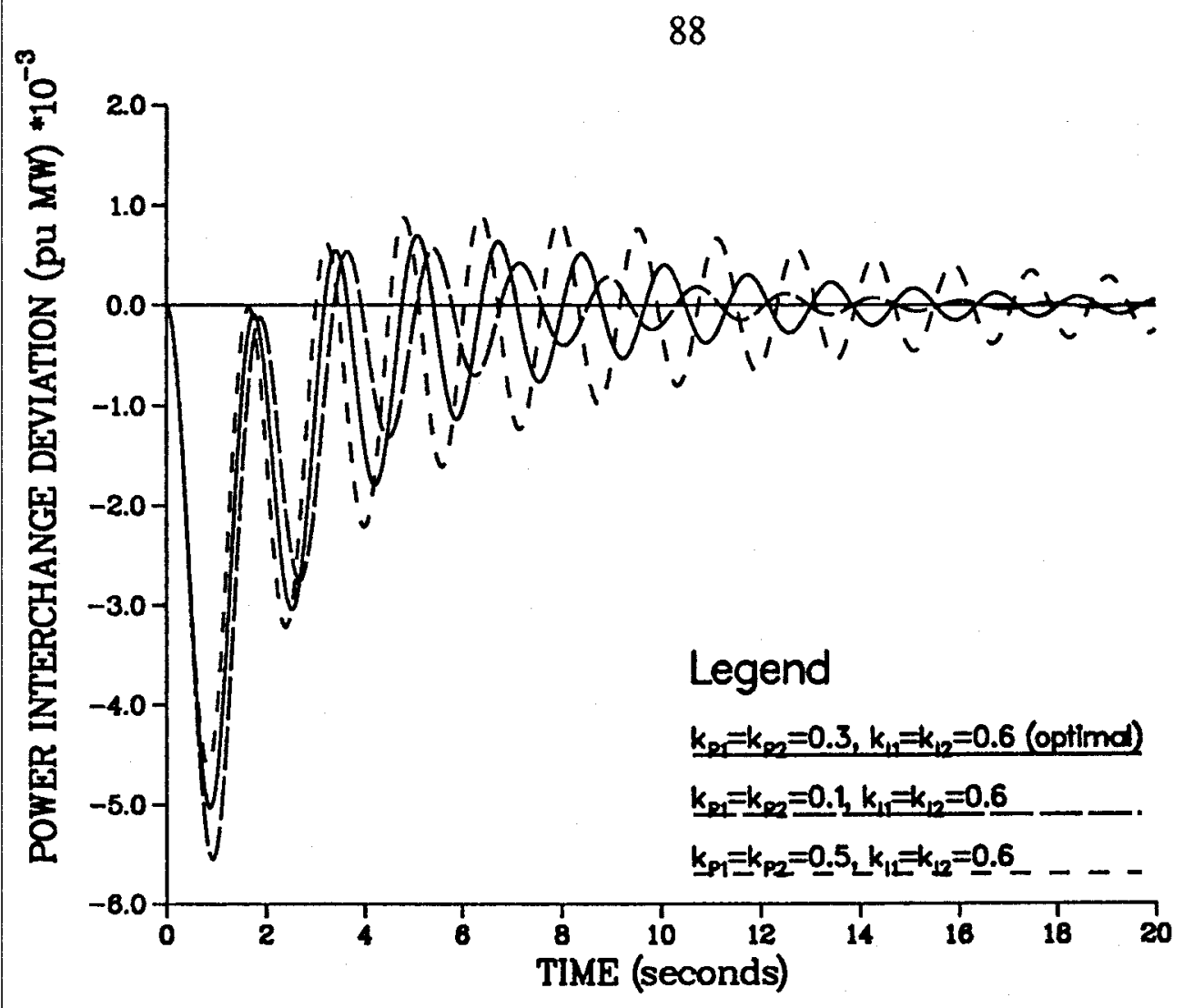

Figure 5.5 Power interchange deviation responses for various AGC proportional gain.

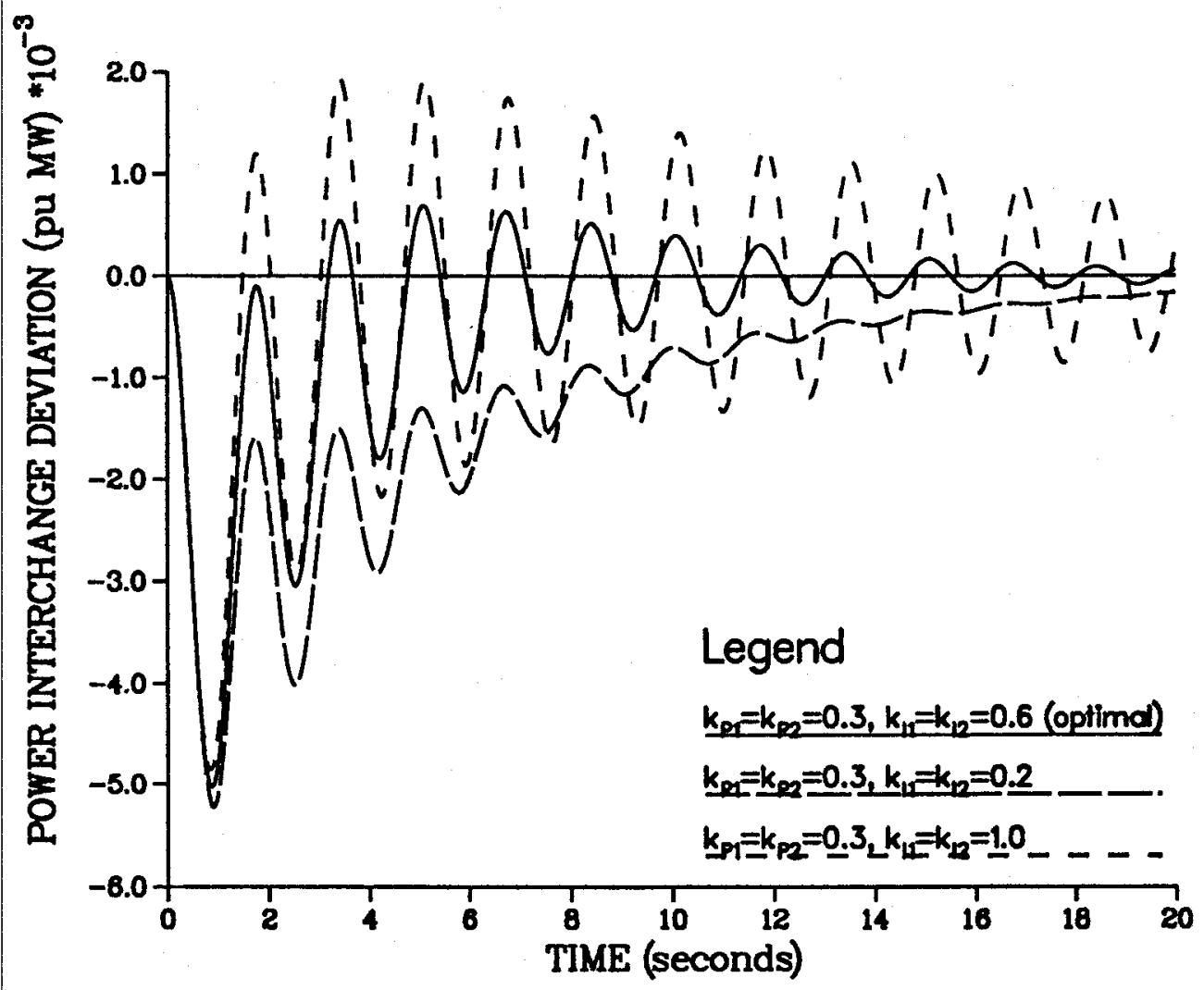

Figure 5.6 Power interchange deviation responses for various AGC integral gain. 


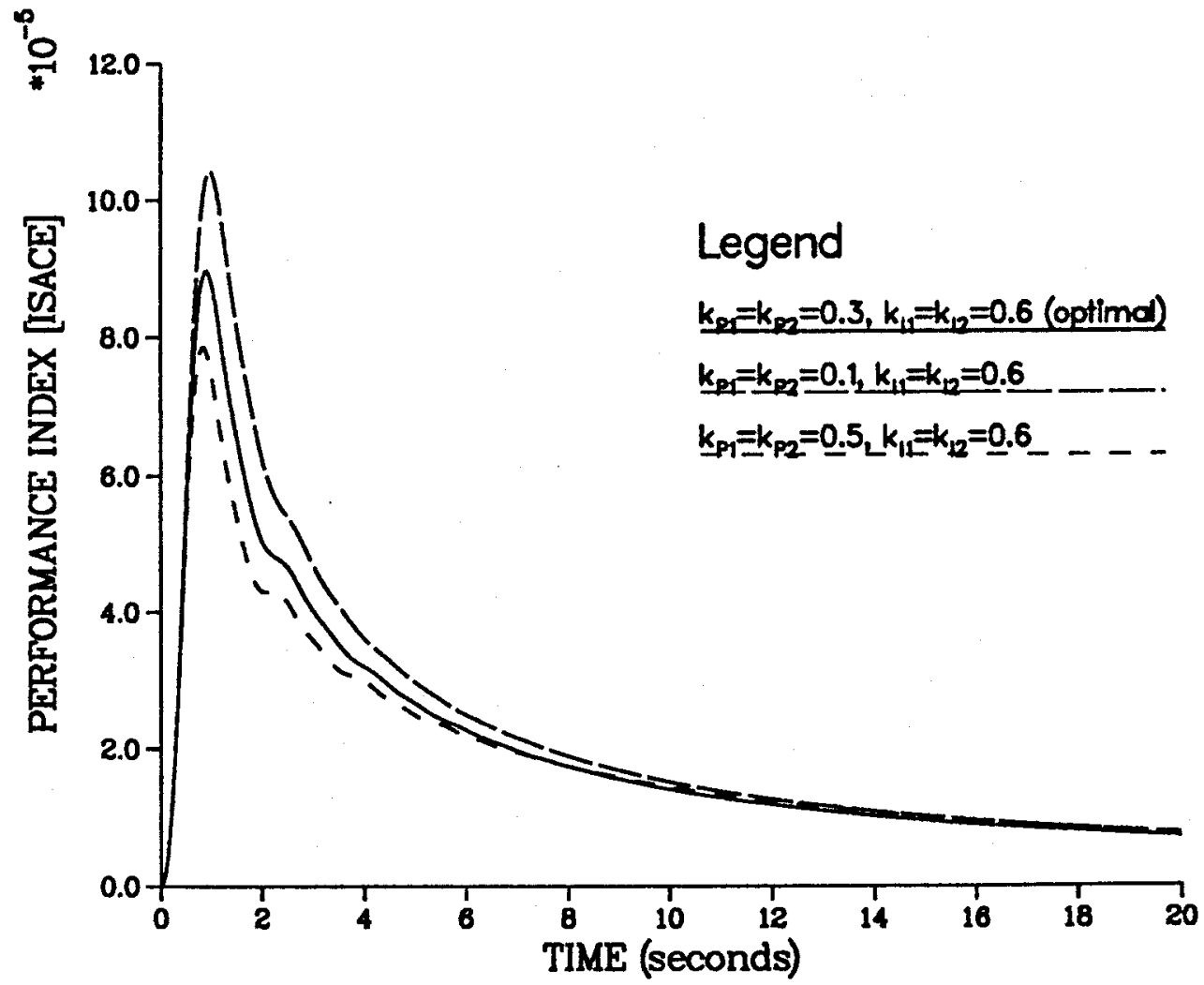

Figure 5.7 Performance index for various AGC proportional gain.

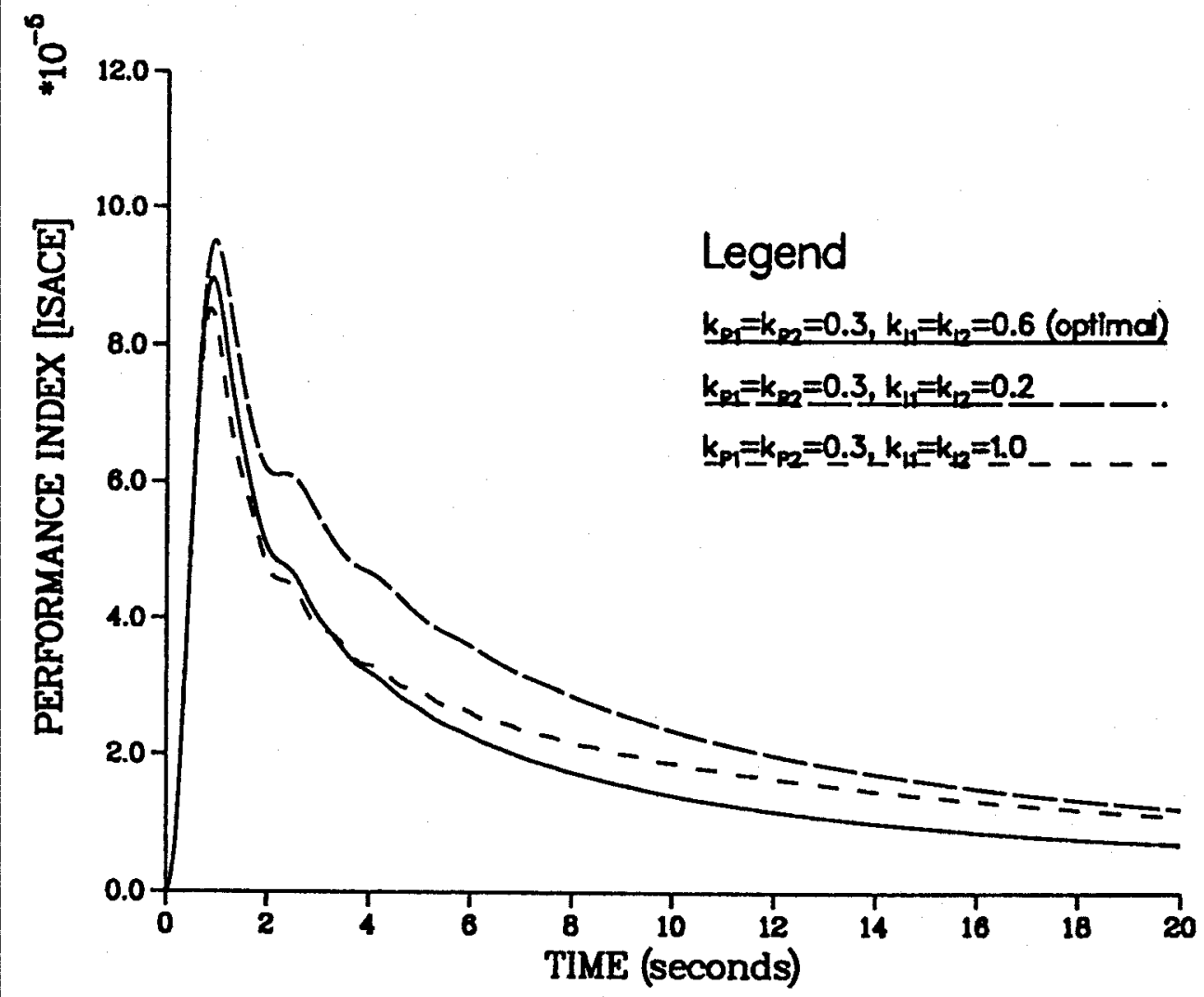

Figure 5.8 Performance index for various AGC integral gain. 


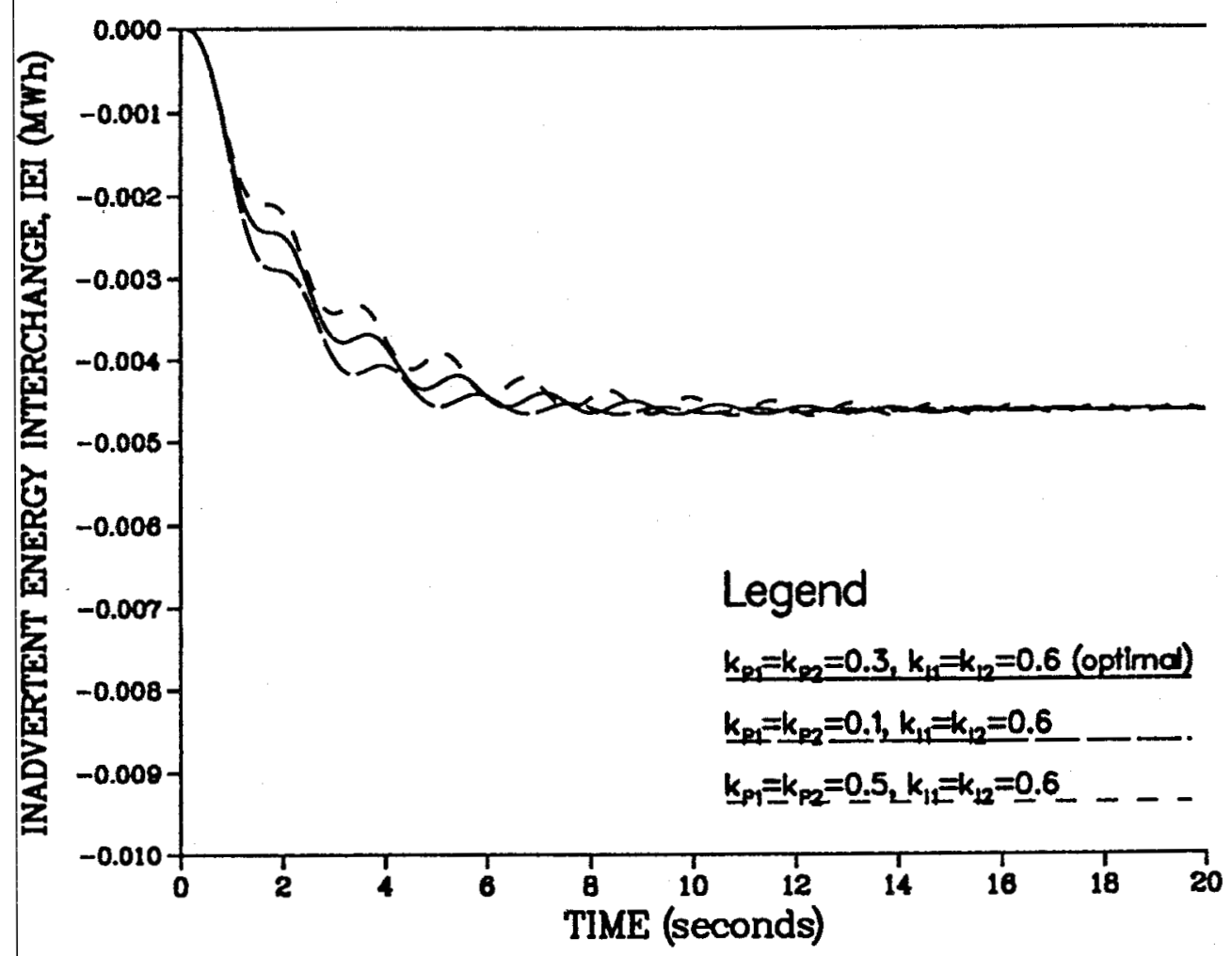

Figure 5.9 Inadvertent energy interchange for various AGC proportional gain.

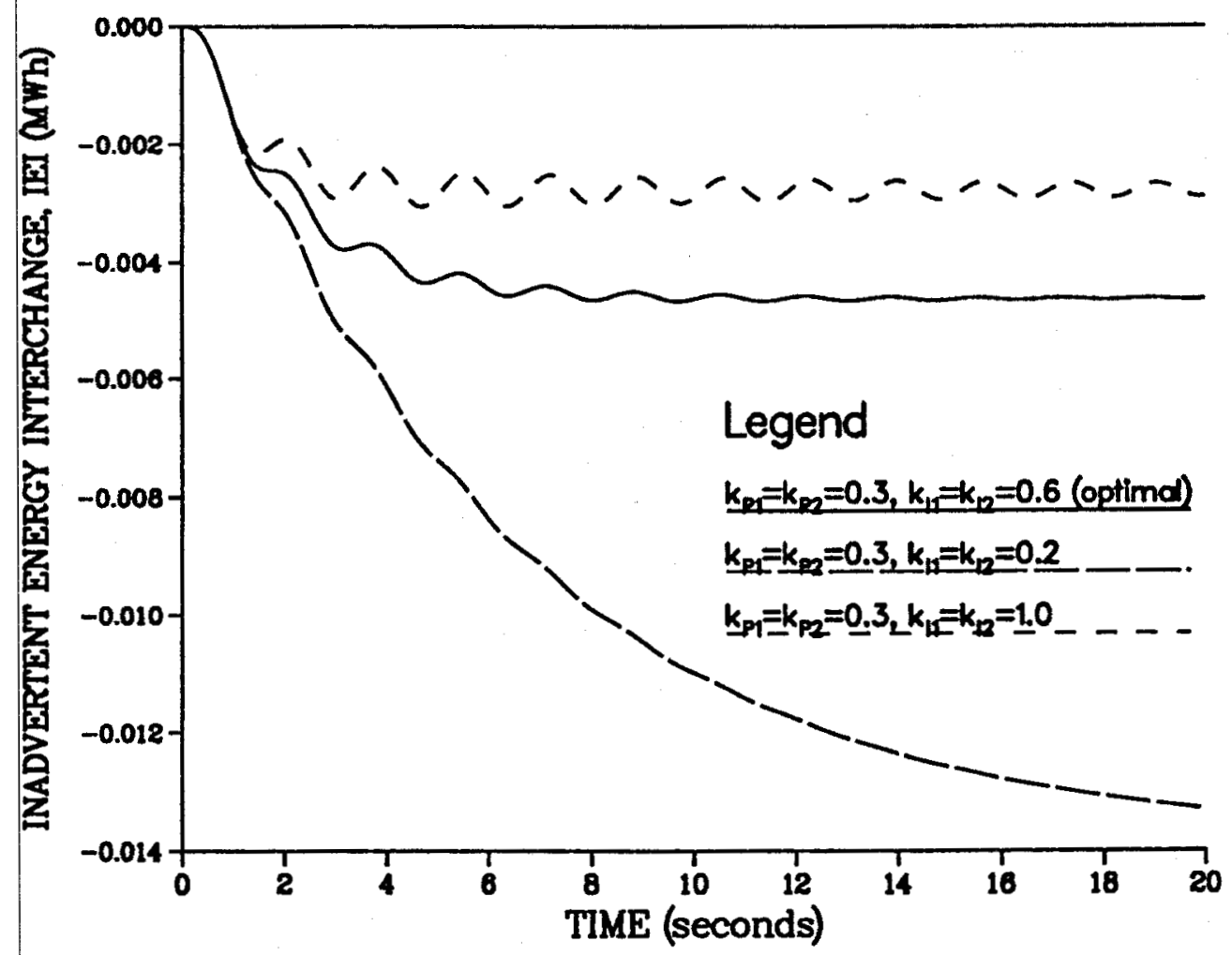

Figure 5.10 Inadvertent energy interchange for various AGC integral gain. 
Table 5.1 Effects of changes of AGC parameters on system performance

\begin{tabular}{||c|c|c|c|c|c|c||}
\hline \hline $\begin{array}{c}\text { AGC } \\
\mathrm{k}_{\mathrm{P} 1}, \mathrm{k}_{\mathrm{P} 2}\end{array}$ & $\begin{array}{c}\mathrm{AGC} \\
\mathrm{k}_{\mathrm{I}}, \mathrm{k}_{\mathrm{L} 2}\end{array}$ & $\begin{array}{c}\text { ISACE } \\
10^{-7}\end{array}$ & $\begin{array}{c}\mathrm{IEI} \\
\mathrm{KWh}\end{array}$ & $\begin{array}{c}\Delta \mathrm{f}_{1} \max \\
\mathrm{Hz}\end{array}$ & $\begin{array}{c}\Delta \mathrm{f}_{2} \max \\
\mathrm{Hz}\end{array}$ & $\begin{array}{c}\Delta \mathrm{P}_{12} \mathrm{max} \\
\text { puMW }\end{array}$ \\
\hline \hline 0.3 & 0.6 & 71.36 & 4.636 & 0.0199 & 0.0150 & 0.00502 \\
\hline 0.1 & 0.6 & 76.10 & 4.627 & 0.0210 & 0.0163 & 0.00555 \\
\hline 0.5 & 0.6 & 76.55 & 4.646 & 0.0190 & 0.0139 & 0.00461 \\
\hline 0.3 & 0.2 & 121.82 & 13.307 & 0.0202 & 0.0153 & 0.00523 \\
\hline 0.3 & 1.0 & 111.26 & 2.882 & 0.0197 & 0.0147 & 0.00486 \\
\hline
\end{tabular}

\subsection{AC/DC System with AGC and Supplementary DC Controls}

The simulation tests for a two area power system interconnected by parallel AC and DC tie lines, with AGC and supplementary DC control (SC), were based in the transfer function block diagram shown in Figure 3.5. The parameter values for this system are shown in Section 2.12 .

The characteristics of the AC link and its normal steady state condition were assumed to be the same as were described in Section 5.3. The DC link was assigned a capacity of $10 \%(200 \mathrm{MW})$ of area capacity. It was assumed that the DC link was in normal steady state operation, such that the DC power interchange deviation, from 
its scheduled value, was zero. For the simulation, conditions for the system were assumed to be in normal steady state condition before it was subjected to a step load increase of $20 \mathrm{MW}$ in Area 1. The imbalance between generation and area load was corrected by the control system comprised of governors, AGC control and the DC system control. The supplementary DC control (SC), part of the DC system control, interacting with the AGC helped to stabilize the dynamic system responses faster than without the supplementary DC control.

A set of simulation tests were executed to estimate the optimal parameters of the SC controller maintaining the optimal AGC controller parameters constant as computed in the previous section. The optimal SC controller parameters were:

* $\mathrm{k}_{\mathrm{p}}=0.0$ (proportional gain)

* $\mathrm{k}_{\mathrm{I}}=12.0$ (integral gain)

The simulation results illustrated in Figures 5.11 to 5.20 and Table 5.2 show the effects of changes of the SC controller parameters on the system dynamic responses.

Figures 5.11 and 5.12 illustrate the effects of changes in proportional gain and integral gain, respectively, of the SC controller on the frequency deviation responses in Area 1. In general, the shapes of the curves are very similar with minor differences in the amplitudes of the swings. The amplitude of the swing increases as the $k_{p}$ and/or $\mathrm{k}_{\mathrm{I}}$, of the SC controller increases. The frequency responses are well damped 
coming back to scheduled values in about 10 seconds. The fast response of the DC control make it possible to drop the high frequency oscillation effectively (compare Figures 5.1 and 5.11).

Figures 5.13 shows that the frequency deviation responses in Area 2 remain practically the same as the $k_{\mathrm{p}}$ of the SC controller is varied. Figure 5.14 shows that the swing of the frequency deviation response in Area 2 increases significatively as the $\mathrm{k}_{\mathrm{I}}$ decreases.

Figures 5.15 and 5.16 illustrate power interchange effects. The power interchange deviation responses are slightly sensitive to changes of $\mathrm{k}_{\mathrm{p}}$ (Figure 5.15); but very sensitive to changes of $k_{I}$ (Figure 5.16). As $k_{1}$ increases the swing of the power interchange settles down faster.

Figures 5.17 and 5.18 show that the performance index is only slightly affected by variations of $\mathrm{k}_{\mathrm{P}}$ or $\mathrm{k}_{\mathrm{I}}$ around their optimal values.

Figures 5.19 and 5.20 show that the inadvertent energy interchange (IEI) maintains the same value for different values of $k_{p}$ (figure 5.19). However, it shows large changes as $k_{1}$ is varied. The IEI decreases as $k_{1}$ increases.

Table 5.2 illustrates the system performance for various values of the parameters of the supplementary DC controller. 


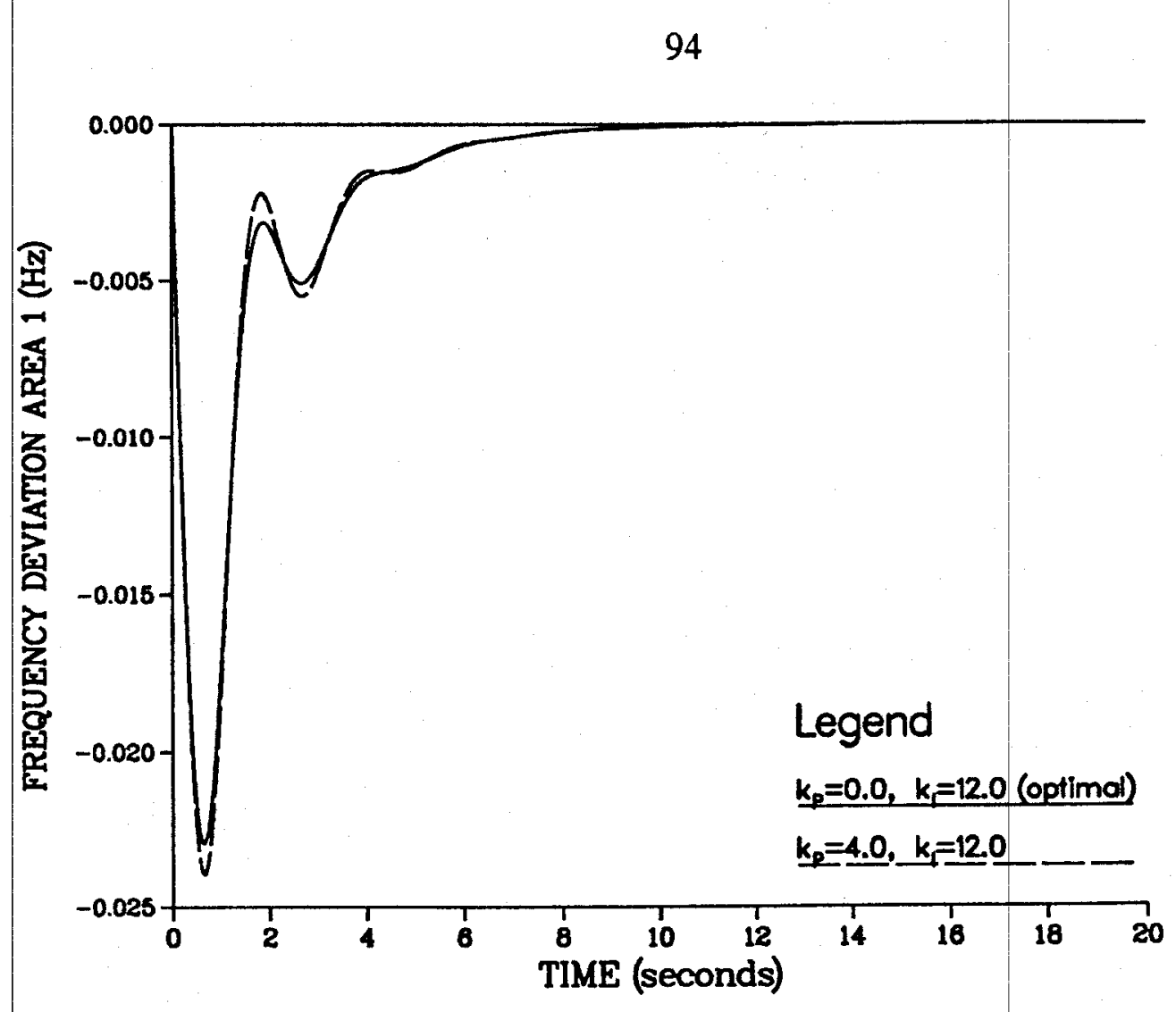

Figure 5.11 Frequency deviation responses in Area 1 for various SC controller proportional gain.

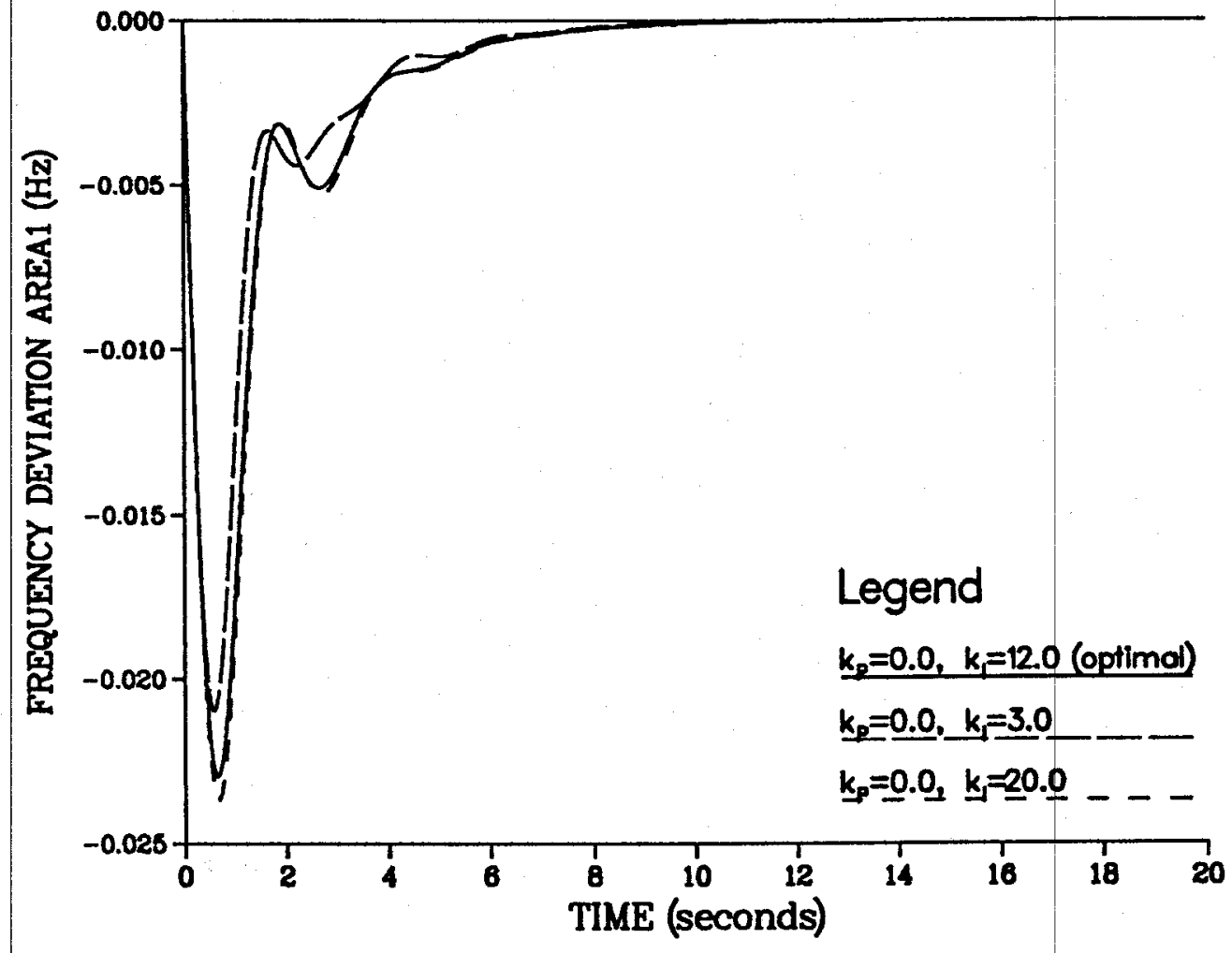

Figure 5.12 Frequency deviation responses in Area 1 for various SC controller integral gain. 


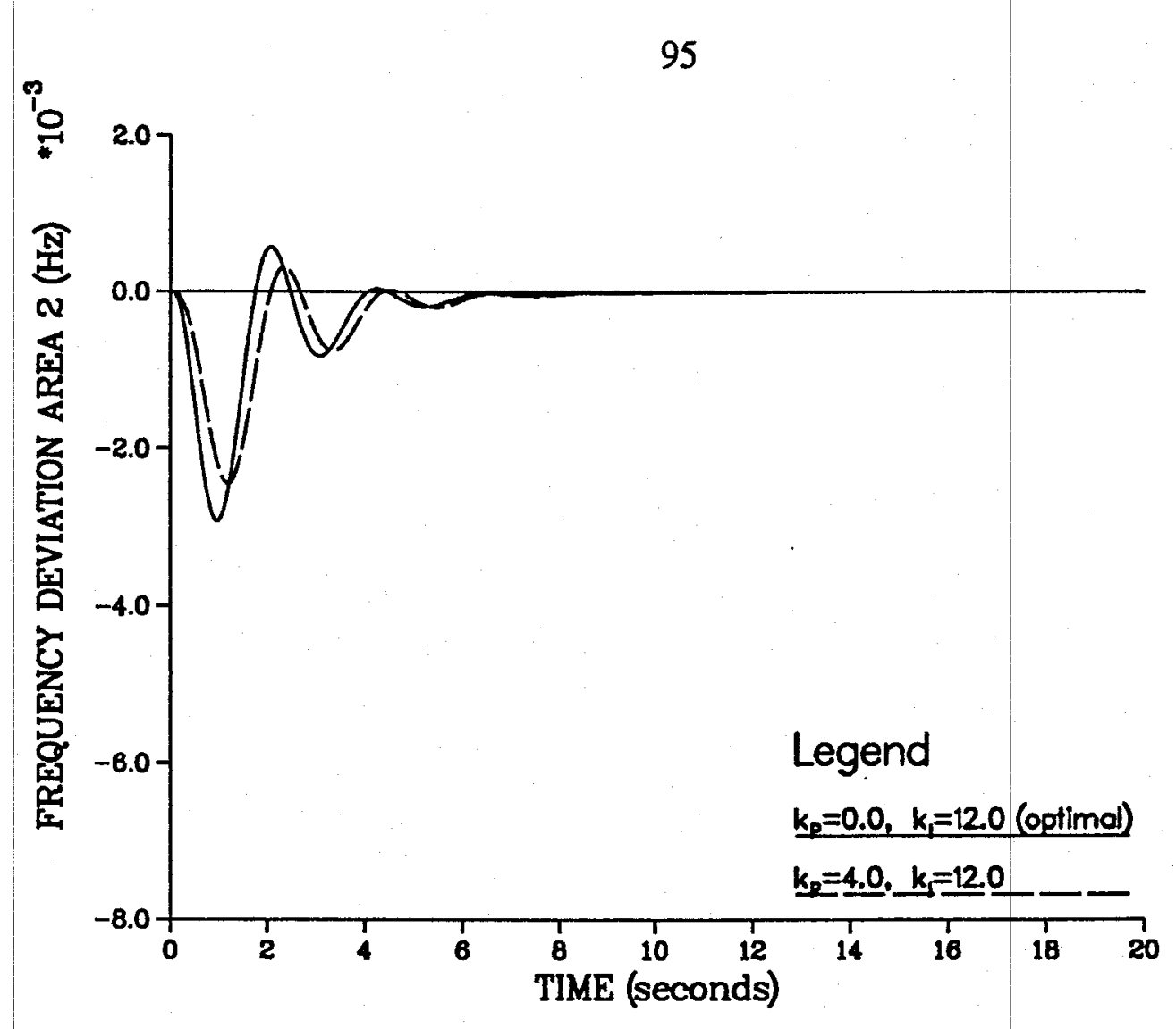

Figure 5.13 Frequency deviation responses in Area 2 for various SC controller proportional gain.

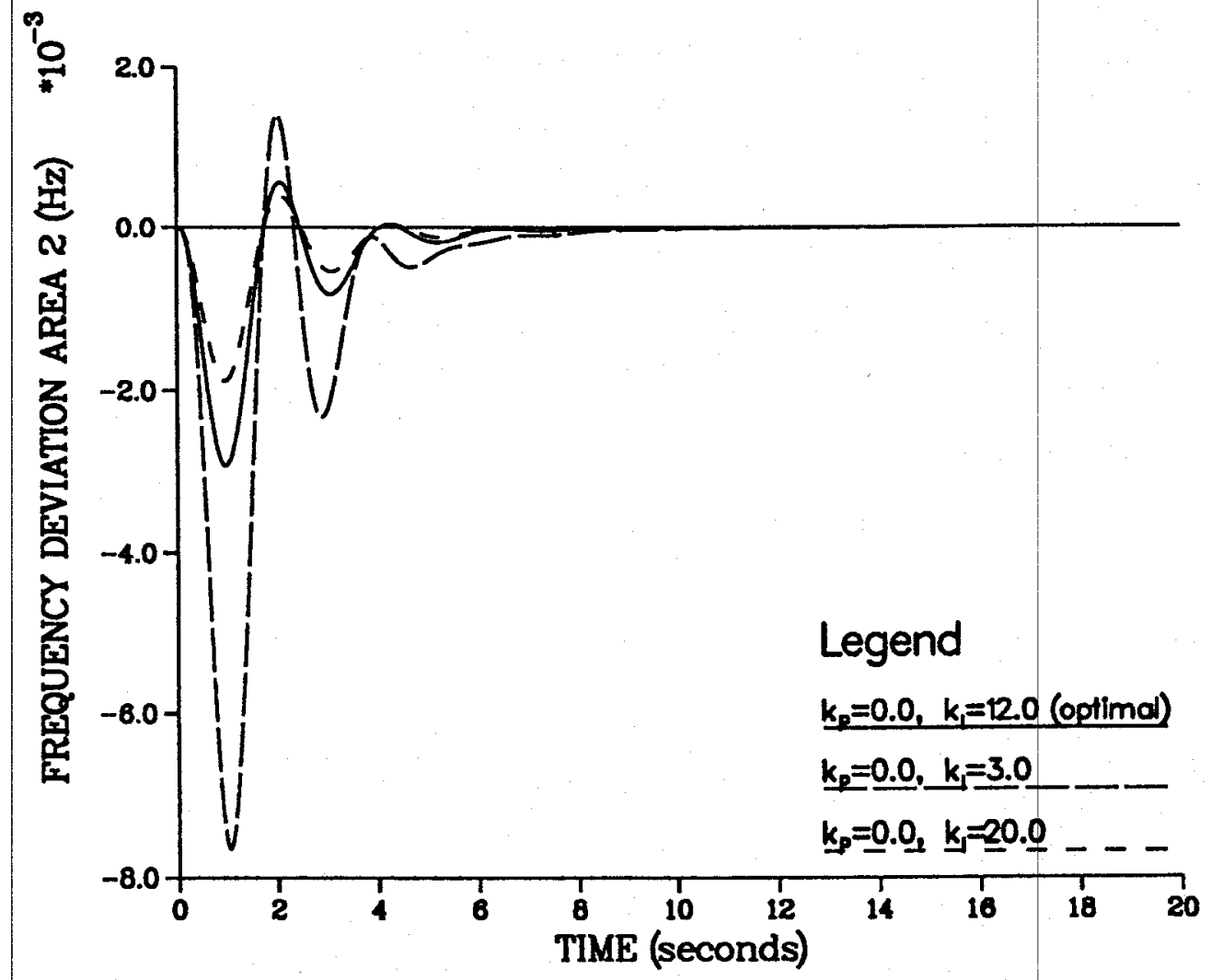

Figure 5.14 Frequency deviation responses in Area 2 for various SC controller integral gain. 


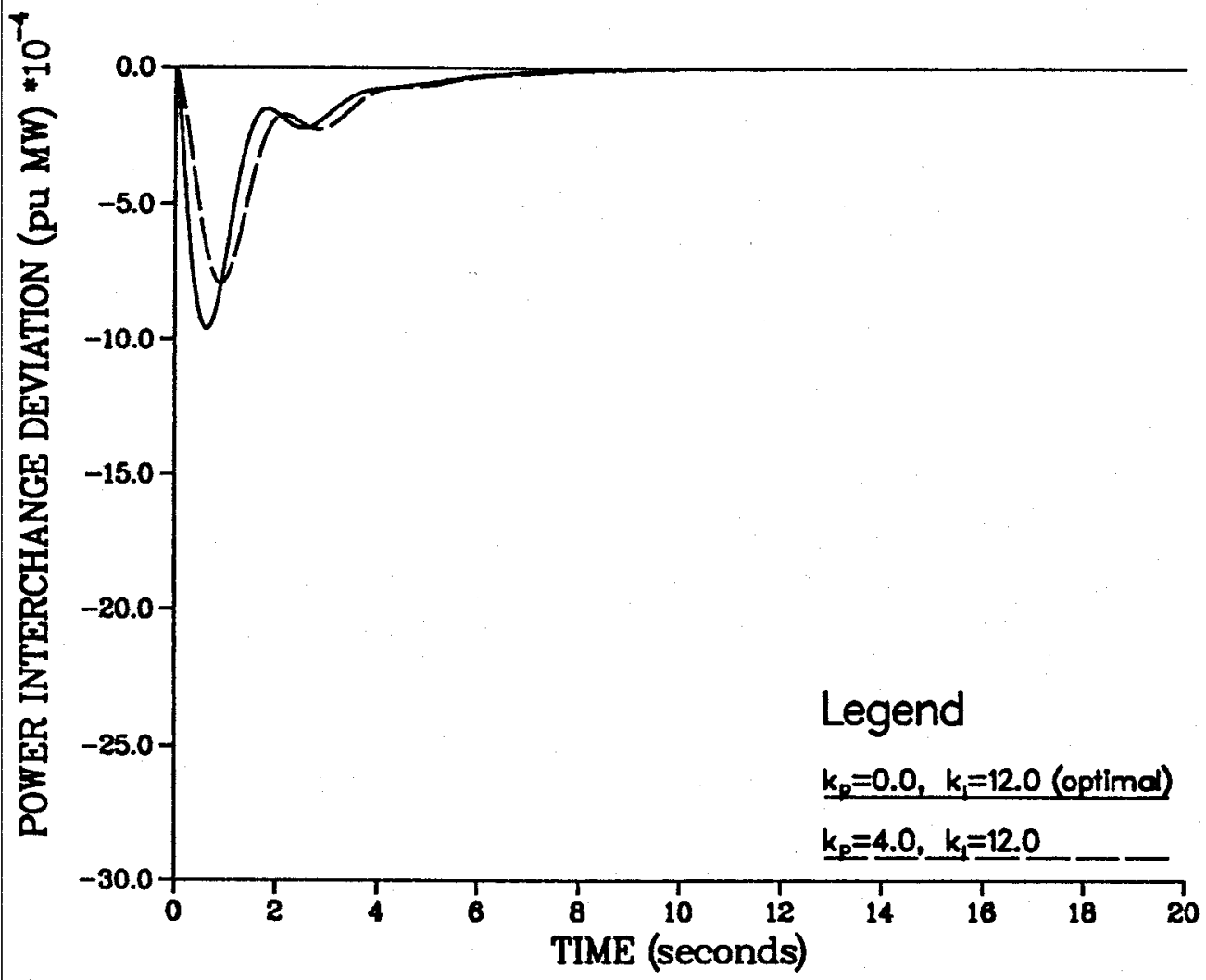

Figure 5.15 Power interchange deviation responses for various SC controller proportional gain.

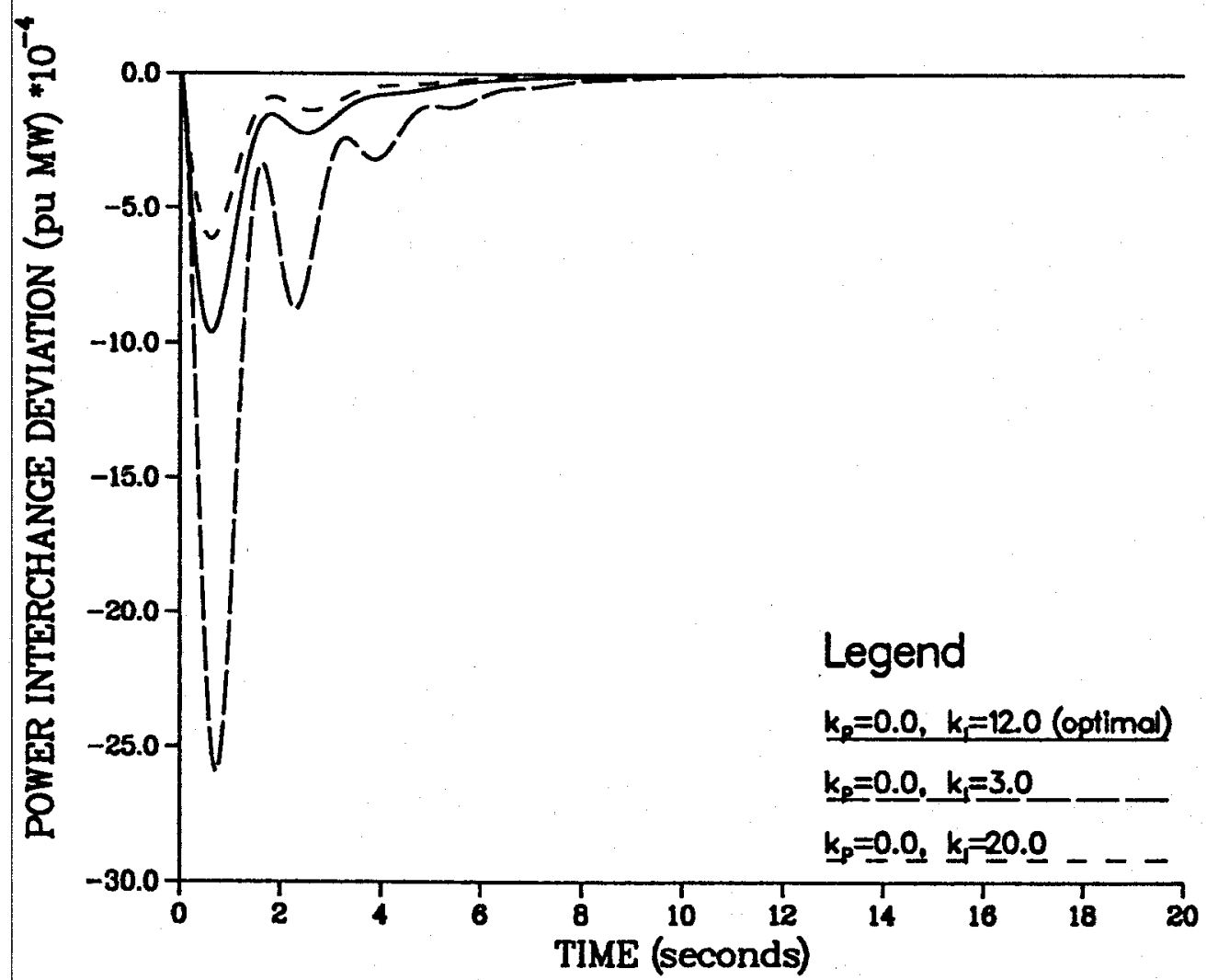

Figure 5.16 Power interchange deviation responses for various SC controller integral gain. 


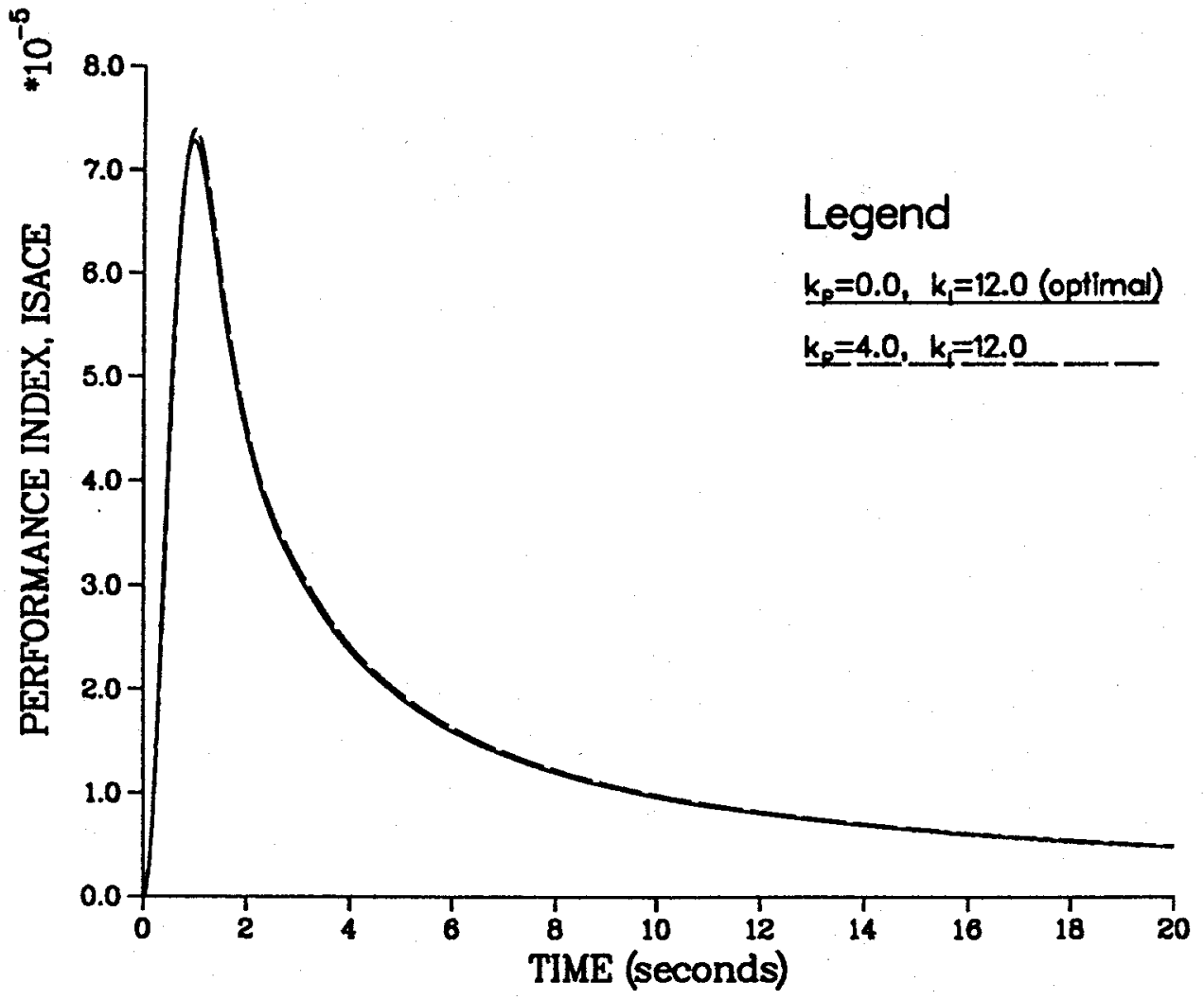

Figure 5.17 Performance index for various SC controller proportional gain.

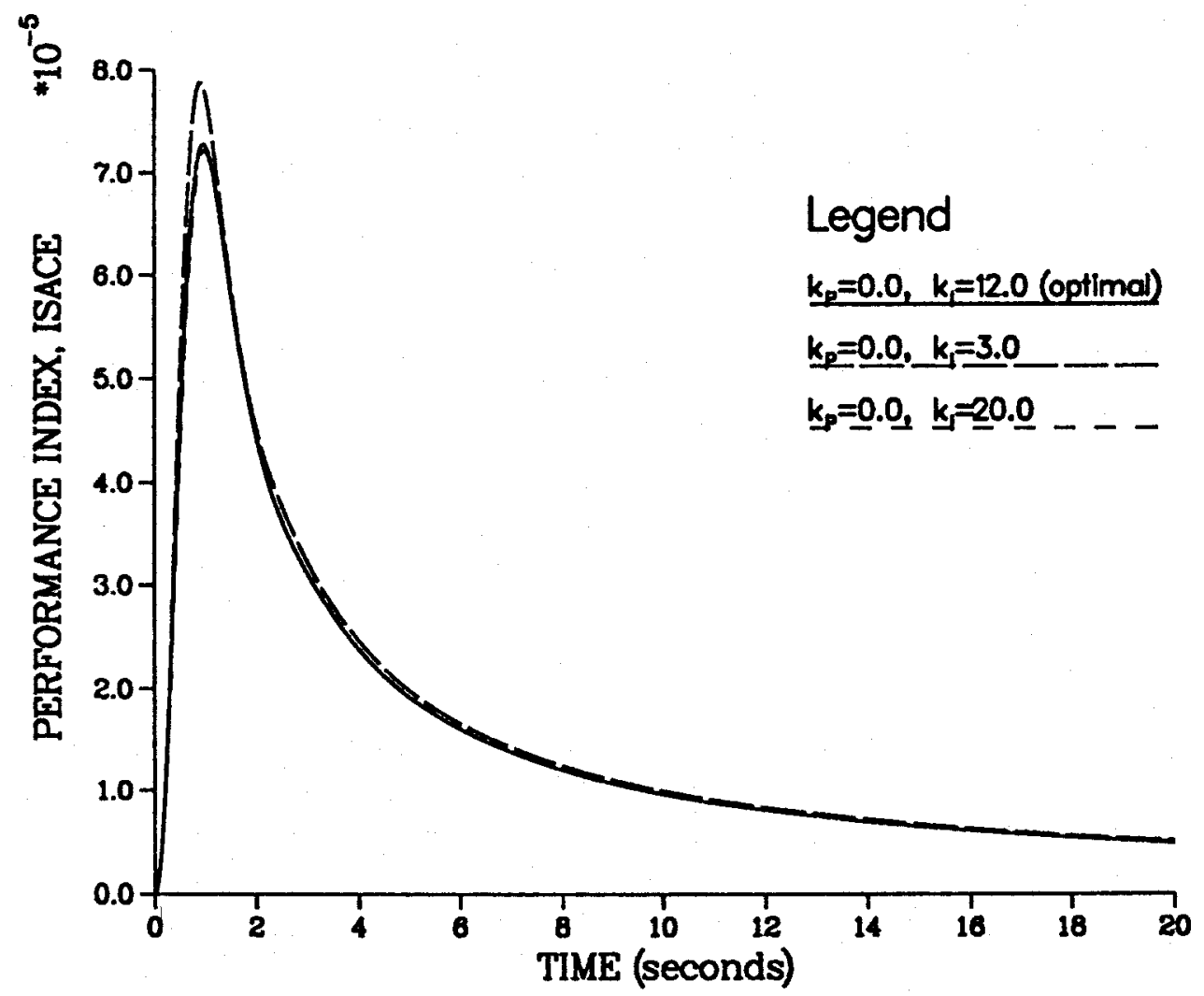

Figure 5.18 Performance index for various SC controller integral gain. 


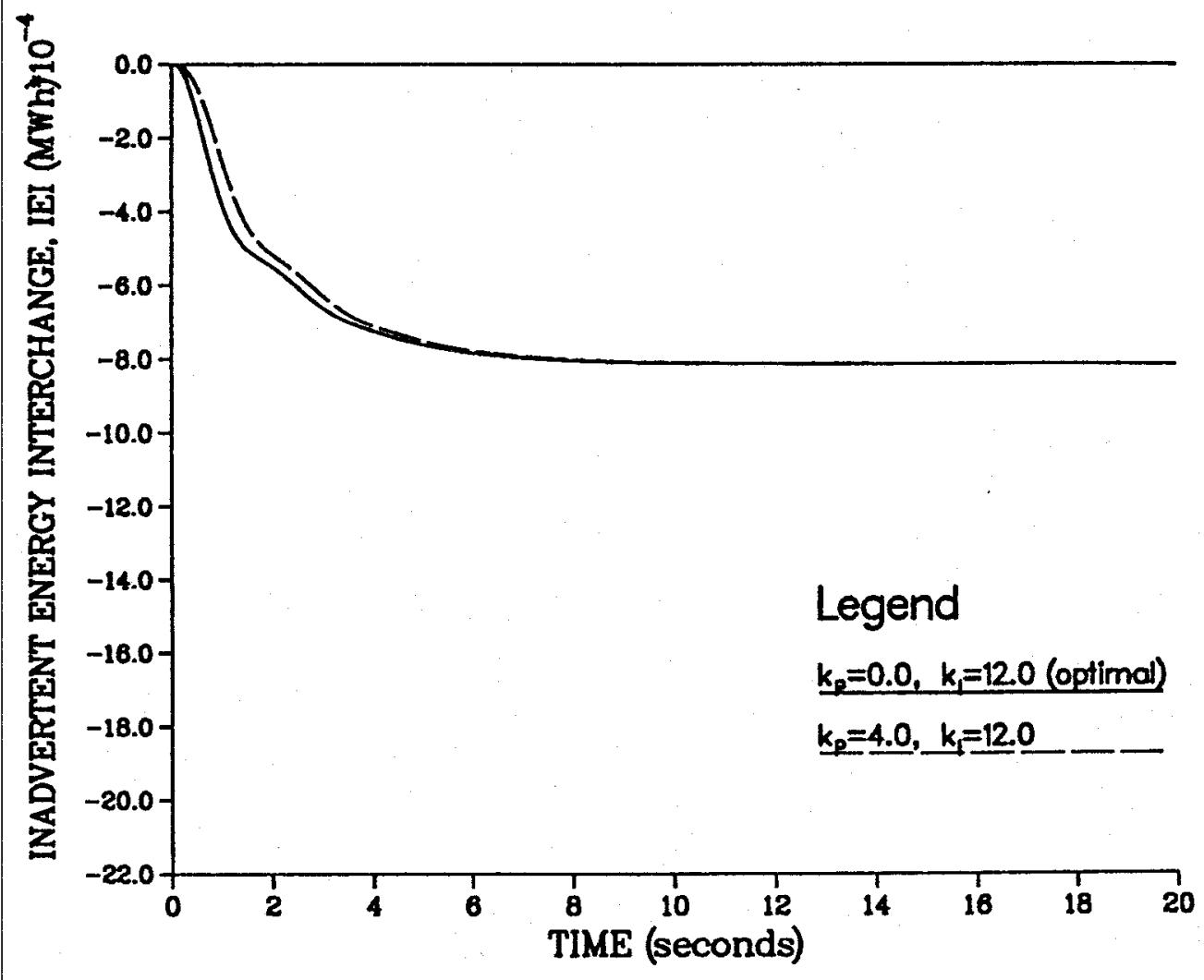

Figure 5.19 Inadvertent energy interchange for various SC controller proportional gain.

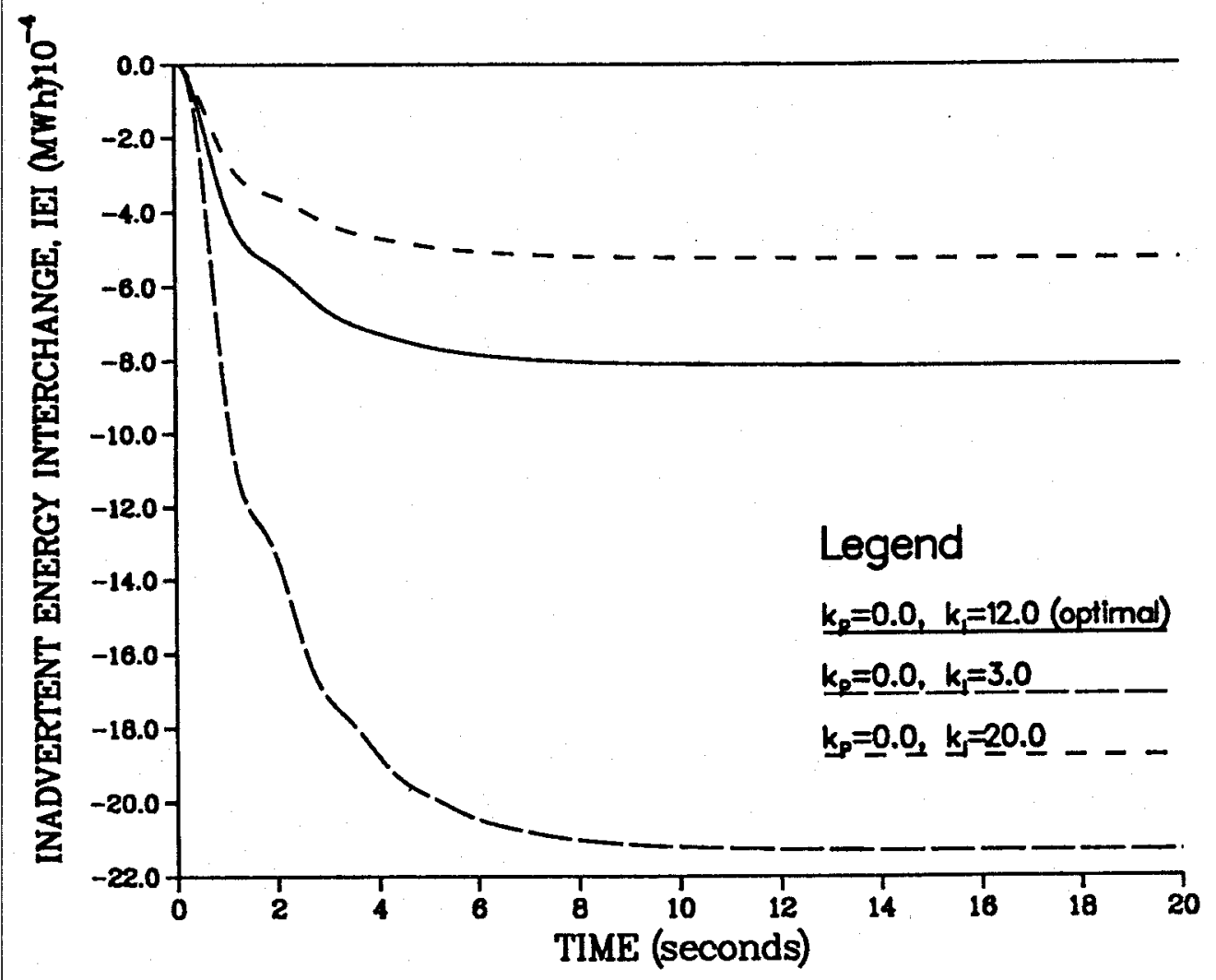

Figure 5.20 Inadvertent energy interchange for various SC controller integral gain. 
Table 5.2 Effects of changes of SC controller parameters on system performance.

\begin{tabular}{|c|c|c|c|c|c|c|}
\hline $\begin{array}{c}\mathrm{SC} \\
\mathrm{k}_{\mathrm{p}}\end{array}$ & $\mathrm{SC}$ & $\mathrm{ISACE}$ & $\mathrm{IEI}$ & $\Delta \mathrm{f}_{1} \max$ & $\Delta \mathrm{f}_{2} \max$ & $\Delta \mathrm{P}_{12} \max$ \\
$\mathrm{k}$ & $10^{-7}$ & $\mathrm{KWh}$ & $\mathrm{Hz}$ & $\mathrm{Hz}$ & $\mathrm{puMW}$ \\
\hline \hline 0.0 & 12.0 & 48.12 & 0.8142 & 0.0230 & 0.0029 & 0.00096 \\
\hline 4.0 & 12.0 & 48.09 & 0.8142 & 0.0240 & 0.0025 & 0.00079 \\
\hline 0.0 & 3.0 & 49.82 & 2.1318 & 0.0210 & 0.0077 & 0.00259 \\
\hline 0.0 & 20.0 & 48.22 & 0.5255 & 0.0237 & 0.0019 & 0.00061 \\
\hline
\end{tabular}

The dynamic responses of other variables such as area control error, deviation in generated power, AC power interchange deviation, DC power interchange deviation and control signals for various parameters of the supplementary DC controller are illustrated in Appendix C.

The system frequency and net power interchange come back to scheduled values in less than 10 seconds, because of the system control action. However, the power transfers in the AC link and DC link reach new steady state values of operation. The changes in DC power (positive) and AC power (negative) are about 1.8 times the change in area load. 


\subsection{AC/DC System with AGC and SC Controls, Including DC Power Limiter}

Usually, if the DC control is fully utilized, it is possible to achieve full power changes at very fast rates (20 to $50 \mathrm{~ms})$. However, when long distance communication is involved due to the distance between converter stations, the possibility of false signals causing very large power changes must be considered. Also large steady state deviation of power interchange on the $\mathrm{AC}$ and $\mathrm{DC}$ links would cause problems of operation. To avoid such occurrences, it is desirable to limit the DC power interchange to fixed step changes. The selection of the size of DC power step change is a compromise between reliability and fast response.

For the simulation purposes reported in this research, it was assumed that the DC power limiter maintained a single limit level during the simulation period. This is expressed as a percentage of DC link capacity.

\subsubsection{System Dynamic Responses for Various DC Power Limiter Settings}

A series of simulation tests was carried out to examine the effects of changes of the DC power limiter (DCPL) on power system responses. The disturbance applied to the system was an area load step change of $1 \%$ (20 MW) of area capacity. The selected levels of DC power limiter were $3 \%, 5 \%$ and $10 \%$ of DC link capacity, and the related optimal parameters of the SC control were:

$* \mathrm{k}_{\mathrm{P}}=0, \mathrm{k}_{\mathrm{l}}=1.5 ; \mathrm{DCPL}=3 \%(6 \mathrm{MW})$

$* \mathrm{k}_{\mathrm{P}}=0, \mathrm{k}_{\mathrm{I}}=2.8 ; \mathrm{DCPL}=5 \%(10 \mathrm{MW})$

${ }^{*} \mathrm{k}_{\mathrm{P}}=0, \mathrm{k}_{\mathrm{I}}=9.6 ; \mathrm{DCPL}=10 \%(20 \mathrm{MW})$ 
As the dynamic changes of the DC power were limited to a smaller range the optimal integral gain of the SC controller was found to be smaller.

Figures 5.21 to 5.27 and Table 5.3 illustrate the effects of changes of DC power limiter settings on system responses. The main aspect observed from the simulation results is the time required for the system responses to settle down to steady state condition. System frequency (Figures 5.21 and 5.22) and power interchange (Figure 5.23) come back to scheduled values faster as the permissible $\mathrm{DC}$ power change is larger. In addition the $\mathrm{AC}$ power deviation response (Figure 5.25 ) is stabilized faster for larger DCPL. The swings of the responses are larger as the range of DC power changes is limited to smaller amounts. The performance index (Figure 5.27) and the inadvertent energy interchange (Figure 5.24) are smaller as the DCPL is increased. 


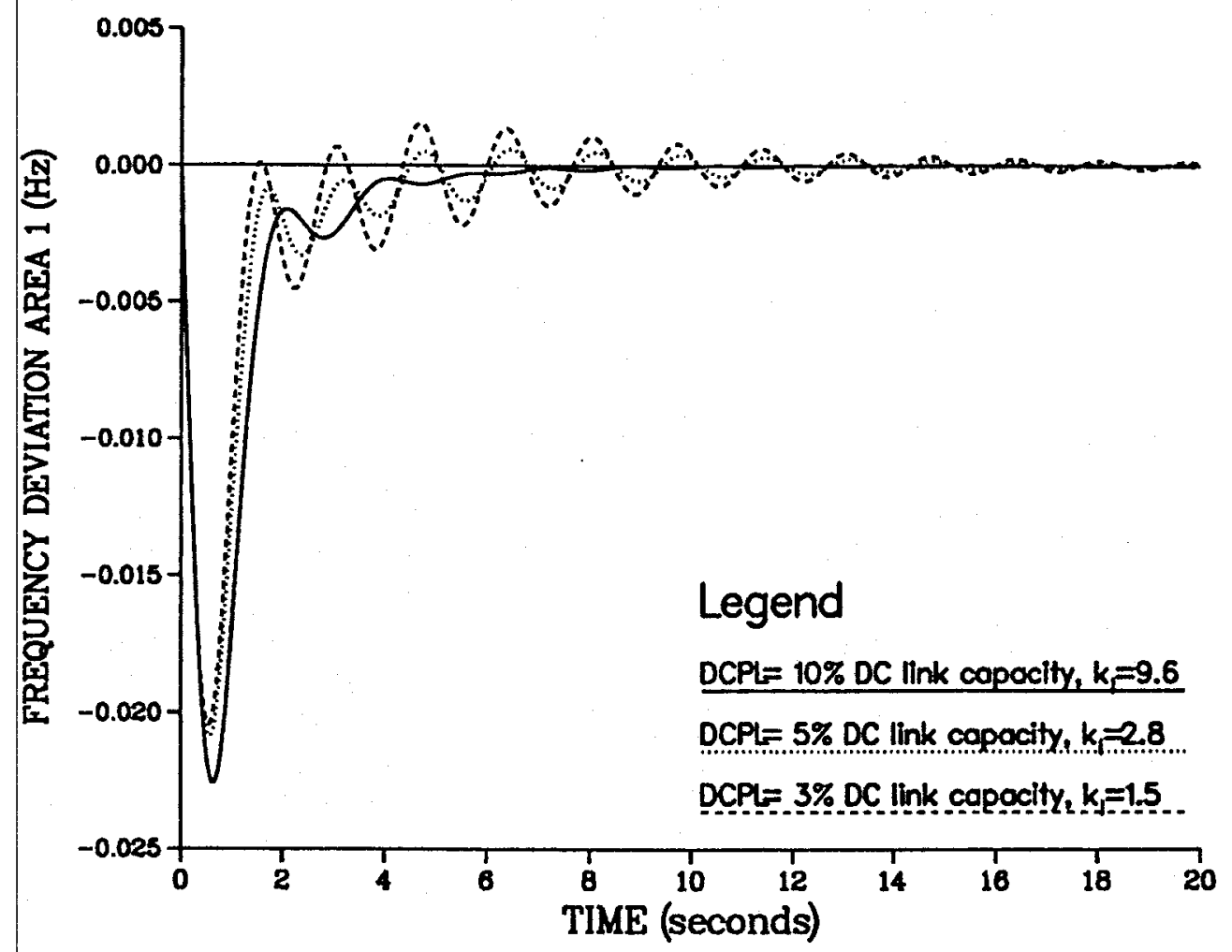

Figure 5.21 Frequency deviation responses in Area 1 for various DC power limiter.

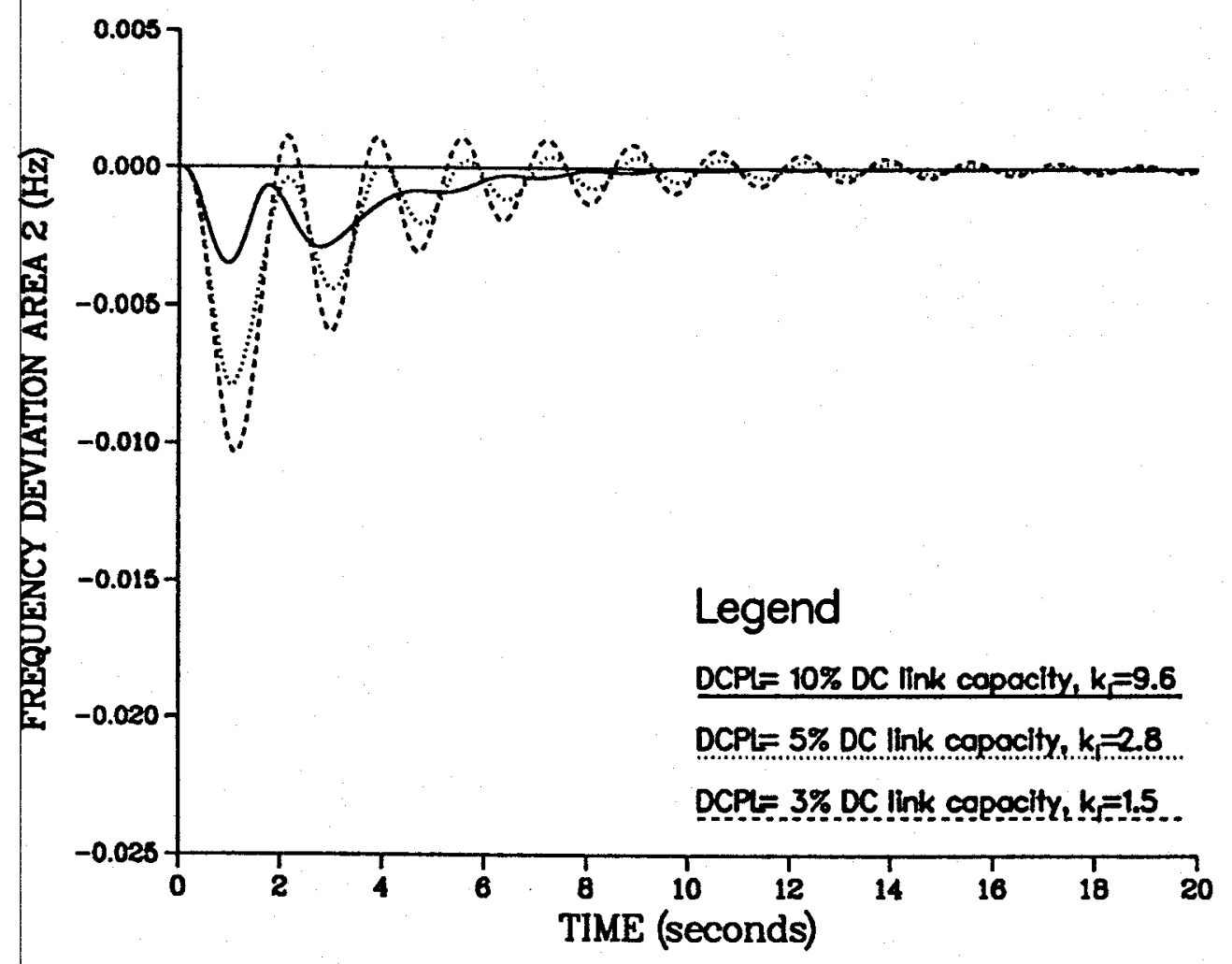

Figure 5.22 Frequency deviation responses in area 2 for various DC power limiter. 


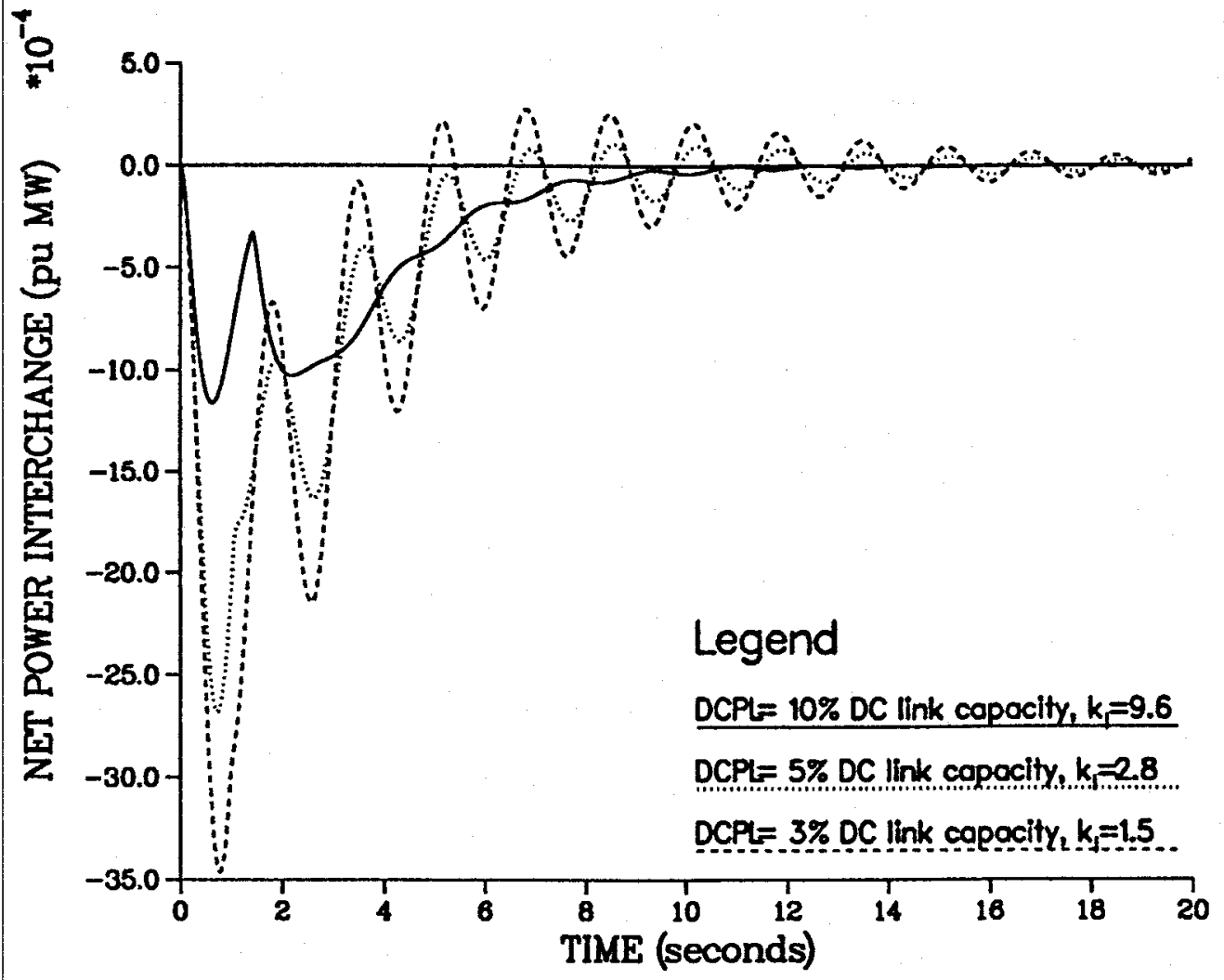

Figure 5.23 Power interchange deviation responses for various DC power limiter.

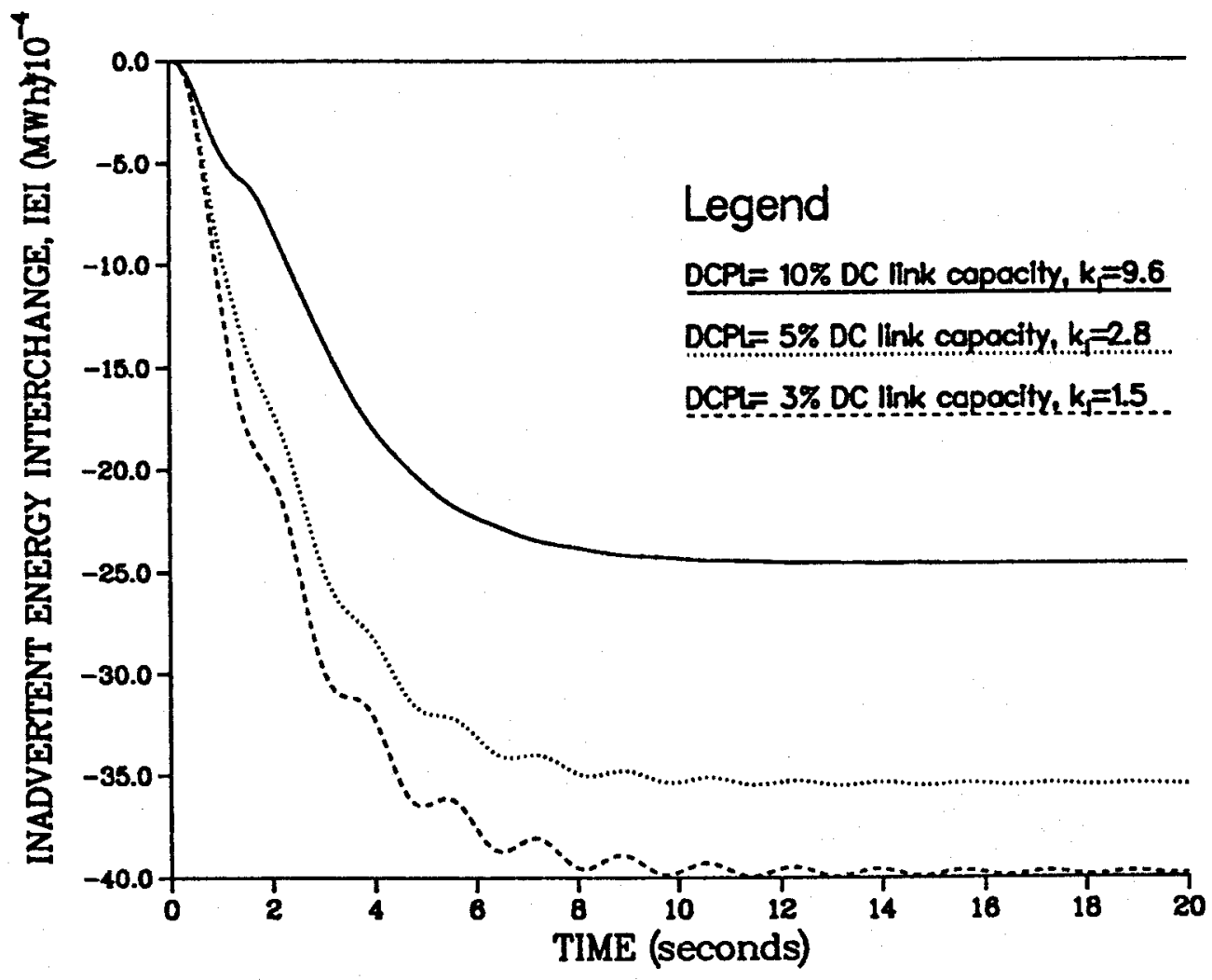

Figure 5.24 Inadvertent energy interchange for various DC power limiter. 


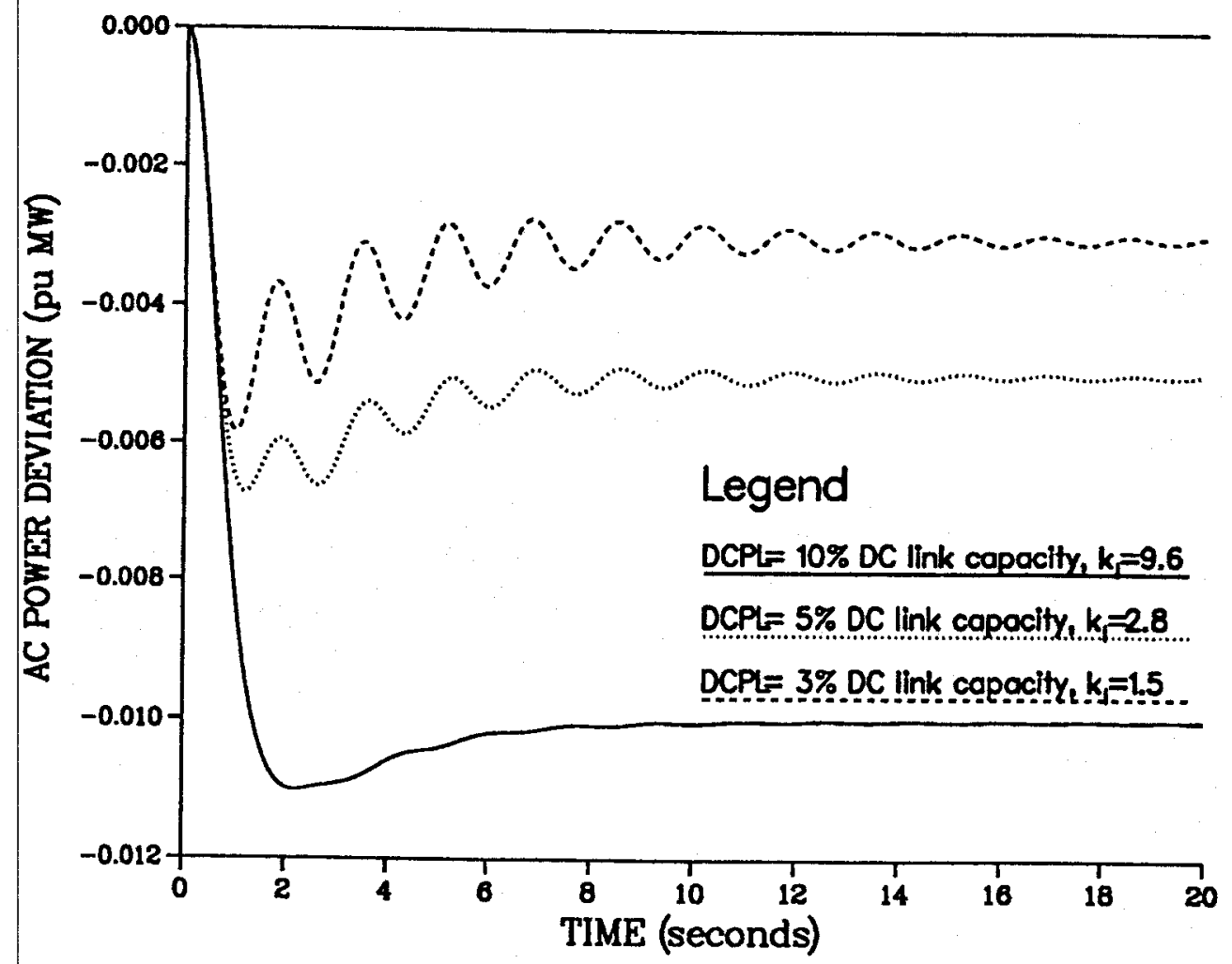

Figure 5.25 AC power interchange deviation responses for various DC power limiter.

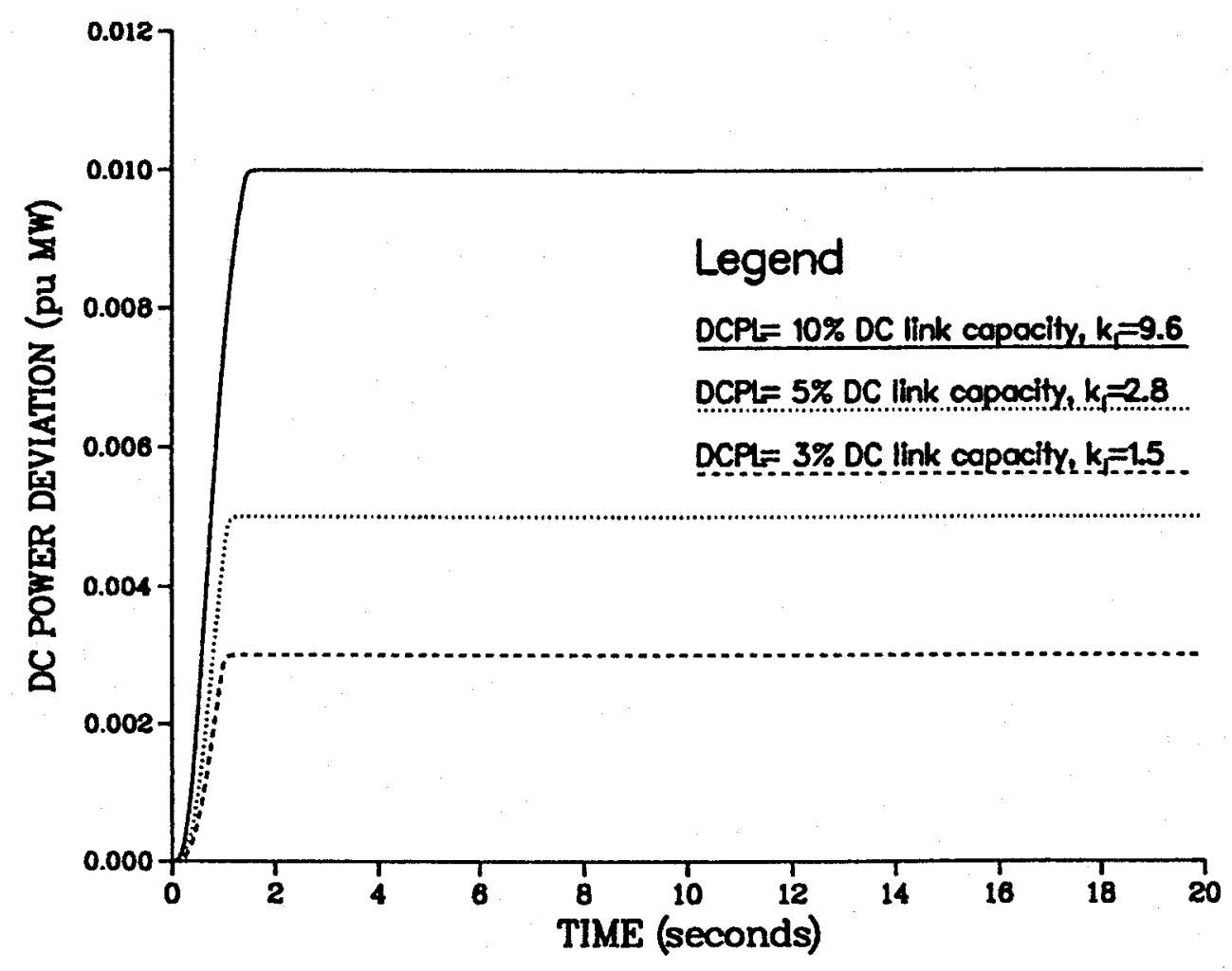

Figure 5.26 DC power interchange deviation responses for various DC power limiter. 


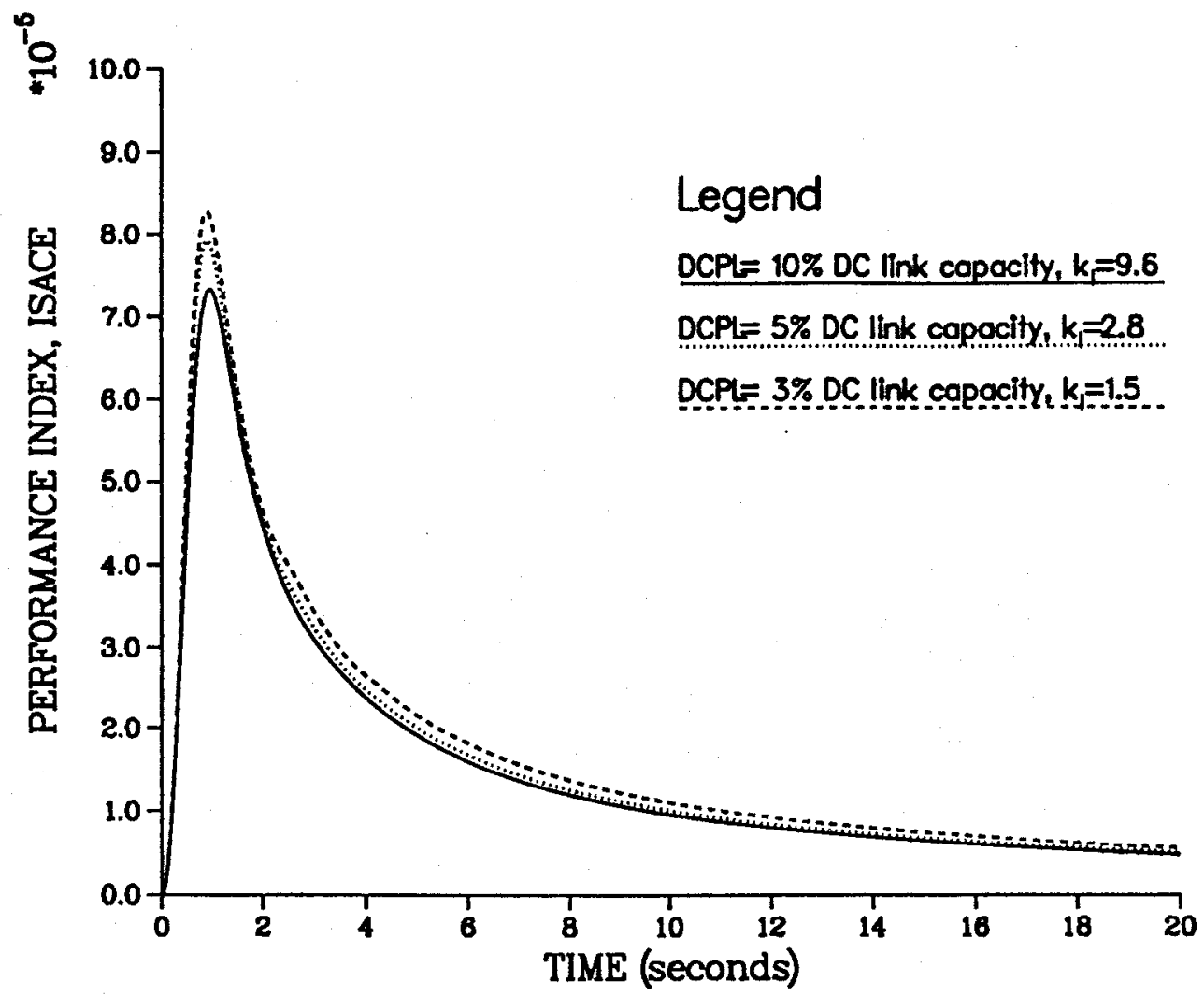

Figure 5.27 Performance index for various DC power limiter settings.

Table 5.3 Effects of changes of DC power limiters on system performance.

\begin{tabular}{||c|c|c|c|c|c|c|c||}
\hline \begin{tabular}{c|c} 
DCPL \\
$\%$
\end{tabular} & $\mathrm{SC}$ & $\mathrm{SC}$ & $\mathrm{ISACE}$ & $\mathrm{IEI}$ & $\Delta \mathrm{f}_{1} \max$ & $\Delta \mathrm{f}_{2} \max$ & $\Delta \mathrm{P}_{12} \max$ \\
$\mathrm{k}$ & $\mathrm{k}_{\mathrm{I}}$ & $10^{-7}$ & $\mathrm{KWh}$ & $\mathrm{Hz}$ & $\mathrm{Hz}$ & $\mathrm{puMW}$ \\
\hline \hline 3 & 0.0 & 1.5 & 55.59 & 3.9827 & 0.0204 & 0.0104 & 0.00346 \\
\hline 5 & 0.0 & 2.8 & 50.68 & 3.5473 & 0.0208 & 0.0079 & 0.00268 \\
\hline 10 & 0.0 & 9.6 & 48.06 & 2.4597 & 0.0226 & 0.0035 & 0.00116 \\
\hline
\end{tabular}




\subsubsection{System Dynamic Responses for various Step Load Disturbances}

A set of simulations was carried out to evaluate the effects of change in the amount of load disturbance on the power system responses. The DC power limiter utilized in these tests was $10 \%$ (20 MW) of DC link capacity. The selected step load disturbances $\left(\Delta P_{\mathcal{L}}\right)$ applied to area 1, expressed in percentage of area capacity, and the associated optimal parameters of the supplementary DC controller were:

$$
\begin{aligned}
& * \mathrm{k}_{\mathrm{P}}=0, \mathrm{k}_{\mathrm{I}}=11.8 ; \Delta \mathrm{P}_{\mathrm{L} 1}=0.5 \%(10 \mathrm{MW}) \\
& * \mathrm{k}_{\mathrm{P}}=0, \mathrm{k}_{\mathrm{I}}=9.6 ; \Delta \mathrm{P}_{\mathrm{LI}}=1.0 \%(20 \mathrm{MW}) \\
& { }^{*} \mathrm{k}_{\mathrm{P}}=0, \mathrm{k}_{\mathrm{I}}=2.7 ; \Delta \mathrm{P}_{\mathrm{Ll}}=2.0 \%(40 \mathrm{MW})
\end{aligned}
$$

The optimal integral gain of the supplementary controller decreases as the step load disturbance increases.

Figures 5.28 to 5.34 and Table 5.4 illustrate the effects of changes of step load disturbances on system dynamic responses. In general, as the step load disturbance is increased, the swing of the system responses increase and the dynamic response settles down more slowly. Performance index and inadvertent energy interchange decrease as the step load disturbance applied to the system is decreased. 


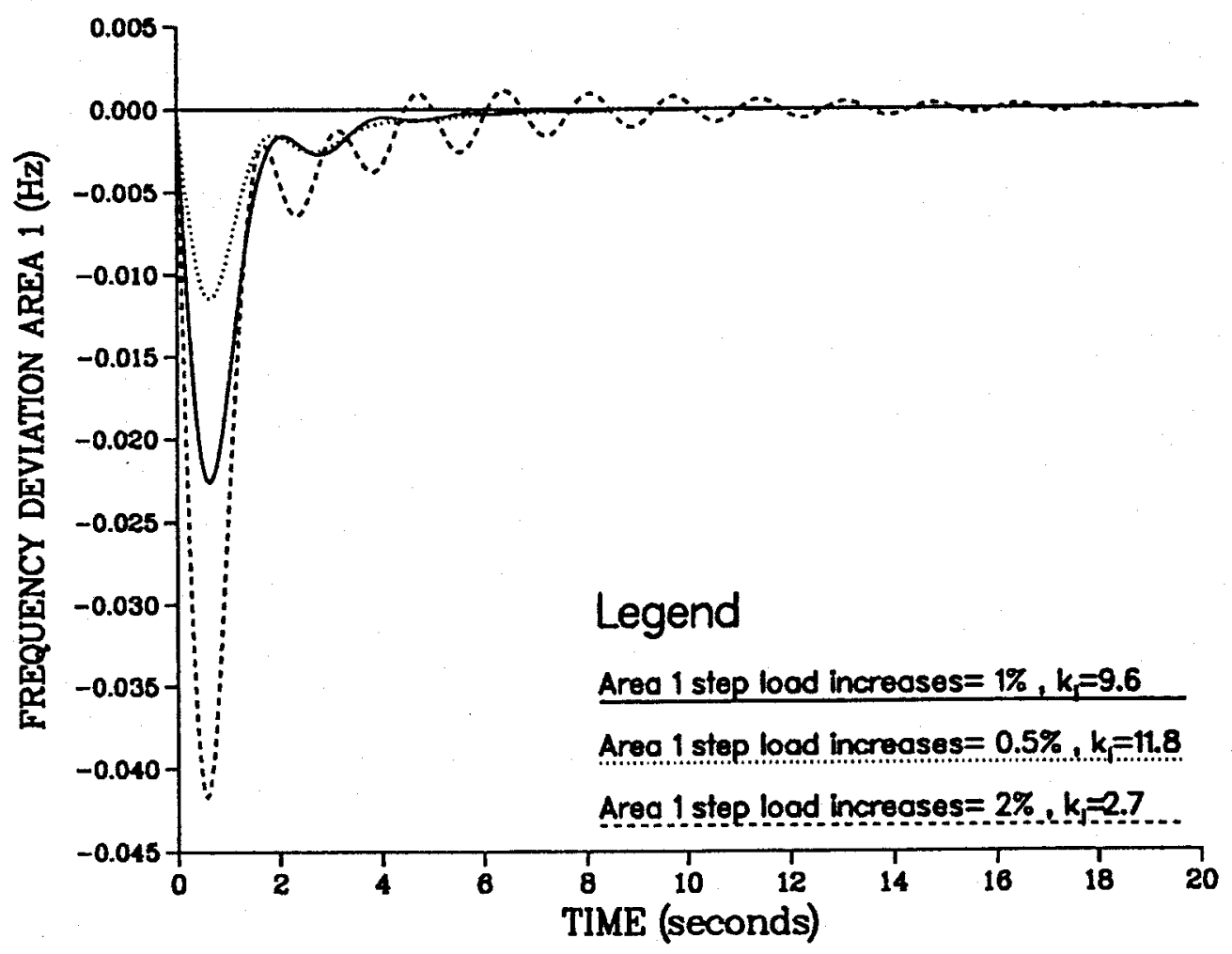

Figure 5.28 Frequency deviation responses in Area 1 for various step load disturbances in area 1.

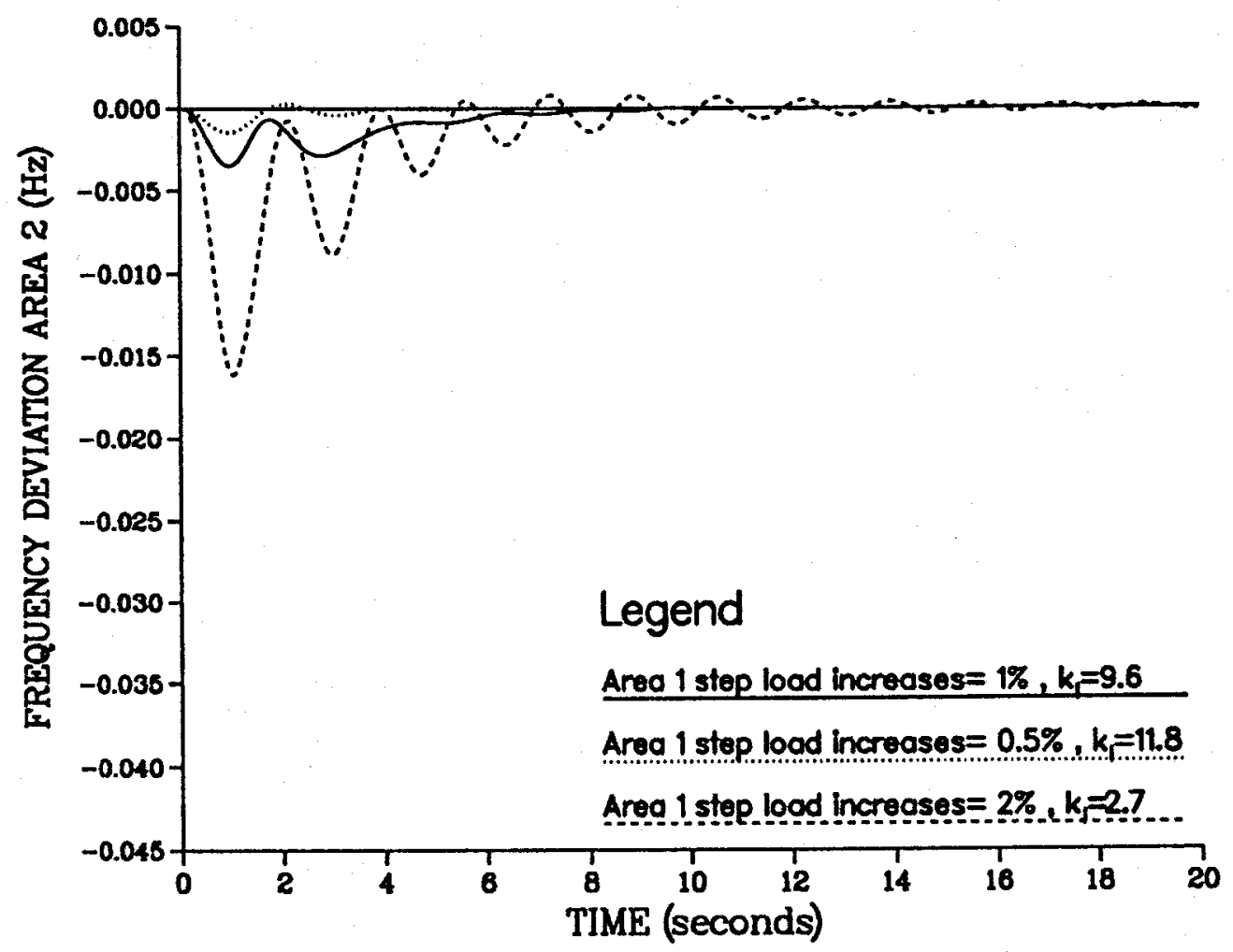

Figure 5.29 Frequency deviation responses in Area 2 for various step load disturbances in area 1. 


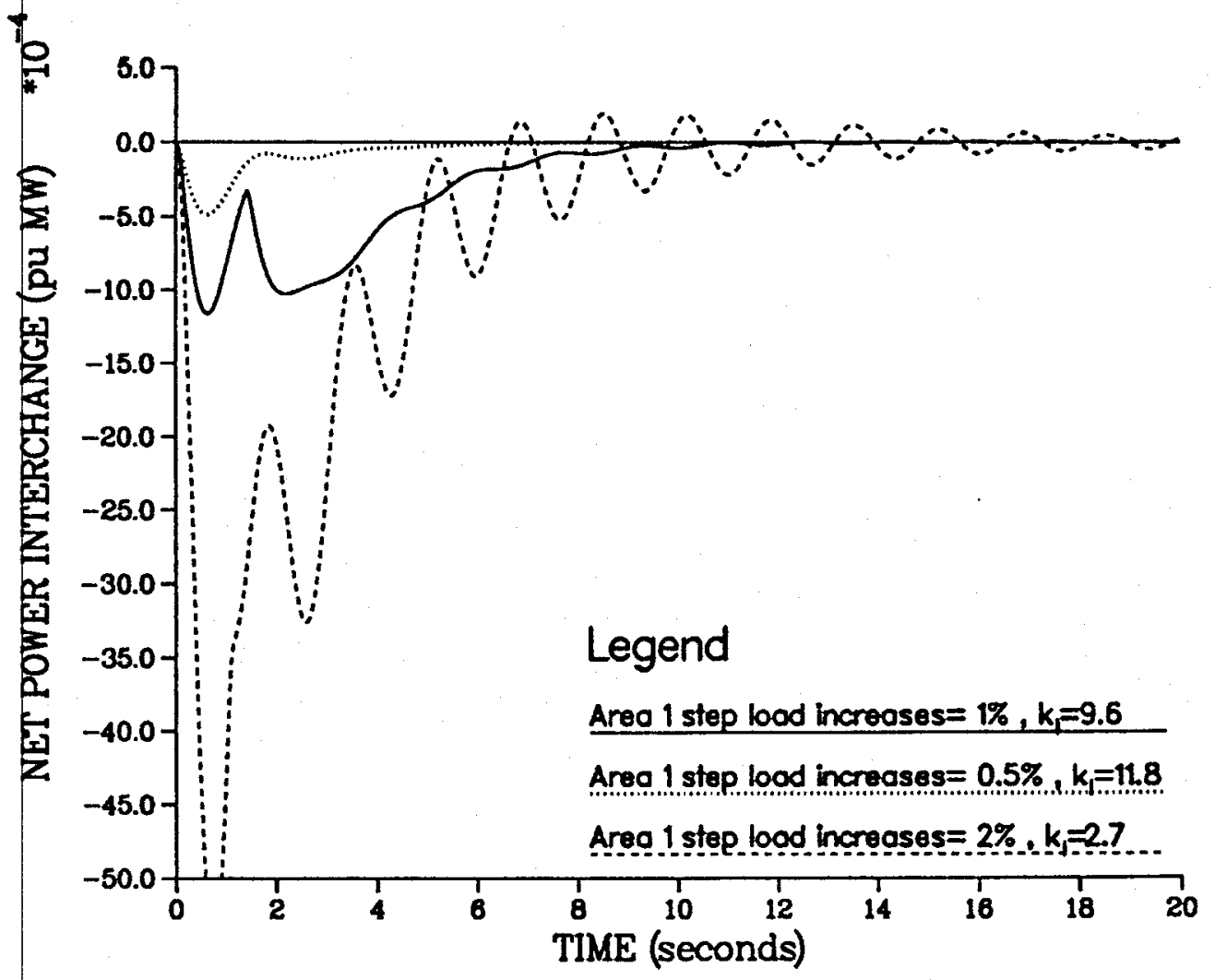

Figure 5.30 Power interchange deviation responses for various step load disturbances in Area 1.

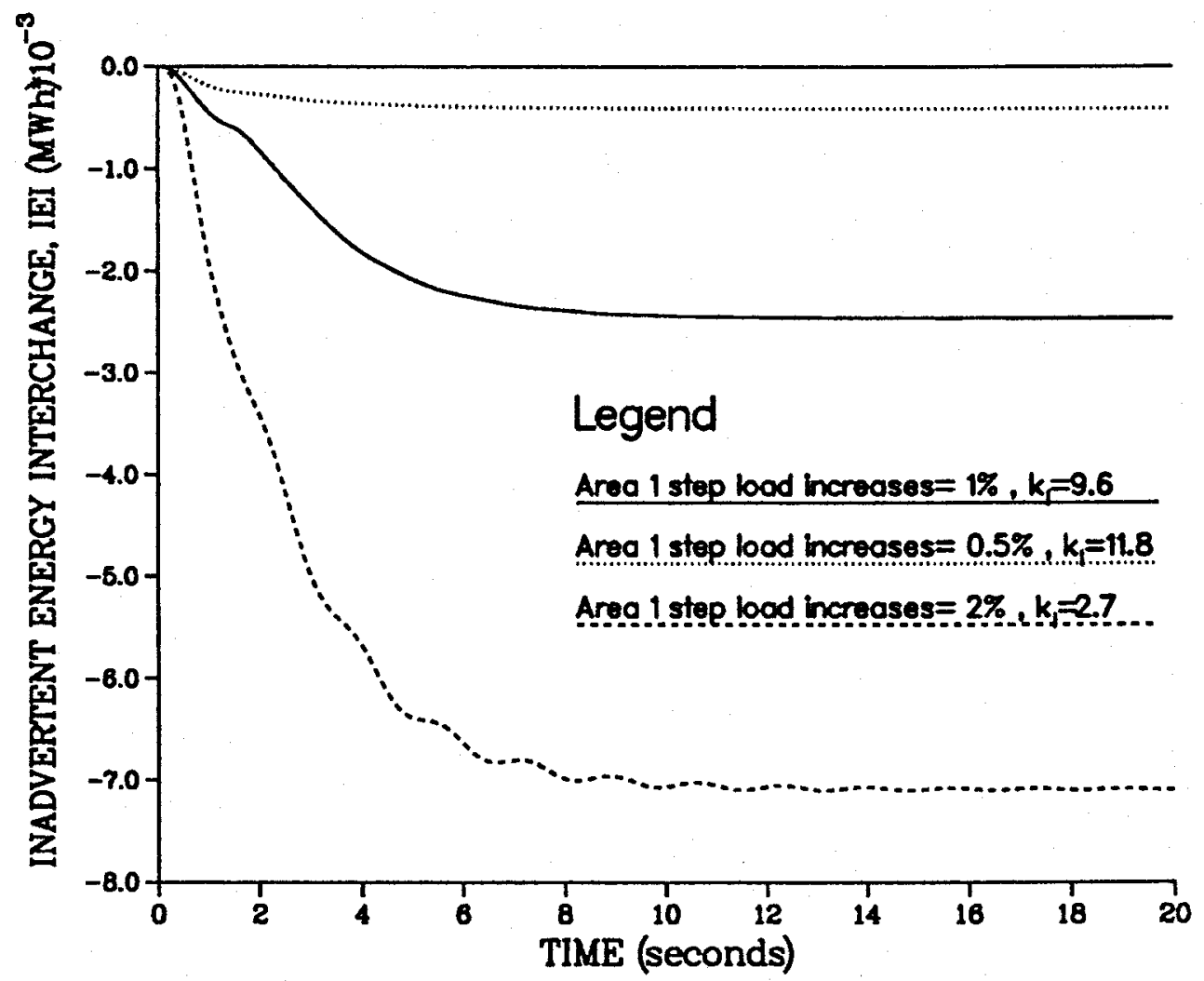

Figure 5.31 Inadvertent energy interchange for various step load disturbances in Area 1. 


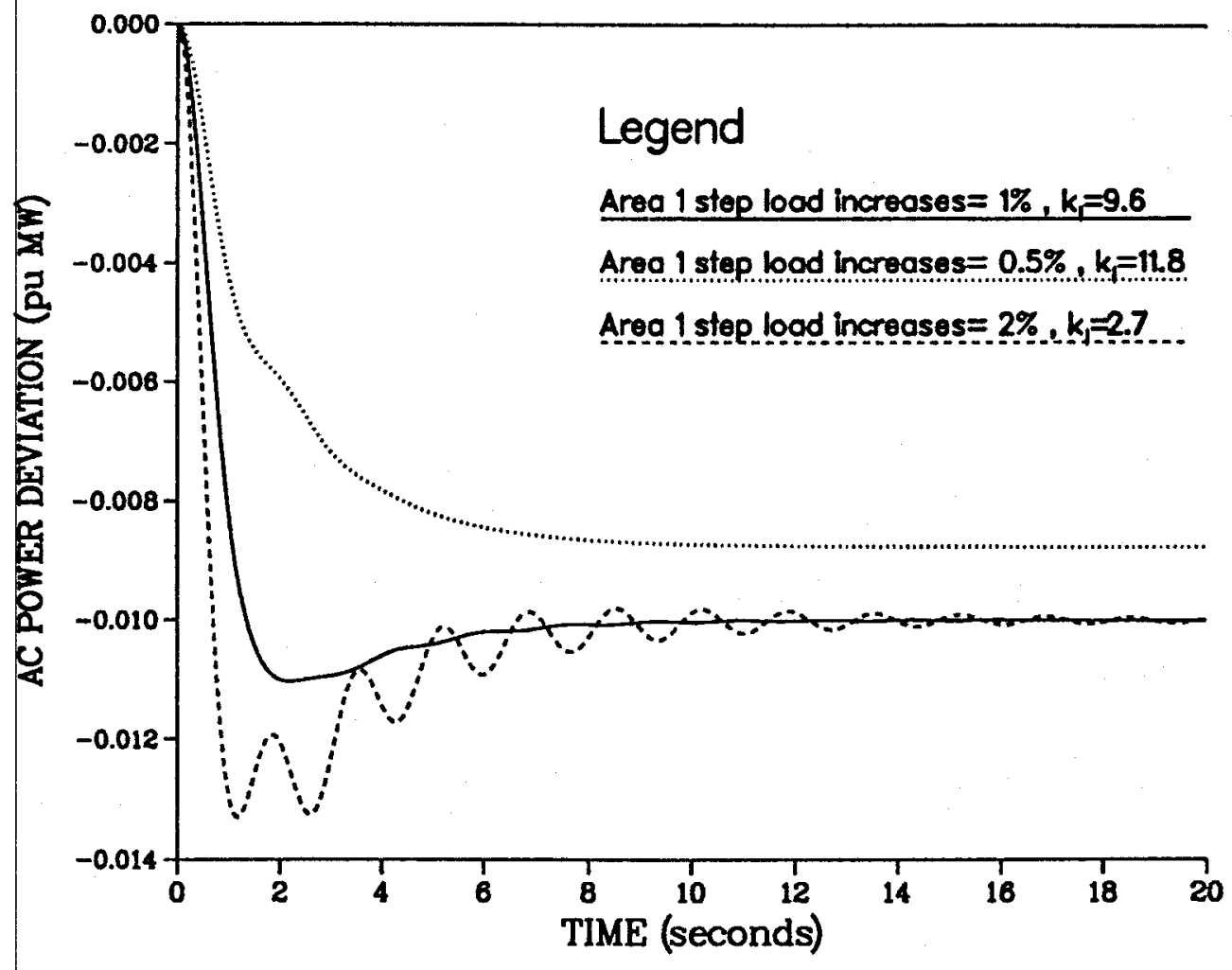

Figure 5.32 AC power interchange deviation responses for various step load disturbances in Area 1.

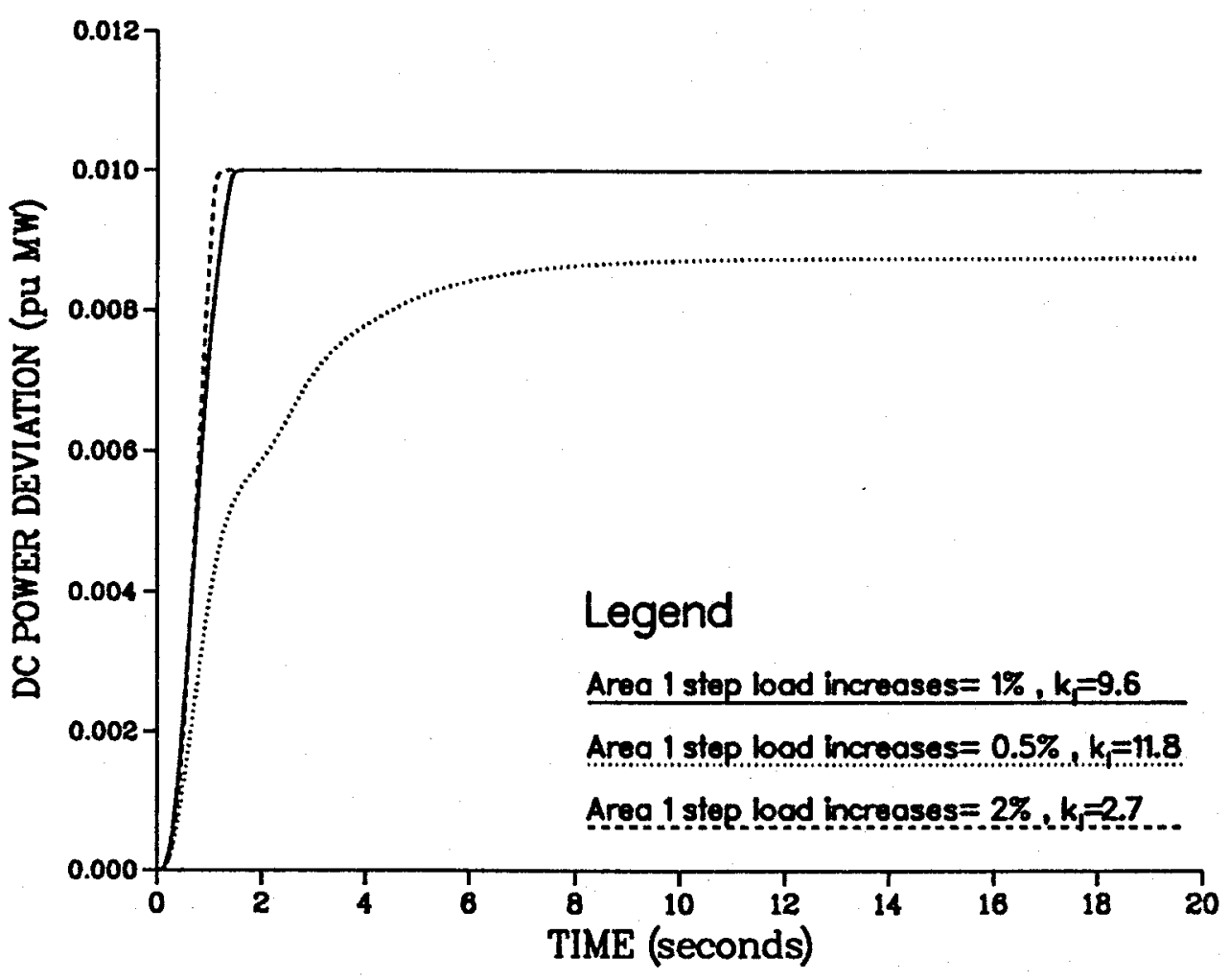

Figure 5.33 DC power interchange deviation responses for various step load disturbances in Area 1. 


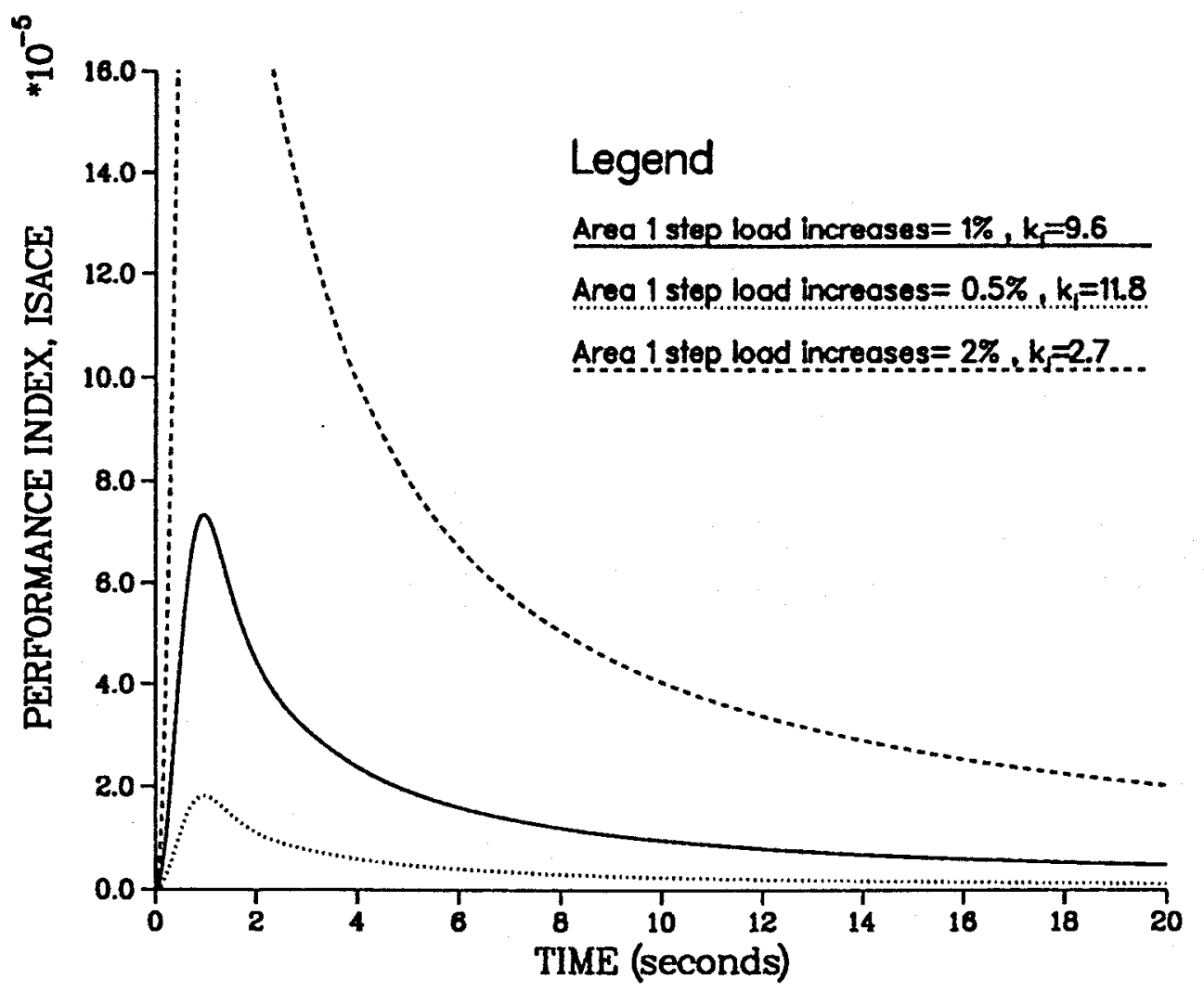

Figure 5.34 Performance index for various step load disturbances in Area 1.

Table 5.4 Effects of changes of step load disturbance in Area 1 on power system performance.

\begin{tabular}{|c|c|c|c|c|c|c|c|}
\hline $\begin{array}{c}\Delta \mathrm{P}_{\mathrm{L} 1} \\
\%\end{array}$ & $\begin{array}{l}\mathrm{SC} \\
\mathrm{k}_{\mathrm{P}}\end{array}$ & $\begin{array}{l}\mathrm{SC} \\
\mathrm{k}_{\mathrm{I}}\end{array}$ & $\begin{array}{c}\text { ISACE } \\
10^{-7}\end{array}$ & $\begin{array}{c}\text { IEI } \\
\text { KWh }\end{array}$ & $\begin{array}{c}\Delta \mathrm{f}_{1} \max \\
\mathrm{Hz}\end{array}$ & $\begin{array}{c}\Delta \mathrm{f}_{2} \max \\
\mathrm{Hz}\end{array}$ & $\begin{array}{l}\Delta \mathrm{P}_{12} \max \\
\text { puMW }\end{array}$ \\
\hline 0.5 & 0.0 & 2.7 & 12.02 & 0.4127 & 0.0115 & 0.0015 & 0.00049 \\
\hline 1.0 & 0.0 & 9.6 & 48.06 & 2.4597 & 0.0226 & 0.0035 & 0.00116 \\
\hline 2.0 & 0.0 & 11.8 & 202.65 & 7.0942 & 0.0417 & 0.0161 & 0.00546 \\
\hline
\end{tabular}




\subsection{Simulation Results for Various Interconnection Types and Control Systems of the Two Area Power System}

In this section, a set of simulation results is presented for different interconnection types and control system characteristics of the two area power system. These simulation tests were carried out to compare system dynamic responses under similar operation conditions of the power system. The following cases were considered in the simulation process:

i) Two area power system interconnected by two AC tie lines, with AGC control.

ii) Two area power system interconnected by $\mathrm{AC}$ and $\mathrm{DC}$ tie lines, with AGC and constant DC power controls.

iii) a) Two area power system interconnected by a AC and DC tie lines, with AGC and Supplementary DC controls.

b) Two area power system interconnected by $\mathrm{AC}$ and $\mathrm{DC}$ tie lines, with AGC control and supplementary DC control including DC power limiter.

$\mathrm{AC}$ and $\mathrm{DC}$ links were set to have the same capacity (10\% of area capacity). The interconnected power system was operating at a power angle of $30^{\circ}$ between system areas and the power transfer between areas was $200 \mathrm{MW}(10 \%$ of area capacity). Therefore the synchronizing torque coefficient $T_{12}$ was equal to 1.088 $\mathrm{puMW} / \mathrm{Hz}$ for the two area power system interconnected by two $\mathrm{AC}$ lines. $\mathrm{T}_{12}$ was set at $0.544 \mathrm{puMW} / \mathrm{Hz}$ for the remainder of the cases described above. 
The step load disturbance applied to the model system in Area 1 was 1\% (20 MW) of area capacity for all the cases. The DC power limiter of the DC control system, included in the third case, was $10 \%$ (20 MW) of DC link capacity.

The parameters of the AGC and SC controllers were optimal. These values are given in the previous section with the exception of the system which included two AC tie lines. The optimal parameters of the AGC controller for a two area power system interconnected by two AC tie lines are:

${ }^{*} \mathrm{k}_{\mathrm{P} 1}=\mathrm{k}_{\mathrm{P} 2}=0 ; \mathrm{k}_{\mathrm{I} 1}=\mathrm{k}_{\mathrm{I} 2}=0.5$

Figures 5.35 to 5.41 and Table 5.5 illustrate the system dynamic responses for various interconnection types and control systems of the TAIPS, under the operating conditions described above.

In the systems where no supplementary DC control is included, the system dynamic responses have practically the same settling down times in both cases. The oscillation frequency of the system responses is higher for the TAIPS interconnected by two AC lines with AGC control than the TAIPS interconnected by AC and DC lines with AGC and constant DC power control.

Figure 5.35 shows the frequency deviation responses in Area 1. By the action of SC control the frequency deviation response is damped faster, so the system frequency comes back to scheduled values in about 10 seconds or less. The first swing 
of the frequency deviation in Area 1 is larger for the TAIPS which includes SC control.

Figures 5.36 shows the frequency deviation responses in Area 2. The SC control action increases the damping of the dynamic frequency deviation response significatively. Moreover the first swing of frequency deviation in Area 2 is largely reduced. Therefore the dynamic frequency changes are very small in the system area which is not subjected to load disturbance.

Figure 5.37 shows that the power interchange deviation responses experience a significant damping improvement because of the SC control action. The dynamic response settles down in about $10 \mathrm{~s}$ for the SC control which include DCPL, and in about $7 \mathrm{~s}$ for the SC control without DCPL.

Figure 5.38 illustrates that the inadvertent energy interchange is drastically reduced by the action of the SC control, reaching a minimum value for the system without DCPL.

Figures 5.39 and 5.40 show the area control error dynamics in Area 1 and Area 2 respectively. In both control areas the control error signal is reduced (mainly in Area 2) and quickly stabilized by the action of SC control. Therefore the governing system operation in both areas would be minimized because of the control error minimization. Since the system damping is mainly provided by the faster SC 
control, Area 2 has very low sensitivity, to load changes in Area 1.

Figure 5.41 illustrates the performance of the TAIPS measured by the performance index ISACE. By the action of the SC control the ISACE is minimized, so the control effectiveness is increased such that the dynamic performance of the TAIPS is improved.

Table 5.5 summarizes some of the main characteristics of the system performance for the different cases examined in this section. The reduction of the values of ISACE and IEI are significant, because of the SC control. The DCPL causes a very small change in the ISACE, but it causes an increase in the IEI.

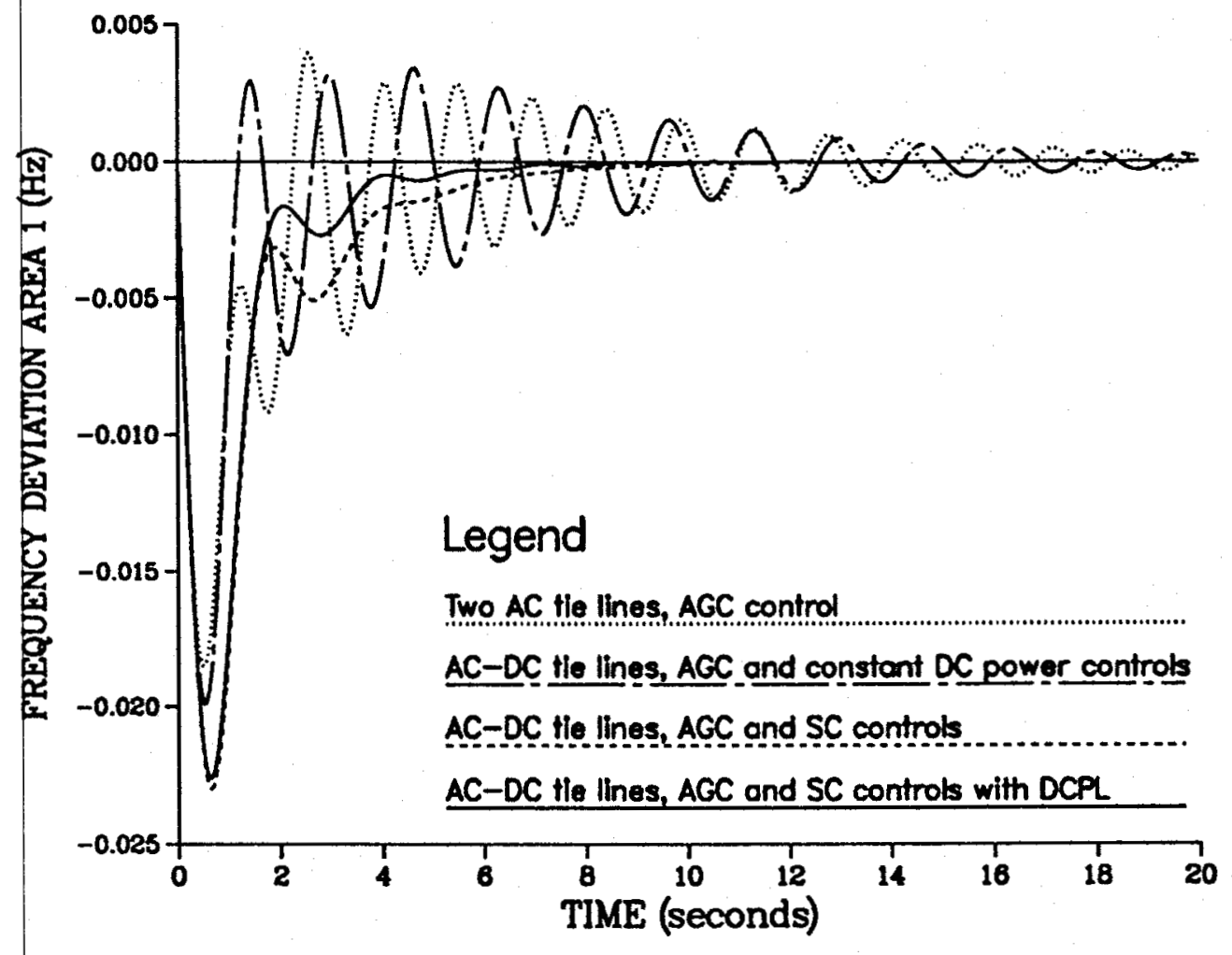

Figure 5.35 Frequency deviation responses in Area 1 for various interconnection types and control systems of the TAIPS. 


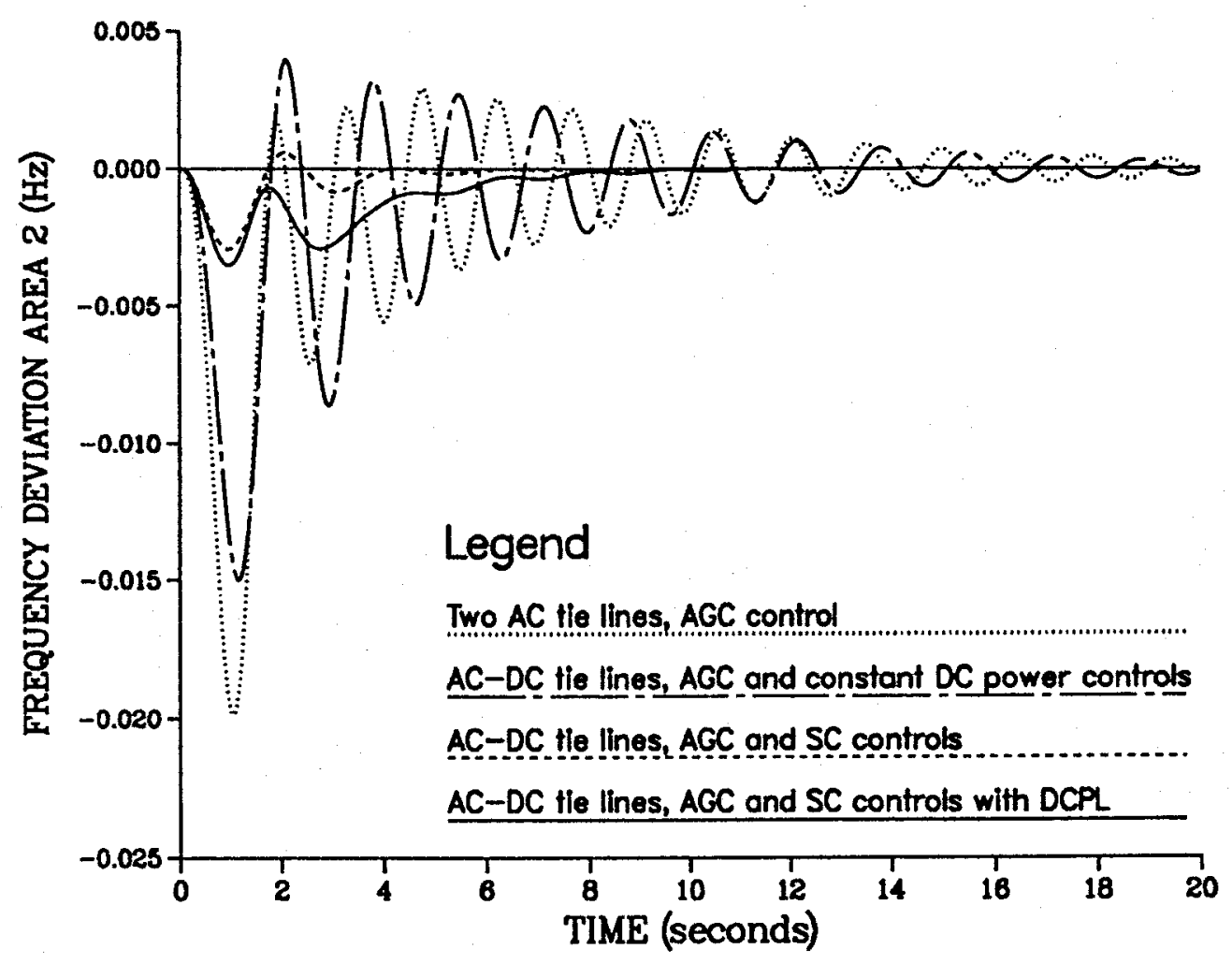

Figure 5.36 Frequency deviation responses in Area 2 for various interconnection types and control systems of the TAIPS.

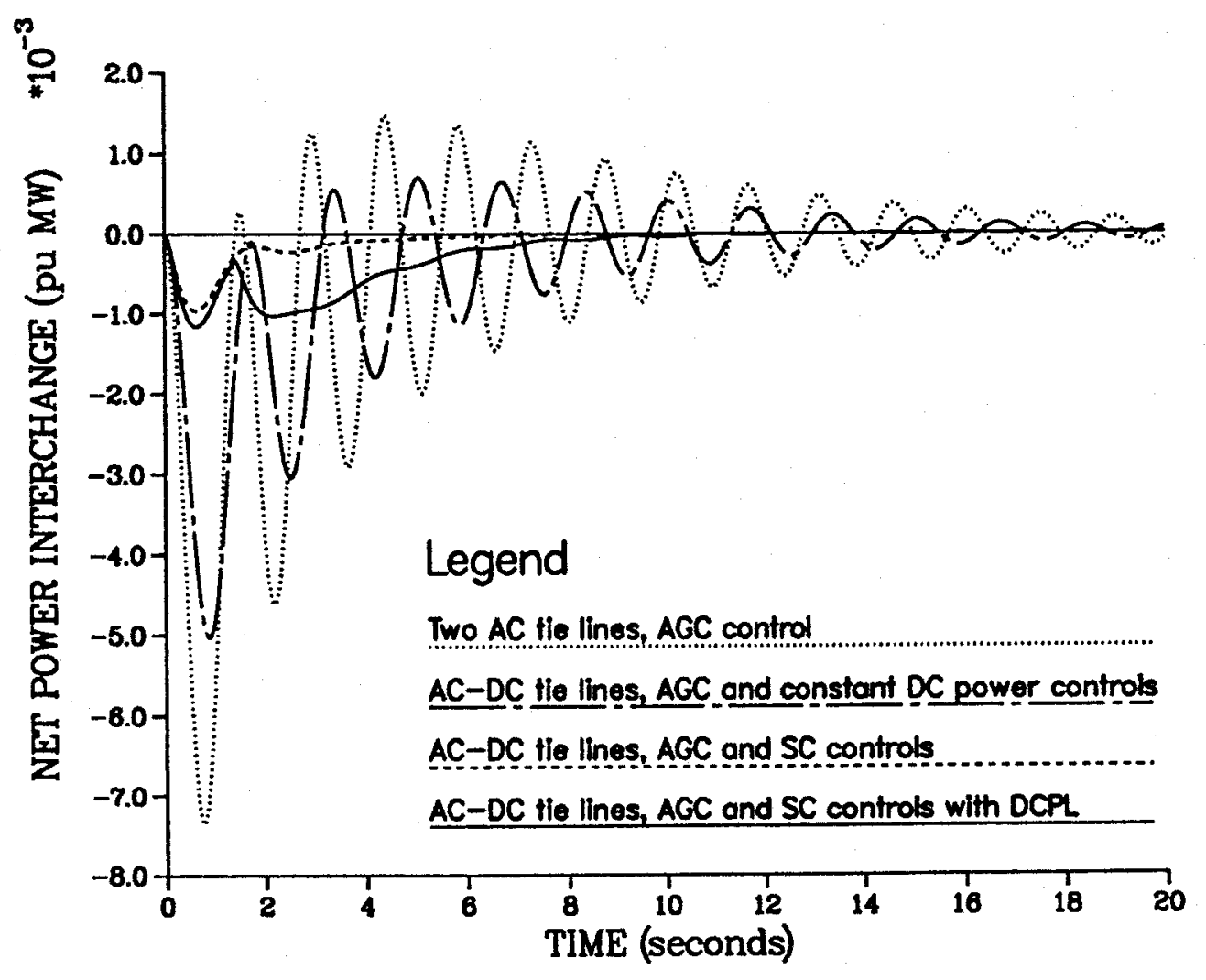

Figure 5.37 Power interchange deviation for various interconnection types and control systems of the TAIPS. 


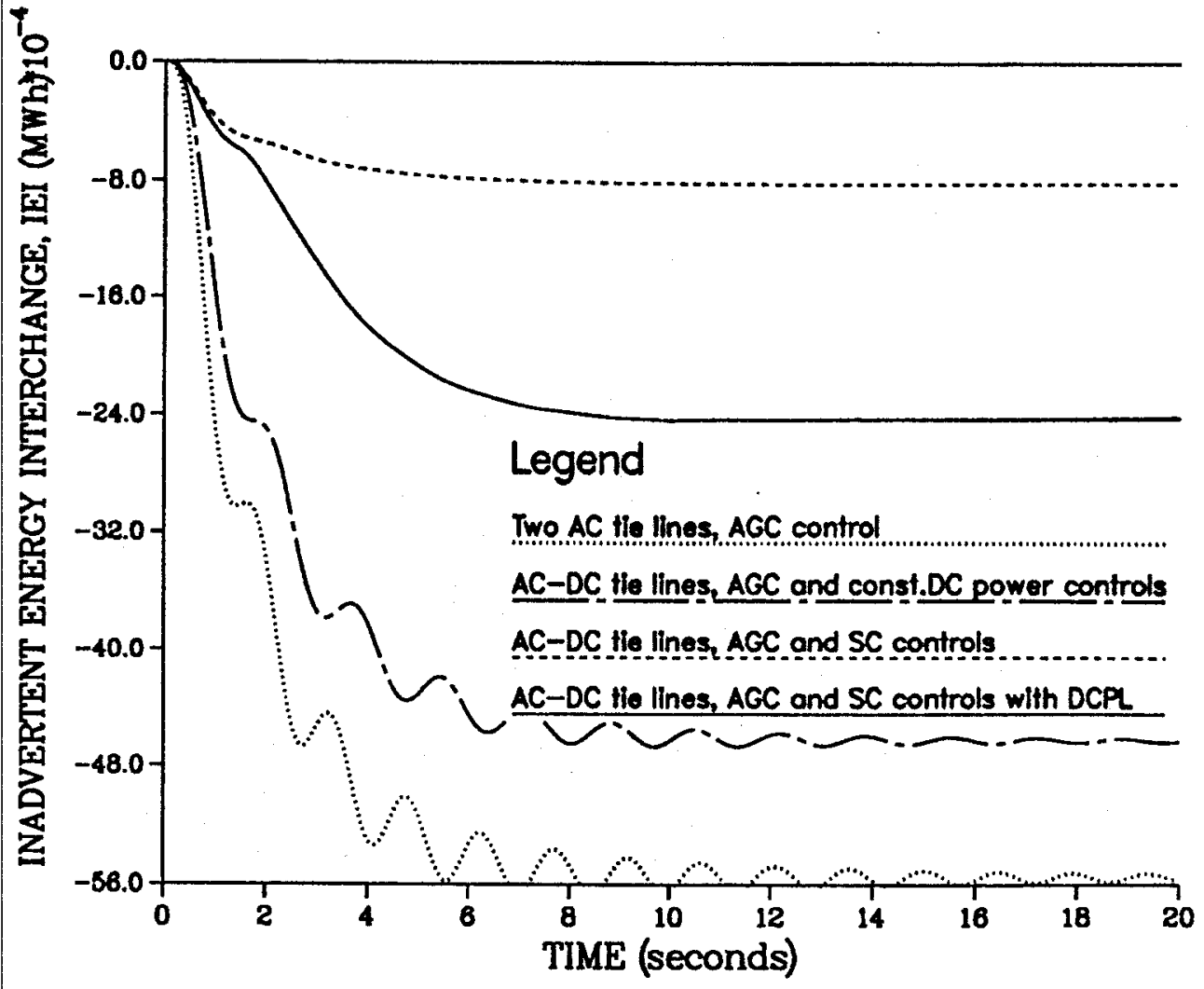

Figure 5.38 Inadvertent energy interchange for various interconnection types and control systems of the TAIPS.

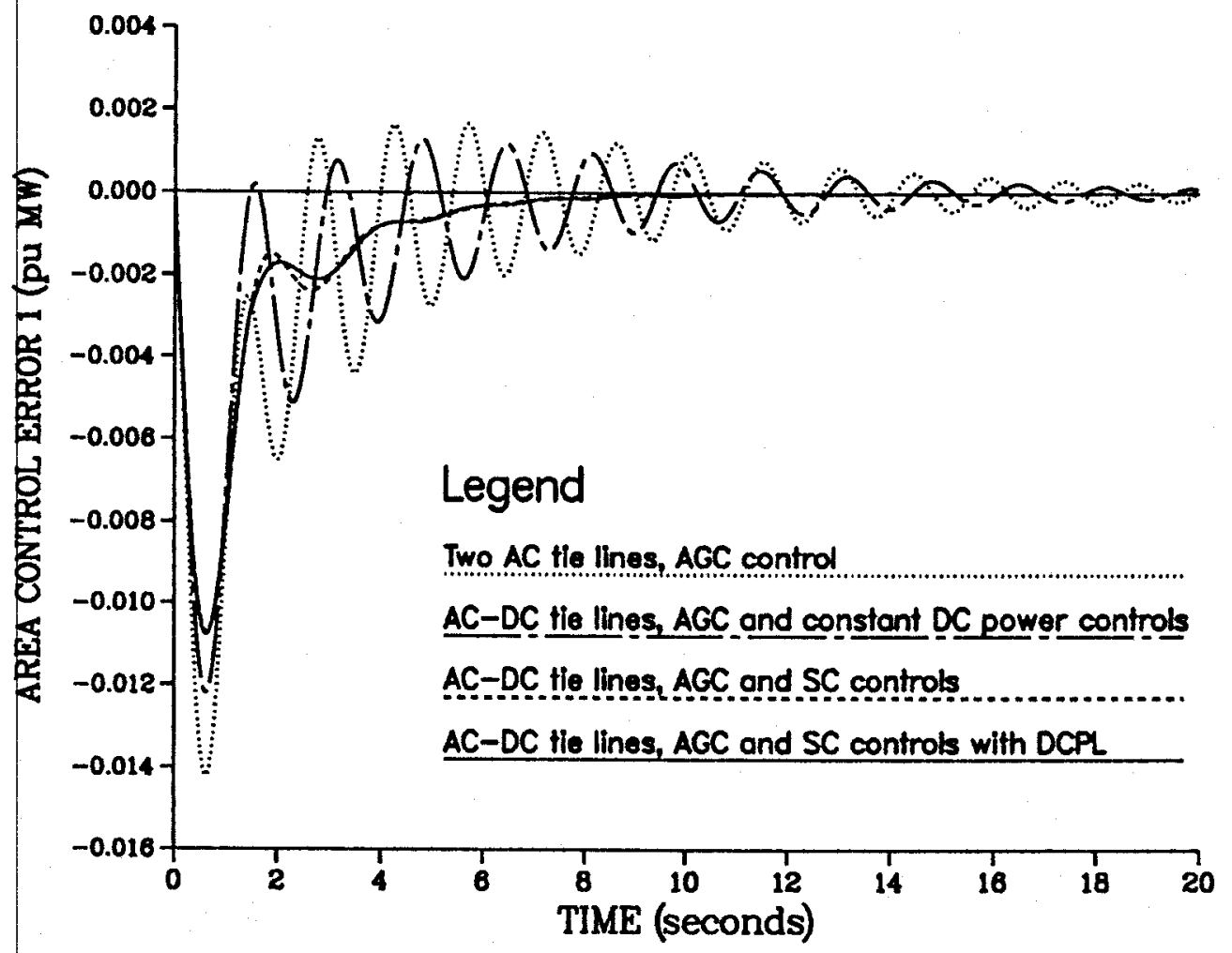

Figure 5.39 Control error of Area 1 for various interconnection types and control systems of the TAIPS. 


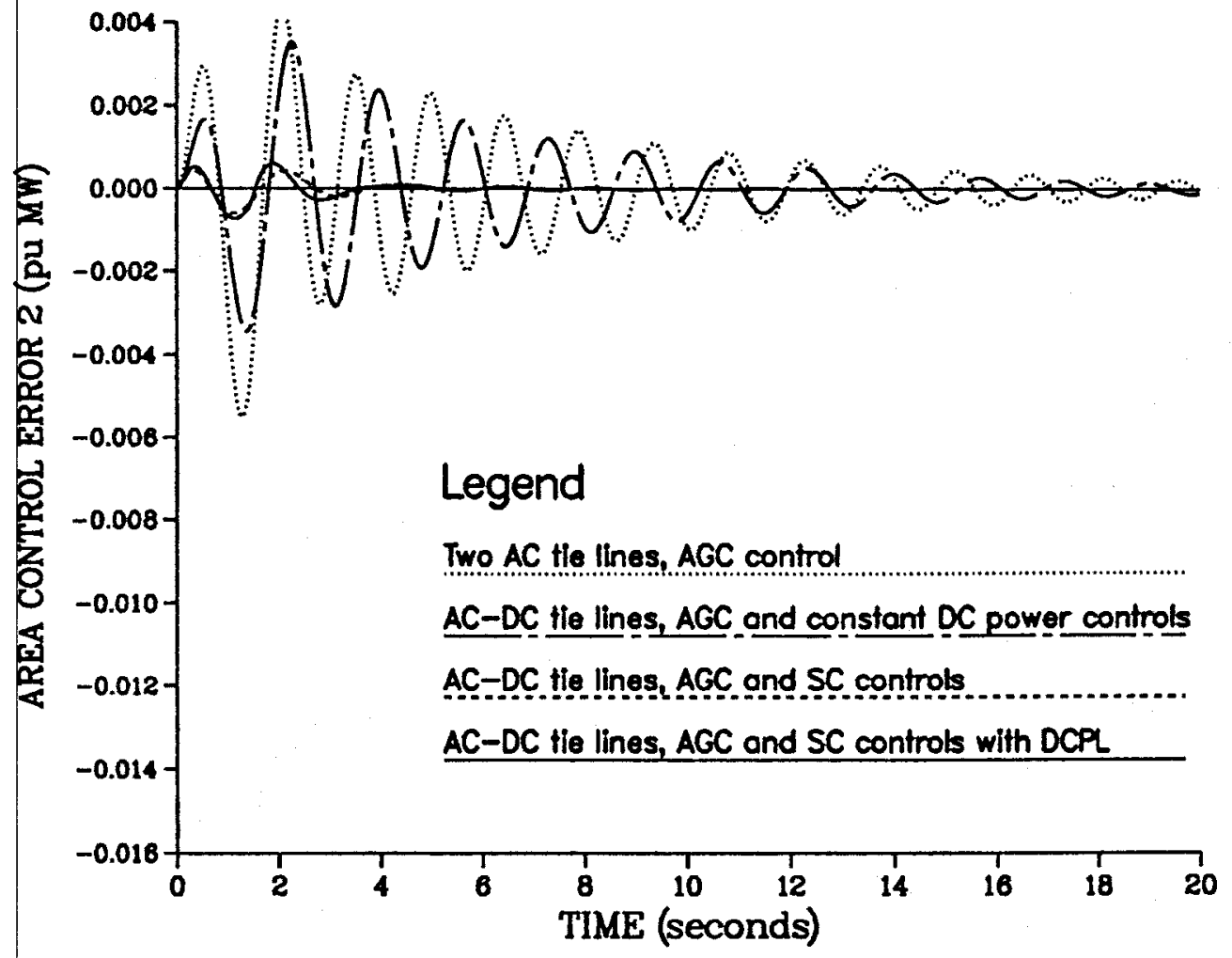

Figure 5.40 Control error of Area 2 for various interconnection types and control systems of the TAIPS.

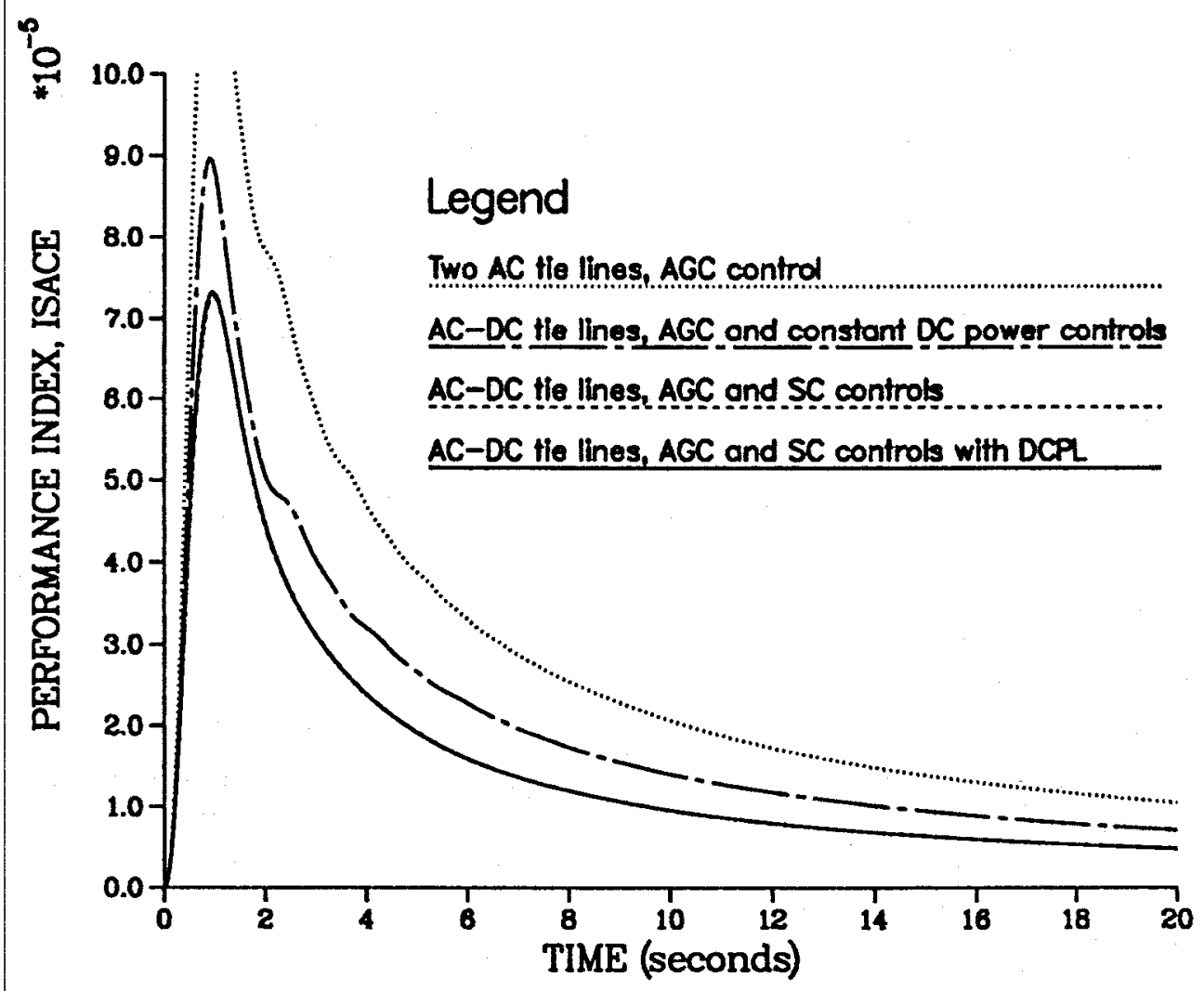

Figure 5.41 Performance index for various interconnection types and control systems of the TAIPS. 
Table 5.5

System performance for various interconnection types and control systems of the TAIPS.

\begin{tabular}{|c||c|c|c|c|c|c|c|c|c|}
\hline $\begin{array}{c}\text { TAIPS } \\
\text { characteristics }\end{array}$ & $\mathrm{k}_{\mathbf{P}}$ & $\mathrm{k}_{\mathbf{I}}$ & $\mathrm{k}_{\mathbf{P}}$ & $\mathrm{k}_{\mathrm{I}}$ & $10^{-7}$ & $\mathrm{KWh}$ & $\mathrm{Hz}$ & $\mathrm{Hz}$ & $\begin{array}{c}\text { AGC } \\
\mathrm{HuMW}\end{array}$ \\
\hline $\begin{array}{c}\text { Two AC tie lines, } \\
\text { AGC control }\end{array}$ & 0.0 & 0.5 & - & -- & 104.91 & 5.5724 & 0.0185 & 0.0199 & 0.00736 \\
\hline $\begin{array}{c}\text { AC-DC tie lines, AGC } \\
\text { and constant DC power } \\
\text { control }\end{array}$ & 0.3 & 0.6 & - & -- & 71.36 & 4.6351 & 0.0200 & 0.0150 & 0.00502 \\
\hline $\begin{array}{c}\text { AC-DC tie lines, } \\
\text { AGC and SC controls }\end{array}$ & 0.3 & 0.6 & 0.0 & 12.0 & 48.12 & 0.8142 & 0.0230 & 0.0029 & 0.00096 \\
\hline $\begin{array}{c}\text { AC-DC tie lines, AGC } \\
\text { and SC controls with } \\
\text { DCPL }\end{array}$ & 0.3 & 0.6 & 0.0 & 9.6 & 48.06 & 2.4597 & 0.0226 & 0.0035 & 0.00116 \\
\hline
\end{tabular}




\subsection{Conclusions}

The simulation results reported in this Chapter illustrate, mainly, the effect of supplementary DC control action on the dynamic performance of the two area interconnected power system following a step load disturbance.

The fast supplementary DC control (SC), based on net power interchange variations, interacts with the conventional $\mathrm{AC}$ controls providing a positive damping to the system dynamic responses. The responses settle down faster, reaching a steady state condition in about $10 \mathrm{~s}$. Furthermore, the optimization of the AGC and SC controller parameters, based on the minimization of the performance index ISACE, has a marked effect on system dynamic performance. The area control error is reduced, avoiding unnecessary governing operations. The inadvertent energy interchange (IEI) is also reduced by action of the SC control, reaching smaller values as the integral gain increases. ISACE and IEI have low sensitivities to variations of the SC controller proportional gain.

The DC power limiter (DCPL) has a significant effect on the IEI value, and less influence on the ISACE value.

The calculated optimal values of the SC controller parameters are different for different sizes of area load disturbances and for different DCPL. This attests to the non-linear behaviour of the power control system. 


\section{SUMMARY AND CONCLUSIONS}

\subsection{Summary}

In this thesis research the dynamic performance of a two area $A C / D C$ power system, with supplementary DC control interacting with the conventional AC controls is described. Emphasis is on the power/frequency control aspects of the overall power system control problem.

The control structure, terminology of interconnected system controls and the general background of HVDC control features are discussed in Chapter 1. The influence of HVDC links on AC systems and a brief review of previously reported studies are also included.

A linear model of a two area power system interconnected by AC and DC tielines including conventional controls (primary governing system, AGC control and constant DC power control) and supplementary DC control is presented in Chapter

2. The linear model was satisfactory for these studies because only small changes around a base reference state were considered. The simplified dynamic model developed involves only the power-frequency interactions. 
The vector state space equations of the two area power system interconnected by an AC tie-line with AGC control, and by parallel AC and DC tie-lines with AGC and supplementary controls, are presented in Chapter 3 . The system state space equations were derived from transfer function block diagrams of the power system.

The results of stability studies of the two-area interconnected power systems are reported in Chapter 4 . The stability analysis was carried out by identification of the eigen-structure of the state space models developed in Chapter 3. The system eigen-structure was obtained from the constant coefficient matrix of the state space vector equation.

Simulation studies to evaluate power system dynamic responses under step load changes and to compute optimal controller parameters are discussed in Chapter 5. Control optimization used to adjust the controller parameters was achieved by minimization of a performance index. The performance index (ISACE) chosen is a function of the control error in both control areas and thus is a measure of control effectiveness. The simulation results illustrate the effects of, variation of controller parameters around the optimal values, variation of the size of step load disturbance and variation of DC power limiter settings, on the dynamic responses of the system. Furthermore, graphical results are presented to illustrate the dynamic performance of the various interconnection types and control features of the interconnected power system under operating conditions which are similar with respect to net power transfer between the two areas for all cases. 


\subsection{Conclusions}

It was found that the stability of the two area power system interconnected by AC and DC tie-lines was significantly improved using DC power modulation with supplementary control. In the $S$ plane, the dominant complex poles (natural oscillation modes $\lambda_{8}$ and $\left.\lambda_{9}\right)$ move from $(-0.18 \pm j 3.76)$ to $(-1.17 \pm j 3.09)$ because of the implementation of the optimal supplementary control. The system damping is increased and the oscillation frequency of the system responses is reduced. Thus the dynamic stability of the system is improved.

The responses of the power system subjected to a step load disturbance in one of the control areas, obtained from the simulation results, illustrate a significant dynamic performance improvement overall for the two area interconnected power system with the supplementary control. The fast DC power modulation, based on the time integral of the net power interchange deviation, interacting with the AGC control makes it possible to restore net power interchange and system frequency back to scheduled values in less than 10 seconds following a disturbance. Furthermore, the control optimization, carried out by minimization of the performance index ISACE, minimizes the area control errors and reduces the inadvertent energy interchange. Since the system damping is provided mainly by the faster supplementary control, the control area which is not subjected to load disturbance is practically insensitive to load changes in the neighbouring control area. 
Summarizing, the optimal supplementary control provides a positive damping to the system dynamic responses. Following a disturbance the system settles down faster, the inadvertent energy interchange is reduced and the system governing operations are reduced. Thus the control effectiveness is improved.

The effects of the DC power limiter on system responses show a small influence on the performance index value, but it causes an increase of the inadvertent energy interchange. It increases the mutual assistance between the individual power systems through the $\mathrm{AC}$ tie-line and hence demands larger angle swings between areas.

The integral action of the supplementary control causes a significant steady state deviation of the power transfer over the $\mathrm{AC}$ and $\mathrm{DC}$ links; one increases while the other decreases. Further research is required on this problem to devise a suitable means to compensate for or avoid it. It is suggested that the addition of a relatively slow "wash-out" action to the supplementary controller would accomplish this.

The values of optimal parameters of the supplementary controller depend on the size of the step load disturbance and of the value of the DC power limiter setting. This is due to the basic non-linear characteristic of the system and on-line tuning of such parameters would be required to maintain optimal performance over a wide range of operation. This area requires further study. 
As real power systems have non linear characteristics, it is recommended that a more detailed TAIPS model including such non-linearities be developed in order to extend the studies for a wider range of disturbances. 


\section{REFERENCES}

1. "Definitions of Terms for Automatic Generation Control on Electric Power Systems", IEEE Standard 94, IEEE Trans. Vol. PAS 89, July/August, 1970, pages $1358-1364$.

2. P. M. Anderson and A.A. Fouad, "Power System Control and Stability", Vol. 1, The IOWA State University Press, Ames, IOWA, USA, 1977.

3. I. J. Nagrath, "Modern Power System Analysis", Tata McGraw-Hill Publishing Company Limited, 1980.

4. M. J. Sterling, "Power System Control", IEE, A. Wheaton \& Co., Exeter, England.

5. O. I. Elgerd, "Electric Energy System Theory", Second Edition, McGraw-Hill, 1982.

6. E. W. Kimbark, "Direct Current Transmission", Vol. 1, John Willey \& Sons, Inc., 1971.

7. E. Ühlman, "Power Transmission by Direct Current", Springer-Verlag, Berlin/Hidelberg, 1975.

8. L. K. Kirchmayer, "Economic Control of Interconnected Power Systems", John Willey \& Sons, Inc., New York 1959.

9. J. Arrillaga, "High Voltage Direct Current Transmission", Peter Peregrinus Ltd., London, UK 1983.

10. Yao-nan Yu, "Electric Power System Dynamics", Academic Press Inc., New York 1983.

11. R. T. Byerly and E. W. Kimbark, "Stability of Large Electric Power Systems", IEEE Press, New York 1974.

12. K. Ogata, "State Space Analysis of Control Systems", Prentice-Hall Inc., Englewod Cliffs, N. J. 1967.

13. O. I. Elgerd, "Control Systems Theory", McGraw-Hill Inc.,1967.

14. R. J. Fleming, "Power System Modelling and Control", Course notes, Dept. of Electrical Engineering, University of Saskatchewan, Saskatoon, Canada 1990. 
15. N. G. Hingorani, J. L. Hay and R. L. Crosbil, "Dynamic Simulation of HVDC Transmission Systems on digital computers", PROC. IEE., Vol. 113, No 5, May 1966, pages 793-802.

16. IEEE Committee Report, "Dynamic Performance Characteristics of North American HVDC Systems for Transient and Dynamic Stability Evaluations", IEEE Trans., Vol. PAS 100, No 7, July 1981, pages 3356-3364.

17. IEEE Committee Report, "Dynamic Models for Steam and Hydroturbines in Power System Studies", IEEE Trans. Vol. PAS 92, Nov/Dec. 1973, pages 1904-1915.

18. C. E. Fosha and E. I. Elgerd, "The Megawatt-Frequency Control Problem: A New Approach Via Optimal Control Theory", IEEE Trans. Vol. PAS 89, No 4, April 1970, pages 563-570.

19. C. W. Taylor and R. L. Cresap, "Real Time Power System Simulation for AGC", IEEE Trans. Vol. PAS 95, 1976, page 375.

20. R. L. Cresap and W. A. Mittelstadt, "Small Signal Modulation of the Pacific HVDC Intertie", IEEE Trans. Vol. PAS 95, 1976, page 536.

21. P. K. Dash, B. Puthal, O. P. Malik and G. S. Hope, "Transient Stability and Optimal Control of a Parallel AC-DC Power System", IEEE Trans. Vol. PAS 95, 1976, page 811.

22. IEEE Committee Report, "Functional Model of Two Terminal HVDC Systems for Transient and Steady State Stability", IEEE Trans. Vol.PAS 103, No 6, June 1984, pages 1249-1255.

23. Yao nan Yu, Khien Vongsuriya and L. N. Wedman, "Application of an Optimal Control Theory to a Power System",IEEE Trans. Vol. PAS 89, No 1, January 1970, pages 55-60.

24. O. I. Elgerd and C. E. Fosha, "Optimum Megawatt-Frequency Control of Multiarea Electric Energy Systems", IEEE Trans. Vol. PAS 89, No , April 1970, pages 556-563.

25. A. Ekstro"m and G. Liss, "A Refined HVDC Control System", IEEE Trans. Vol. PAS 89, No 5, May/June 1970, pages 723-732.

26. P. G. Engstro"m, "Operation and Control of HVDC Transmission", IEEE Trans. Vol. PAS 83, January 1964, pages 71-77. 
27. M. S. Sachdev, R. J. Fleming and J. Chand, "Optimal Control of HVDC Transmission Link", IEEE Trans. Vol. PAS 92, Nov/Dec. 1973, pages 19581965.

28. T. Machida, Y. Yoshida and H. Nakamura, "A Method of Automatic Frequency Ratio Control by a DC System", IEEE Trans. Vol. PAS 86, No 3, March 1967, pages 263-267.

29. Y. Yoshida, T. Machida and N. G. Hingorani, "Analog Computer Study of Automatic Frequency Ratio Control on an HVDC Transmission System", IEEE Trans. Vol. PAS 87, No 3, March 1968, pages 796-807.

30. Y. Yoshida and T. Machida, "Study of the Effect of the DC Link on Frequency Control in Interconnected AC Systems", IEEE Trans. Vol. PAS 88, No 7, July 1969, pages 1036-1042.

31. Xia Zu-zhi, "A Study of Load Frequency Control for Interconnected Power Systems with a HVDC Tie Line", IEE $4^{\text {th }}$ International Conference on AC and DC Transmission, London, Sept. 1985, pages 416-424.

32. N. A. Vovos and G. D. Galanos, "Damping of Power Swings in AC Tie Lines using a Parallel DC Link Operating at Constant Reactive Power Control", IEEE Trans. Vol. PAS 98, No 2, March/April 1979, pages 416-424.

33. J. Nanda, M. L. Kothari and P. S. Satsangi, "Automatic Generation Control of an Interconnected Hydrothermal System in Continuous and Discrete modes considering Generation Rate Constraints", IEE Proced. Vol. 130, Pt.D, No 1, January 1983, pages 416-424.

34. N. Cohn, "Some Aspects of Tie Line Bias Control on Interconnected Power Systems", AIEE Trans. Vol. 75, Feb. 1957, pages 1415-1436.

35. N. G. Hingorani, N. Sato and J. J. Vithayathil, "Use of Fast Power Control on Pacific Northwest-Southwest DC Intertie Operating in Parallel with two AC Interties", IEE High Voltage DC and/or AC Power Transmission, Conference Publication No 107, Nov. 1973, pages 212-220.

36. U. G. Knight, "Operational Aspects of the Comparison between AC \& DC Transmission", IEE High Voltage DC and/or AC Power Transmission, Conference Publication No 107, Nov. 1973, pages 302-306.

37. T. R. Treasure, "Experience with AC Tie Line and Frequency Control on the Vancouver Island HVDC Link",IEE Thyristor an Variable Static Equipment for AC and DC Transmission, Conference Publication, No 205, Nov./Dec. 1981, pages 219-222. 
38. K. R. Padiyar, M. A. Pai and C. Radhakrishna, "Analysis of DC Link Control for System Stabilization", IEE Thyristor an Variable Static Equipment for AC and DC Transmission, Conference Publication No 205, Nov./Dec. 1981, pages 145-147.

39. M. G. Bennett, "Power-Frequency Interactions in an AC/DC/AC System", M.Sc. Thesis, University of Saskatchewan, 1976.

40. H. S. Khalil, "Effect of HVDC Power Modulation on Stability of AC/DC Parallel Power Systems", Ph.D. Thesis, University of Saskatchewan, 1978.

41. K. Kumar, "Effects of Filtering on AGC Systems", M.Sc. Thesis, University of Saskatchewan, 1983.

42. J. Chand, "Stability Analysis of a HVDC Transmission Link", M.Sc. Thesis, University of Saskatchewan, 1971.

43. R. S. Burton, "State Space Representation of a HVDC Tie Line", M.Sc. Thesis, University of Saskatchewan, 1970.

44. D. S. Earle, "Frequency Control Studies in AC-DC Systems", M.Sc. Thesis, University of Saskatchewan, 1968.

45. E. Zhou, "Power System Modelling and Control", Course Notes, Dept. of Electrical Engineering, University of Saskatchewan, 1991.

46. G. S. Christensen, M. E. El-Hawary and S. A. Soliman, "Optimal Control Applications in Electric Power Systems", Plenum Press, New York 1987.

47. J. J. Dougherty and T. Hillesland, "Power System Stability consideration with Dynamically Responsive DC Transmission Lines", IEEE Trans. Vol. PAS 89, No 1, January 1970.

48. B. K. Johnson, "HVDC Models used in Stability Studies", IEEE Trans. on Power Delivery, Vol. 4, No 2, April 1989. 


\section{APPENDIX A}

\section{Simulation Model Structure}

\begin{tabular}{|c|c|c|c|c|c|c|c|c|c|}
\hline \multirow{2}{*}{$\begin{array}{c}\text { Tursim } \\
\text { Block } \\
\text { number } \\
\end{array}$} & \multirow{2}{*}{$\begin{array}{c}\text { Tursim } \\
\text { Block } \\
\text { type } \\
\end{array}$} & \multirow{2}{*}{$\begin{array}{r}\text { TUTsim } \\
\text { Block } \\
\text { inputs } \\
\end{array}$} & \multicolumn{6}{|c|}{$\begin{array}{c}\text { TUTsIM } \\
\text { Block parameters }\end{array}$} & \multirow{2}{*}{$\begin{array}{c}\text { Output } \\
\text { variables } \\
\end{array}$} \\
\hline & & & $\mathbf{P}$ & $\mathbf{R}$ & $\mathbf{T}$ & $I_{c}$ & Min & Max & \\
\hline 1 & SUM & 11,44 & - & - & - & - & - & - & $\left(-A C E_{1}\right)$ \\
\hline 2 & GAI & 1 & $\mathrm{k}_{\mathrm{P} 1}$ & - & - & - & - & - & \\
\hline 3 & GAI & 1 & $\mathrm{k}_{\mathrm{II}}$ & - & - & - & - & - & \\
\hline 4 & INT & 3 & - & - & - & 0 & - & - & \\
\hline 5 & SUM & $-10,-2,-4$ & - & - & - & - & - & - & \\
\hline 6 & FIO & 5 & - & 1 & $\mathrm{~T}_{\mathrm{G} 1}$ & 0 & - & - & $x_{3}$ \\
\hline 7 & FIO & 6 & - & 1 & $\mathrm{~T}_{\mathrm{TI}}$ & 0 & - & - & $\mathrm{x}_{2},\left(\Delta \mathrm{P}_{\mathrm{G} 1}\right)$ \\
\hline 8 & SUM & $-19,7,-44$ & - & - & - & - & - & - & \\
\hline 9 & FIO & 8 & - & $\mathrm{K}_{\mathrm{P} 1}$ & $\mathrm{~T}_{\mathrm{PI}}$ & 0 & - & - & $x_{1},\left(\Delta f_{1}\right)$ \\
\hline 10 & ATT & 9 & $\mathbf{R}_{1}$ & - & - & - & - & - & \\
\hline 11 & GAI & 9 & $\mathrm{~B}_{1}$ & - & - & - & - & - & \\
\hline 12 & SUM & $9,-29$ & - & - & - & - & - & - & \\
\hline 13 & GAI & 12 & $T_{12}$ & - & - & - & - & - & \\
\hline 14 & INT & 13 & - & - & - & 0 & - & - & $x_{7},\left(\Delta P_{A C}\right)$ \\
\hline 15 & MUL & 1,1 & - & - & - & - & - & - & \\
\hline 16 & SUM & 15,32 & - & - & - & - & - & - & \\
\hline 17 & LMI & 16 & - & - & - & 0 & 0 & $T$ & \\
\hline 18 & TIM & - & - & - & - & - & - & - & \\
\hline 19 & CON & - & $\Delta \mathrm{P}_{\mathrm{L} 1}$ & - & - & - & - & - & $\left(\Delta \mathrm{P}_{\mathrm{L} 1}\right)$ \\
\hline 21 & SUM & $31,-44$ & - & - & - & - & - & - & $\left(-A^{-} E_{2}\right)$ \\
\hline 22 & GAI & 21 & $\mathrm{k}_{\mathrm{P} 2}$ & - & - & - & - & - & \\
\hline 23 & GAI & 21 & $\mathrm{k}_{12}$ & - & - & - & - & - & \\
\hline
\end{tabular}




\begin{tabular}{||c|c|c|c|c|c|c|c|c|c||}
\hline 24 & INT & 23 & - & - & - & 0 & - & - & \\
\hline 25 & SUM & $-30,-22,-24$ & - & - & - & - & - & - & \\
\hline 26 & FIO & 25 & - & 1 & $\mathrm{~T}_{\mathrm{G} 2}$ & 0 & - & - & $\mathrm{x}_{6}$ \\
\hline 27 & FIO & 26 & - & 1 & $\mathrm{~T}_{\mathrm{T} 2}$ & 0 & - & - & $\mathrm{x}_{5},\left(\Delta \mathrm{P}_{\mathrm{G} 2}\right)$ \\
\hline 28 & SUM & 44,27 & - & - & - & - & - & - & \\
\hline 29 & FIO & 28 & - & $\mathrm{K}_{\mathrm{P} 2}$ & $\mathrm{~T}_{\mathrm{P} 2}$ & 0 & - & - & $\mathrm{x}_{4},\left(\Delta \mathrm{f}_{2}\right)$ \\
\hline 30 & ATT & 29 & $\mathrm{R}_{2}$ & - & - & - & - & - & \\
\hline 31 & GAI & 29 & $\mathrm{~B}_{2}$ & - & - & - & - & - & \\
\hline 32 & MUL & 21,21 & - & - & - & - & - & - & \\
\hline 40 & GAI & 44 & $\mathrm{k}_{\mathrm{P}}$ & - & - & - & - & - & \\
\hline 41 & GAI & 44 & $\mathrm{k}_{\mathrm{I}}$ & - & - & - & - & - & \\
\hline 42 & INT & 41 & - & - & - & 0 & - & - & \\
\hline 43 & FIO & $-40,-42$ & - & 1 & $\mathrm{~T}_{\mathrm{DC}}$ & 0 & - & - & \\
\hline 44 & SUM & 14,90 & - & - & - & - & - & - & $\mathrm{x}_{11},\left(\Delta \mathrm{P}_{12}\right)$ \\
\hline 49 & LIM & 18 & - & - & - & 0 & $\Delta \mathrm{T}$ & $\mathrm{T}$ & \\
\hline 50 & DIV & 17,49 & - & - & - & - & - & - & $(\mathrm{ISACE})$ \\
\hline 60 & INT & 44 & - & - & - & 0 & - & - & \\
\hline 61 & ATT & 60 & 1.8 & - & - & - & - & - & $(\mathrm{IEI})$ \\
\hline 80 & SUM & $-2,-4$ & - & - & - & - & - & - & $\mathrm{x}_{9}$ \\
\hline 81 & SUM & $-22,-24$ & - & - & - & - & - & - & $\mathrm{x}_{10}$ \\
\hline 90 & LIM & 43 & - & - & - & - & $-\mathrm{DCPL}$ & $+\mathrm{DCPL}$ & $\mathrm{x}_{8},\left(\Delta \mathrm{P}_{\mathrm{DC}}\right)$ \\
\hline
\end{tabular}

The above simulation model structure, developed for the TUTSIM program, is based on the transfer function block diagram of the AC/DC Two Area Interconnected Power System shown in Figure 3.5.

Note:

- $\mathrm{T}$ : simulation time period

- $\Delta \mathrm{T}$ : simulation time step 


\section{APPENDIX B}

AC System Dynamic Responses for Various AGC Controller Parameters

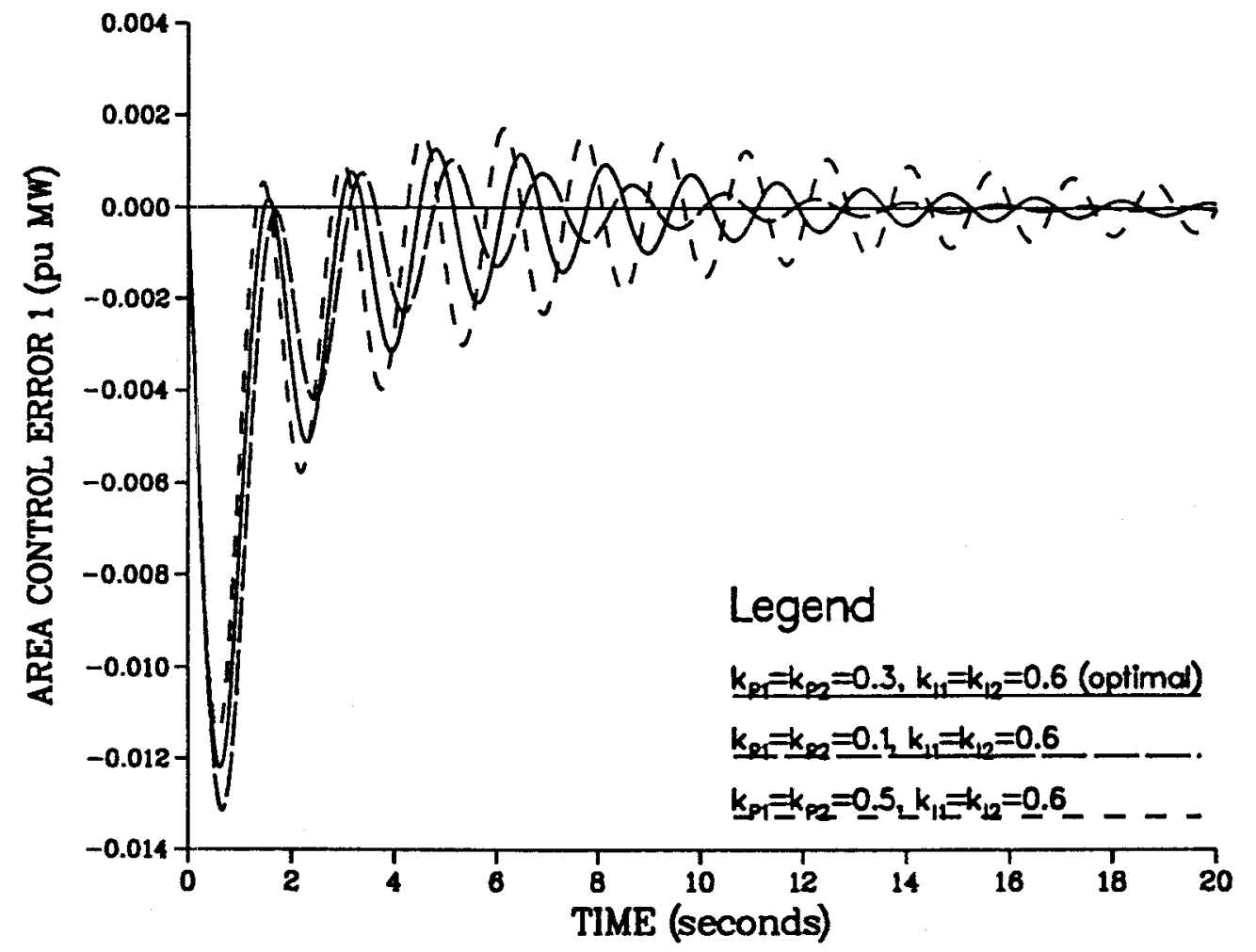

Figure B.1 Control error in Area 1 for various AGC proportional gain.

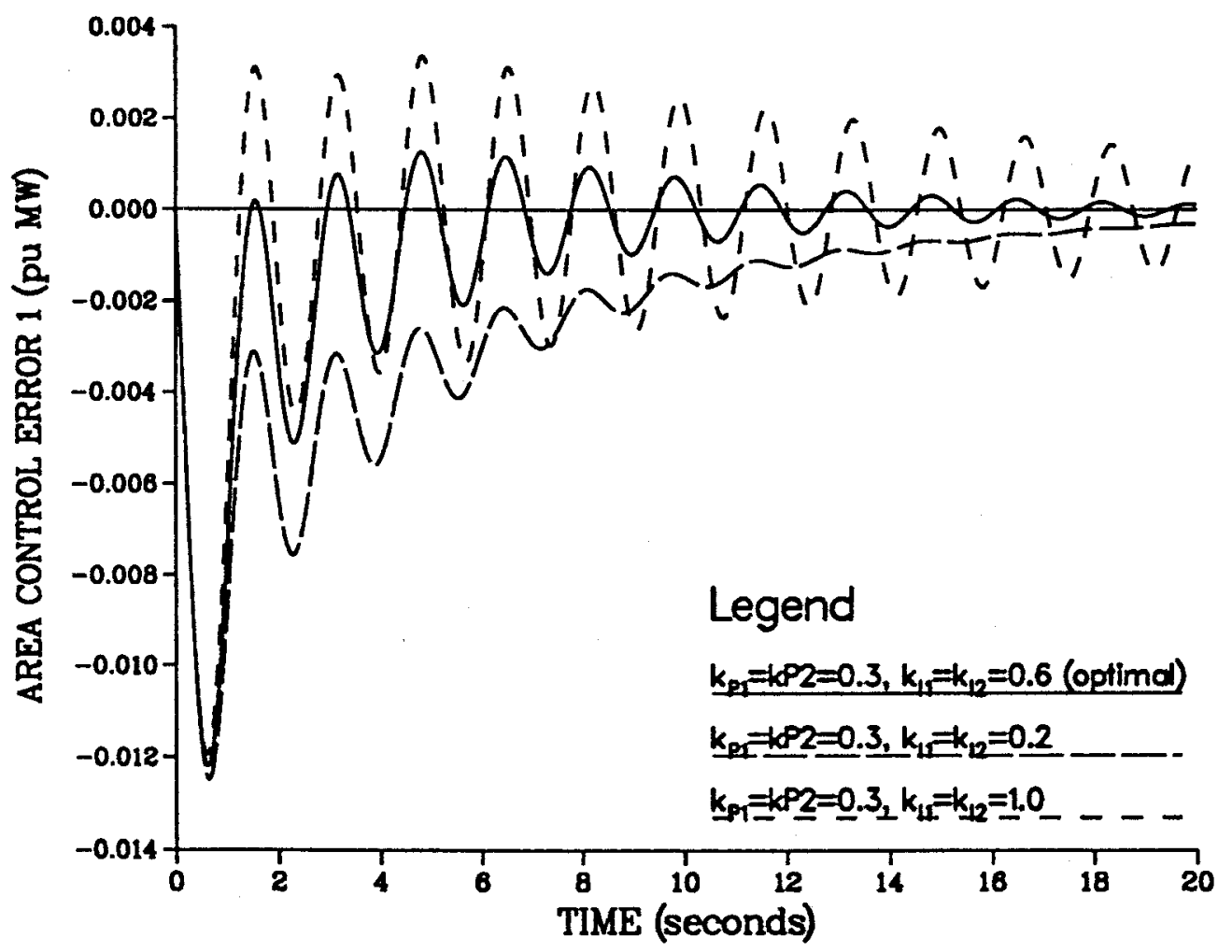

Figure B.2 Control error in Area 1 for various AGC integral gain. 


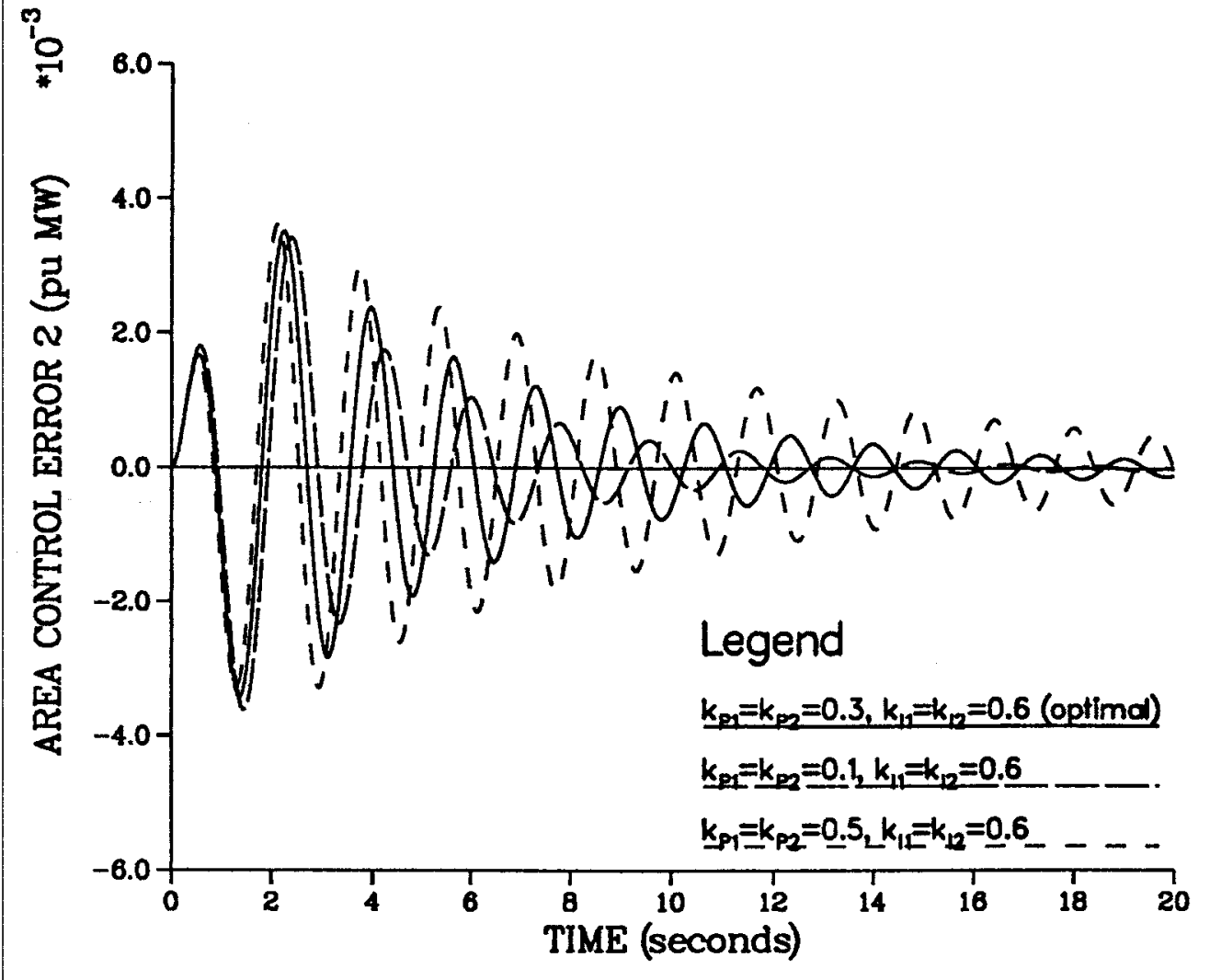

Figure B.3 Control error in Area 2 for various AGC proportional gain.

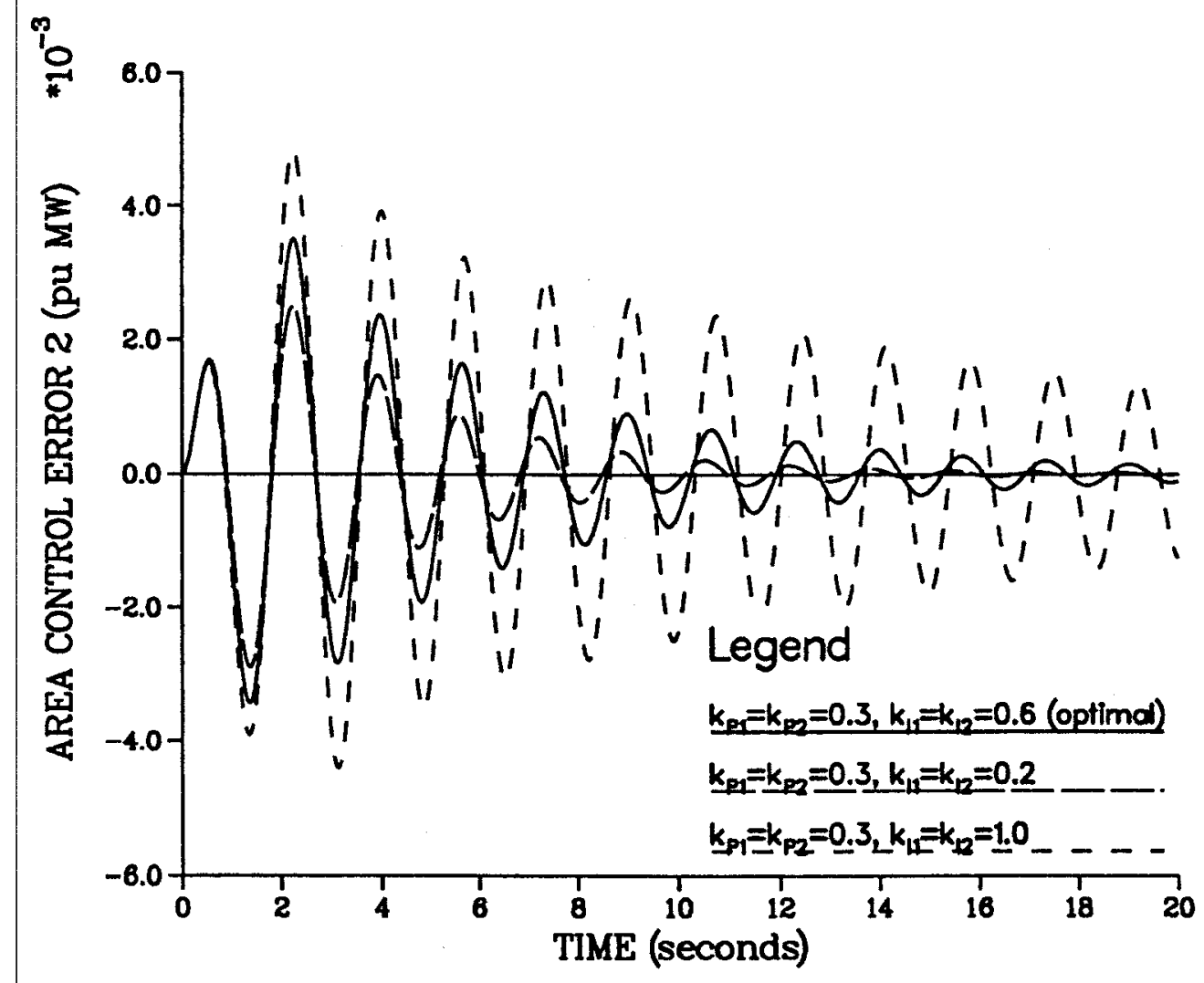

Figure B.4 Control error in Area 2 for various AGC integral gain. 


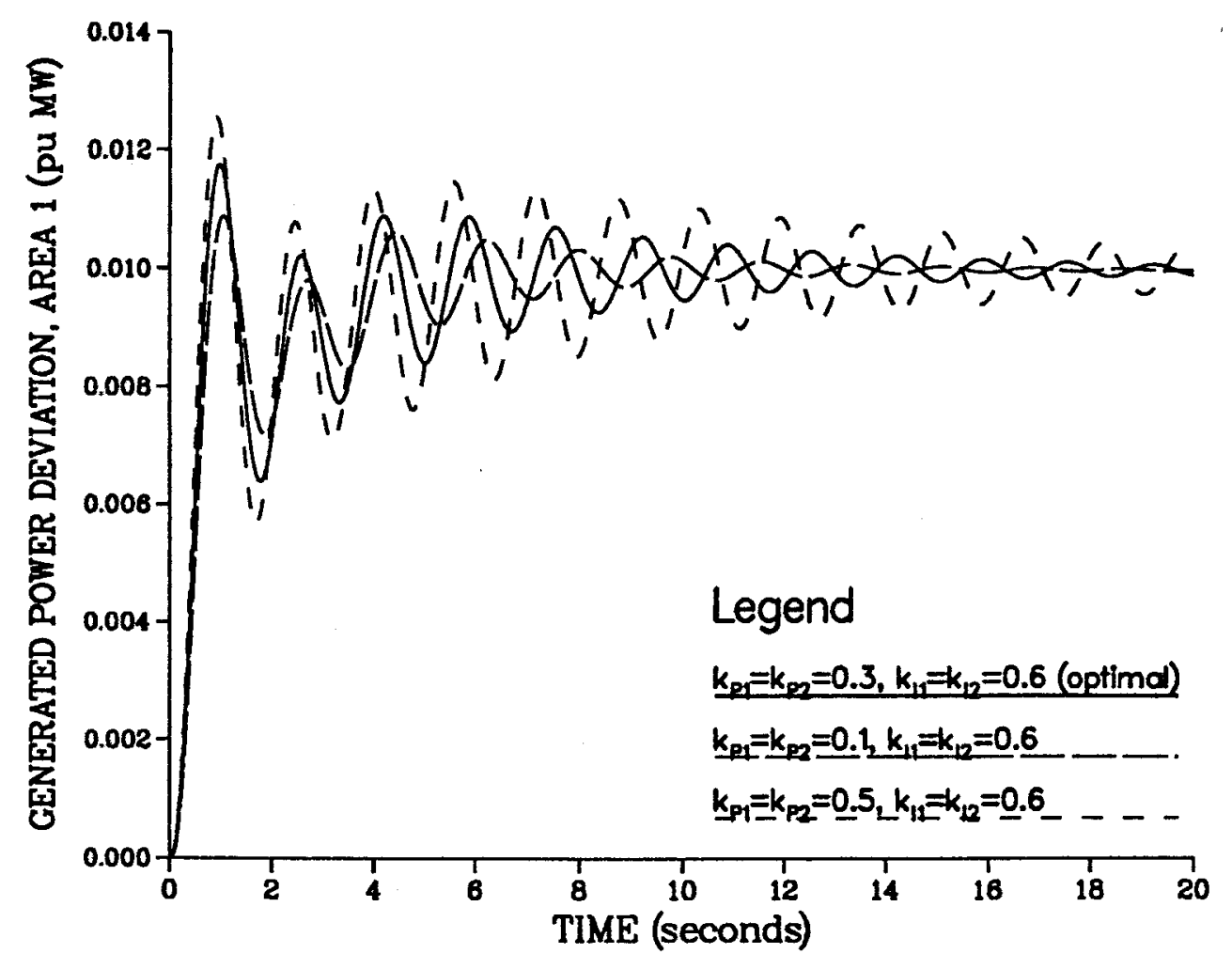

Figure B.5 Generated power deviation in Area 1 for various AGC proportional gain.

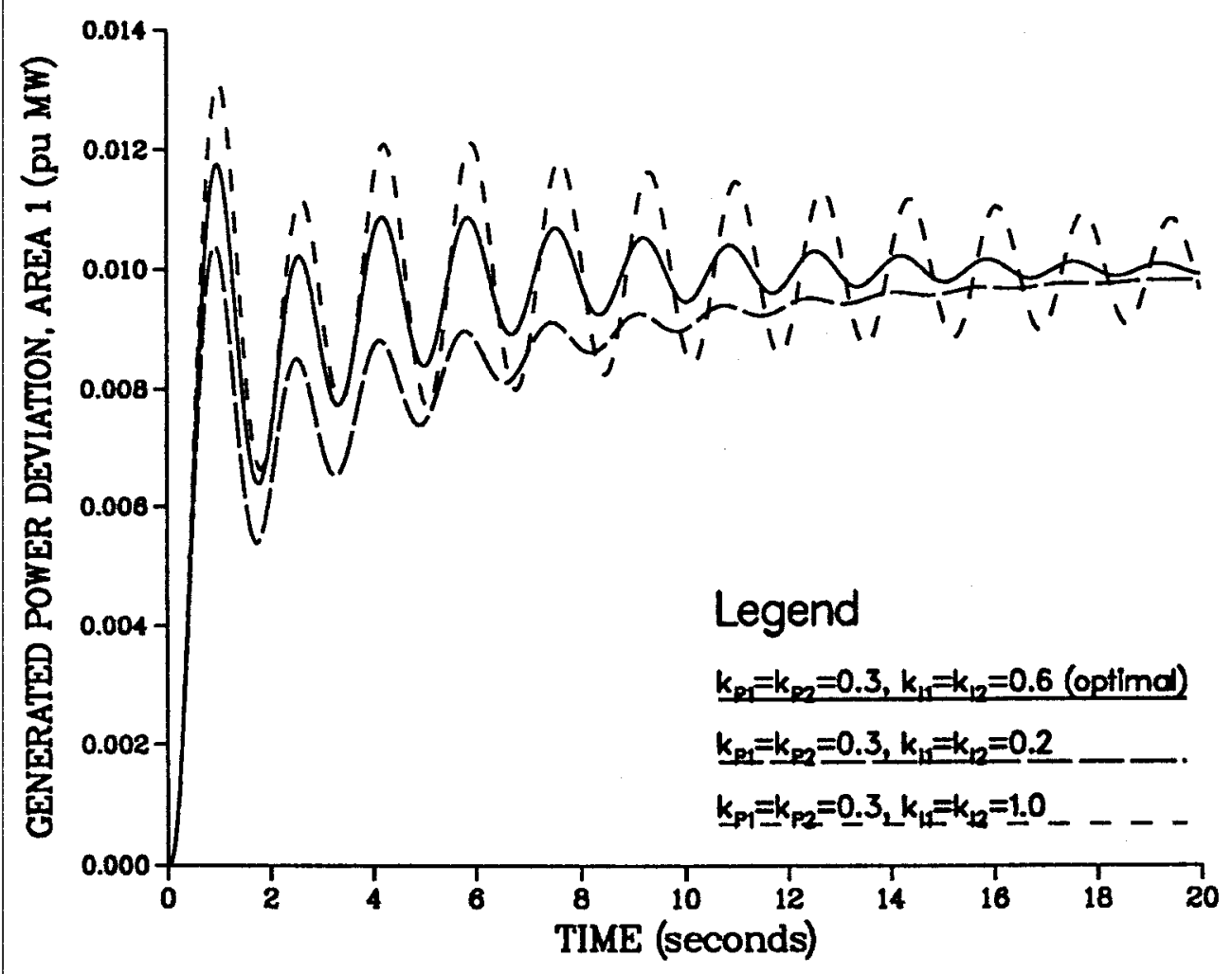

Figure B.6 Generated power deviation in Area 1 for various AGC integral gain. 


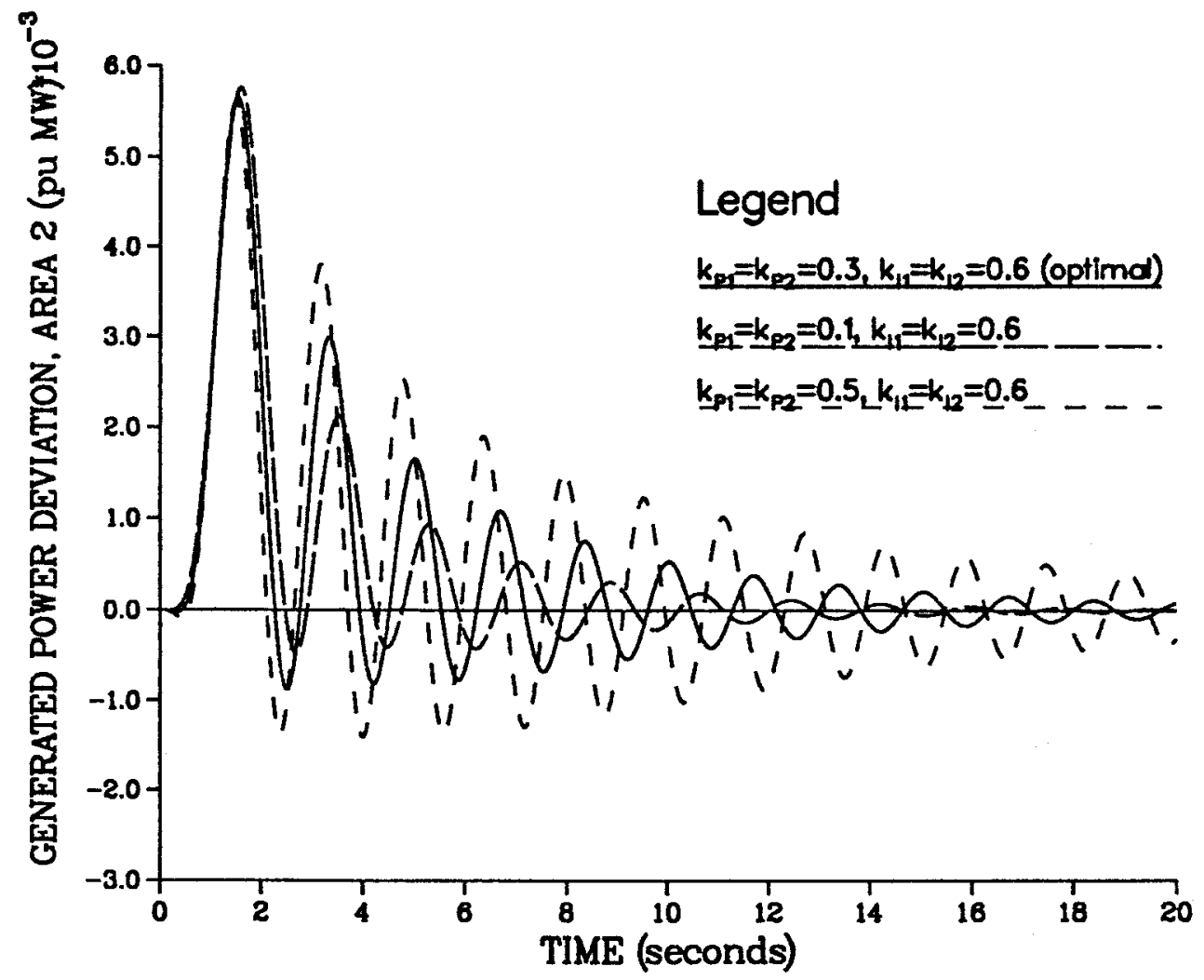

Figure B.7 Generated power deviation in Area 2 for various AGC proportional gain.

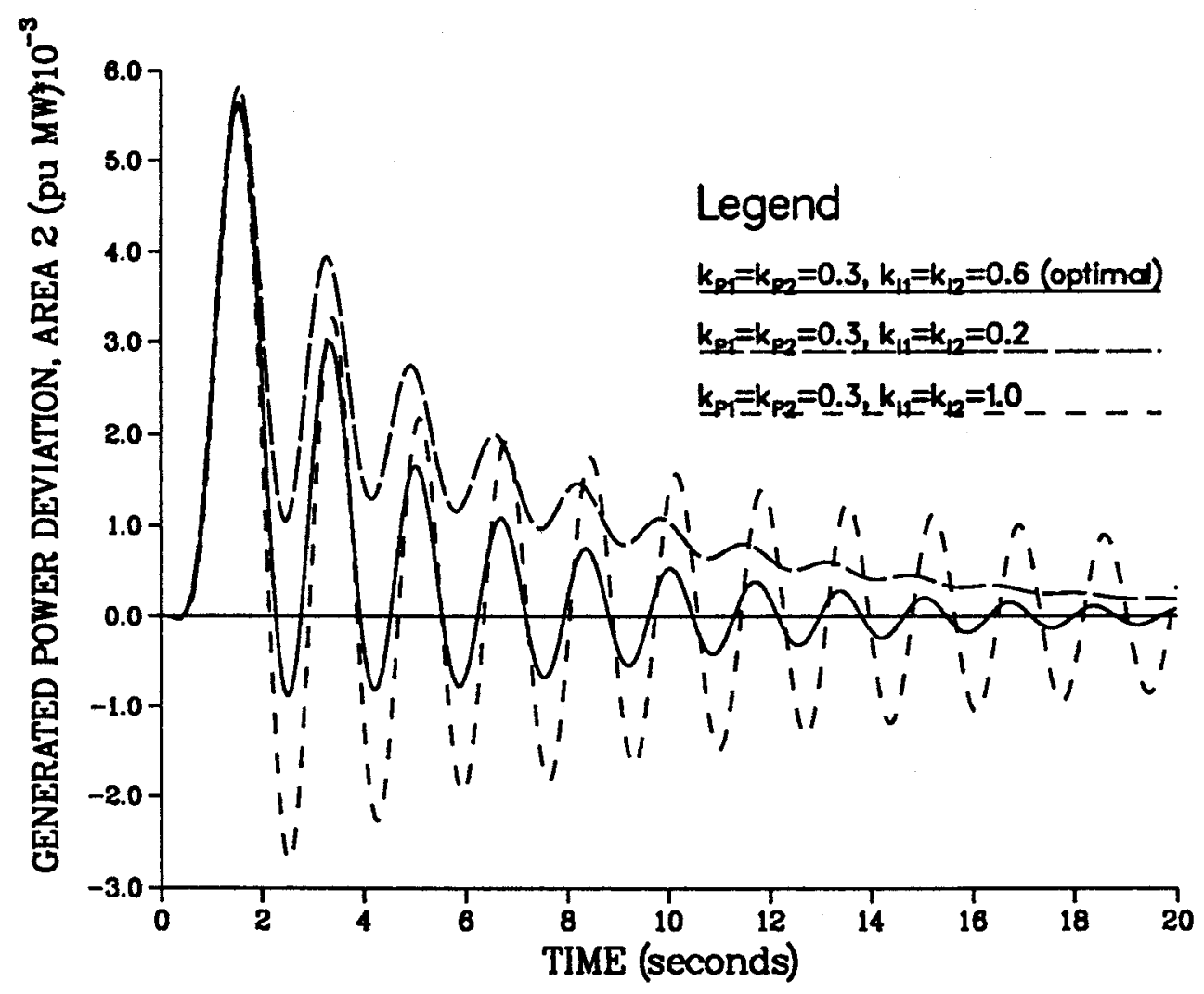

Figure B.8 Generated power deviation in Area 2 for various AGC integral gain. 


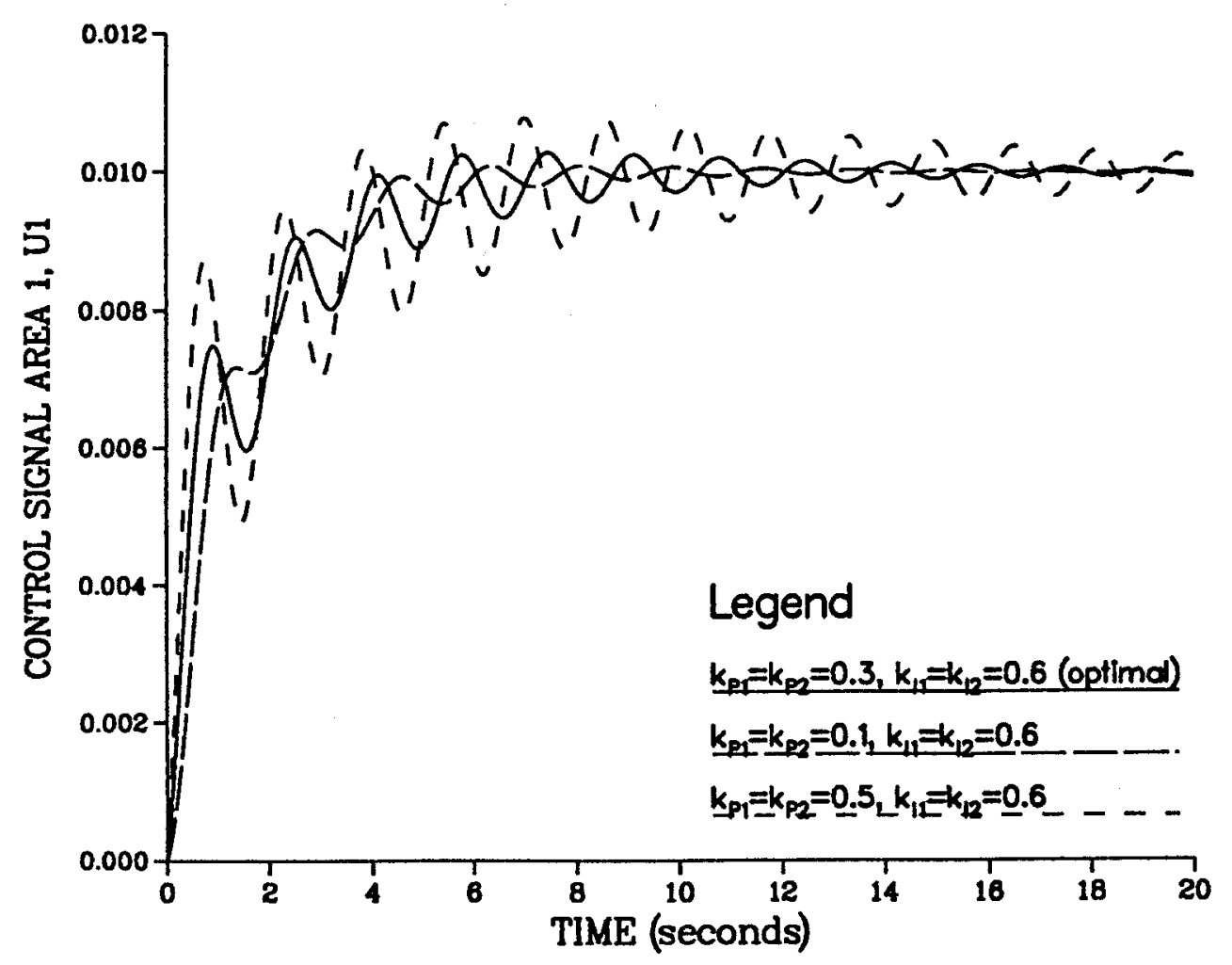

Figure B.9 Control signal in Area 1 for various AGC proportional gain.

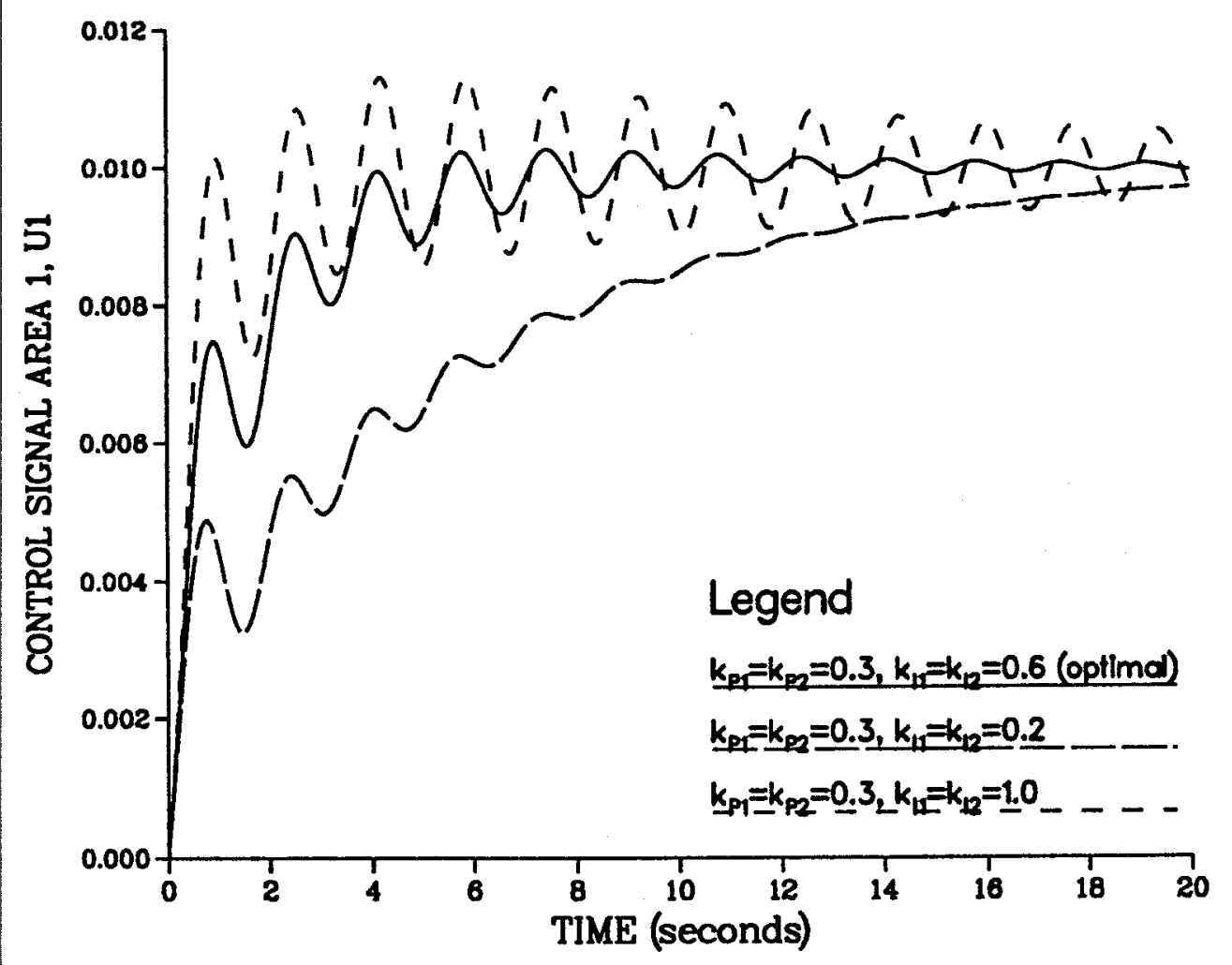

Figure B.10 Control signal in Area 1 for various AGC integral gain. 
\%

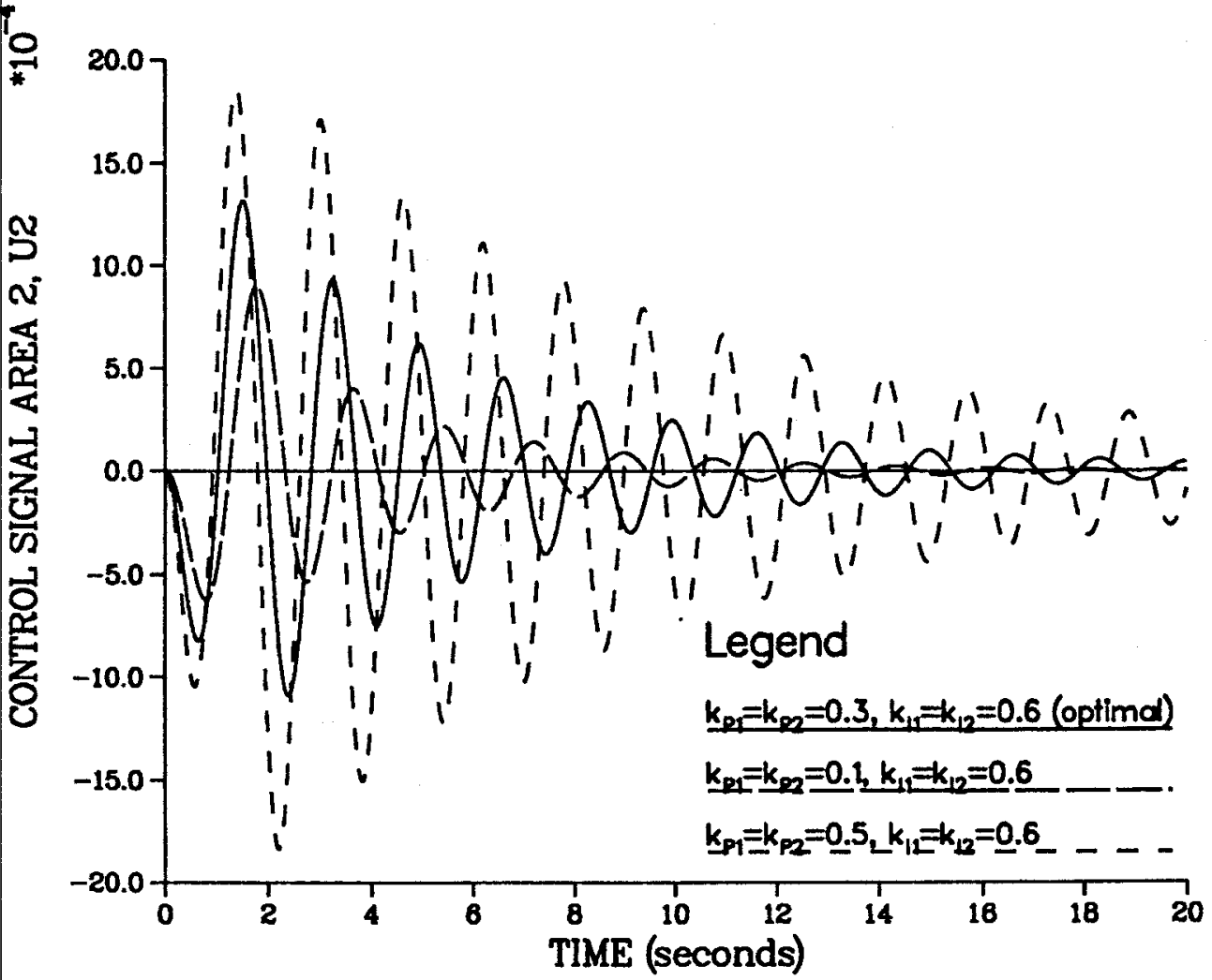

Figure B.11 Control signal in Area 2 for various AGC proportional gain.

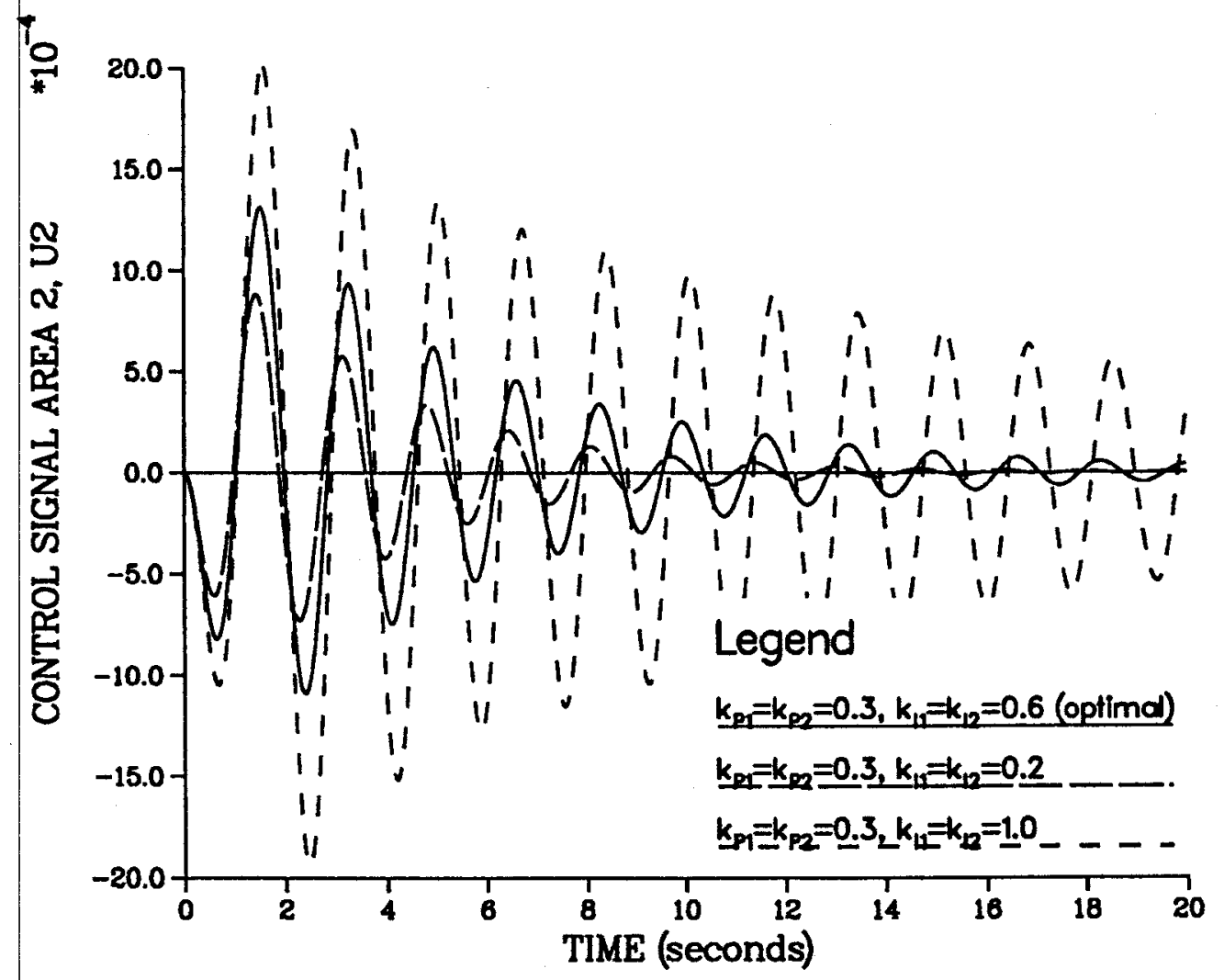

Figure B.12 Control signal in Area 2 for various AGC integral gain. 


\section{APPENDIX C}

AC/DC System Dynamic Responses for Various Supplementary Controller Parameters

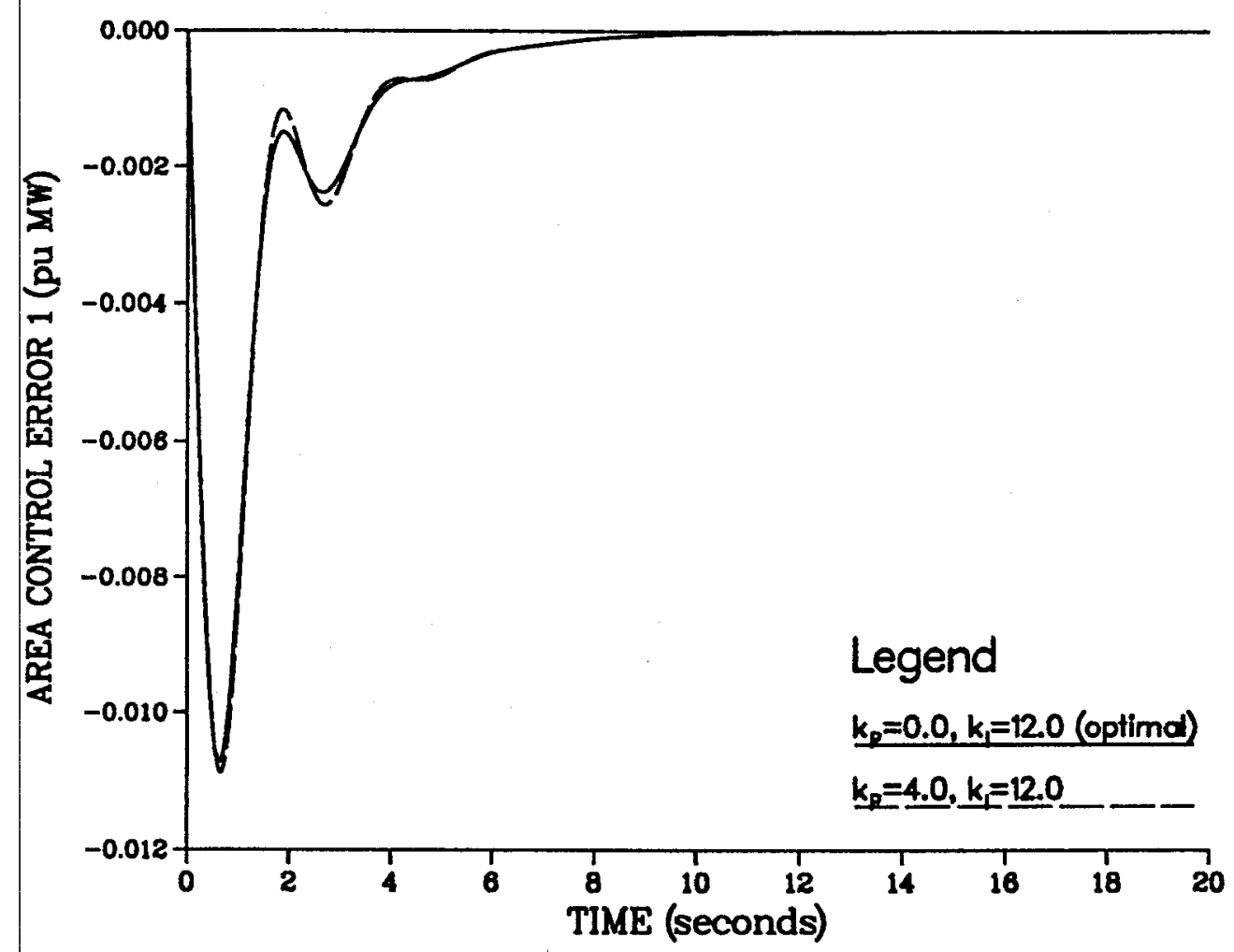

Figure C.1 Control error in Area 1 for various SC controller proportional gain.

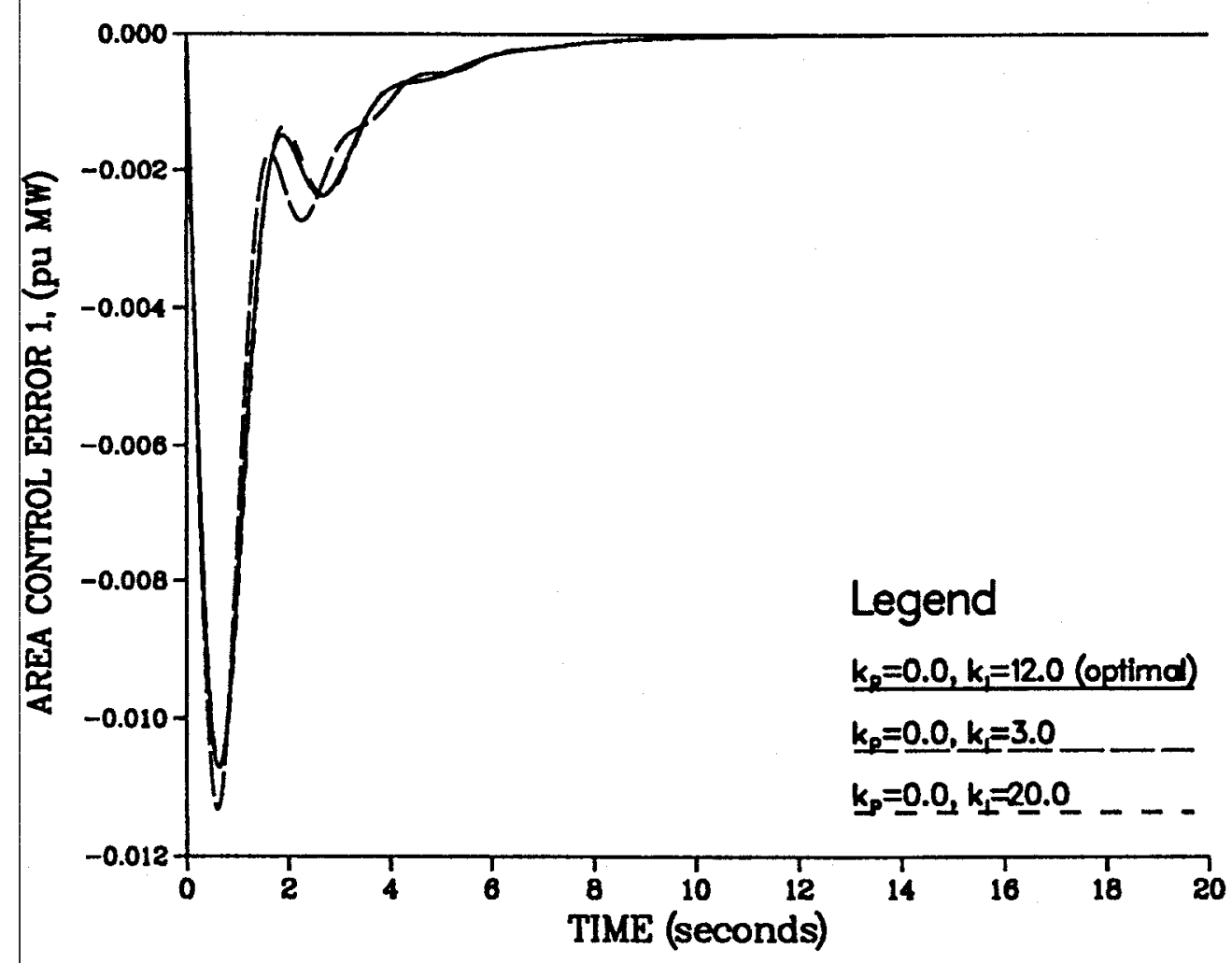

Figure C.2 Control error in Area 1 for various SC controller integral gain. 


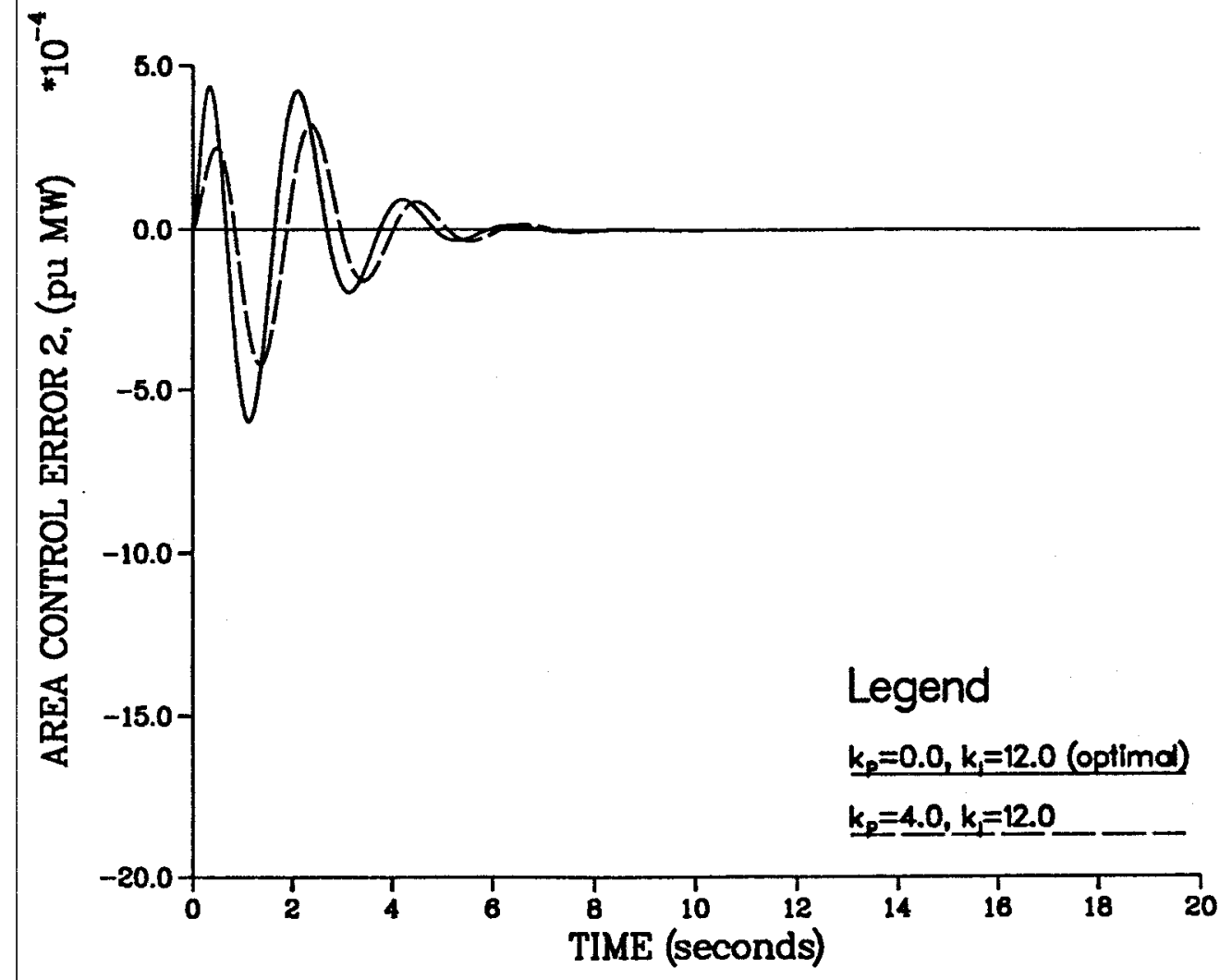

Figure C.3 Control error in Area 2 for various SC controller proportional gain.

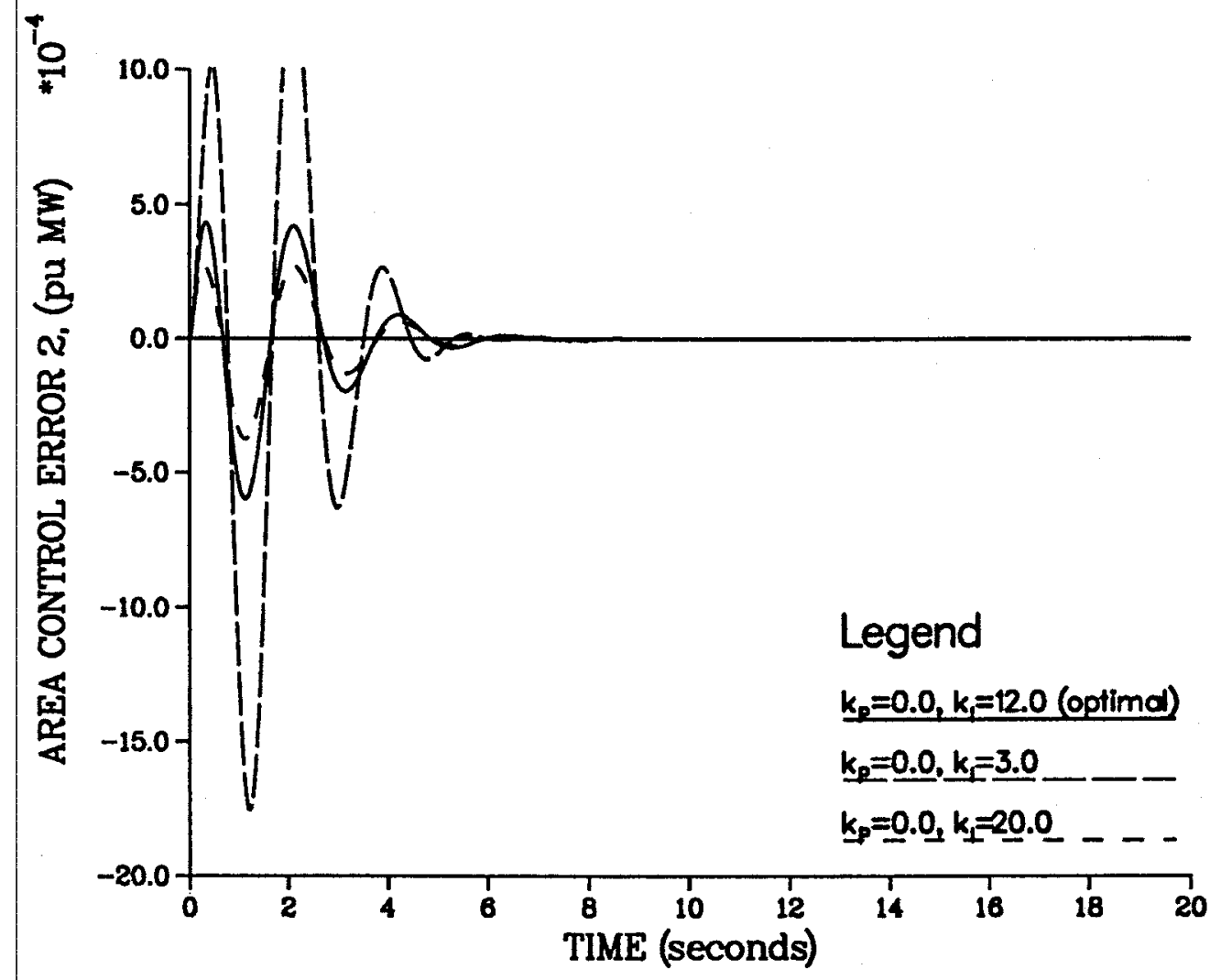

Figure C.4 Control error in Area 2 for various SC controller integral gain. 


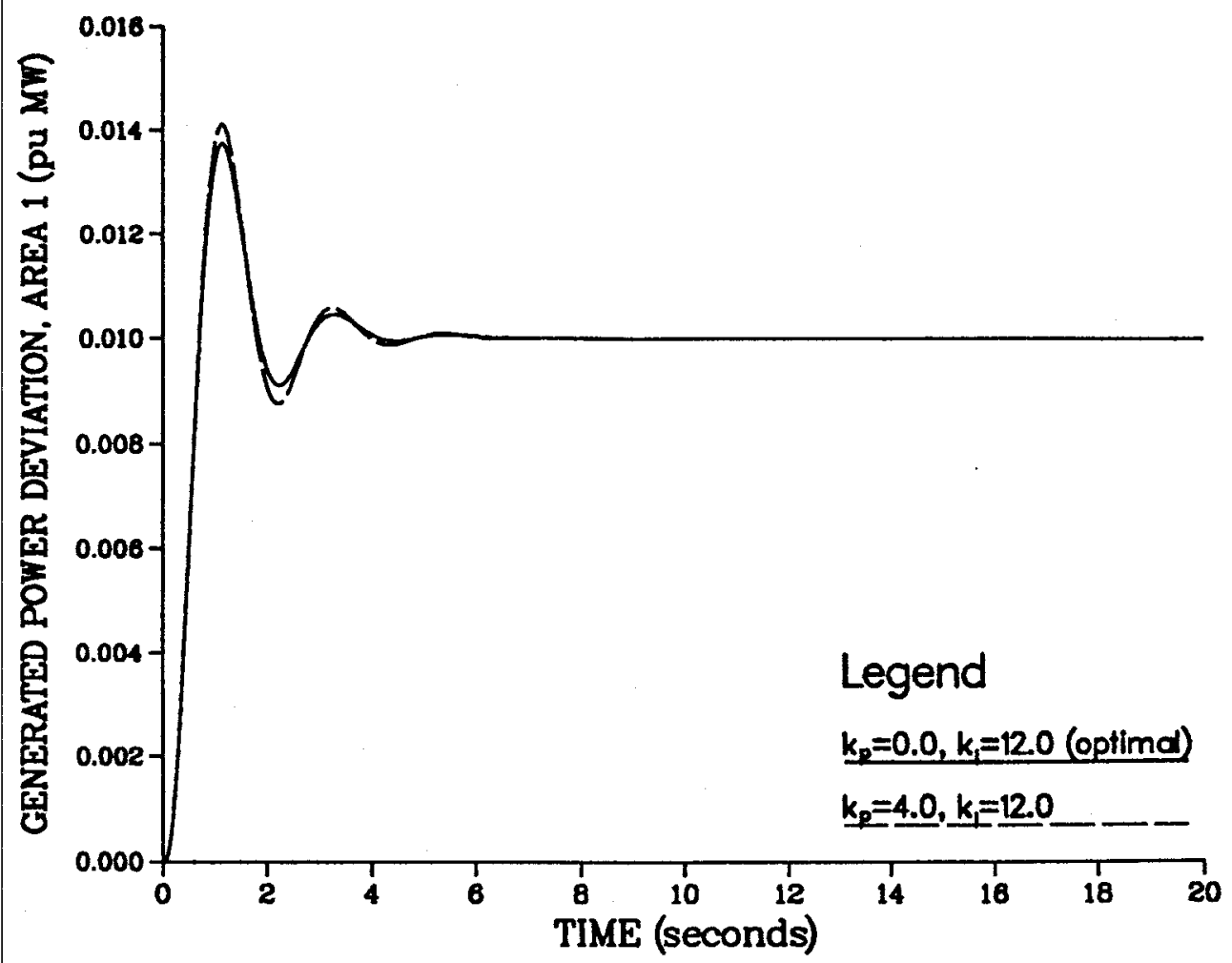

Figure C.5 Generated power deviation in Area 1 for various SC controller proportional gain.

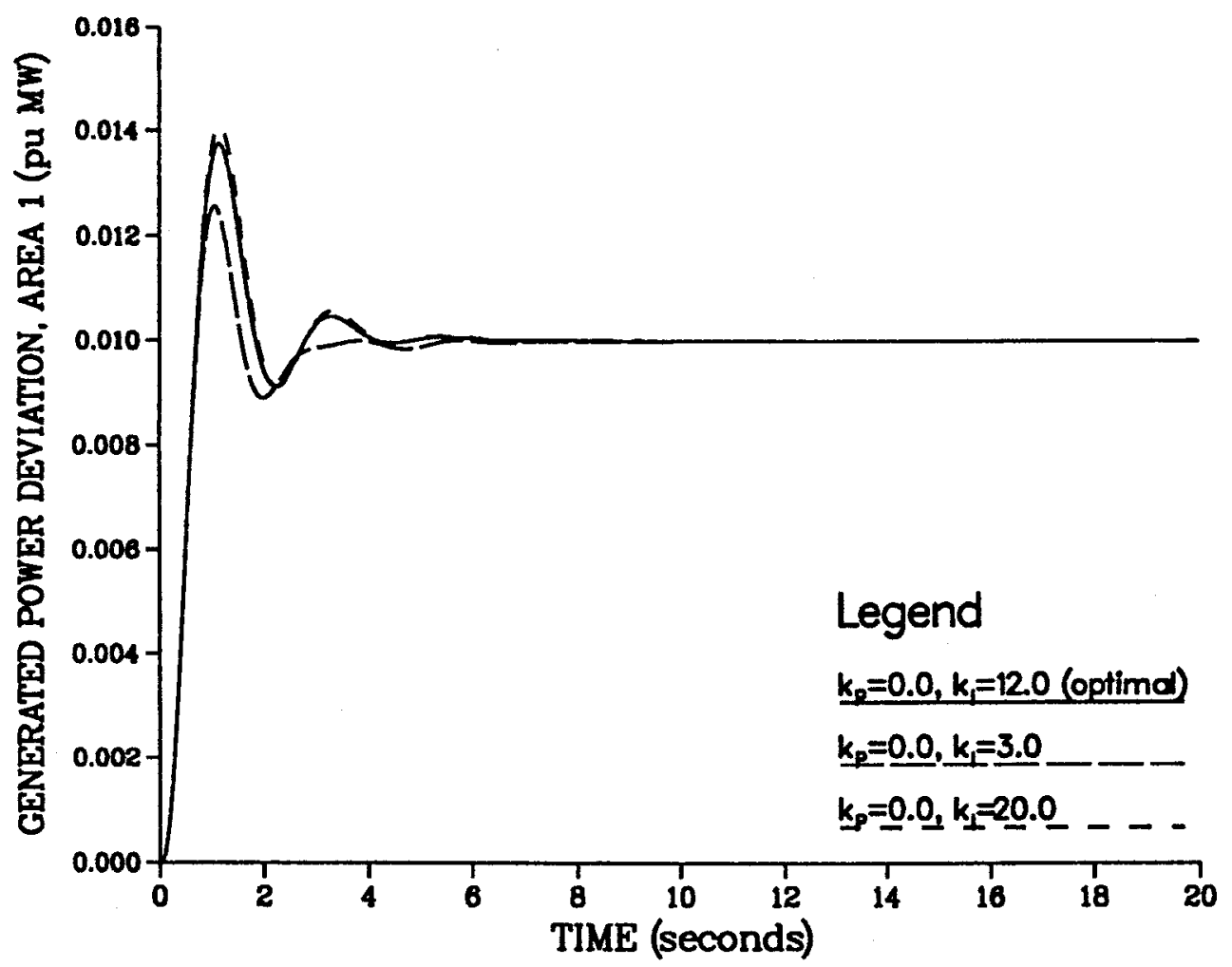

Figure C.6 Generated power deviation in Area 1 for various SC controller integral gain. 


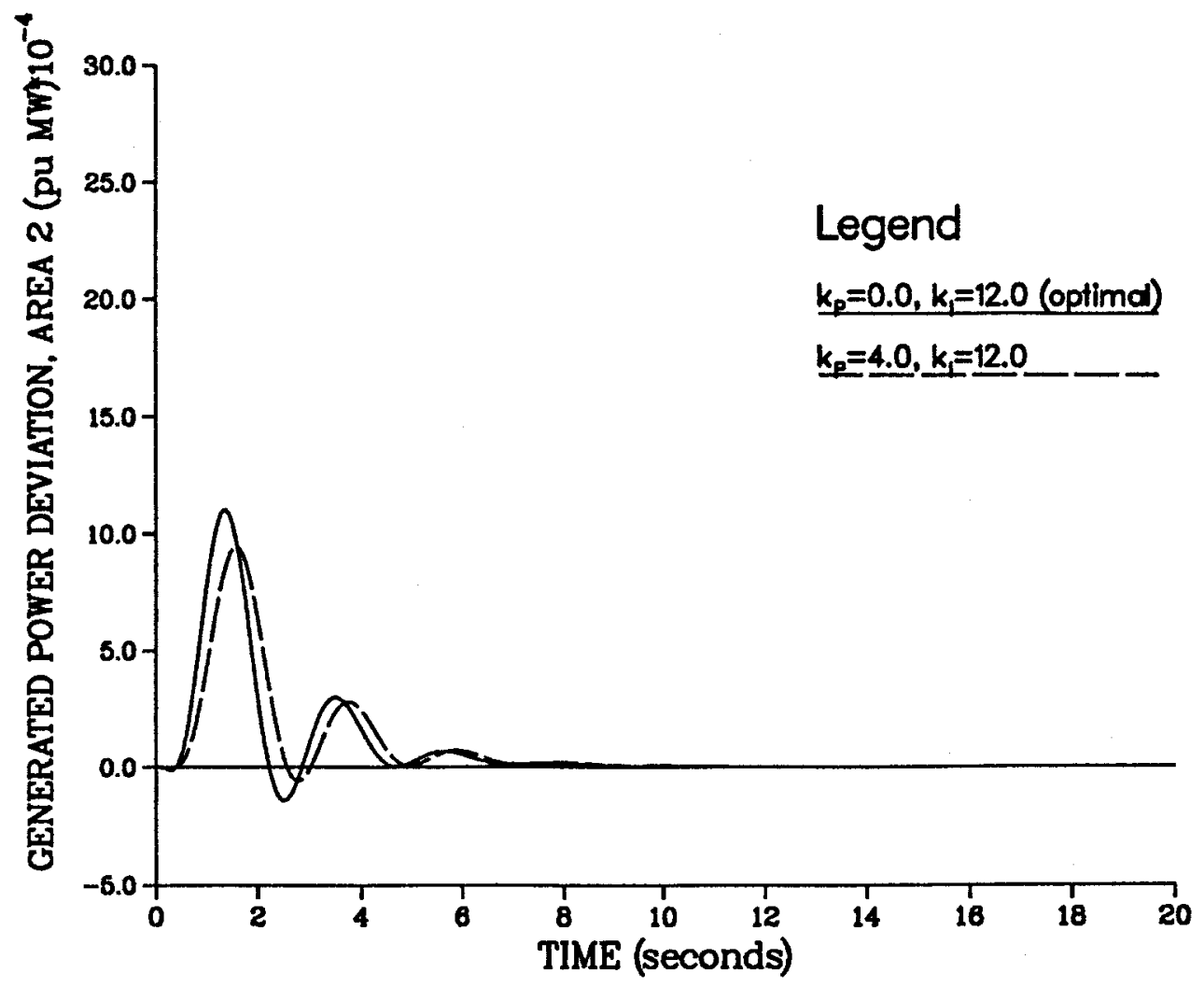

Figure C.7 Generated power deviation in Area 2 for various SC controller proportional gain.

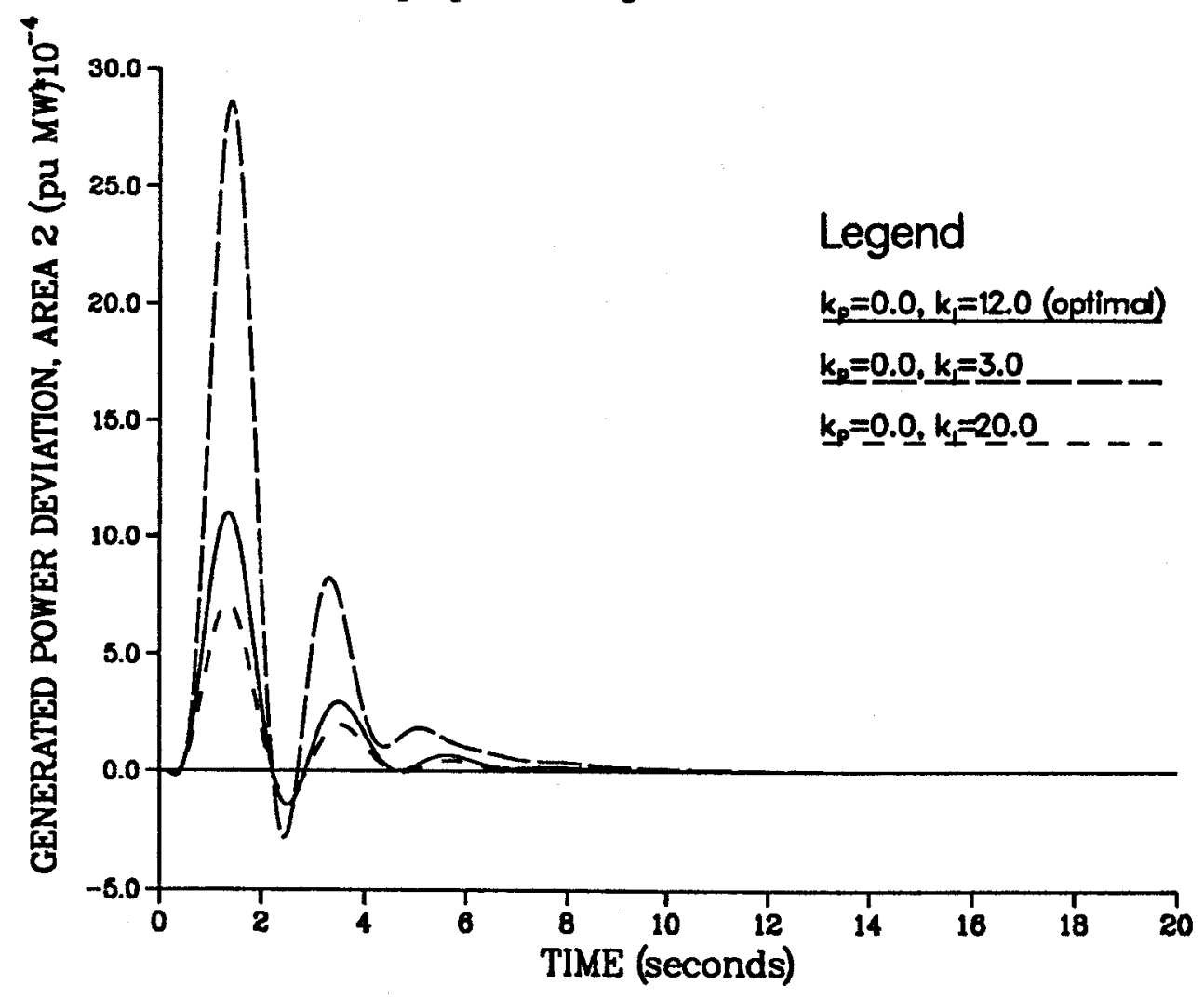

Figure C.8 Generated power deviation in Area 2 for various SC controller integral gain. 


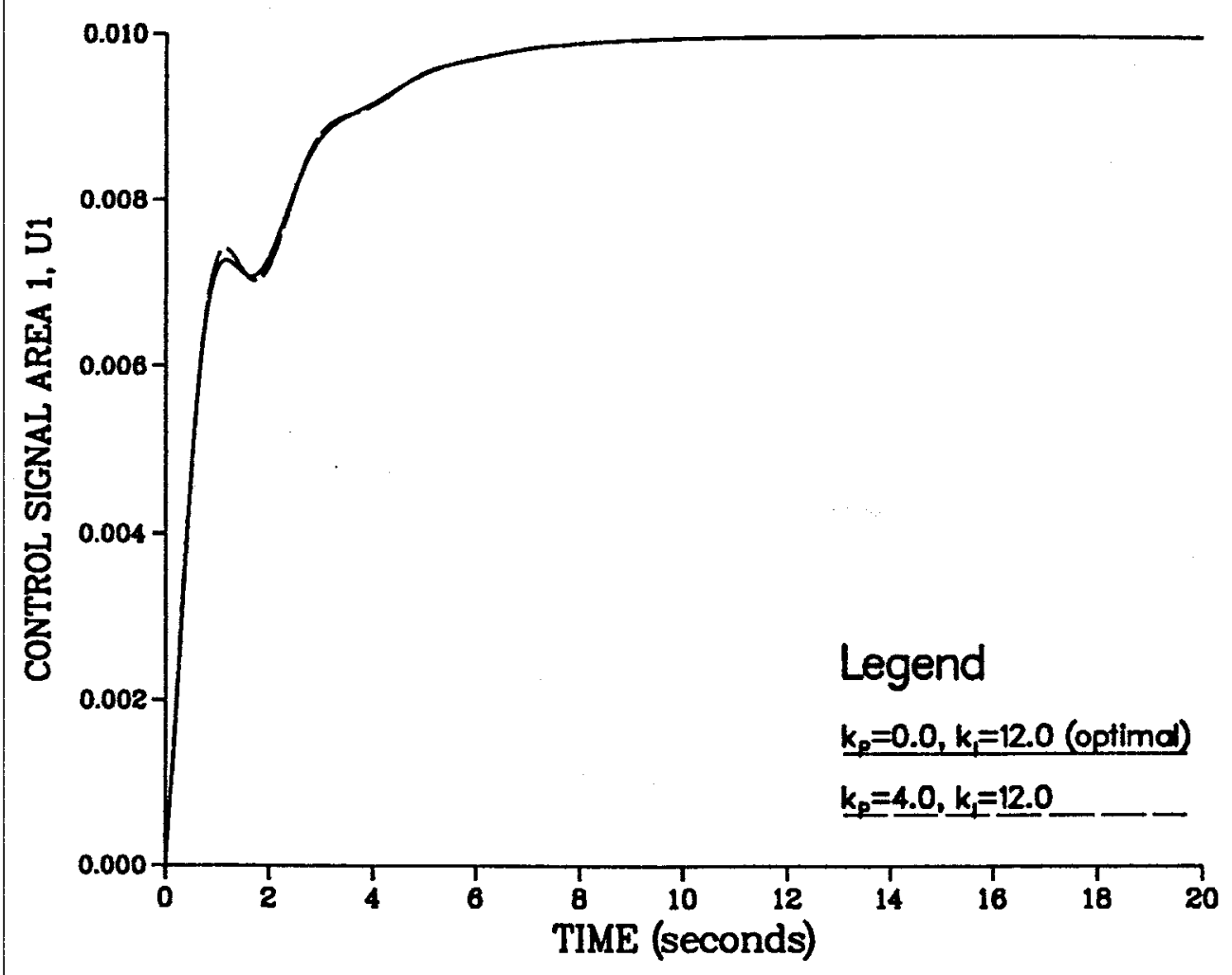

Figure C.9 Control signal in Area 1 for various SC controller proportional gain.

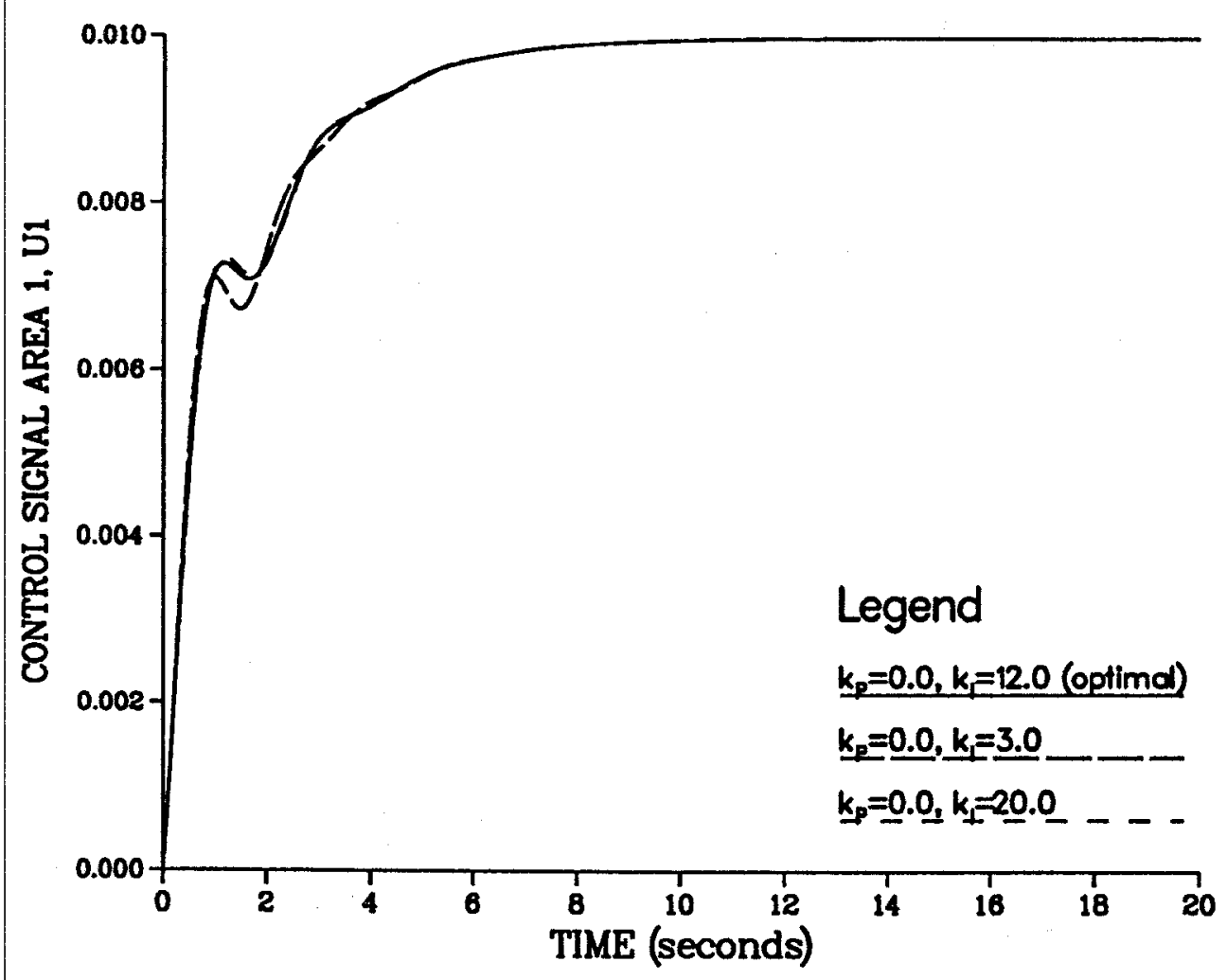

Figure C.10 Control signal in Area 1 for various SC controller integral gain. 


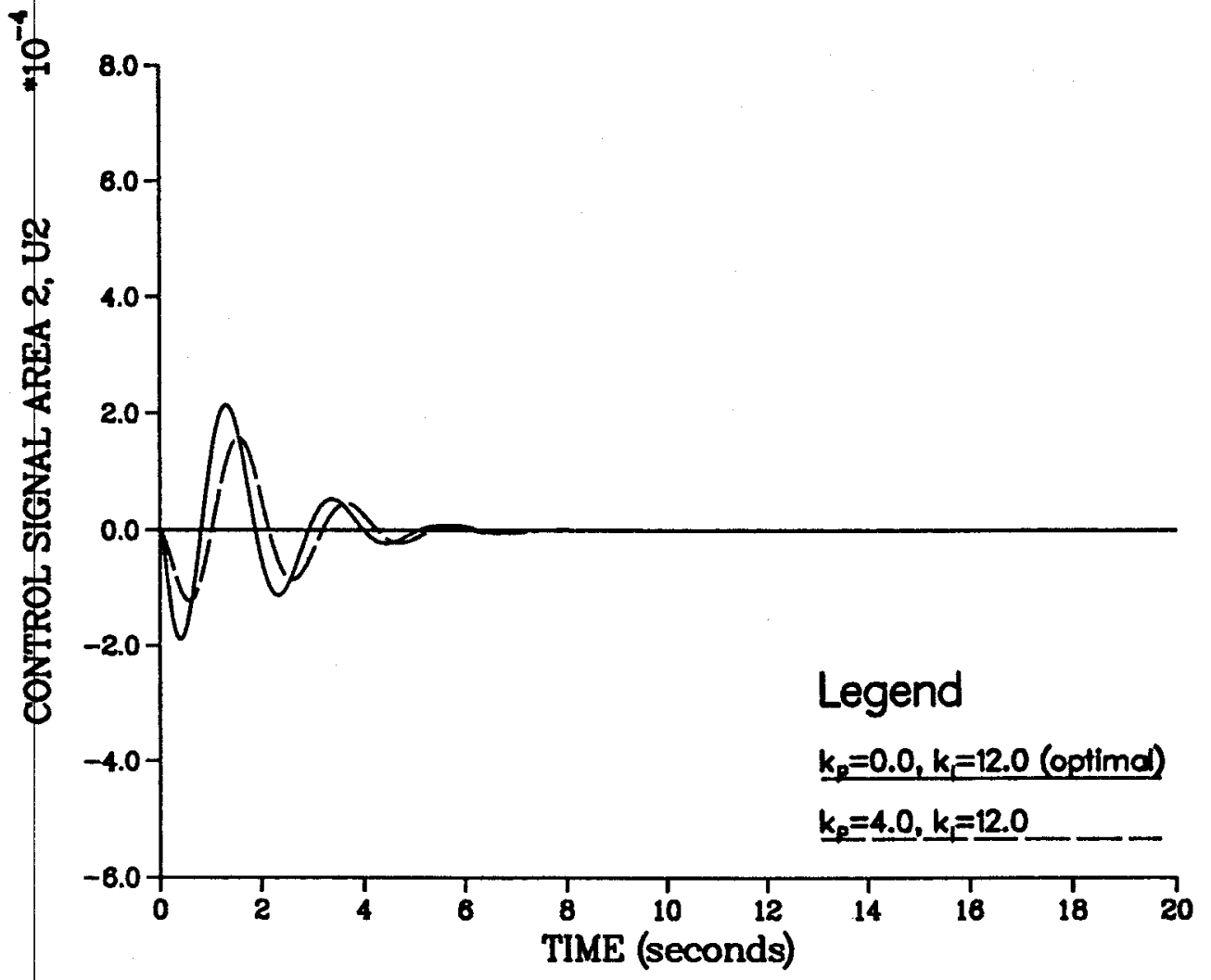

Figure C.11 Control signal in Area 2 for various SC controller proportional gain.

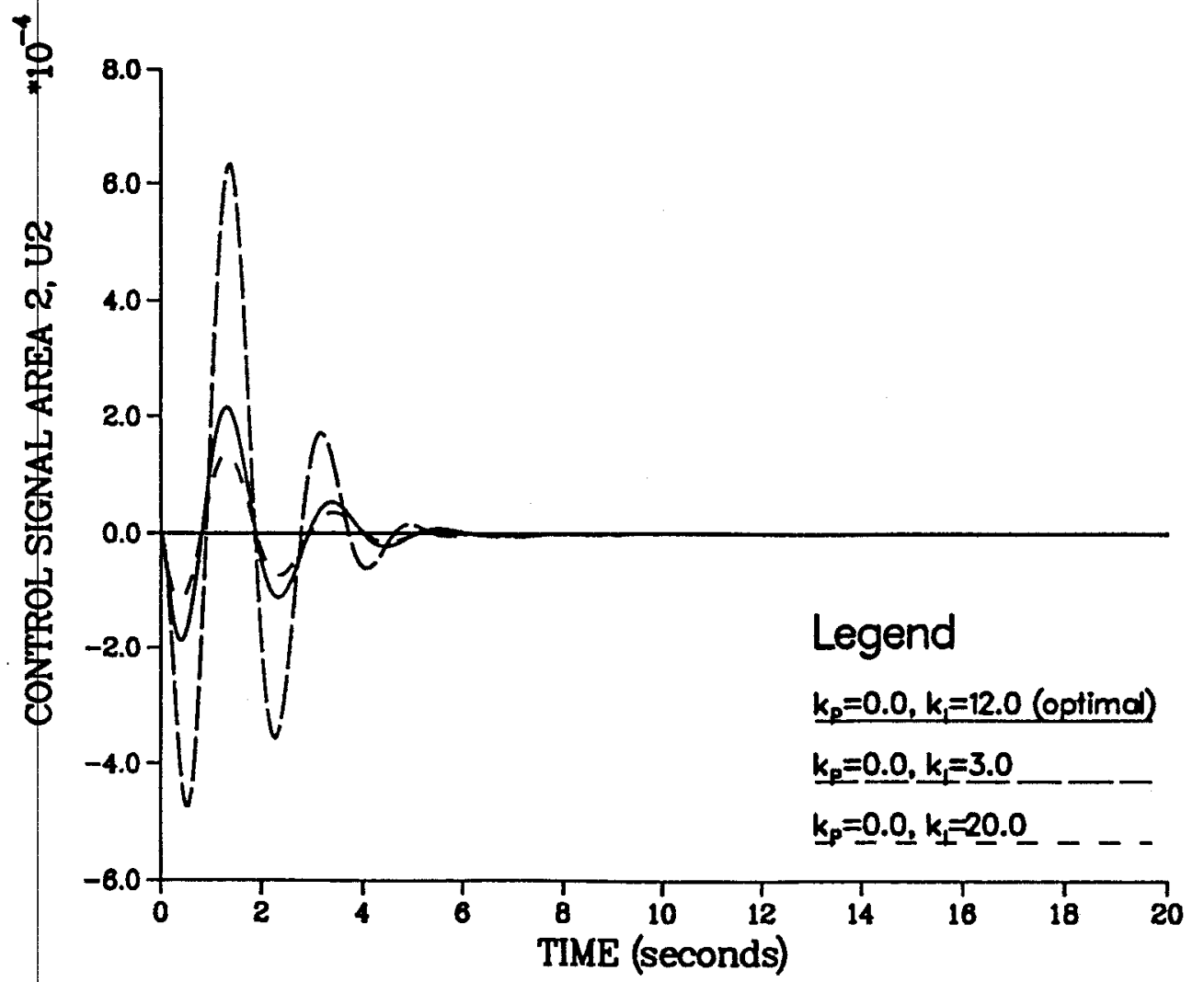

Figure C.12 Control signal in Area 2 for various SC controller integral gain. 


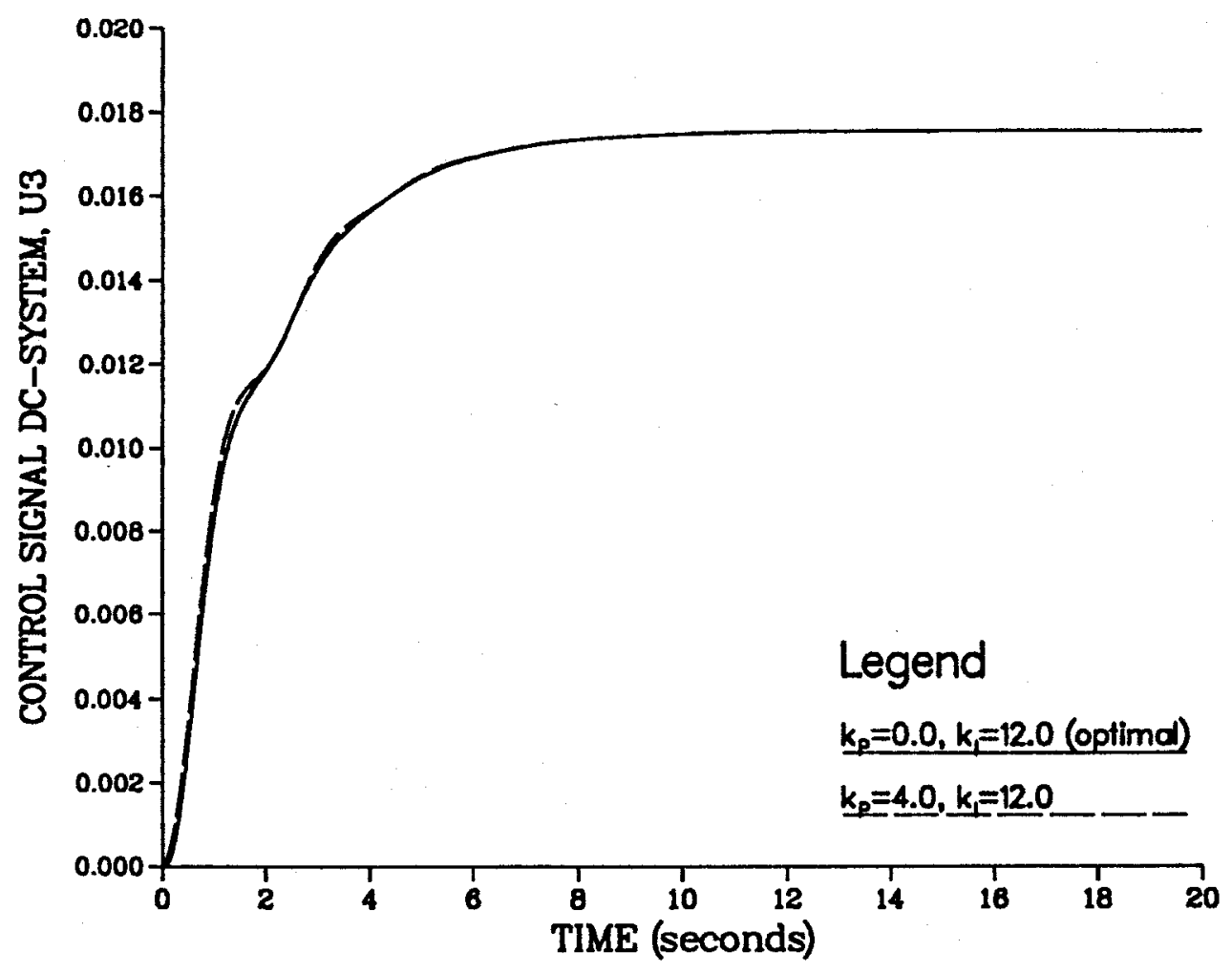

Figure C.13 Control signal DC system for various SC controller proportional gain.

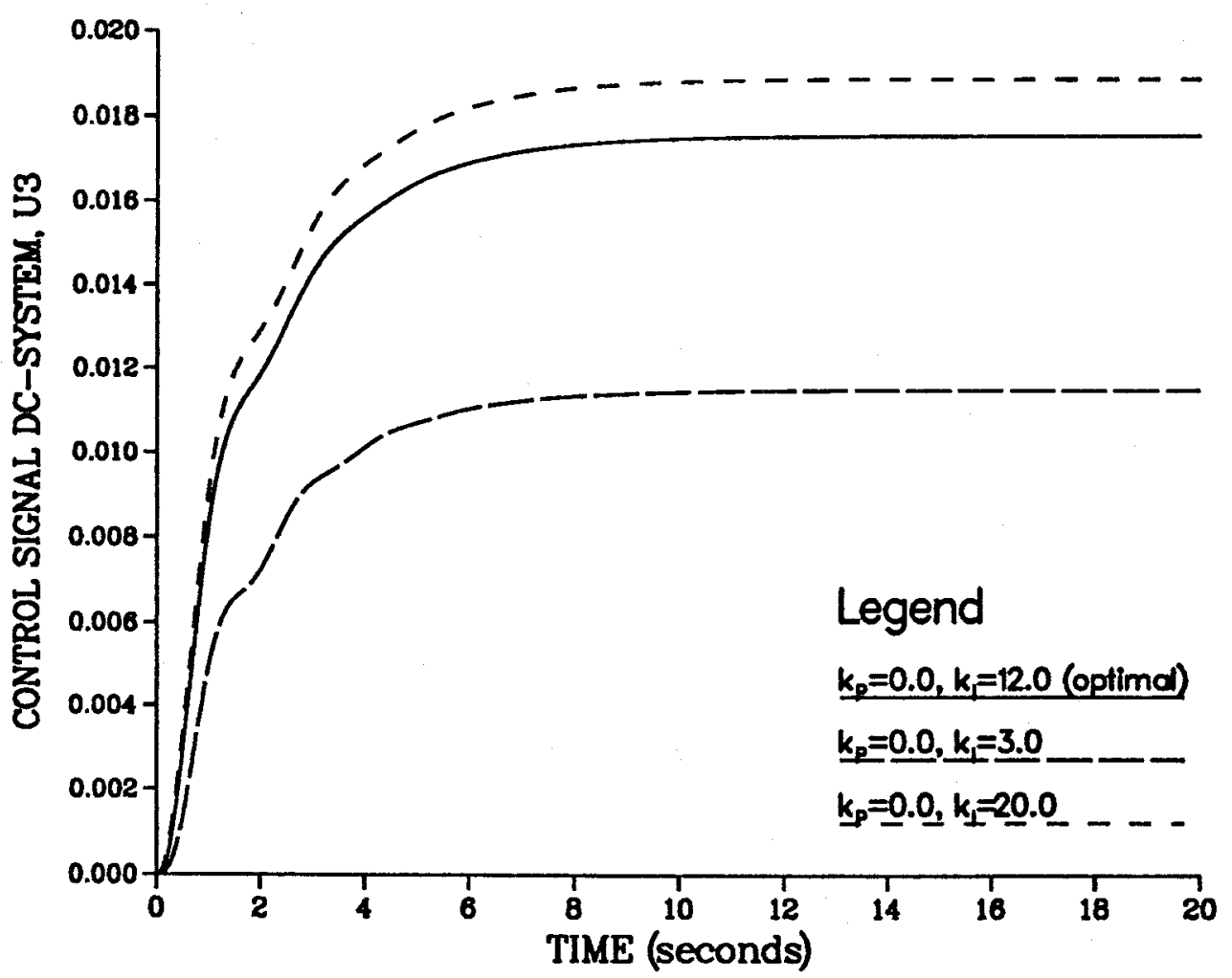

Figure C.14 Control signal DC system for various SC controller integral gain. 


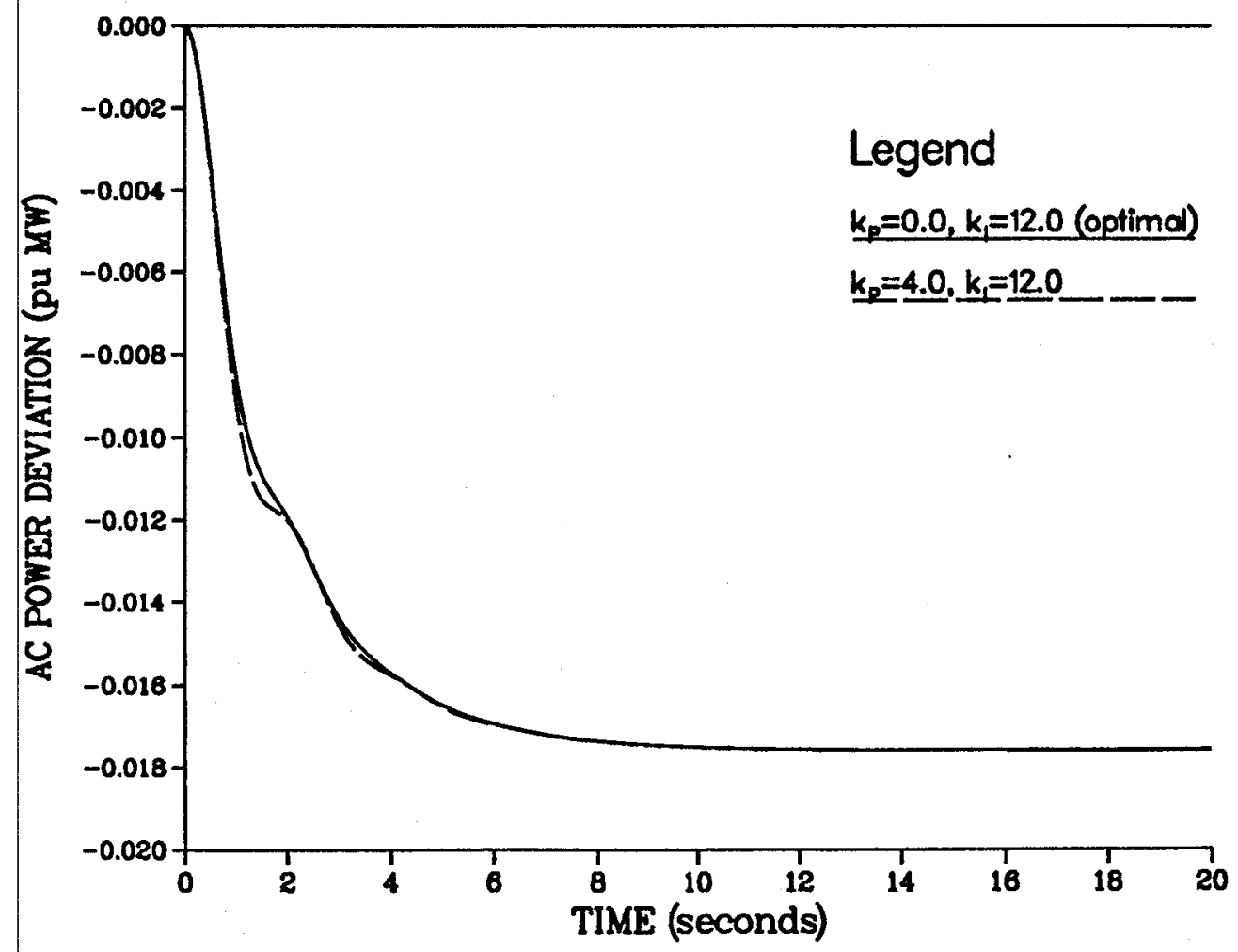

Figure C.15 AC power deviation for various SC controller proportional gain.

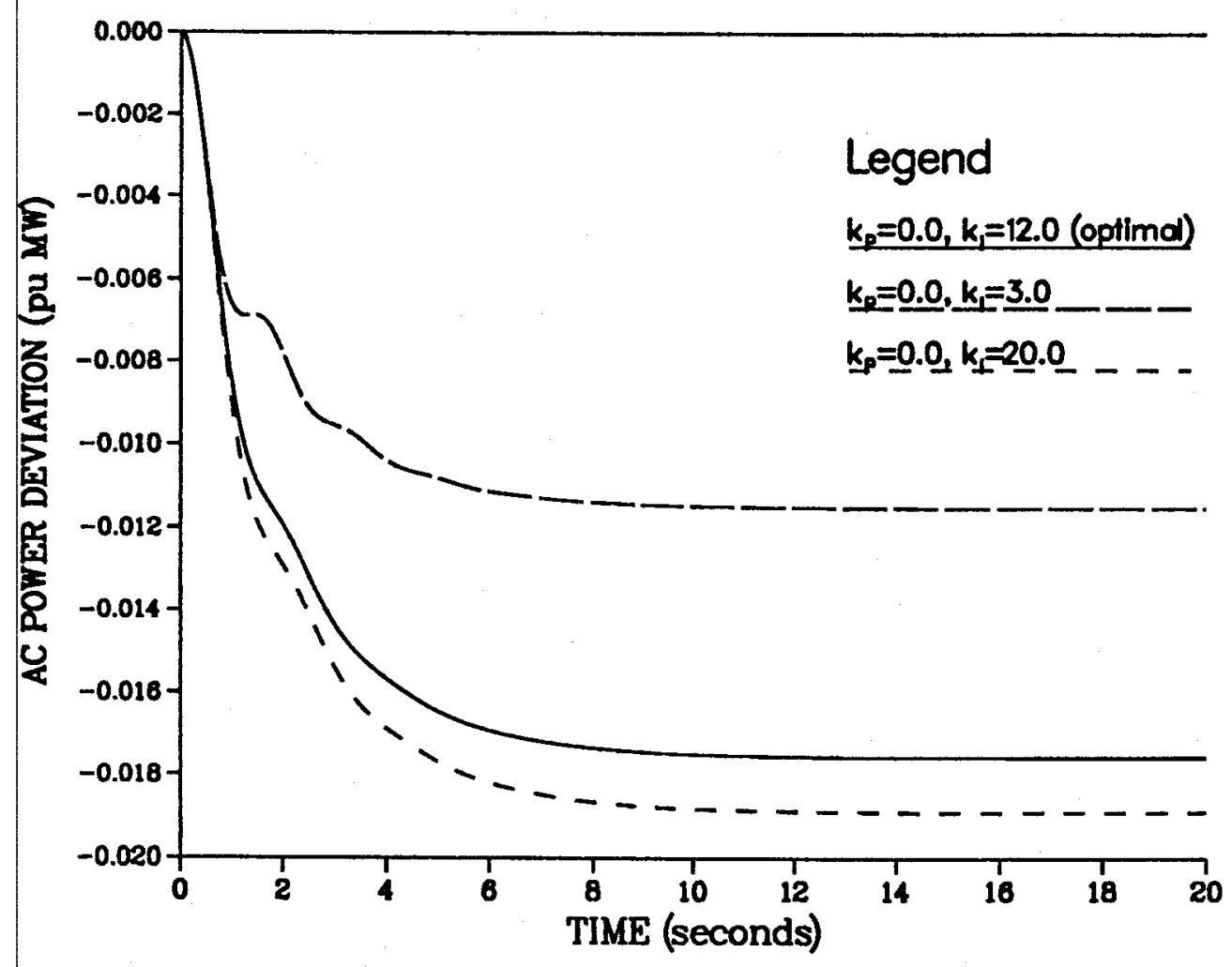

Figure C.16 AC power deviation for various SC controller integral gain. 


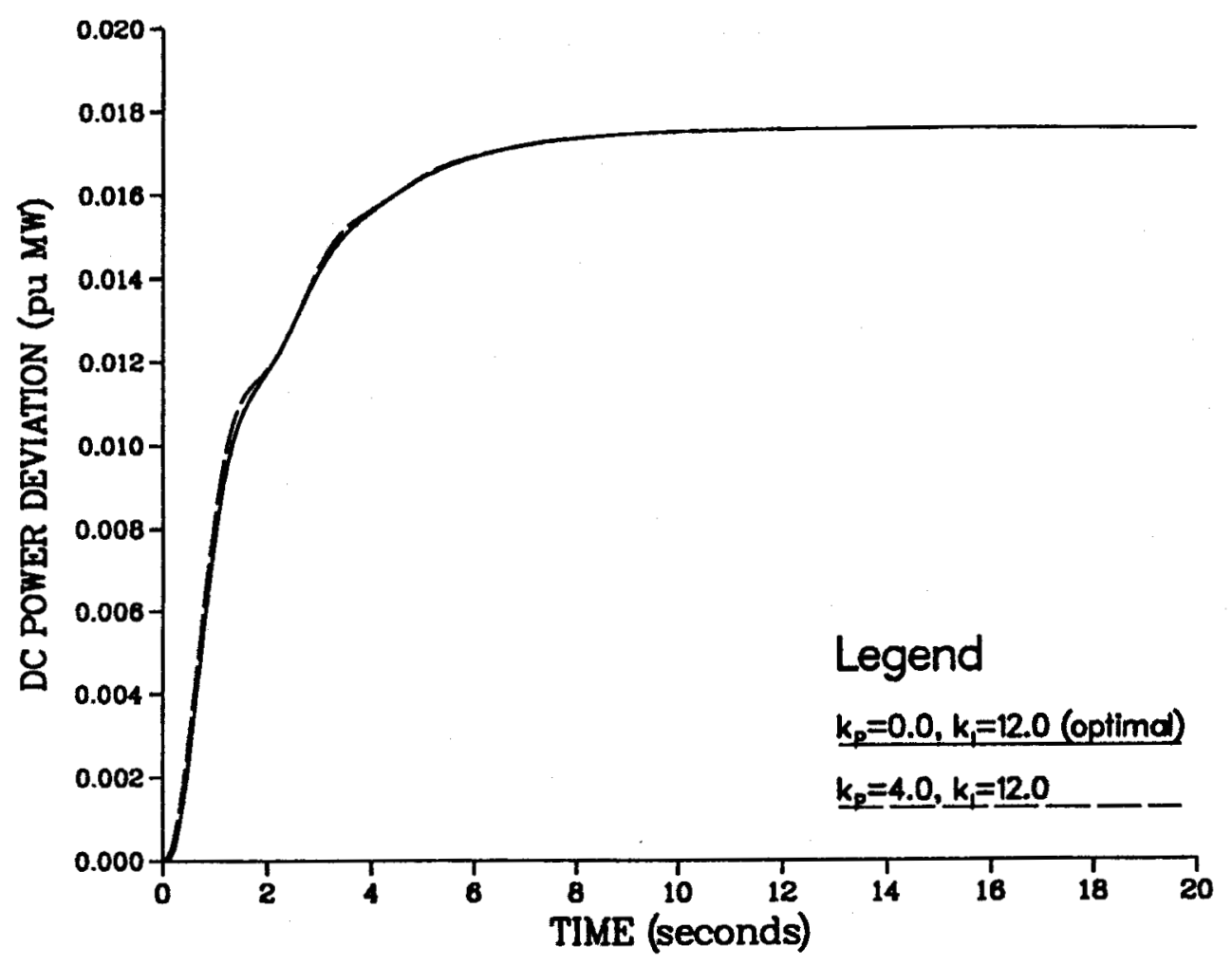

Figure C.17 DC power deviation for various SC controller proportional gain.

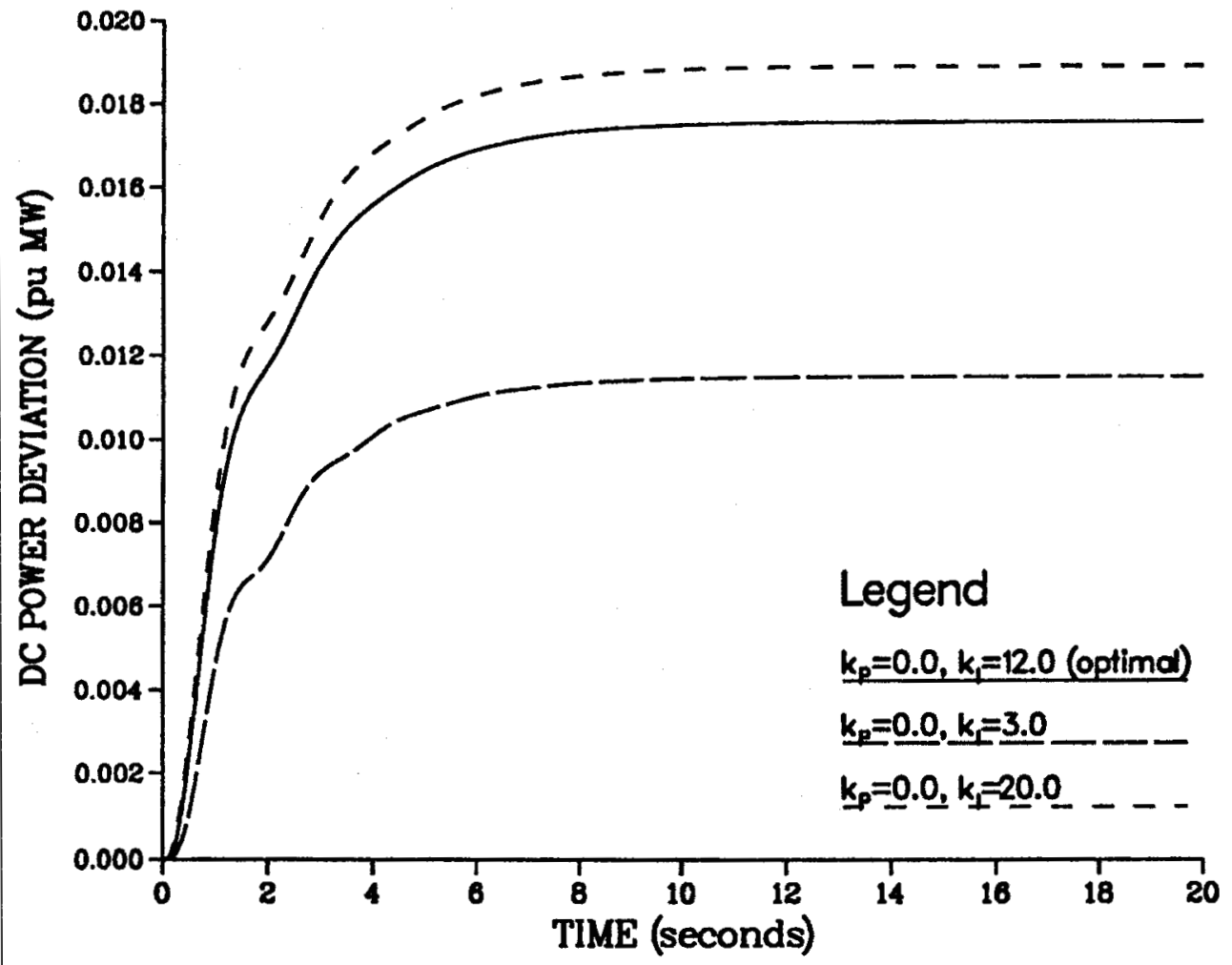

Figure C.18 DC power deviation for various SC controller integral gain. 